\title{
A SEGURANÇA DE ESTRUTURAS DE MADEIRA DETERMINADA A PARTIR DA VARIABILIDADE DA DENSIDADE BÁsICA E DE PROPRIEDADES MECÂNICAS DE MADEIRAS AMAZÔNICAS
}

\section{JADIR DE SOUZA ROCHA}

Tecnólogo em Madeiras

Orientador: Prof. Dr. JOSE NIVALDO GARCIA

\begin{abstract}
Dissertação apresentada à Escola Superior de Agricul tura "Luiz de Queiroz", da Universidade de São Paulo, para obtenção do título de Mestre em Ciências. Área de Concentração: Ciência e Tecnologia de Madeiras.
\end{abstract}

$\begin{array}{llllllllll}P & I & R & A & I & C & A & B & A\end{array}$

Estado de são Paulo - Brasil

Março - 1994 


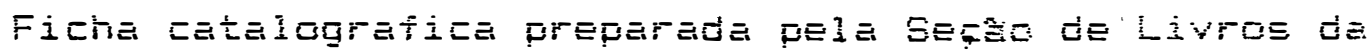

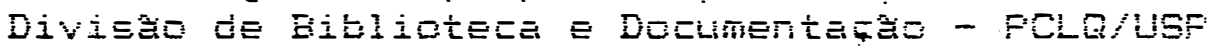

Fideñ, Jadi de ECuza

RS72E A EEguranta dE Estruturas de madeira determinada a partir ḋ variabiidiade da deñidade bisica e de pro-

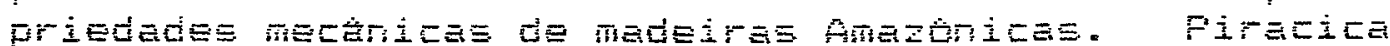
tia, 1974 .

1415.

DiSE. HEStre - ESALD

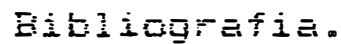

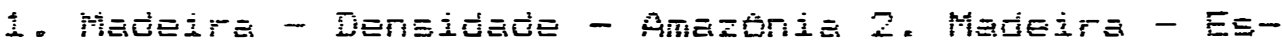

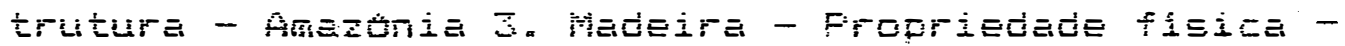

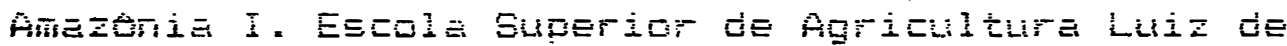
RuEjroz, Fíracisaba 


\title{
A SEgURANÇA DE ESTRUTURAs DE MADEIRA DETERMINADA A PARTIR DA VARIABILIDADE DA DENSIDADE BÁsICA E DE PROPRIEDADES MECÂNICAS DE MADEIRAS AMAZÔNICAS
}

\author{
JADIR DE SOUZA ROCHA
}

Aprovado em: 06.04 .94

Comissão julgadora:

Prof. Dr. José Nivaldo Garcia ESALQ/USP

Prof. Dr. Francisco Rocco Lahr EESC/USP

Dr. Rubens Dias Humphreys IPT

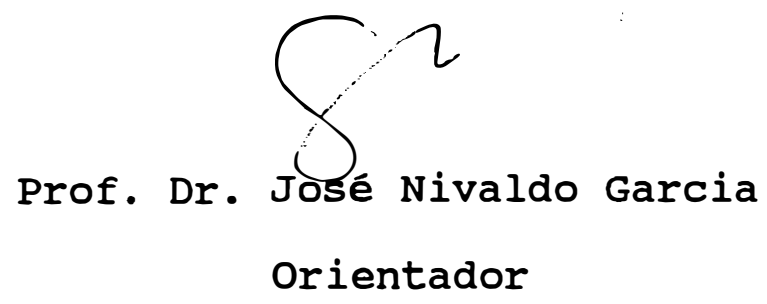


DEDICO ESTA DISSERTAÇÃO

\begin{abstract}
À minha esposa Cecilia e aos meus filhos Sandro, Roberta e Susana, pelo carinho, incentivo e principalmente pela compreensão da minha distância física em suas vio durante o transcorrer deste curso.
\end{abstract}

Aos meus pais e irmãos. 
AGRADECIMENTOS

Ao Prof. Dr. José Nivaldo Garcia, pela valiosa orientação, dedicação, amizade e incentivo durante todo este curso.

Ao Instituto Nacional de Pesquisas da Amazônia - INPA, pela oportunidade que me foi dada para a realização deste curso à nível de mestrado.

Ao Laboratório de Produtos Florestais - LPF do Instituto Brasileiro do Meio Ambiente e Recursos Naturais Renováveis - IBAMA, pelo fornecimento dos dados individuais das propriedades físicas e mecânicas das espécies arbóreas das áreas de Curuá-Una e Tapajós.

Aos funcionários do Departamento de ciências Florestais da ESALQ / USP, especialmente ao Luis Eduardo Facco, pelos serviços computacionais prestados na execução deste trabalho.

A pesquisadora Maria de Jesus Coutinho Varejão, pela amizade e apoio incondicional em todos os momentos do meu afastamento do INPA para a realização deste curso.

Aos pesquisadores Newton Falcão, Francisco Mota e ao Eng@. Francides Gomes Junior e suas famílias, pela preciosa ajuda durante a minha permanência em Piracicaba. Aos pesquisadores José Murilo Ferraz Suano e Mário Siqueira, pela colaboração no levantamento dos dados 
das regiões do Amapá, Balbina, Curuá-Una e Tapajós.

Aos pesquisadores Antonio Azevedo, Basilio

Vianez e Estevão V. C. M. de Paula, pelo incentivo dado à minha carreira de pesquisa.

Aos pesquisadores Alberto Brito, Tereza Bessa,

Vânia câmara e aos técnicos Luis Ramos, Luís Serrão e Márcio siqueira, pela amizade e ajuda prestada no Laboratório de Engenharia da Madeira da CPPF/INPA.

Aos pesquisadores Francisco Vasconcelos e Jorge Freitas e ao Eng̊. Domingos Macedo pela colaboração expontânea.

Aos professores do curso de pós-graduação em Ciência e Tecnologia de Madeiras, pela amizade e incentivos recebidos.

À Sra. Mercedes Oliveira Ramos pela amizade, incentivo e fé.

À amiga Graciena Xavier pelo apoio recebido junto ao PDIRH/INPA.

À todos os colegas dos cursos de pós-graduação em Ciência e Tecnologia de Madeiras e Ciências Florestais. 
SUMÁRIO

IIBTA DE FIGURAB......................... ix

IIBTA DE TABELAB ........................ xiv

8IMBOLOGIA............................ xvi

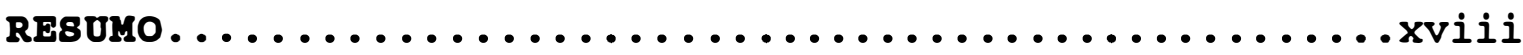

gUVMARY ................................. xxi

1. INTRODUÇÃO................................ 1

2. REVIBÃo DE IITERATURA...................... 6

2.1. Variabilidades das propriedades físicas e mecânicas da madeira...................... 7

2.2. Principais causas das variabilidades das propriedades físicas e mecânicas da madeira...... 12

2.2.1. Variabilidade da densidade.......... 12

2.2.2. Variabilidade da retração............. 14

2.2.3. Variabilidades das propriedades mecânicas............................... 17

2.2.4. Influência da umidade nas propriedades

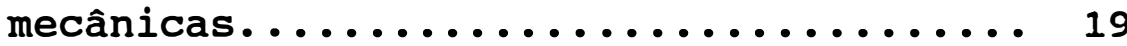

3. MATERIAL E MÉTODO8........................ 22

3.1. Regiōes de origem das espécies estudadas....... 22

3.2. Seleção das espécies................... 23

3.3. Amostragem......................... 23 
vii

3.4. Espécies estudadas...................... 24

3.5. Preparação das amostras.................. 29

3.6. Realização dos ensaios.................... 29

3.7. Análises estatisticas................... 30

3.7.1. Coeficiente de variação............. 31

3.7.2. Análise da variância da regressão..... 31

3.7.3. Formação dos grupos de espécies por classes de densidade básica.......... 31

3.7.4. Distribuição Weibull.............. 33

3.7.5. Ajuste para a distribuição dos dados.... 38

3.7.6. Teste de normalidade dos dados observa-

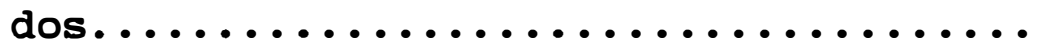

4. RESULTADOS E DI8CU88Ão....................... 40

4.1. Variabilidades da densidade básica, retrações tangencial, radial e volumétrica e propriedades mecânicas das madeiras estudadas nas condições verde e seca..........................

4.2. Relações entre retrações tangencial, radial e volumétrica e entre propriedades mecânicas nas condições verde e seca com a densidade básica • 44

4.3. Agrupamento de espécies................. 56

4.4. Ajuste para a distribuição dos dados.......... 60

4.5. Teste de normalidade dos dados observados...... 61 
4.6. Distribuição Weibull para a densidade básica e o módulo de ruptura à flexão estática das madeiras amazônicas nas condições verde e seca...

4.7. Densidade básica da madeira como um estimador de propriedades mecânicas................ 68

4.8. Distribuição Weibull para grupos de espécies... 69

4.9. Probabilidades de segurança das estruturas baseadas nos grupos de espécies.............. 73

4.10. Cálculo da segurança desejada através da variabilidade da densidade básica........... 86

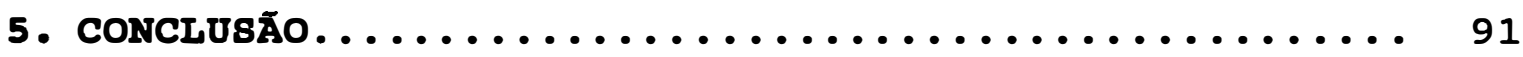

6. REFERÊNCIAS BIBLIOGRÁFICAS . . . . . . . . . . . . . . 95

ANEXOS 1................................ 102

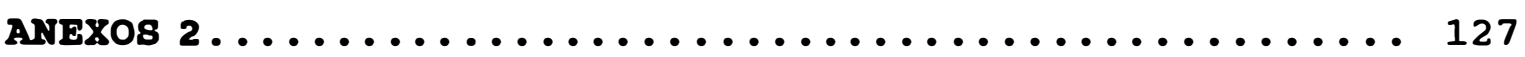

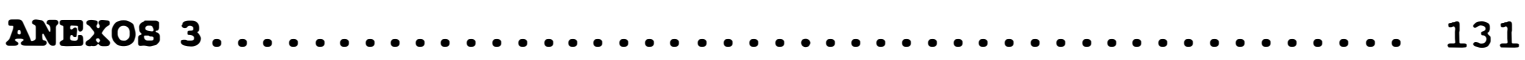

ANEXOS 4................................... 134

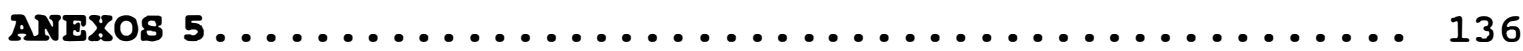

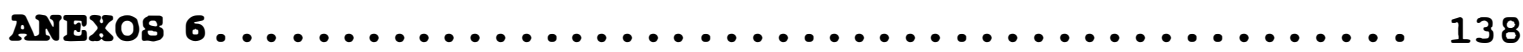




\section{IISTAS DE FIGURAS}

FIGURA 1. Relação entre retração e conteúdo de umidade com a remoção dos extrativos e com a presença dos mesmos na madeira de kenuar (CHOONG \& ACHMADI , 1991) ........................ 16

FIGURA 2. Relação entre módulo de elasticidade $\left(E_{f}\right)$ à flexão estática na condição verde e densidade básica (valores individuais reunindo todas as regiōes $). \ldots \ldots \ldots \ldots \ldots \ldots \ldots \ldots \ldots \ldots \ldots \ldots \ldots \ldots \ldots \ldots$

FIGURA 3. Relação entre módulo de elasticidade $\left(E_{f}\right)$ à flexão estática na condição seca e densidade básica (valores individuais reunindo todas as regions) $\ldots \ldots \ldots \ldots \ldots \ldots \ldots \ldots \ldots \ldots \ldots \ldots \ldots$

FIGURA 4. Relação entre módulo de ruptura $\left(f_{f}\right)$ à flexão estática na condição verde e densidade básica (valores individuais reunindo todas as

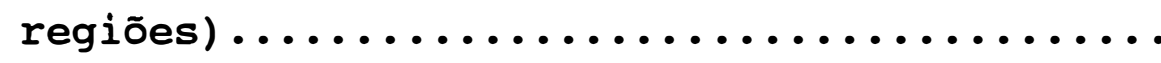

FIGURA 5. Relação entre módulo de ruptura $\left(f_{f}\right)$ à flexão estática na condição seca e densidade básica (valores individuais reunindo todas as regiones) $\ldots \ldots \ldots \ldots \ldots \ldots \ldots \ldots \ldots \ldots \ldots \ldots \ldots \ldots$ 
FIGURA 6. Relação entre tensão no limite de resistência $\left(f_{c}\right)$ à compressão paralela às fibras na condição verde e densidade básica (valores individuais reunindo todas as regiōes) ...... 50

FIGURA 7. Relação entre tensão no limite de resistência $\left(f_{c}\right)$ à compressão paralela às fibras na condição seca e densidade básica (valores individuais reunindo todas as regiōes) ....... 50

FIGURA 8. Relação entre módulo de resistência no limite de proporcionalidade $\left(f_{\mathrm{cn}}\right)$ à compressão normal às fibras na condição verde e densidade básica (valores individuais reunindo todas as regiōes) $\ldots \ldots \ldots \ldots \ldots \ldots \ldots \ldots \ldots \ldots \ldots$

FIGURA 9. Relação entre módulo de resistência no limite de proporcionalidade $\left(f_{c n}\right)$ à compressão normal às fibras na condição seca e densidade básica (valores individuais reunindo todas as regiões)

FIGURA 10. Relação entre tensão no limite de resistência $\left(f_{s}\right)$ ao cisalhamento paralelo às fibras na condição verde e densidade básica (valores individuais reunindo todas as regiōes)...

FIGURA 11. Relação entre tensão no limite de resistência $\left(f_{s}\right)$ ao cisalhamento paralelo às fibras na condição seca e densidade básica (valores individuais reunindo todas as regiōes) ...... 
FIGURA 12. Relação entre retração tangencial (Rt) e densidade básica (valores individuais reunindo todas as regiōes) .............. 55

FIGURA 13. Relação entre retração radial ( $R r)$ e densidade básica (valores individuais reunindo todas as regiōes) ..................... 55

FIGURA 14. Relação entre retração volumétrica (Rv) e densidade básica (valores individuais renindo todas as regiōes) ................ 56

FIGURA 15. Frequências de espécies arbóreas amazônicas por intervalos de classes de densidade básica.............................

FIGURA 16. f.d.p. ajustada aos dados observados de Db das madeiras da floresta amazônica estudadas na condição verde.....................

FIGURA 17. f.d.p. ajustada aos dados observados de Db das madeiras da floresta amazônica estudadas na condição seca.....................

FIGURA 18. F.d.a. ajustada aos dados observados de Db das madeiras da floresta amazônica estudadas na condição verde....................

FIGURA 19. F.d.a. ajustada aos dados observados de Db das madeiras da floresta amazônica estudadas na condição seca...................... 
FIGURA 20. f.d.p. ajustada aos dados observados do $f_{f} e$ aos dados do $f_{f}$ estimados através dos valores da Db das madeiras da floresta amazônica estudadas na condição verde............ 66

FIGURA 21. f.d.p. ajustada aos dados observados do $f_{f} e$ aos dados do $f_{f}$ estimados através dos valores da Db das madeiras da floresta amazônica estudadas na condição seca...............

FIGURA 22. F.d.a. ajustada aos dados observados do $f_{f} e$ aos dados do $f_{f}$ estimados através dos valores da $\mathrm{Db}$ das madeiras da floresta amazônica estudadas na condição verde...............

FIGURA 23. F.d.a. ajustada aos dados observados do $f_{f} e$ aos dados do $f_{f}$ estimados através dos valores da Db das madeiras da floresta amazônica estudadas na condição seca...............

FIGURA 24. F.d.a. ajustada aos dados observados do $f_{f} e$ aos dados do $f_{f}$ estimados através dos valores observados da Db nos grupos de espécies 1 a 4 das madeiras da floresta amazônica estudadas na condição verde............. 70

FIGURA 25. F.d.a. ajustada aos dados observados do $f_{f} e$ aos dados do $f_{f}$ estimados através dos valores observados da Db nos grupos de espécies 5 a 8 das madeiras da floresta amazônica estudadas na condição verde............. 71 
FIGURA 26. F.d.a. ajustada aos dados observados do $f_{f} e$ aos dados do $f_{f}$ estimados através dos valores observados da Db nos grupos de espécies 1 a 4 das madeiras da floresta amazônica es-

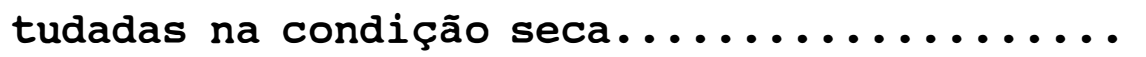

FIGURA 27. F.d.a. ajustada aos dados observados do $f_{f} e$ aos dados do $f_{f}$ estimados através dos valores observados da $\mathrm{Db}$ nos grupos de espécies 5 a 8 das madeiras da floresta amazônica estudadas na condição seca................

FIGURA 28. F.d.a. ajustada aos dados observados de Db para os grupos de espécies 1 a 4 das madei-

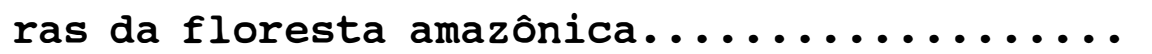

FIGURA 29. F.d.a. ajustada aos dados observados de Db para os grupos de espécies 5 a 8 das madeiras da floresta amazônica............. 90 


\section{LISTAS DE TABELAS}

TABELA 1. Valores médios dos coeficientes de variação de aproximadamente 50 espécies de madeiras

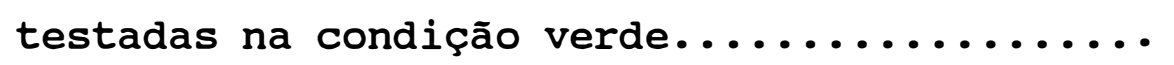

TABELA 2. Valores médios dos coeficientes de variação de 87 espécies coletadas nas regiões do Amapá, Balbina-AM, Curuá-Una e Tapajós-PA, testadas na condição seca ( $12 \%$ de umidade)...... 9

TABELA 3. Relações entre propriedades mecânicas de 39 espécies testadas na condição verde e densi-

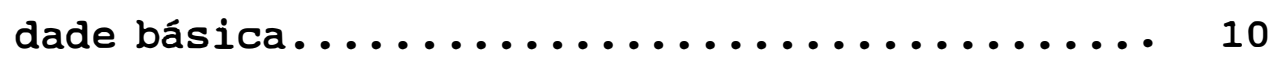

TABELA 4. Relações entre propriedades mecânicas de 39 espéćies testadas à $12 \%$ de umidade e densidade básica..........................

TABELA 5. Relações entre propriedades mecânicas de 87 espécies testadas à $12 \%$ de umidade e densida-

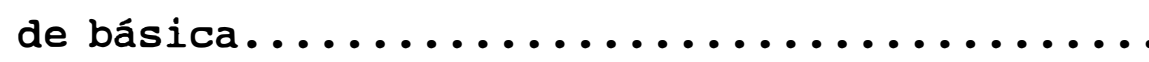

TABELA 6. Relações entre retração e densidade básica e propriedades mecânicas com densidade básica.. 12

TABELA 7. Relação das espécies estudadas no Amapá..... 24

TABELA 8. Relação das espécies estudadas em Balbina.... 25

TABELA 9. Relação das espécies estudadas em Curuá-Una.. 26

TABELA 10. Relação das espécies estudadas no Tapajós... 28 
TABELA 11. Valores dos coeficientes de variação e das probabilidades de $F$, para a densidade básica, retrações tangencial, radial e volumétrica e propriedades mecânicas das espécies do Amapá, Balbina, Curuá-Una e Tapajós, nas condições verde e seca à $12 \%$ de umidade.....

TABELA 12. Análise da variância da regressão obtida entre as retrações tangencial, radial e volumétrica e densidade básica e entre propriedades mecânicas nas condições verde e seca à $12 \%$ de umidade e densidade básica........ 45

TABELA 13. Relação das espécies contidas nos grupos.... 58

TABELA 14. Estimativas dos parâmetros a, b e c, da distribuição Weibull feitas em função da densidade básica observada das madeiras amazônicas estudadas nas condições verde e seca.... 65 
$x v i$

\section{SIMBOLOGIA}

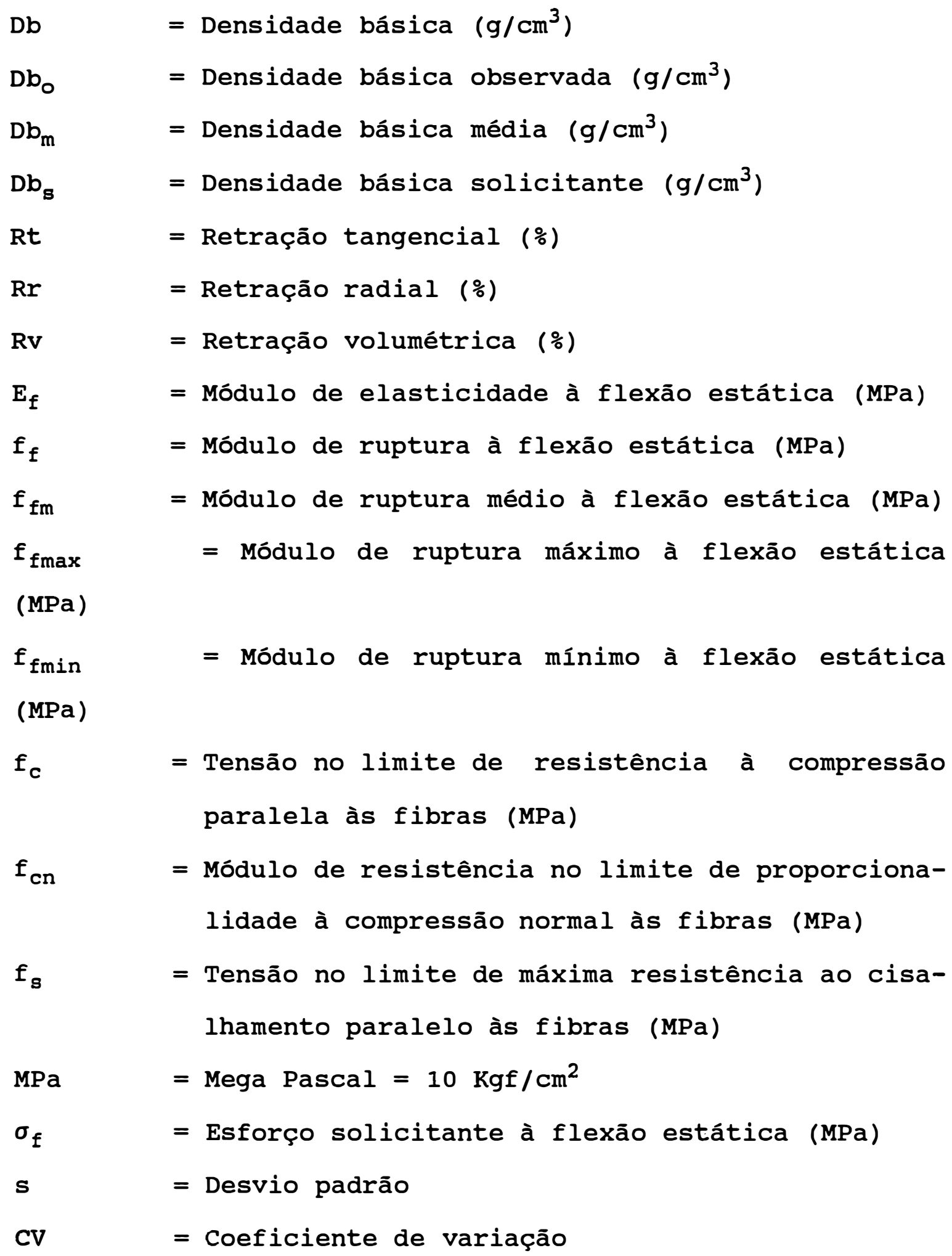


$\mathrm{R}^{2} \quad=$ Coeficiente de determinação

F

= Parâmetro estatístico da distribuição $\mathbf{F}$ de Snedecor

$\mathrm{P} \quad=$ Probabilidade $(\%)$

$\mathrm{P}_{\mathrm{r}} \quad$ = Probabilidade de ruína

$\mathrm{P}_{\mathrm{s}} \quad=$ Probabilidade de segurança

F.d.a. = Função de densidade acumulada da distribuição Weibull

f.d.p. = Função de densidade probabílistica da distribuição Weibull

a $\quad=$ Parâmetro da posição da distribuição Weibull

b = Parâmetro da escala da distribuição Weibull

c $\quad$ = Parâmetro da forma da distribuição Weibull

N $\quad=$ Tamanho da amostra

$\mathrm{u} \quad=$ Número de desvios padrão expresso pela diferença entre um determinado número e a média 


\section{A SEGURANÇA DE ESTRUTURAs DE MADEIRA DETERMINADA A PARTIR DA VARIABILIDADE DA DENSIDADE BÁsICA E DE PROPRIEDADES MECÂNICAS DE MADEIRAS AMAZÔNICAS}

Autor: Jadir de souza Rocha Orientador: Prof. Dr. José Nivaldo Garcia

\section{RESUMO:}

Para o desenvolvimento deste trabalho foram utilizados os dados individuais de densidade básica, de retrações e de cinco propriedades mecânicas nas condições verde e seca à $12 \%$ de umidade, obtidos de 150 espécies arbóreas, originárias das regiões do Estado do Amapá, Balbina no Estado do Amazonas, Curuá-Una e Tapajós no Pará.

$$
\text { Quantificaram-se as variabilidades das }
$$

propriedades das espécies em cada uma destas regiões e também na floresta amazônica como um todo.

Avaliaram-se as relações entre retrações e densidade básica e entre propriedades mecânicas e densidade básica .

Formaram-se grupos de espécies a partir dos intervalos de classes adotados para a densidade básica.

Foram ajustadas as frequências de densidades probabilística e acumulada da distribuição Weibull para cada grupo para os dados de densidade básica e do módulo de ruptura à flexão estática, sendo que neste último caso, as 
xix

curvas foram estimadas sobre os próprios dados do módulo de ruptura observados e também sobre os dados do módulo de ruptura estimados a partir da própria densidade básica.

Estas curvas de frequência obtidas, foram então, utilizadas na elaboração de um critério prático de medição da segurança das estruturas.

Os resultados obtidos revelam que:

- As variabilidades das propriedades estudadas tem a mesma ordem de grandeza em todas as regiōes e mesmo na floresta amazônica como um todo.

- As correlações entre retrações e densidade básica evidenciam que as primeiras não são diretamente proporcionais à segunda, enquanto que, entre propriedades mecânicas e densidade básica, os níveis de correlações são considerados satisfatórios;

- A formação de grupos de espécies por classes de densidade básica, possibilita maior e melhor aproveitamento volumétrico das madeiras amazônicas por unidade de área;

- A teoria desenvolvida possibilita quantificar a segurança das estruturas de madeira, tanto com os valores do módulo de ruptura à flexão estática como através de densidade básica ;

- Os resultados alcançados com a aplicação da distribuição Weibull, permitem assegurar que a simples determinação da densidade básica é suficiente para estimar as propriedades de resistência em amostras pequenas, livres de defeitos, 
para usá-las nos cálculos das estruturas de madeira;

- Os níveis de segurança adotados pela norma brasileira nas estruturas de madeira são, do ponto de vista material, exageradamente elevados. Esta constatação implica na necessidade de reavaliação dos níveis de segurança das estruturas de madeira. 
$\mathbf{x x i}$

\section{THE SECURITY OF TIMBER STRUCTURES DETERMINED FROM \\ THE VARIABILITY OF BASIC DENSITY AND FROM THE \\ MECHANICAL PROPERTIES OF AMAZONIAN TIMBERS}

Author: Jadir de souza Rocha

Adviser: Prof. Dr. José Nivaldo Garcia

\section{SUMOMARY:}

To develop this research, individual data on basic density, skrinkage, and five mechanical properties, were used upon wet and dry conditions this at $12 \%$ of humidity.

The data were obtained from 150 wood tree species collected from three regions: State of Amapá, state of Amazonas (Balbina), and state of Pará (Curuá-Una and Tapajós)

The species' properties variability was determined for each region as well as for the whole of the Amazonian rain forest.

The relationship between shrinkage and basic density, and between mechanical properties and basic density were evaluated.

Groups of species were organized based on basic density using class intervals with the related property.

The probalisty density function and the 
xxii

correlative distribution function from the Weibull distribution were adjusted for each group of basic density on modulus of rupture at static bending. From this group the curves were estimated from the data of modulus of rupture observed, and also from modulus of rupture at static bending data estimated from the basic density.

Finally, the security of timber structures was investigated.

The results showed that:

- The variability of the studied properties for each region and for the amazonian rain forest, seemed entirely uniform.

- The relationship between shrinkage and basic density makes clear that the first one isn't directly related with the second one. Meanwhile, between mechanical properties and basic density, the correlations are much higher.

- The classification of the species by class intervals of basic density, would allow for a better utilization of the Amazonian timbers per unity of area.

- The results obtained with the Weibull distribution, showed that: the determination of the basic density in small samples without defects is sufficient to estimate mechanical properties, for current use in timber structures calculus.

- The theory developed on this work let us to evaluate the security of wood structures, using data related to modulus 
xxiii

of rupture at static bending, or basic density.

- Levels of security adopted by the Brazilian standard for wood structure are extremely high. 


\section{IMTYRODUÇĀ̄o}

A madeira é um material heterogêneo por ser formada por diversos tipos de células capacitadas a desempenhar, na árvore, funções específicas e também por ser constituída de uma série de compostos químicos orgânicos e inorgânicos, além de sofrer influência de fatores que afetam o desenvolvimento das árvores, tais como clima, solo, local de crescimento e genéticos. Consequentemente, este conjunto de fatores são responsáveis pelas variabilidades das características e propriedades da madeira.

A experiência e a literatura têm mostrado que as variabilidades nas propriedades físicas e mecânicas da madeira não ocorrem somente entre diferentes espécies, mas também entre árvores de uma mesma espécie e na madeira de uma mesma árvore. Nem mesmo duas amostras de uma mesma árvore apresentam valores de propriedades físicas e mecânicas absolutamente iguais.

Assim, as propriedades físicas e mecânicas são dependentes da estrutura anatômica e composição química da madeira e, estas por sua vez, são normalmente influenciadas pelos fatores já mencionados. 
Em se tratando do imenso potencial florestal da Amazônia, sabe-se que a heterogeneidade da floresta é responsável pela grande diversidade de espécies arbóreas, onde, a maioria delas, apresenta um reduzido número de árvores por hectare.

Se por um lado, se considera que esta heterogeneidade da floresta se apresenta como um fator negativo, no que diz respeito à baixa quantidade volumétrica de madeira obtida de uma espécie por unidade de área, por outro lado é substancialmente positivo, tendo-se em vista que a grande diversidade de espécies possibilita um adequado agrupamento de espécies para as diversas categorias de usos finais. É necessário, entretanto, o conhecimento das variabilidades de suas características e propriedades e de suas implicaçōes no uso final.

Estimativas referentes ao potencial florestal da região amazônica, revelam que em território brasileiro, a floresta cobre aproximadamente 260 milhōes de hectares (KNOWLES, 1971; PANDOLFO, 1978, 1979) .

Essa vasta extensão, divide-se em cerca de 6,5 milhōes de hectares na floresta de várzea e os 253,5 milhões de hectares restantes são ocupados pela floresta de terrafirme (PANDOLFO, 1978, 1979). Segundo a autora os inventários florestais realizados na região, registram um potencial médio de $90 \mathrm{~m}^{3} /$ ha para a várzea e $178 \mathrm{~m}^{3} /$ ha para a terra-firme. Estudos realizados por KNOWLES (1971), revelam 
que o volume de madeira em pé de todas as árvores que apresentam diâmetro à altura do peito, maior do que $25 \mathrm{~cm}$, totalizam em média $200 \mathrm{~m}^{3} / \mathrm{ha}$. PANDOLFO (1978, 1979), baseando-se nos dados do Projeto RADAM, assegura que o volume de madeira em pé na região é superior a 45,5 bilhões de metros cúbicos.

Da literatura existente sobre estudos tecnologicos das madeiras da Amazônia Brasileira, pode-se estimar um total de 250 espécies, das quais, aproximadamente 50, são comercializadas em volume significativo.

Levando-se em consideração que na Amazônia Brasileira existem cerca de 3000 espécies arbóreas, enquanto, LOUREIRO et alii (1977), admitem a existência de 4000 espécies, pode-se concluir que a participação de espécies da floresta amazônica é muito pequena para o comércio de madeiras tropicais.

Esse pequeno aproveitamento das madeiras da região tem duas causas principais a saber:

- A exploração seletiva das madeiras, isto é, são extraídas da floresta somente as espécies tradicionalmente comercializadas ao longo dos anos.

- o desconhecimento tecnológico em torno da maioria das madeiras da Amazônia Brasileira.

Mediante os dados apresentados, estudos a cerca das variabilidades das madeiras amazônicas, como também a criação de alternativas que possam viabilizar a obtenção 
das características e propriedades das espécies pouco conhecidas e/ou desconhecidas, de forma mais rápida, devem ser intensificados cada vez mais, objetivando maior e melhor utilzação do imenso potencial florestal da região amazônica. Por essa razão, o presente trabalho pretende alcançar os objetivos seguintes:

- Quantificar as variabilidades de propriedades físicas e mecânicas de espécies arbóreas, determinadas nas condiçōes verde e seca, de diferentes regiōes da Amazônia Brasileira e também na floresta amazônica como um todo;

- Estudar as relaçōes entre as propriedades mecânicas, determinadas nas condiçōes verde e seca com a densidade básica, na tentativa de criar-se um indicador que possibilite estimar as propriedades mecânicas da madeira;

- Propor e comparar as formas de distribuição dos valores das propriedades físicas e mecânicas das madeiras amazônicas, determinadas na condição verde, com aquelas determinadas na condição seca;

- Fazer uma avaliação crítica da necessidade de estudarem-se as madeiras nas condiçōes verde e seca;

- Formar grupos de espécies visando a utilização de espécies não tradicionais, sem prejuízo da qualidade e segurança das estruturas, e com possibilidade de obter maior disponibilidade volumétrica de madeira por unidade de área;

- Quantificar a segurança das estruturas de madeira, através da distribuição Weibull e compará-la com as seguranças 
exigidas pela norma brasileira e com aquela calculada sobre uma suposta distribuição normal. 


\section{REVI8Āo DE IITERAYURA}

A consulta bibliográfica foi dividida em duas fases, onde:

- Buscou-se na literatura informaçōes a cerca de investigaçōes que quantifiquem as variabilidades das propriedades físicas e mecânicas da madeira, dando-se maior enfâse, sobretudo, no que diz respeito aos estudos realizados com espécies arbóreas da região amazônica;

- Posteriormente, fez-se levantamento bibliográfico obvjetivando ampliar o conhecimento referente aos resultados e consideraçōes mais importantes a cerca das influências de fatores inerentes à madeira, evidenciando aqueles que são os principais responsáveis pelas variabilidades das propriedades fisicas e mecânicas da madeira. Desse modo, procurou-se informaçōes no que tange à influência da estrutura anatômica, efeitos dos extrativos e da umidade da madeira visando explicar de forma consistente as causas das variabilidades das citadas propriedades. 
2.1. Variabilidades das propriedades fisicas e mecânicas da madeira

Nas investigações realizadas por PAULA et alii (1986), com propriedades mecânicas de trinta e nove espécies arbóreas do Estado do Amazonas, verificou-se que algumas espécies apresentaram uma grande variação nos seus resultados, sendo comum nas que possuem cerne e alburno distintos. Observou-se também que, outras espécies com densidade básica similares mostram valores das propriedades mecânicas bastante diferenciados. Com relação a esta última observação, NASCIMENTO (1993), realizando análises estatísticas objetivando investigar as variabilidades da densidade básica e de propriedades mecânicas de madeiras da Amazônia, constatou situação idêntica.

Nesse caso particular, ROCHA et alii (1988), ressaltam que não se deve afirmar de imediato, que quanto mais densa for a madeira, mais resistente ela será, pois a organização e dimensões dos elementos anatômicos exercem influências na resistência da madeira. Portanto, em função disso, as propriedades mecânicas podem ser aumentadas ou diminuidas, quando amostras de madeira são submetidas a determinados tipos de esforços.

Dezesseis espécies arbóreas amazônicas coletadas de mais de uma centena de serrarias instaladas nas cidades de Belém, Manaus e Santarém, foram estudadas por 
SLOOTEN et alii (1976). Os valores médios dos coeficientes de variação de algumas propriedades mecânicas na condição verde, variaram de $4,0 \%$ a $37,0 \%$

O U.S. FOREST PRODUCTS LABORATORY (1974), determinou os coeficientes de variação para algumas propriedades mecânicas de madeiras comercializadas nos Estados Unidos, conforme Tabela 1. Os valores obtidos são baseados nos resultados de testes de aproximadamente 50 espécies ensaiadas na condição verde. o autor admite ainda que para a condição seca (12\% de umidade), as madeiras apresentam valores, aproximadamente, na mesma grandeza.

Tabela 1 .

Valores médios dos coeficientes de variação de aproximadamente 50 espécies de madeiras testadas na condição verde

\begin{tabular}{ccccccc}
$\begin{array}{c}\text { Propriedades } \\
\text { físicas e mecânicas }\end{array}$ & Db & $E_{f}$ & $f_{f}$ & $f_{c}$ & $f_{c n}$ & $f_{s}$ \\
\hline $\begin{array}{c}\text { coeficiente de } \\
\text { variação }(\%)\end{array}$ & 10 & 22 & 16 & 18 & 28 & 14
\end{tabular}

Fonte: U. S. FOREST PRODUCTS LABORATORY (1974) - adaptada

NASCIMENTO (1993), encontrou os coeficientes de variação de madeiras testadas à $12 \%$ de umidade, as quais são originárias das regiōes do Amapá, Balbina-AM, Curuá-Una e Tapajós-PA. Os resultados apresentados na Tabela 2, são os valores médios dos coeficientes de variação englobando essas 
quatro regiōes.

Tabela 2 .

Valores médios dos coeficientes de variação de 87 espécies coletadas nas regiōes do Amapá, Balbina-AM, Curuá-Una e Tapajós-PA, testadas na condição seca ( $12 \%$ de umidade)

$\begin{array}{cccccccc}\begin{array}{c}\text { Propriedades } \\ \text { fisicas e mecânicas }\end{array} & \mathrm{Db} & \mathrm{E}_{\mathrm{f}} & \mathrm{f}_{\mathrm{f}} & \mathrm{f}_{\mathrm{c}} & \mathrm{f}_{\mathrm{cn}} & \mathrm{f}_{\mathrm{s}} \\ \begin{array}{c}\text { coeficiente de } \\ \text { variação (\%) }\end{array} & 24,9 & 23,2 & 31,6 & 28,7 & 46,4 & 33,5\end{array}$

Fonte: NASCIMENTO (1993) - adaptada

Observando-se as duas tabelas, verifica-se que os coeficientes de variação encontrados por NASCIMENTO (1993), são bastante elevados em relação aos obtidos pelo U. S. FOREST PRODUCTS LABORATORY (1974), sendo que neste último, existe excessão no módulo de elasticidade à flexão estática $\left(E_{f}\right)$

As investigaçōes realizadas por PAULA et alii (1986), permitiram-lhes afirmar que o coeficiente de variação em relação à média de uma mesma espécie ensaiada na condição seca, é superior aos valores obtidos na condição verde. Os autores explicam que a causa desta maior variação deve-se ao fato de que a madeira, ao ser submetida ao processo de climatização para alcançar o teor de $12 \%$ de umidade, sofre alteraçōes físico-químicas, as quais contribuem para aumentar 
a variação da resistência de uma mesma espécie.

Procurando relacionar propriedades mecânicas e densidade básica de madeiras do Estado do Amazonas, PAULA et alii (1986), através de uma análise de regressão simples, encontraram coeficientes de determinação $\left(R^{2}\right)$. variando de 0,64 a 0,76 para madeiras testadas na condição verde e 0,58 a 0,77 para madeiras secas a $12 \%$ de umidade, conforme Tabelas 3 e 4 .

Os coeficientes de determinação obtidos por NASCIMENTO (1993), em madeiras do Amapá, Balbina, Curuá-Una e Tapajós, todas testadas à $12 \%$ de umidade, variaram de 0,56 a 0,88 , conforme Tabela 5. Dentre essas quatro áreas, as madeiras de Balbina foram as que apresentaram coeficientes de determinação mais próximos dos obtidos por PAULA et alii (1986), principalmente na condição verde.

Tabela 3. Relaçōes entre propriedades mecânicas de 39 espécies testadas na condição verde e densidade básica

\begin{tabular}{cc}
\hline Regressão & $\mathrm{R}^{2}$ \\
\hline $\mathrm{E}_{f} \times \mathrm{Db}$ & 0,65 \\
$\mathrm{f}_{f} \times \mathrm{Db}$ & 0,76 \\
$f_{c} \times \mathrm{Db}$ & 0,76 \\
$f_{c n} \times \mathrm{Db}$ & 0,72 \\
$\mathrm{f}_{s} \times \mathrm{Db}$ & 0,64 \\
\hline Fonte: PAULA et alii (1986) & - adaptada
\end{tabular}


Tabela 4 .

Relaçōes entre propriedades mecânicas de 39 espécies testadas à $12 \%$ de umidade e densidade básica

\begin{tabular}{cc}
\hline Regressão & $\mathrm{R}^{2}$ \\
\hline $\mathrm{E}_{f} \times \mathrm{Db}$ & 0,61 \\
$f_{f} \times \mathrm{Db}$ & 0,58 \\
$f_{c} \times \mathrm{Db}$ & 0,76 \\
$f_{c \mathrm{D}} \times \mathrm{Db}$ & 0,77 \\
$f_{s} \times \mathrm{Db}$ & 0,59 \\
\hline
\end{tabular}

Fonte: PAULA et alii (1986) - adaptada

Tabela 5. Relaçōes entre propriedades mecânicas de 87 espécies testadas à $12 \%$ de umidade e densidade básica

\begin{tabular}{lcccc}
\hline & \multicolumn{4}{c}{ REGIÕES } \\
\cline { 2 - 5 } Regressão & Amapá & Balbina & Curuá-Una & Tapajós \\
\hline$E_{f} \times \mathrm{Db}$ & 0,78 & 0,69 & 0,74 & 0,56 \\
$f_{f} \times \mathrm{Db}$ & 0,88 & 0,72 & 0,83 & 0,68 \\
$f_{c} \times \mathrm{Db}$ & 0,86 & 0,78 & 0,79 & 0,68 \\
$f_{c n} \times \mathrm{Db}$ & 0,81 & 0,70 & 0,88 & 0,67 \\
$f_{\mathbf{s}} \times \mathrm{Db}$ & 0,69 & 0,66 & 0,76 & 0,56 \\
\hline
\end{tabular}

Fonte: NASCIMENTO (1993)

Nos estudos desenvolvidos por CHIMELO (1980), com 32 espécies arbóreas da estação experimental de CuruáUna, foram obtidos coeficientes de determinação variando de 0,02 a 0,09 nas relaçōes entre as retraçōes tangencial e radial e densidade básica e de 0,63 a 0,78 nas relaçōes entre 
propriedades mecânicas (condição verde) e densidade básica, conforme Tabela 6 .

Tabela 6. Relações entre retração e densidade básica e propriedades mecânicas com densidade básica

\begin{tabular}{lc}
\hline Regressão & $\mathrm{R}^{2}$ \\
\hline$R t \times \mathrm{Db}$ & 0,02 \\
$\mathrm{Rr} \times \mathrm{Db}$ & 0,09 \\
$\mathrm{E}_{f} \times \mathrm{Db}$ & 0,68 \\
$\mathrm{f}_{\mathrm{f}} \times \mathrm{Db}$ & 0,78 \\
$f_{c} \times \mathrm{Db}$ & 0,78 \\
$f_{c \mathrm{c}} \times \mathrm{Db}$ & 0,73 \\
$f_{s} \times \mathrm{Db}$ & 0,66 \\
\hline
\end{tabular}

Fonte: CHIMELO (1980) - adaptada

\subsection{Principais causas das variabilidades das propriedades físicas e mecânicas da madeira}

\subsubsection{Variabilidade da densidade}

Estudos efetuados por KOLLMANN \& CÔTÉ (1968), revelam que variações na densidade da madeira são ocasionadas pelas diferenças na sua estrutura e devido à presença de constituintes estranhos. Segundo estes autores, a estrutura da madeira é caracterizada por quantidades proporcionais de diferentes tipos de células, tais como fibras, traqueídes, vasos, parênquimas, canais de resinas, raios e pelas suas dimensões, especialmente no que concerne à espessura das 
paredes celulares.

Também a localização no sentido longitudinal e transversal na árvore, exerce um considerável efeito sobre a densidade da madeira e, consequentemente, sobre as propriedades mecânicas.

De acordo com Prutz (1941), citado por KOLLMANN \& CÔTÉ (1968), madeiras tropicais são em média 23\% mais pesadas do que espécies temperadas do hemisfério norte e de zona subtropical. Madeiras com grande quantidade de constituintes minerais (oxilato e silicato de cálcio) são pesadas e duras. É mencionando ainda que a presença de tiloses nos vasos aumenta a densidade, como também a presença de alto conteúdo de resina.

As principais caracteristicas das madeiras pesadas são compacidade do tecido fibroso, pequena quantidade de vasos e parênquimas, além de uma forte lignificação das paredes celulares. Ao passo que, madeiras com tecido parenquimático abundante, poros numerosos ou de grande diâmetro, pequena porcentagem de fibras, paredes delgadas, são consideradas leves (PEREIRA, s/d).

GARCIA \& QUIRINO (1993), estudando a madeira de ipê (Tabebuia sp), constataram que a remoção de extrativos, equivalente a $6,27 \%$ do peso das amostras, ocasionou um decréscimo de $2,30 \%$ no valor da densidade básica.

Segundo considerações feitas por JANKOWSKY 
(1979), a deposição dos extrativos pode ocorrer nos espaços intra e inter-celulares, na superfície e no interior da parede celular, contribuindo para aumentar o peso seco da madeira e também, diminuirá a disponibilidade dos espaços para a fixação das moléculas de água. o autor explica que isso acontece devido à absorção da umidade do ar pela madeira ocorrer quase que exclusivamente na parede celular e que sua espessura, normalmente, tem relação com a densidade básica. Visando detectar a localização dos extrativos na madeira, CHOONG (1969), relata que aqueles solúveis em água localizam-se, na sua totalidade, dentro da parede celular. Enquanto, aqueles insolúveis em água concentram-se, em uma moderada quantidade, nos capilares grossos, podendo portanto, afetar o peso da madeira. Por essa razão, o autor admite que a remoção dos extrativos dos capilares, deve afetar a higroscopicidade e, consequentemente, ocasionar a diminuição do peso inerte da madeira.

Investigações realizadas por FOELKEL et alii (1974), em espécies plantadas de Eucalyptus, mostraram que uma dada espécie, com o aumento da idade, ocorreu um ligeiro acréscimo na densidade básica, aumentando os teores de extrativos.

2.2.2. Variabilidade da retração

Nas observações feitas por STAMM (1964), é 
revelado que os raios, alternância dos lenhos inicial e tardio, a quantidade de pontoaçōes e respectivas localizações, assim como o desvio de orientação das microfibrilas, quando estas contornam as pontoaçōes, afetam a retração transversal da madeira.

Os efeitos combinados da retração tangencial e radial ocasionam a mudança da forma das peças da madeira por causa das diferenças na retração e curvatura dos anéis de crescimento (U. S. FOREST PRODUCTS LABORATORY, 1974). É explicado também que madeira de reação ou madeira de compressão, em espécies de madeira mole ou madeira de tensão em espécies de madeiras duras, tendem a se contrair excessivamente ao longo da grã. Madeira próxima ao centro da árvore (madeira juvenil), de algumas espécies, também se contrae excessivamente. Madeira com grã reversa, exibe diminuta retração longitudinalmente.

Em estudo recente, CHOONG \& ACHMADI (1991), desenvolvendo experimentação com 16 espécies de madeiras tropicais, verificaram que a remoção dos extrativos provocou uma retração excessiva nas madeiras, conforme pode ser observado na Figura 1.

Estudos desenvolvidos por TARKOW \& KRUEGER (1961), e Stone \& Scallan (1967), citados por CHAFE (1987), revelam que apreciáveis quantidades de extrativos localizamse nas paredes celulares da madeira. Conforme os relatos destes autores, pode-se admitir que devido aos extrativos 
ocuparem espaços nas paredes celulares, os mesmos são, em efeito, agentes de enchimento natural que contribuem para uma menor retração da madeira durante a remoção da água.

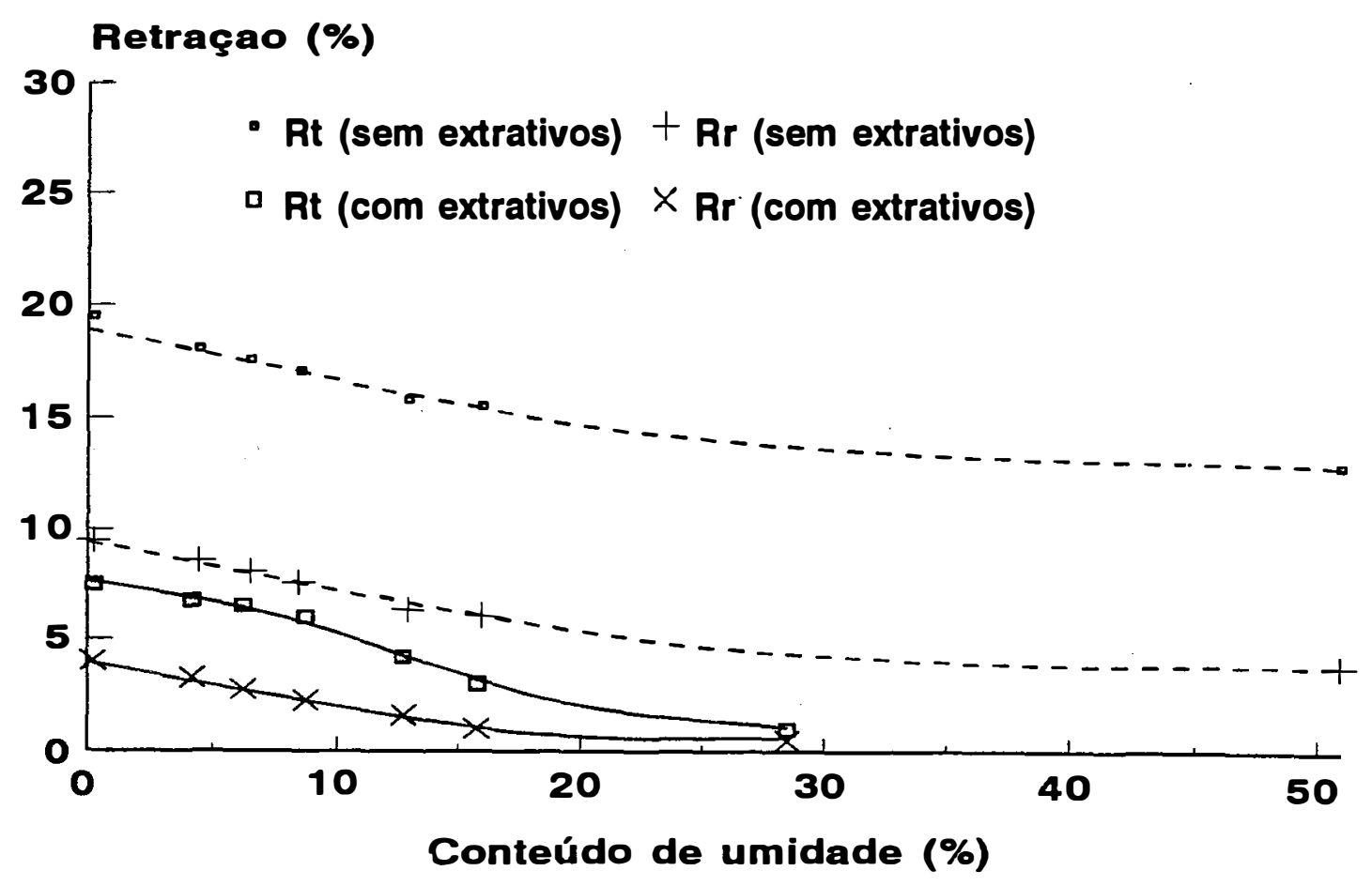

Figura 1. Relação entre retração e conteúdo de umidade com a remoção dos extrativos e com a presença dos mesmos na madeira de kenuar (CHOONG \& ACHMADI, 1991)

ARGANBRIGHT (1971), explica que a influência dos extrativos, não somente nas propriedades mecânicas, mas também nas propriedades físicas, depende dos diferentes componentes químicos que compreendem os extrativos totais e suas quantidades relativas. 


\subsubsection{Variabilidades das propriedades mecânicas}

De uma maneira geral, a literatura menciona que as propriedades mecânicas da madeira não variam somente com a densidade, mas também com a estrutura anatômica, os extrativos e a umidade.

Segundo considerações feitas por BURGER \& RICHTER (1991), os vasos, devido à sua grande dimensão, e às paredes delgadas, são estruturas fracas. Portanto, sua abundância, dimensão e distribuição influem na resistência mecânica da madeira. O lenho com porosidade em anel (poros grandes acumulados no inicio do periodo vegetativo) é menos resistente a determinados esforços mecânicos do que o lenho com porosidade difusa (poros distribuldos uniformemente ao longo do anel de crescimento). Os autores revelam também que - parênquima axial é um tecido fraco, cuja abundância e distribuição, principalmente quando se apresenta formando amplas faixas contínuas, pode ocasionar um considerável decréscimo nas propriedades mecânicas da madeira.

As investigações realizadas por PANSHIN \& ZEEUW (1970), revelam que a capacidade da madeira em resistir a um determinado esforço não é somente concernente à quantidade total do material presente na parede celular, mas também das proporções dos componentes da parede celular existentes em uma dada amostra de madeira e, ainda da quantidade de extrativos no lúmen das células. 
Uma amostra de madeira apresentando fibras a um determinado ângulo em relação ao eixo longitudinal, estará sujeita aos esforços diretos de tração e compressão, contribuindo para que os componentes dos esforços sejam induzidos por meio da grã. Isto torna a madeira menos resistente neste sentido do que ao longo do seu eixo longitudinal. Desse modo, madeiras com ângulo de inclinação acentuado da grã, apresentam baixa resistência mecânica (KOLLMANN \& CÔTÉ, 1968).

Luxford (1931), citado por ARGANBRIGHT (1971), revela que, aumentando os teores de extrativos da madeira, geralmente, aumentam os valores de propriedades mecânicas, tais como compressão paralela às fibras, módulo de ruptura à flexão estática e resistência ao choque.

o grau com que os extrativos influenciam a resistência, é aparentemente, uma função de suas quantidades, do teor de umidade da madeira e da propriedade mecânica considerada. Um pequeno acréscimo no módulo de ruptura e na resistência à compressão paralela às fibras tem sido detectado em algumas espécies que contém extrativos (U. $\mathrm{S}$. FOREST PRODUCTS LABORATORY, 1974).

Pesquisas desenvolvidas por ARGANBRIGHT (1971), visando detectar possíveis influências dos extrativos na madeira de "redwood" (Sequoia sempervirens) submetida ao ensaio de flexão estática nas condições verde e seca à $12 \%$ de umidade, revelaram que a presença de extrativos não aumenta 
a resistência à flexão, como anteriormente foi mencionado por Luxford (1931). Os valores do módulo de ruptura, verde e seco, não apresentaram relaçāo com a quantidade de extrativos presentes. Enquanto que, os valores do módulo de elasticidade, verde e seco, diminuíram com o aumento da quantidade de extrativos.

A razão pela qual o módulo de elasticidade é afetado pelos extrativos, enquanto, o módulo de ruptura não sofre a influência destes, ainda permanece inexplicável. Todavia, o autor admite que os extrativos afetam a resistência com a mesma intensidade que a água.

visando investigar os efeitos dos extrativos na compressão paralela às fibras, GARCIA \& QUIRINO (1993), realizaram experimentaçāo com a madeira de ipê (Tabebuia sp) e constataram que a remoção de apenas $1,9 \%$ de extrativos ocasionou um decréscimo de $17,30 \%$ naquela propriedade.

\subsubsection{Influência da umidade nas propriedades mecânicas}

As propriedades mecânicas da madeira variam inversamente com o conteúdo de umidade abaixo do ponto de saturação das fibras. Este comportamento é compreensível quando se considera a expansão ou a contração que ocorre na madeira, quando ela ganha ou perde umidade. Em efeito, as variaçōes na umidade produzem diferenças no peso específico 
da madeira e consequentemente resultam em variações na resistência (PANSHIN \& ZEEUW, 1970).

$$
\text { KOLLMANN \& CÔTÉ (1968), explicam que o }
$$

decréscimo da resistência da madeira quando esta ganha umidade até o ponto de saturação das fibras, é compreendido por considerar que as moléculas de água são depositadas dentro das micelas e desse modo ocasionam um aumento das distâncias entre as mesmas. Devido a este fato, ocorre uma redução das forças de atração entre as micelas, contribuindo assim para diminuir a coesão.

Tem sido largamente evidenciado que as propriedades mecânicas da madeira, permanecem estáveis quando ocorrem variações da sua umidade acima do ponto de saturação das fibras. Porém, nos experimentos desenvolvidos por WILSON, CARLSON \& LUXFORD (1960), foi constatado que a madeira apresenta uma ligeira variação nas propriedades mecânicas acima do referido ponto. Nesse caso particular, deve ser admitida a possibilidade de que as amostras não estavam no seus pontos de saturação reais, por não apresentarem umidade uniforme, ou seja, possuiam níveis de umidade diferenciados entre a superfície e as regiōes mais internas das amostras. objetivando quantificar a influência da umidade nos módulos de ruptura e elasticidade à flexão estática de duas espécies de madeira, JOHNSON (1965), utilizou amostras nas condições verde e seca ao ar, climatizadas ou não. Constatou que no módulo de ruptura das 
amostras secas ao ar, houve um acréscimo de $43 \%$ em relação às amostras em estado verde. Enquanto, no módulo de elasticidade, o acréscimo foi de aproximadamente $18 \%$. Investigaçōes feitas por FINDLAY (1975), revelam que a madeira seca à $12 \%$ de umidade, quando submetida ao esforço de compressão paralela às fibras, pode apresentar o dobro da resistência alcançada quando a madeira está no estado verde. 


\section{MATERIAT B MÉTODOS}

Para o desenvolvimento deste trabalho foram utilizados os dados de propriedades físicas e mecânicas de 150 espécie de madeira, obtidas a partir de amostras, livres de defeitos, nas condiçōes verde e seca à $12 \%$ de umidade. Os dados foram obtidos dos projetos de caracterização tecnológica realizados pelo Laboratório de Produtos Florestais (LPF) do Instituto Brasileiro do Meio Ambiente e Recursos Naturais Renováveis (IBAMA) e pela Coordenação de Pesquisas em Produtos Florestais (CPPF) do Instituto Nacional de Pesquisas da Amazônia (INPA)

\subsection{Regiōes de origem das espécies estudadas}

O LPF estudou espécies arbóreas das regiōes de Curuá-Una e Tapajós, ambas localizadas no Estado do Pará. Enquanto, a CPPF estudou espécies da área da hidrelétrica de Balbina, no Município de Presidente Figueiredo no Estado do Amazonas e espécies do Estado do Amapá. 


\subsection{Seleção das espécies}

Foi realizada com base nos inventários préexploratórios efetuados em cada uma dessas áreas. Os requisitos para a seleção concentraram-se em espécies pouco conhecidas e/ou desconhecidas, com diâmetro à altura do peito (DAP) maior ou igual a $40 \mathrm{~cm}$.

Deve ser ressaltado que devido a algumas espécies tradicionais que encontravam-se estudadas apenas parcialmente por outras instituiçōes, O LPF e a CPPF coletaram-nas para a complementação de estudos que são imprescindíveis para maior e melhor utilização das mesmas.

\subsection{Amostragem}

Foi realizada de acordo com o sistema de amostragem ao acaso, conforme as especificaçōes das normas COPANT (1972). Essas normas estabelecem que, em estudos tecnológicos, para se obter um valor médio mais confiável para as propriedades físicas e mecânicas, deve-se tomar, pelo menos, três árvores para cada espécie a ser ensaiada. Quando não se tem um conhecimento prévio da espécie, é recomendado trabalhar, preferivelmente, com uma segurança estatística de $95 \%$ e um intervalo de confiança de $\pm 15 \%$, para o qual deve tomar-se o número mínimo de cinco árvores para cada espécie. Apesar das recomendaçōes das normas COPANT 
quanto ao número de árvores a serem ensaiadas, houve falhas na identificação de algumas espécies no momento do abate. Após a identificação botânica e anatômica, detectou-se que determinadas espécies estavam apenas com duas árvores. Tendo em vista que tais espécies apresentavam diâmetro grande e, consequentemente, apreciável volume de madeira, tanto o LPF quanto a CPPF resolveram incluí-las nos estudos.

\subsection{Espécies estudadas}

Do Estado do Amapá foram estudadas 15 espécies, de Balbina 36, de Curuá-Una 69 e no Tapajós 29, perfazendo um total de 150 espécies. As espécies, com seus respectivos nomes comum e científico, encontram-se nas Tabelas 7, 8, 9 e 10, respectivamente para o Estado do Amapá, região de Balbina, de Curuá-Una e do Tapajós.

Tabela 7. Relação das espécies estudadas no Amapá

\begin{tabular}{ll}
\hline \multicolumn{1}{c}{ Nome cientifico } & Nome vulgar \\
\hline Alexa imperatricis (Schomb) Baill & melancieira \\
Couratari guianensis Aubl. & tauari \\
Eperua sp. & s/ nome vulgar \\
Eschweilera sagotiana & matá-matá-branco \\
Lecythis poiteaui & jarana \\
Manilkara amazonica (Huber) standly & maparajuba \\
Parkia nitida Miq. & fava \\
Parkia ulei Kuhlm & fava \\
Parinari montana & uchirana \\
Peltogyne paradoxo Ducke & coatá-quiçaua \\
\hline \hline
\end{tabular}


continuação

\begin{tabular}{ll}
\hline Protium tenuifolium (Engl.) & breu \\
Sacoglottis guianensis Benth. & achuá \\
Sclerolobium sp. & tachi-branco \\
Tetragastris panamensis (Engl.) 0. & breu-branco \\
Kuntze & \\
Thyrsodium guianensis Aubl. & s/ nome vulgar \\
Vochysia guianensis Aubl. & quari
\end{tabular}

Tabela 8. Relação das espécies estudadas em Balbina

\begin{tabular}{|c|c|}
\hline Nome cientifico & Nome vulgar \\
\hline $\begin{array}{l}\text { Aldina heterophylla Spr. ex. Benth. } \\
\text { Alexa grandiflora Ducke } \\
\text { Andira parviflora Ducke } \\
\text { Aspidosperma obscurinervium Azambuja } \\
\text { Brosimum rubescens Taubert } \\
\text { Buchenavia oxycarpa Eichler } \\
\text { Carapa guianensis Aubl. } \\
\text { Cariniana integrifolia Ducke } \\
\text { Cedrelinga catenaeformis Ducke } \\
\text { Clarisia racemosa R. \& Pav. } \\
\text { Corythophora rimosa W. Rodr. } \\
\text { Couratari stellata A. C. Smith } \\
\text { Dipteryx odorata (Aubl.) Willd } \\
\text { Dipteryx polyphylla (Huber) Ducke } \\
\text { Enterolobium schomburgkii Benth. } \\
\text { Erisma uncinatum Warm. } \\
\text { Eschweilera odora (Poepp) Miers } \\
\text { Goupia glabra Aubl. } \\
\text { Guarea trichilioides L. } \\
\text { Hymenolobium excelsum Benth. } \\
\text { Hymenolobium pulcherrimum Ducke } \\
\text { Iryanthera tricornis Ducke } \\
\text { Jacaranda copaia (Aubl.) D. Don } \\
\text { Licaria aritu Ducke } \\
\text { Licaria canela (Helssn) Kostern } \\
\text { Manilkara huberi (Ducke) A. Chev. } \\
\text { Mezilaurus itauba (Melssn) Taub. } \\
\text { Nectandra rubra (Mez) C. K. Allen } \\
\text { Pithecelobium racemosum Ducke } \\
\text { Pouteria guianensis Aubl. }\end{array}$ & $\begin{array}{l}\text { macucu-de-paca } \\
\text { melancieira } \\
\text { sucupira-vermelha } \\
\text { piquiá-marfim } \\
\text { pau-rainha } \\
\text { tanimbuca } \\
\text { andiroba } \\
\text { tauari } \\
\text { cedrorana } \\
\text { guariúba } \\
\text { castanha-jacaré } \\
\text { tauari } \\
\text { cumaru } \\
\text { cumarurana } \\
\text { sucupira-amarela } \\
\text { quarubarana } \\
\text { matá-matá-preto } \\
\text { cupiuba } \\
\text { gitó } \\
\text { angelim-da-mata } \\
\text { angelim-pedra } \\
\text { ucuúba-punã } \\
\text { caroba } \\
\text { louro-aritu } \\
\text { louro-chumbo } \\
\text { maçaranduba } \\
\text { itaúba-amarela } \\
\text { louro-gamela } \\
\text { angelim-rajado } \\
\text { abiurana-abiu }\end{array}$ \\
\hline
\end{tabular}


continuação

Qualea paraensis Ducke

Scleronema micranthum Ducke

Simaruba amara Aubl.

Swartzia panacoco (Kubl.) Cowan

Tabebuia serratifolia (Vani) Nich.

Vataireopsis sp. mandioqueira

cardeiro

marupá

coração-de-negro

pau-d'arco

angelim

Tabela 9. Relação das espécies estudadas em Curuá-Una

\begin{tabular}{|c|c|}
\hline Nome cientifico & Nome vulgar \\
\hline $\begin{array}{l}\text { Aniba canelilla (H. B. K.) Mez } \\
\text { Astronium gracile Engl. } \\
\text { Astronium lecointei Ducke } \\
\text { Astronium ulei Mattick } \\
\text { Bowdichia nitida Spruce ex Benth } \\
\text { Brosimum alicastrum Swartz } \\
\text { Clarisia racemosa Ruiz \& Pav. } \\
\text { Cassia scleroxylon Ducke } \\
\text { Couratari oblongifolia Ducke \& R. } \\
\text { Knuth } \\
\text { Dialium guianense (Aubl.) Sandw. } \\
\text { Didymopanax morototoni (Aubl.) Decne } \\
\text { \& Planch } \\
\text { Dinizia excelsa Ducke } \\
\text { Diploon venezuelana Aubrév. } \\
\text { Dipteryx odorata Willd } \\
\text { Drypetes variabilis Uittien } \\
\text { Endopleura uchi (Huber) Cuatr. } \\
\text { Enterolobium schomburgkii Benth } \\
\text { Erisma uncinatum Warm. } \\
\text { Eschweilera amara (Aubl.) NDZ. } \\
\text { Eschweilera sp. } \\
\text { Franchetella gongrijpii (Eyma) } \\
\text { Aubrév. } \\
\text { Glycydendron amazonicum Ducke } \\
\text { Goupia glabra Aubl. } \\
\text { Guatteria olivacea R. E. Fries } \\
\text { Hymenaea courbaril L. var courbaril } \\
\text { Hymenaea parviflora Huber } \\
\text { Hymenolobium modestum Ducke }\end{array}$ & $\begin{array}{l}\text { preciosa } \\
\text { muiracatiara } \\
\text { muiracatiara } \\
\text { muiracatiara } \\
\text { sucupira } \\
\text { janitá } \\
\text { guariúba } \\
\text { muirapixuna } \\
\text { tauarí } \\
\text { jutaí-pororoca } \\
\text { morototó } \\
\text { angelim-pedra } \\
\text { verdadeiro } \\
\text { abiurana-seca } \\
\text { cumaru } \\
\text { pau-branco } \\
\text { uchi-liso } \\
\text { fava-de-rosca } \\
\text { quarubarana } \\
\text { matá-matá-vermelho } \\
\text { matá-matá-ci } \\
\text { abiurana-branca }\end{array}$ \\
\hline
\end{tabular}


continuação

\begin{tabular}{|c|c|}
\hline $\begin{array}{l}\text { Inga alba Willd. } \\
\text { Inga paraensis Ducke } \\
\text { Lecythis pisonis Cambess. Subsp. } \\
\text { usitata (Miers) Mori \& Prance } \\
\text { Licania octandra (Hoffm. ex Roem \& } \\
\text { Schult) o. Kuntze } \\
\text { Licaria rigida (Kosterm.) Kosterm. } \\
\text { Lueheopsis duckeana Burret } \\
\text { Malouetia duckei Mgf. } \\
\text { Manilkara amazonica (Huber) Standley } \\
\text { Micropholis venulosa (Mart. \& Eichl.) } \\
\text { Pière } \\
\text { Nemaluma anomala (Pires) Pires } \\
\text { (ined.) } \\
\text { Ocotea neesiana (Miq.) Kosterm. } \\
\text { Ocotea sp. } \\
\text { Onychopetalum amazonicum R. E. Fries } \\
\text { Ormosia paraensis Ducke } \\
\text { Parkia paraensis Ducke } \\
\text { Parkia pendula Benth. ex Walp. } \\
\text { Piptadenia suaveolens Miq. } \\
\text { Planchonella pachycarpa Pires (ined.) } \\
\text { Pouteria caimito (R. \& P.) Radlk. } \\
\text { Protium sp. } \\
\text { Protium tenuifolium (Engl.) Engl. } \\
\text { Qualea albiflora Warm. } \\
\text { Qualea brevipedicellata stafleu } \\
\text { Rollinia exsucca (Dun) A. D. C. } \\
\text { Roupala montana Aubl. } \\
\text { Sandwithiodoxa egregia (Sandw.) Aubr. } \\
\text { \& Pellegr. } \\
\text { Sclerolobium chrysophyllum Poepp \& } \\
\text { Endl. } \\
\text { Sclerolobium paraense Huber } \\
\text { Sclerolobium poeppigianum Baill. } \\
\text { Sterculia speciosa K. Schum } \\
\text { Tymphonia globulifera L. } \\
\text { Tetragastris altissima (Aubl.) Swartz } \\
\text { Tetragastris panamensis (Engl.) O. } \\
\text { Kuntze } \\
\text { Trattinickia burserifolia (Mart.) } \\
\text { Willd. } \\
\text { Trattinickia cf. Burserifolia Mart. } \\
\text { Trichilia lecointei Ducke }\end{array}$ & $\begin{array}{l}\text { louro-canela } \\
\text { louro-canela } \\
\text { envira-preta } \\
\text { tento } \\
\text { fava-arara-tucupi } \\
\text { faveira-bolota } \\
\text { fava-folha-fina } \\
\text { abiu-casca-grossa } \\
\text { abiurana } \\
\text { breu-manga } \\
\text { breu-preto } \\
\text { mandioqueira-lisa } \\
\text { mandioqueira-áspera } \\
\text { envira } \\
\text { faeira } \\
\text { abiu-pitomba } \\
\text { tachi-pitomba }\end{array}$ \\
\hline
\end{tabular}


continuação

Vatairea paraensis Ducke

Vatairea sericea Ducke

Vochysia guianensis Aubl.

Vochysia melinonii Beckmann

Xylopia nitida Dun. fava-amargosa

faveira-bolacha

guaruba-rosa

guaruba-rosa

envira-branca

Tabela 10. Relação das espécies estudadas no Tapajós

\begin{tabular}{|c|c|}
\hline Nome cientifico & Nome vulgar \\
\hline $\begin{array}{l}\text { Alexa grandiflora Ducke } \\
\text { Anacardium spruceanum Benth. ex Engl. } \\
\text { Bertholletia excelsa Humb. \& Bonpl. } \\
\text { Brosimum acutifolium Huber } \\
\text { Carapa guianensis Aubl. } \\
\text { Copaifera reticulata Ducke } \\
\text { Cordia Bicolor D. C. } \\
\text { Cordia goeldiana Huber } \\
\text { Couratari guianensis Aubl. } \\
\text { Couratari oblogifolia Ducke el Knuth } \\
\text { Couratari stellata A. C. Smith } \\
\text { Erisma uncinatum Warm. } \\
\text { Iryanthera grandis Ducke } \\
\text { Jacaranda copaia (Aubl.) D. Don. } \\
\text { Joanesia heveoides Ducke } \\
\text { Laetia procera (P. et E.) Eichl. } \\
\text { Maquira sclerophylla (Ducke) C. C. } \\
\text { Berg. } \\
\text { Mezilaurus itaúba (Meissn.) Taubert } \\
\text { ex Mez } \\
\text { Nectandra rubra (Mez) C. K. Allen } \\
\text { Onychopetalum amazonicum R. E. Fries } \\
\text { Parkia pendula Benth. ex Walp. } \\
\text { Piptadenia suaveolens Miq. } \\
\text { Protium Heptaphyllum (Aubl.) March } \\
\text { Qualea cf. lancifolia Ducke } \\
\text { Sclerolobium aff. chrysophyllum } \\
\text { Poepp. \& Endl. } \\
\text { Simaruba amara Aubl. } \\
\text { Tterculia pilosa Ducke } \\
\text { Tachigalia myrmecophilla Ducke }\end{array}$ & $\begin{array}{l}\text { melancieira } \\
\text { caju-açu } \\
\text { castanheira } \\
\text { mururé } \\
\text { andiroba } \\
\text { copaíba } \\
\text { freijó } \\
\text { freijó } \\
\text { tauari } \\
\text { tauari } \\
\text { tauari } \\
\text { quarubarana } \\
\text { ucuubarana } \\
\text { para-pará } \\
\text { castanha-de-arara } \\
\text { pau-jacaré } \\
\text { muiratinga } \\
\text { itaúba-amarela }\end{array}$ \\
\hline
\end{tabular}


continuação

Tratattinickia burserifolia (Mart.)

breu-sucuruba

willd.

\subsection{Preparação das amostras}

Cada árvore foi seccionada em toras com o comprimento de $4 \mathrm{~m}$, sendo selecionada aleatoriamente, uma tora. De cada tora, foram retiradas quatro vigas com seção transversal de 8 × $8 \mathrm{~cm}$ e comprimento necessário para se confeccionar todas as amostras necessárias. Dessas quatro vigas, duas foram retiradas do cerne e duas do alburno, sendo que uma foi usada para ensaios na condição verde e outra para a condição seca, à $12 \%$ de umidade. No caso das espécies que não apresentavam cerne e alburno distintos, foram retiradas duas vigas próximas à medula e duas próximas à periferia da tora.

Cada viga foi retirada devidamente orientada, isto é, com faces tangencial e radial bem definidas.

\subsection{Realização dos ensaios}

Foram realizados ensaios para as determinaçōes da densidade básica (Db), retração tangencial (Rt), radial (Rr) e volumétrica (Rv), módulos de ruptura $\left(f_{f}\right)$ e 
elasticidade $\left(E_{f}\right)$ à flexão estática, tensão no limite de resistência à compressão paralela às fibras $\left(f_{c}\right)$, módulo de resistência no limite de proporcionalidade à compressão normal às fibras $\left(f_{c n}\right)$ e tensão no limite de resistência ao cisalhamento paralelo às fibras $\left(f_{g}\right)$.

Todos estes ensaios foram realizados de acordo com as especificaçōes das normas COPANT (1971 e 1972).

\subsection{Análises estatisticas}

Os coeficientes de variação (CV) para cada variável medida e de determinação $\left(R^{2}\right)$ das análises de regressão, foram calculados através do programa statistical Analysis System - SAS versão 6.03. Para o cálculo da distribuição WEIBULL, utilizou-se uma planilha eletrônica Quattro-Pro versão 3.0. Para testar o ajuste da distribuição Weibull aos dados foi utilizada a técnica conhecida como gráfico $Q-Q$. Esta técnica é baseada no gráfico dos quantis da distribuição envolvida. Para o teste de normalidade das distribuições das variáveis (densidade básica e módulo de ruptura à flexão estática), utilizou-se a linguagem estatística Generalized Linear Iterative Models - GLIM. 


\subsubsection{Coeficiente de variação}

Determinaram-se os coeficientes de variação das espécies ensaiadas nas condiçōes verde e seca a $12 \%$ de umidade, tanto para cada região como para o conjunto das quatro regiões. As variáveis analisadas foram: Db, $R t, R r$, $R v, E_{f}, f_{f}, f_{c}, f_{c n} e f_{s}$. Os resultados obtidos encontram-se na Tabela 11 .

\subsubsection{Análise da variância da regressão}

Esta análise teve por objetivo avaliar a variabilidade dos modelos lineares que relacionam a densidade básica com as retraçōes tangencial, radial e volumétrica e com as propriedades mecânicas, nas condiçōes verde e seca à 12\% de umidade, em cada região, como também englobando todas as quatro regiōes. Os resultados encontram-se na Tabela 12 .

3.7.3. Formação dos grupos de espécies por classes de densidade básica

Os grupos foram formados definindo-se classes para a densidade básica, ignorando as demais propriedades. As classes por densidade básica formadas foram as seguintes: 
Grupos

1

2

3

4

5

6

7

8
Classes de densidade básica $\left(\mathrm{g} / \mathrm{cm}^{3}\right)$

0,25 a 0,34

0,35 a 0,44

0,45 a 0,54

0,55 a 0,64

0,65 a 0,74

0,75 a 0,84

0,85 a 0,94

0,95 a 1,14

Observa-se que 0 grupo 8 apresenta um intervalo de classe igual a $0,19 \mathrm{~g} / \mathrm{cm}^{3}$, e enquanto os outros grupos apresentam intervalo de $0,09 \mathrm{~g} / \mathrm{cm}^{3}$. Tomou-se esta decisão porque, no caso da formação de mais uma classe com densidade variando de $1,05 \mathrm{~g} / \mathrm{cm}^{3}$ a $1,14 \mathrm{~g} / \mathrm{cm}^{3}$, teria-se apenas uma espécie contida nela, a qual apresentava somente quatro indivíduos e, consequentemente, esta pequena frequência seria insuficiente para uma satisfatória distribuição do grupo.

Todos os grupos foram formados com os valores de densidade básica individual das espécies. Desse modo, algumas espécies que apresentavam grande dispersão dos valores individuais, para a definição do grupo a que a mesma deveria pertencer, foi baseada na maior concentração de individuos dentro de um dado intervalo de classe.

Esta definição dos intervalos de classes por 
densidade possibilitou a formação de oito grupos. As espécies que compõem cada grupo encontram-se na Tabela 13.

\subsubsection{Distribuição Weibull}

Inicialmente havia sido prevista a aplicação dos métodos dos percentis e o da máxima verossimilhança para - ajuste dos valores observados de densidade básica para as funçōes de densidades probabilística e acumulada. Todavia, tendo-se verificado que nos estudos desenvolvidos por NASCIMENTO (1993), o método da máxima verossimilhança se ajustou melhor aos valores observados, optou-se portanto, pelo mesmo, principalmente, porque este fornece estimadores mais consistentes (MCGULLACH \& NELDER, 1969).

o primeiro passo para avaliar a precisão do ajuste da distribuição Weibull em relação aos dados observados de densidade básica para os grupos de espécies, foi determinar a amplitude de classe a ser usada. Desse modo, testaram-se as amplitudes de 0,$01 ; 0,02 ; 0,03$ e 0,05. Enquanto, no geral, a amplitude usada foi de 0,09 que se encontrou na primeira tentativa, a qual possibilitou o número adequado de 10 classes.

Em seguida foram estimados os parâmetros da distribuição Weibull para todas estas amplitudes. Mediante análises dos gráficos das distribuiçōes, constatou-se que a amplitude de 0,02 foi a que apresentou a maior precisão. 
Obteve-se um satisfatório número de classes por grupo, proporcionando portanto, uma frequência adequada para a formação de uma distribuição estimada. Esta foi submetida à técnica de gráfico $Q-Q$, descrita mais adiante.

A amplitude de classe para as propriedades mecânicas foi feita da maneira seguinte:

- observando-se o número de classes da densidade de cada grupo de espécie, foram tomados os valores mínimos e máximos de cada propriedade mecânica. Dividiu-se então pelo número de classe do seu respectivo grupo de densidade, obtendo-se assim o mesmo número de classe dentro do grupo para cada propriedade. Enquanto, no geral, foi feita a divisão pelo número de classes de densidade.

Finalmente foram estimados os parâmetros da distribuição Weibull para a densidade básica e propriedades mecânicas nas condições verde e seca a $12 \%$ de umidade.

Johnson \& Kotz (1970), citados por BATISTA (1989), apresentaram as Equações 1 e 2, onde, na Equação 1, sua função de densidade probabilística (f.d.p.) é apresentada de diversas formas, sendo comum nos trabalhos de distribuição de diâmetro apresentá-la da maneira seguinte: 


$$
f(x)=\left(\frac{c}{b}\right)\left(\frac{x-a}{b}\right)^{c-1} \exp \left(-\left(\frac{x-a}{b}\right)^{c}\right)
$$

para $x \geq a$ e $f(x)=0$ para $x<a$ onde,

$x$ é a variável aleatória $e, a \geq 0, b>0$ e $c>0$, são os parâmetros da distribuição.

A sua função de densidade acumulada (f.d.a.)

é dada por:

$$
F(x)=\int_{0}^{+\infty} f(x) d x-1-\exp \left(-\left(\frac{x-a}{b}\right)^{c}\right)
$$

Estas Equaçōes 1 e 2, foram adaptadas para este trabalho de distribuição de densidade básica das madeiras da região amazônica, conforme Equaçōes 3 e 4 .

$$
f(D b)=\frac{C}{b}\left(\frac{D b-D b_{\min }}{b}\right)^{c-1} e^{-\left(\frac{D b-D b_{\min }}{b}\right)^{c}}
$$

onde:

$$
\begin{aligned}
& \mathbf{f}=\text { frequência de densidade probabilística } \\
& \mathrm{Db}=\text { centro de classe da densidade básica } \\
& \mathrm{Db}_{\min }=\text { centro de classe da densidade básica mínima } \\
& \mathrm{b}=\text { parâmetro da escala da distribuição Weibull } \\
& \mathrm{C}=\text { parâmetro da forma da distribuição Weibull }
\end{aligned}
$$




$$
F(D b)=1-e^{-\left(\frac{D b-D b_{\min }}{b}\right) c}
$$

onde:

$$
\text { F = frequência de densidade acumulada }
$$

o parâmetro (a), da distribuição Weibull, foi obtido tomando-se um valor da densidade básica imediatamente abaixo ao limite inferior da maior dispersão de uma dada espécie, que faz parte de cada grupo. Nesse caso, o parâmetro (a) teve os valores seguintes: 0,$24 ; 0,32 ; 0,34 ; 0,42 ; 0,52$; 0,$66 ; 0,70 ; 0,92$.

A estimativa do parâmetro (c) foi feita de acordo com as frequências observadas dos dados. Para isto, utilizando-se a Equação 5, em um processo iterativo. Portanto, fez-se sucessivas operações por tentativa, até que a equação fosse igualada a zero e/ou, no mínimo, próximo desse valor.

$$
\frac{1}{c}=\frac{\sum_{i=1}^{n} f_{i}\left(D b-D b_{\min }\right)^{c} \ln \left(D b-D b_{\min }\right)}{\sum_{i=1}^{n} f_{i}\left(D b-D b_{\min }\right)^{c}}+\frac{\sum_{i=1}^{n} f_{i} \ln \left(D b-D b_{\min }\right)}{n}=0
$$

onde:

$$
\begin{aligned}
& \mathrm{f}_{\mathrm{i}}=\text { frequência da densidade básica dentro da classe } \\
& \mathrm{n}=\text { tamanho da amostra }
\end{aligned}
$$


Através da Equação 6, estimou-se o parâmetro (b), utilizando-se o valor do parâmetro (c) calculado anteriormente.

$$
b=\frac{\sum_{i=1}^{n} f_{i}\left(D b-D b_{\min }\right)^{\frac{1}{c}}}{n}
$$

Para as determinaçōes das frequências de densidade probabilistica e de densidade acumulada, foram utilizadas as Equaçōes 3 e 4 .

Posteriormente, fez-se os ajustes da maneira seguinte:

- Para a densidade básica foram plotados os dados observados tanto na curva de frequência de densidade probabilistica, quanto na frequência de densidade acumulada e, também na distribuição Weibull utilizando-se o método da máxima verossimilhança;

- Para as propriedades de resistência, além de terem sido plotados os dados observados nas curvas de frequência de densidade probabilistica e acumulada, comparou-se a distribuição Weibull através do método da máxima verossimilhança, tanto em função de cada propriedade mecânica, como também em função da densidade básica. 


\subsubsection{Ajuste para a distribuição dos dados}

Um método prático para comparar uma distribuição amostral com uma teórica conhecida, é através do gráfico $Q-Q$, ou gráfico dos quantis das distribuiçōes envolvidas.

Um quantil, para uma variável aleatória contínua com distribuição de frequências acumuladas $\mathrm{F}(\mathrm{x})$, é um número $Q t(p)$, tal que:

$$
F(Q t(p))=p \text { ou } Q t(p)=F^{-1}(p)
$$

onde $F^{-1}(\cdot)$ é a função inversa de $F(\cdot)$. Intuitivamente um Qt(p) é um valor tal que, uma fração $p$, da distribuição de frequências acumuladas, ocorre para valores menores ou iguais a $\operatorname{Qt}(\mathrm{p})$.

Os quantis empiricos computados para uma amostra $x_{1}, x_{2}, \ldots, x_{n}$ são indicados por Qe(p). Seja $x_{(1)}$, .... $x_{(n)}$ uma amostra ordenada na ordem crescente. Logo, Qe $(p i)=x_{(i)}$, onde $p i=(i-0,5) / n$. Ou seja, a fração pi da amostra é menor ou igual a Qe(pi).

Plotando-se os valores de Qe(pi) e Qt(p), $i=1, \ldots, n$, tem-se o gráfico $Q-Q$. Assim, se a amostra provém de uma população com a distribuição teórica escolhida, o gráfico terá que ser aproximadamente uma reta. Desvios dessa reta estarão indicando-a quanto a distribuição observada se desvia da distribuição teórica. Segundo Sokal \& Rohlf (1981), citados por DIAZ et alii (1992), os Q-Q plots são versōes 
gráficas do que se conhece com o nome de Teste de Aderência ou "Bondade" do Ajuste, dos quais o teste de KolmogorovSmirnov e o teste de Chi-quadrado são os mais frequentemente usados.

\subsubsection{Teste de normalidade dos dados observados}

A verificação da normalidade dos dados foi realizada somente com as variáveis densidade básica e o módulo de ruptura à flexão estática. Tomou-se essa decisão em razão de que as mesmas foram as únicas utilizadas no segmento que abrangeu a discussão à cerca das estruturas de madeira. Para testar a normalidade utilizou-se a linguagem estatística (Generalized Linear Iterative Models GLIM) •

A nível de exemplo, para o teste de consistência da distribuição das duas variáveis, o GLIM determina o valor da estatística de Anderson e Darling, que possibilita a condução do teste de normalidade.

Segundo STEPHENS (1974), essa estatística, geralmente, tem maior poder quando comparada aos demais testes de normalidade. 


\section{RE8ULTADOS B DI8CU88Ão}

Dentro deste segmento serão apresentados os resultados concernentes aos objetivos propostos neste trabalho. Estes serão acompanhados de abordagens visando melhor entendimento das variabilidades da madeira, dentro e entre propriedades, os níveis de relaçōes entre ambas, os principais fatores que exercem influências nos seus valores, a importância da formação de grupos de espécies com base em uma única propriedade (densidade básica). Será também discutida uma forma mais viável do emprego da madeira em estruturas, sem necessitar de recorrer aos dados tabelados das propriedades mecânicas e, finalmente, discutir a segurança das estruturas de madeira.

4.1. Variabilidades da densidade básica, retrações tangencial, radial e volumétrica e propriedades mecânicas das madeiras estudadas nas condições verde e seca

Na Tabela 11, observa-se que dentre todas as propriedades, a densidade básica é a que apresenta a menor 
variabilidade.

Esse resultado era de se esperar, haja visto que fatores inerentes à madeira, tais como tipos, arranjo e dimensões dos elementos anatômicos, composição, quantidade e localização dos extrativos da madeira, exercem menor influência na variabilidade da densidade do que na retração e nas propriedades mecânicas, durante as suas determinações.

Tabela 11. Valores dos coeficientes de variação e das probabilidades de F, para a densidade básica, retraçōes tangencial, radial e volumétrica e propriedades mecânicas das espécies do Amapá, Balbina, Curuá-Una e Tapajós, nas condições verde e seca à $12 \%$ de umidade

\begin{tabular}{|c|c|c|c|c|c|c|c|c|c|c|}
\hline \multirow{2}{*}{ Propriedades } & \multicolumn{2}{|c|}{ Amapá } & \multicolumn{2}{|c|}{ Balbina } & \multicolumn{2}{|c|}{ Curuá-Una } & \multicolumn{2}{|c|}{ Tapajós } & \multicolumn{2}{|c|}{ Geral } \\
\hline & CV (\%) & Prob>F & CV (\%) & Prob>F & CV (\%) & Prob>F & CV $(\%)$ & Prob>F & CV (\%) & Prob>F \\
\hline $\begin{array}{l}\text { Db } \\
R t \\
R r \\
R v \\
\text { Ef (verde) } \\
E_{f} \text { (12\%) } \\
f_{f} \text { (verde) } \\
f_{f}(12 \%) \\
f_{c} \text { (verde) } \\
f_{c}(12 \%) \\
f_{c n}(v e r d e) \\
f_{c n}(12 \%) \\
f_{s}(\text { verde) } \\
f_{s}(12 \%)\end{array}$ & $\begin{array}{r}6,52 \\
12,80 \\
15,49 \\
11,75 \\
10,99 \\
6,87 \\
18,03 \\
11,22 \\
11,02 \\
12,29 \\
20,42 \\
13,37 \\
10,78 \\
15,27\end{array}$ & $\begin{array}{l}0,0001 \\
0,0001 \\
0,0001 \\
0,0001 \\
0,0001 \\
0,0001 \\
0,0001 \\
0,0001 \\
0,0001 \\
0,0001 \\
0,0001 \\
0,0001 \\
0,0001 \\
0,0001\end{array}$ & $\begin{array}{r}7,87 \\
14,20 \\
16,61 \\
13,62 \\
14,39 \\
11,90 \\
14,33 \\
17,29 \\
16,94 \\
14,05 \\
24,44 \\
17,04 \\
18,61 \\
16,99\end{array}$ & $\begin{array}{l}0,0001 \\
0,0001 \\
0,0001 \\
0,0001 \\
0,0001 \\
0,0001 \\
0,0001 \\
0,0001 \\
0,0001 \\
0,0001 \\
0,0001 \\
0,0001 \\
0,0001 \\
0,0001\end{array}$ & $\begin{array}{r}7,58 \\
11,57 \\
16,07 \\
10,40 \\
11,22 \\
9,37 \\
12,90 \\
13,43 \\
13,39 \\
11,80 \\
22,04 \\
15,80 \\
14,13 \\
14,26\end{array}$ & $\begin{array}{l}0,0001 \\
0,0001 \\
0,0001 \\
0,0001 \\
0,0001 \\
0,0001 \\
0,0001 \\
0,0001 \\
0,0001 \\
0,0001 \\
0,0001 \\
0,0001 \\
0,0001 \\
0,0001\end{array}$ & $\begin{array}{r}9,58 \\
14,28 \\
20,92 \\
13,42 \\
13,90 \\
12,95 \\
13,13 \\
13,26 \\
15,90 \\
12,72 \\
25,13 \\
22,39 \\
17,66 \\
21,01\end{array}$ & $\begin{array}{l}0,0001 \\
0,0001 \\
0,0001 \\
0,0001 \\
0,0001 \\
0,0001 \\
0,0001 \\
0,0001 \\
0,0001 \\
0,0001 \\
0,0001 \\
0,0001 \\
0,0001 \\
0,0001\end{array}$ & $\begin{array}{r}8,03 \\
13,89 \\
18,03 \\
13,61 \\
12,61 \\
10,84 \\
13,97 \\
14,39 \\
14,73 \\
12,76 \\
25,09 \\
17,30 \\
15,83 \\
15,88\end{array}$ & $\begin{array}{l}0,0001 \\
0,0001 \\
0,0001 \\
0,0001 \\
0,0001 \\
0,0001 \\
0,0001 \\
0,0001 \\
0,0001 \\
0,0001 \\
0,0001 \\
0,0001 \\
0,0001 \\
0,0001\end{array}$ \\
\hline
\end{tabular}

Na determinação da densidade básica, em cada amostra, o volume é o mesmo para todas, haja visto que as 
mesmas foram confeccionadas com dimensōes padronizadas e que, teoricamente, as amostras estando saturadas, não ocorre variação nas suas dimensōes. o que varia é a quantidade de massa, sendo que durante à secagem pode ocorrer uma volatilização parcial de extrativos, caso, a espécie contenha substâncias voláteis.

Na retração, a remoção da água ocasiona a redução das dimensōes das amostras, cujo decréscimo depende do ponto de saturação das fibras de cada espécie, dos tipos, teores e localização dos extrativos e da estrutura anatômica, onde cada espécie é um caso particular.

As propriedades de resistência, além de dependerem da quantidade de massa lenhosa, ainda sofrem influências dos extrativos, do arranjo e dimensōes dos elementos anatômicos e da umidade.

Os coeficientes de variação obtidos para densidade básica são compatíveis com o que foi encontrado pelO U. S. FOREST PRODUCTS LABORATORY (1974), cOm 50 espécies de madeiras, com excessão do $\mathrm{CV}$ do $\mathrm{E}_{\mathrm{f}}$. Entretanto, em comparação com os obtidos por NASCIMENTO (1993), mostraram-se similares somente por regiōes, porém, para o conjunto de todas as regiōes, a autora obteve uma variação superior a três vezes ao obtido neste trabalho.

Nas retraçōes, o menor coeficiente obtido foi nas madeiras de curuá-Una (tangencial), enquanto o maior, foi nas madeiras de Tapajós (radial). Mediante os valores 
observados, a retração volumétrica das madeiras das quatro regiões varia de $10,40 \%$ a $13,62 \%$. Esta variabilidade está relativamente compativel com 0 U. S. FOREST PRODUCTS LABORATORY (1974), o qual admite que as variabilidades na retração transversal e volumétrica, pode ser expressa por um coeficiente de variação de aproximadamente $15 \%$

Nas propriedades mecânicas, os menores coeficientes de variação foram obtidos no módulo de elasticidade à flexão estática $\left(E_{f}\right)$. Enquanto os maiores coeficientes de variação foram obtidos no módulo de resistência no limite de proporcionalidade à compressão normal às fibras $\left(f_{c n}\right)$.

Comparando as variabilidades das propriedades de resistência entre madeiras nas condições verde e seca, observa-se que $\circ \mathrm{E}_{\mathrm{f}}$ à $12 \%$ de umidade, apresentou menor variabilidade. No $f_{f}$ à $12 \%$, observa-se maior variabilidade. $A f_{c}$, apresentou situação idêntica ao ocorrido no $E_{f} \cdot O$ mesmo fato ocorreu com $\circ f_{c n}$. Enquanto, na $f_{s}$ a situação foi similar ao $f_{f}$.

De uma maneira geral, observa-se que os coeficientes de variação obtidos das madeiras ensaiadas na condição seca, foram menores do que os obtidos com as madeiras na condição verde. Estes resultados divergem das afirmações de PAULA et alii (1986), os quais encontraram situação inversa.

$\mathrm{Na}$ tentativa de explicar a acentuada 
variabilidade no $f_{c n}$, admite-se que a causa, é a sua determinação imprecisa, pois a placa metálica não age somente na área da amostra que é comprimida pela mesma, tendo em vista que a sua ação de compressão produz tensão nas regiōes da superficie superior da amostra que não se encontram sob tensão.

Na realidade, neste tipo de ensaio, ocorre uma compressão normal às fibras na área que está sendo comprimida pela placa. Enquanto, nas regiōes da superfície superior da amostra que não estão sendo comprimidas pela mesma, está ocorrendo um esforço de cisalhamento perpendicular às fibras. Isto pode ser observado perfeitamente em muitas amostras que mostram fissuras nas suas extremidades próximas à superfície superior.

Os valores das probabilidades de F, significam se existem diferenças entre espécies, tanto para cada região como para a Amazônia como um todo. Portanto, de acordo com os valores apresentados na Tabela 11, pode-se observar que existem diferenças significativas entre espécies, em cada uma das regiōes como em toda a Amazônia, ao nível de $1 \%$.

4.2. Relaçōes entre retraçōes tangencial, radial e volumétrica e entre propriedades mecânicas nas condiçōes verde e seca com a densidade básica

Nas relaçōes entre propriedades mecânicas e 
densidade básica apresentadas na Tabela 12, verifica-se que nas espécies da região de Tapajós, a maioria dos coeficientes de determinação são ligeiramente inferiores aos das demais regiōes. Enquanto que, os maiores coeficientes de determinação em quase sua totalidade entre as quatro regiōes, foram obtidos com as espécies do Amapá.

Tabela 12. Análise da variância da regressão obtida entre as retraçōes tangencial, radial e volumétrica e densidade básica e entre propriedades de resistência nas condiçōes verde e seca à $12 \%$ de umidade e densidade básica

\begin{tabular}{|c|c|c|c|c|c|c|c|c|c|c|}
\hline \multirow{2}{*}{ Regressão } & \multicolumn{2}{|c|}{ Amapá } & \multicolumn{2}{|c|}{ Balbina } & \multicolumn{2}{|c|}{ Curuá-Una } & \multicolumn{2}{|c|}{ Tapajós } & \multicolumn{2}{|c|}{ Geral } \\
\hline & $R^{2}$ & Prob>F & $R^{2}$ & Prob>F & $R^{2}$ & Prob>F & $R^{2}$ & Prob>F & $R^{2}$ & Prob>F \\
\hline 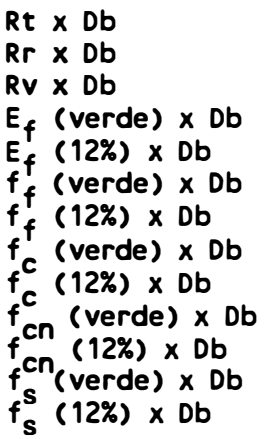 & $\begin{array}{l}0,22 \\
0,37 \\
0,32 \\
0,75 \\
0,78 \\
0,66 \\
0,82 \\
0,75 \\
0,76 \\
0,68 \\
0,69 \\
0,65 \\
0,56\end{array}$ & $\begin{array}{l}0,0001 \\
0,0001 \\
0,0001 \\
0,0001 \\
0,0001 \\
0,0001 \\
0,0001 \\
0,0001 \\
0,0001 \\
0,0001 \\
0,0001 \\
0,0001 \\
0,0001\end{array}$ & $\begin{array}{l}0,02 \\
0,28 \\
0,12 \\
0,65 \\
0,65 \\
0,73 \\
0,68 \\
0,73 \\
0,68 \\
0,68 \\
0,69 \\
0,56 \\
0,55\end{array}$ & $\begin{array}{l}0,0674 \\
0,0001 \\
0,0001 \\
0,0001 \\
0,0001 \\
0,0001 \\
0,0001 \\
0,0001 \\
0,0001 \\
0,0001 \\
0,0001 \\
0,0001 \\
0,0001\end{array}$ & $\begin{array}{l}0,02 \\
0,10 \\
0,04 \\
0,57 \\
0,54 \\
0,76 \\
0,63 \\
0,75 \\
0,63 \\
0,70 \\
0,74 \\
0,59 \\
0,54\end{array}$ & $\begin{array}{l}0,0073 \\
0,0001 \\
0,0001 \\
0,0001 \\
0,0001 \\
0,0001 \\
0,0001 \\
0,0001 \\
0,0001 \\
0,0001 \\
0,0001 \\
0,0001 \\
0,0001\end{array}$ & $\begin{array}{l}0,14 \\
0,08 \\
0,11 \\
0,52 \\
0,52 \\
0,74 \\
0,71 \\
0,71 \\
0,65 \\
0,65 \\
0,63 \\
0,53 \\
0,51\end{array}$ & $\begin{array}{l}0,0001 \\
0,0018 \\
0,0002 \\
0,0001 \\
0,0001 \\
0,0001 \\
0,0001 \\
0,0001 \\
0,0001 \\
0,0001 \\
0,0001 \\
0,0001 \\
0,0001\end{array}$ & $\begin{array}{l}0,08 \\
0,22 \\
0,13 \\
0,61 \\
0,58 \\
0,76 \\
0,69 \\
0,77 \\
0,70 \\
0,65 \\
0,73 \\
0,63 \\
0,59\end{array}$ & $\begin{array}{l}0,0001 \\
0,0001 \\
0,0001 \\
0,0001 \\
0,0001 \\
0,0001 \\
0,0001 \\
0,0001 \\
0,0001 \\
0,0001 \\
0,0001 \\
0,0001 \\
0,0001\end{array}$ \\
\hline
\end{tabular}

Ainda, com relação às associaçōes entre propriedades de resistência e densidade básica, os menores coeficientes de determinação ocorreram entre a tensão no limite de máxima resistência ao cisalhamento paralelo às 
fibras $\left(f_{s}\right)$ com a densidade básica $(D b)$, tanto na condição verde como seca, com excessão da associação entre o módulo de elasticidade à flexão estática $\left(E_{f}\right)$ com a densidade básica, cujos valores dos coeficientes de determinação podem ser considerados similares.

Pode-se observar também que em muitas das relações entre propriedades de resistência e densidade básica, os valores globais dos coeficientes de determinação são ligeiramente superiores aos valores obtidos para cada região. Estes resultados divergem da afirmação de NASCIMENTO (1993), a qual menciona que as relações em cada região são melhores do que na região amazônica como um todo.

Comparando os valores dos coeficientes de determinação obtidos neste trabalho com os apresentados por CHIMELO (1980), PAULA et alii (1986) e NASCIMENTO (1993), observou-se que tanto os valores por região, quanto no global, com as madeiras nas condições verde e seca, são compativeis com os resultados encontrados por PAULA et alii (1986) e por CHIMELO (1980), apenas para a condição verde. Com relação os valores dos coeficientes de determinação obtidos por NASCIMENTO (1993), constatou-se que em Balbina e em Tapajós, os resultados apresentaram algumas semelhanças. Enquanto, no Amapá e Curuá-Una, principalmente nesta última região, os valores são bastante diferenciados. No caso do Amapá, deve ser ressaltado que a autora incluiu nos estudos, algumas espécies que tinham somente uma árvore. 
Enquanto em Curuá-Una, foram estudadas um terço de espécies a menos do que o número de espécies que fazem parte deste trabalho.

De acordo com os resultados obtidos, e baseando-se também em dezenas de experimentos, onde, todos apresentam boas associações entre as propriedades de resistência e a densidade básica, pode-se assegurar que tais propriedades são diretamente proporcionais à densidade básica. Isto pode ser observado nas Figuras 2 a 11 , onde uma boa porcentagem da variação daquelas propriedades mecânicas, tanto na condição verde como seca, pode ser explicada pelos modelos. As variações que ocorreram nos valores dos coeficientes de determinação podem ser explicadas pela influência da estrutura anatômica e componentes químicos da madeira (principalmente os extrativos), conforme resultados e considerações obtidos na literatura.

Nos valores dos coeficientes de determinação entre madeiras nas condições verde e seca, verifica-se alternância entre algumas associaçōes, ora com valores altos, ora com valores baixos. Nas madeiras do Amapá, observa-se quase sempre que os valores dos coeficientes de determinação para as madeiras na condição seca são superiores em relação àqueles do estado verde. Nas madeiras do Tapajós, por outro lado, quase todos os coeficientes de determinação na condição verde, foram superiores aos valores obtidos na condição seca. 


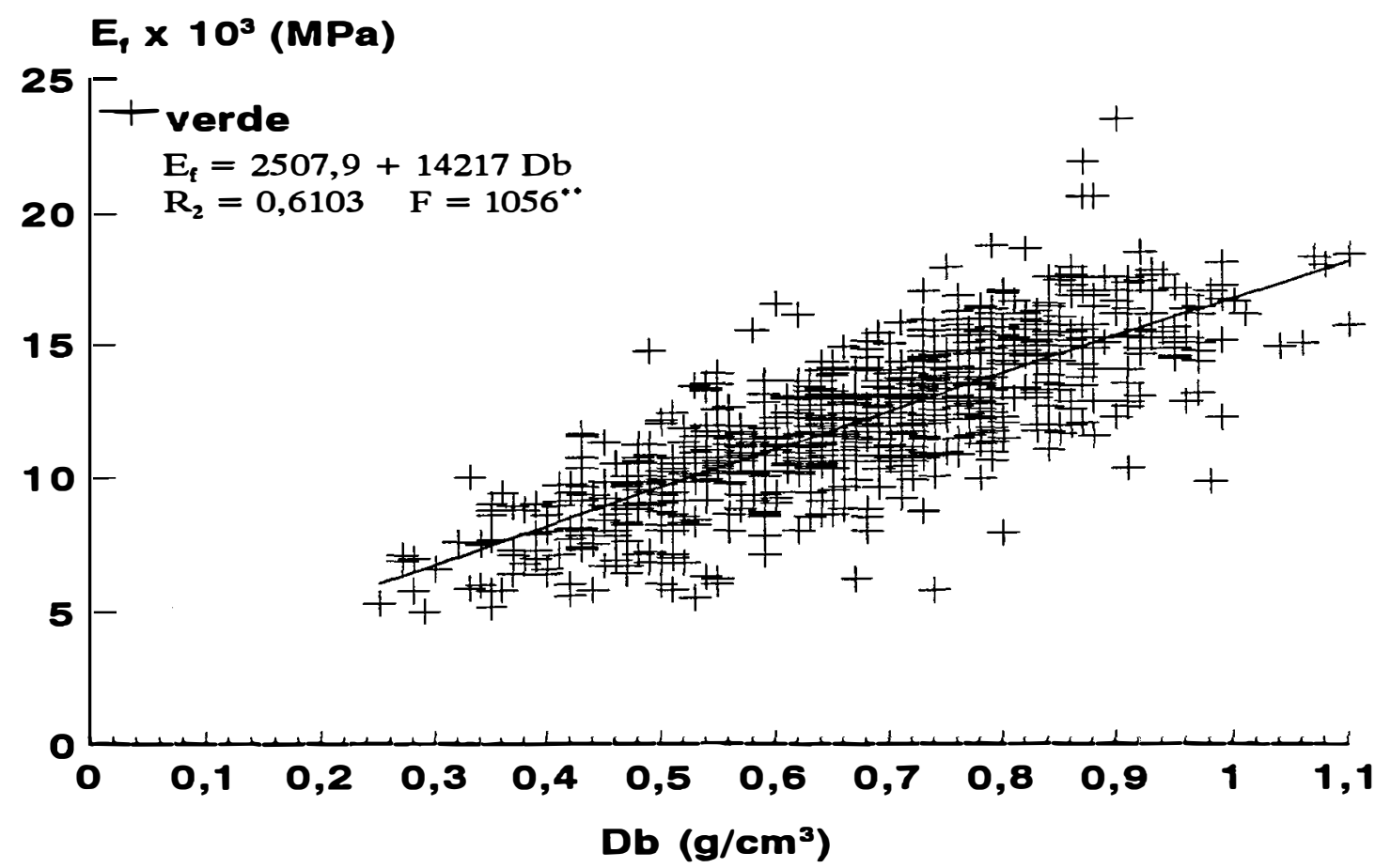

Figura 2. Relação entre módulo de elasticidade $\left(E_{f}\right)$ à flexão estática na condição verde e densidade básica (valores individuais reunindo todas as regiōes)

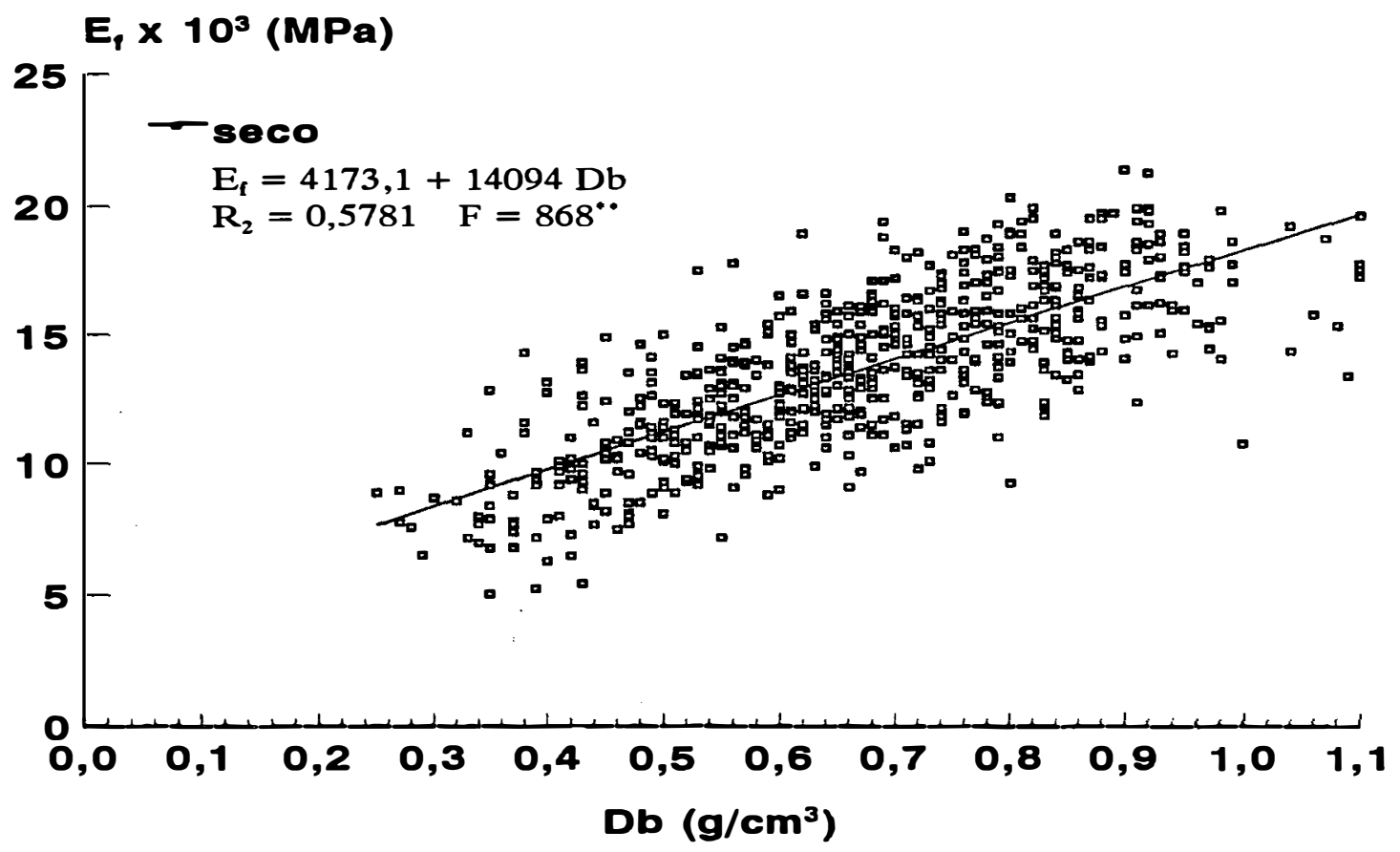

Figura 3. Relação entre módulo de elasticidade $\left(E_{f}\right)$ à flexão estática na condição seca e densidade básica (valores individuais reunindo todas as regiōes) 


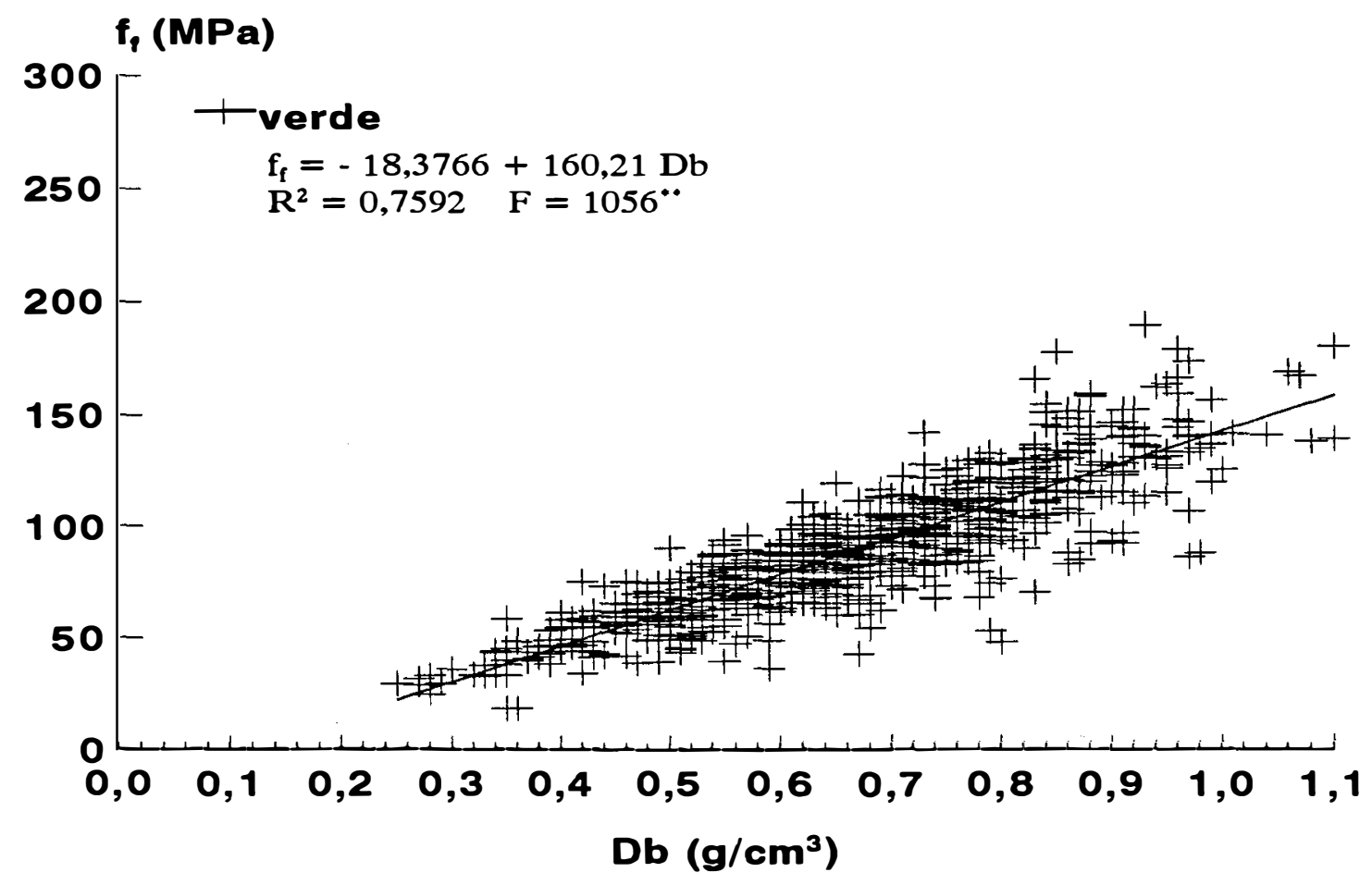

Figura 4. Relação entre módulo de ruptura $\left(f_{f}\right)$ à flexão estática na condição verde e densidade básica (valores individuais reunindo todas as regiōes)

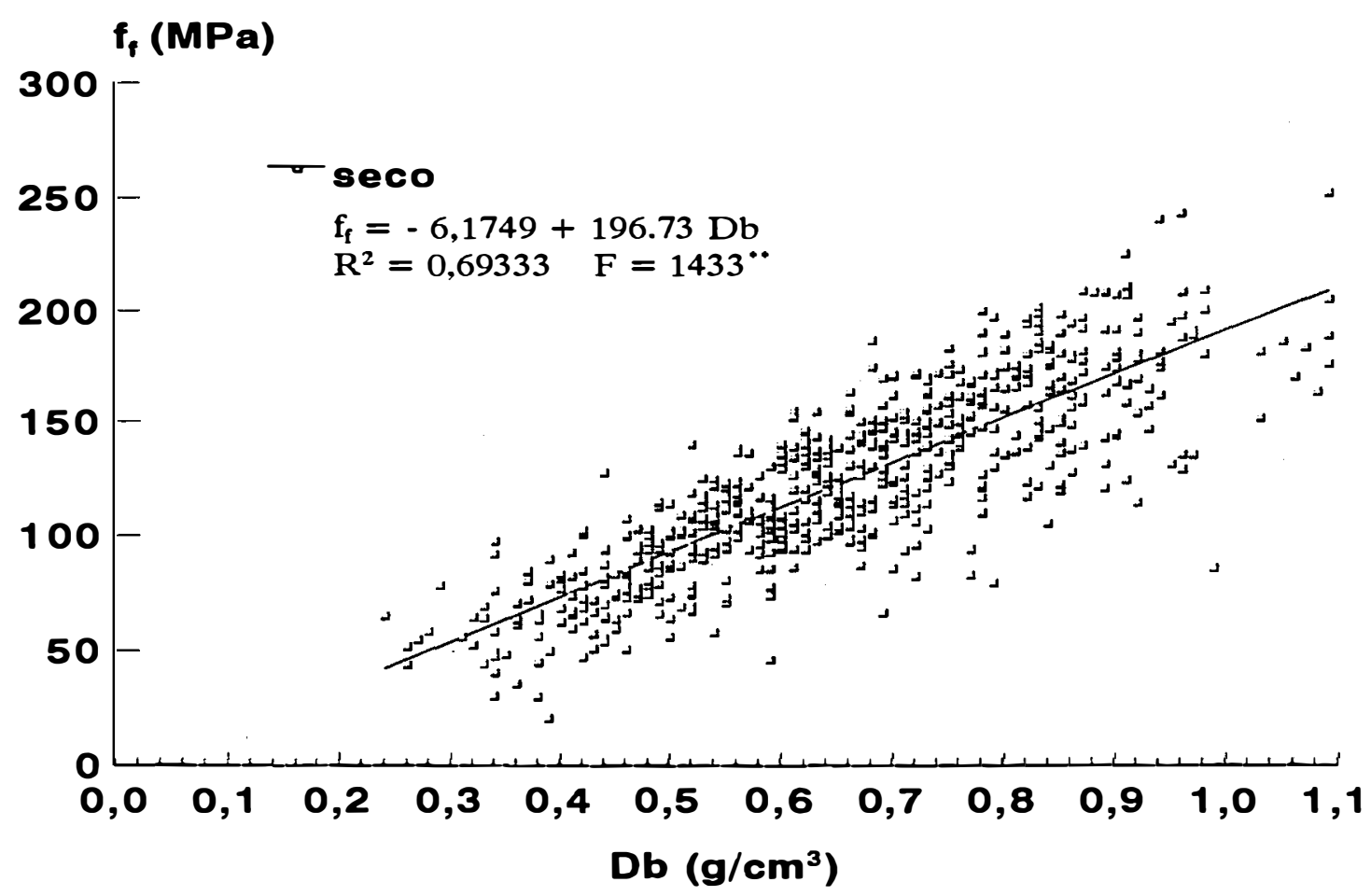

Figura 5. Relação entre módulo de ruptura $\left(f_{f}\right)$ à flexão estática na condição seca e densidade básica (valores individuais reunindo todas as regiōes) 


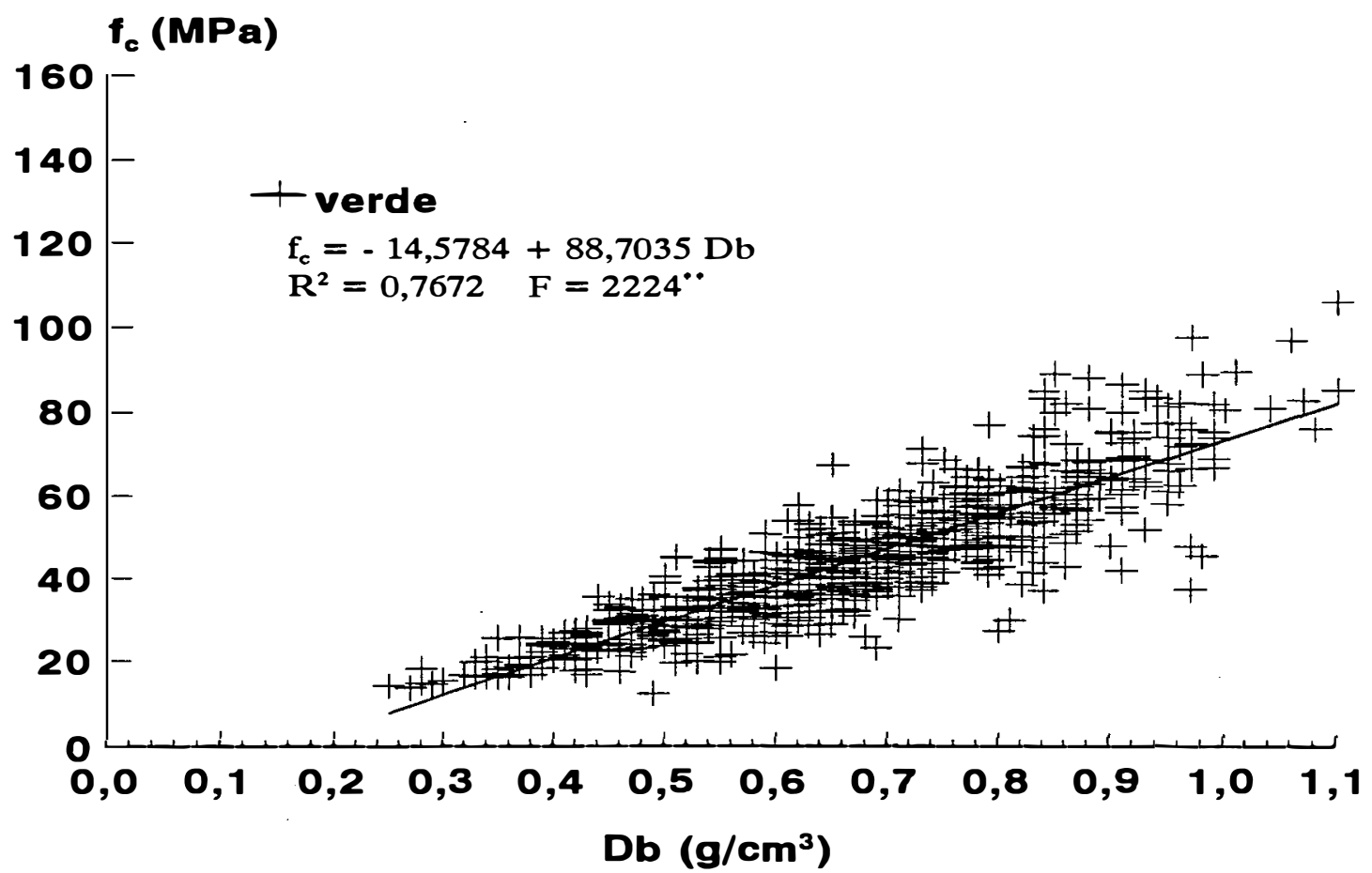

Figura 6. Relação entre tensão no limite de resistência ( $f_{c}$ ) à compressão paralela às fibras na condição verde e densidade básica (valores individuais reunindo todas as regiões)

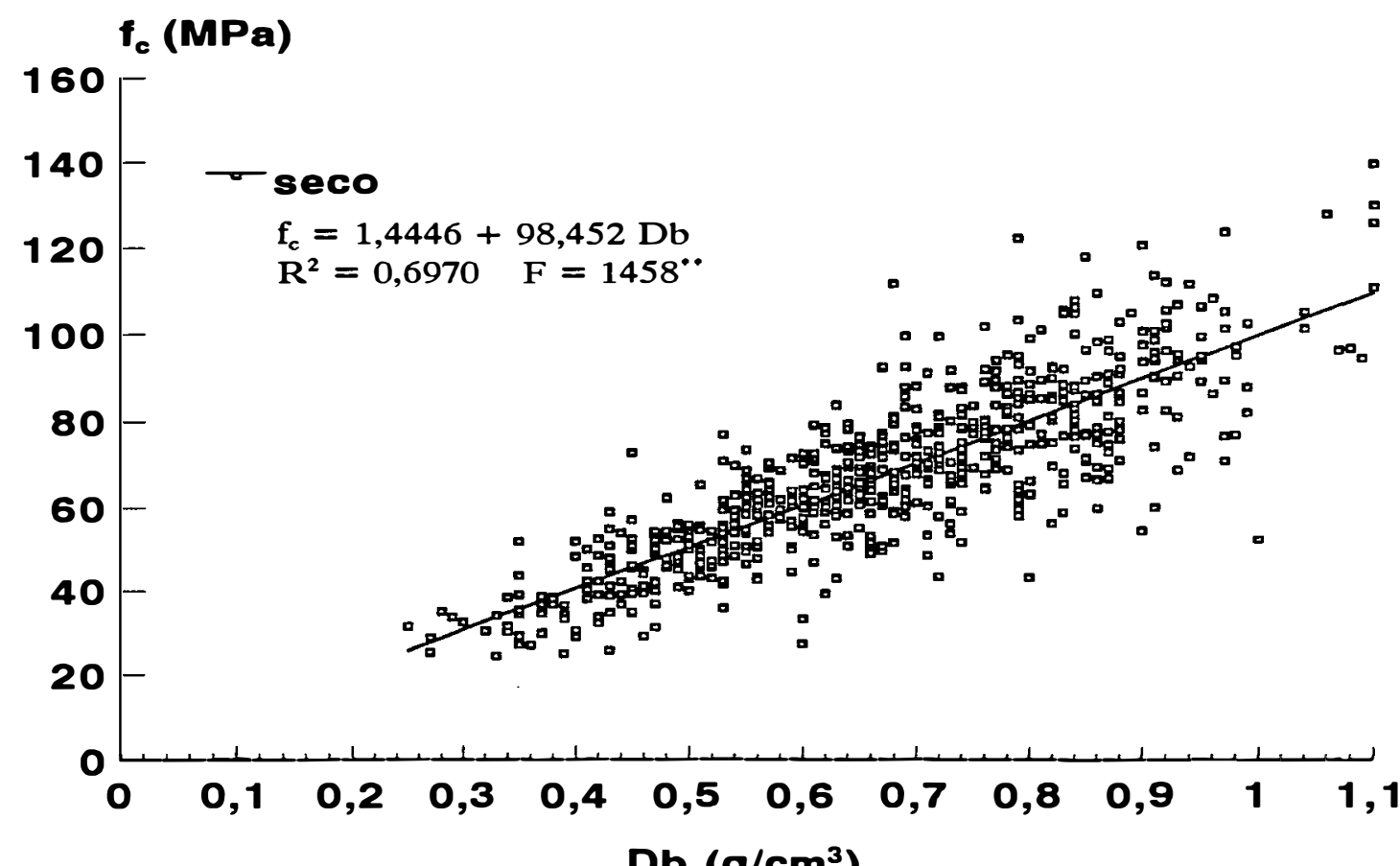

Figura 7. Relação entre tensão no limite de resistência ( $f_{c}$ ) à compressão paralela às fibras na condição seca e densidade básica (valores individuais reunindo todas as regiōes) 


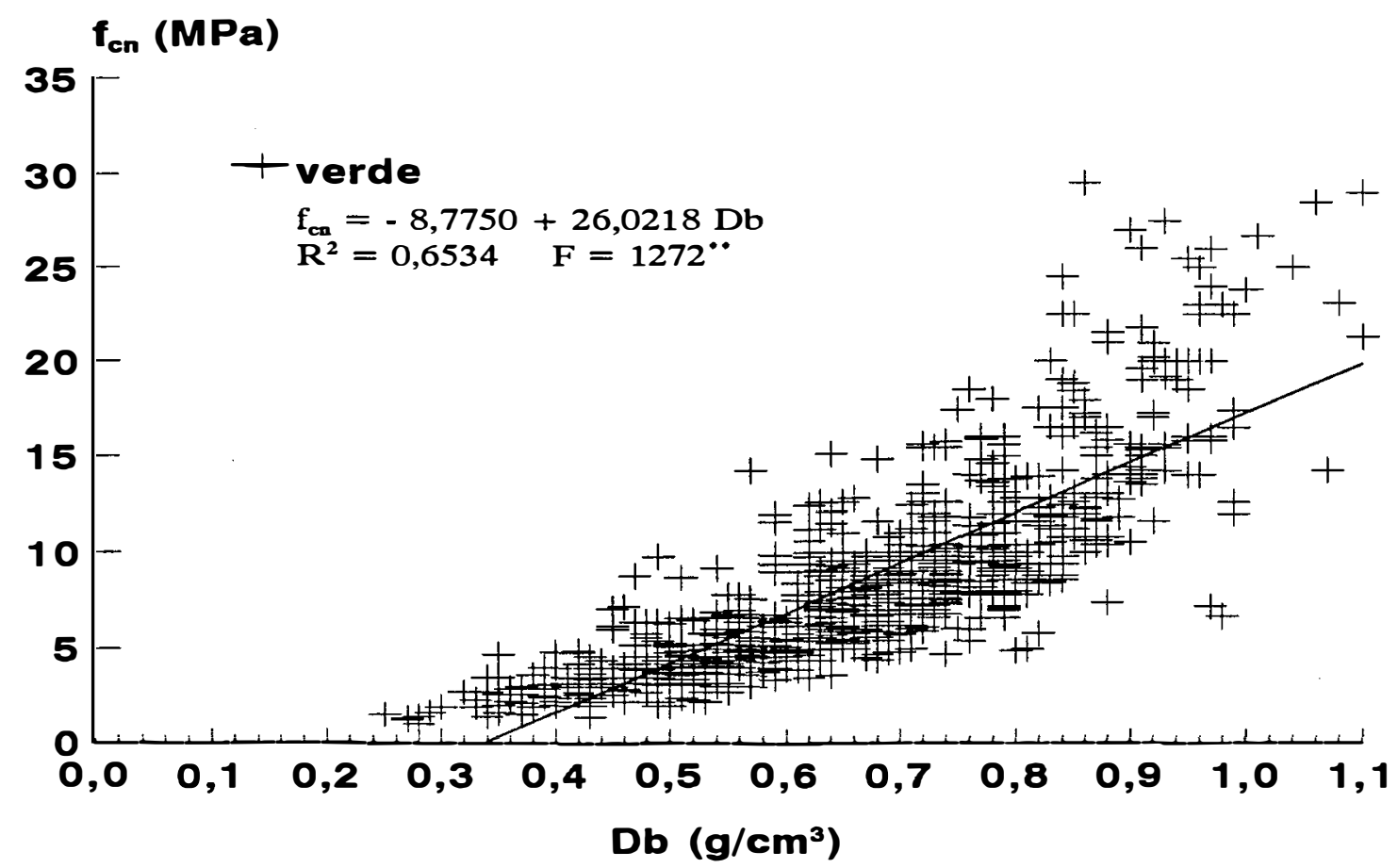

Figura 8. Relação entre módulo de resistência no limite de proporcionalidade $\left(f_{c n}\right)$ à compressão normal às fibras na condição verde e densidade básica (valores individuais reunindo todas as regiōes)

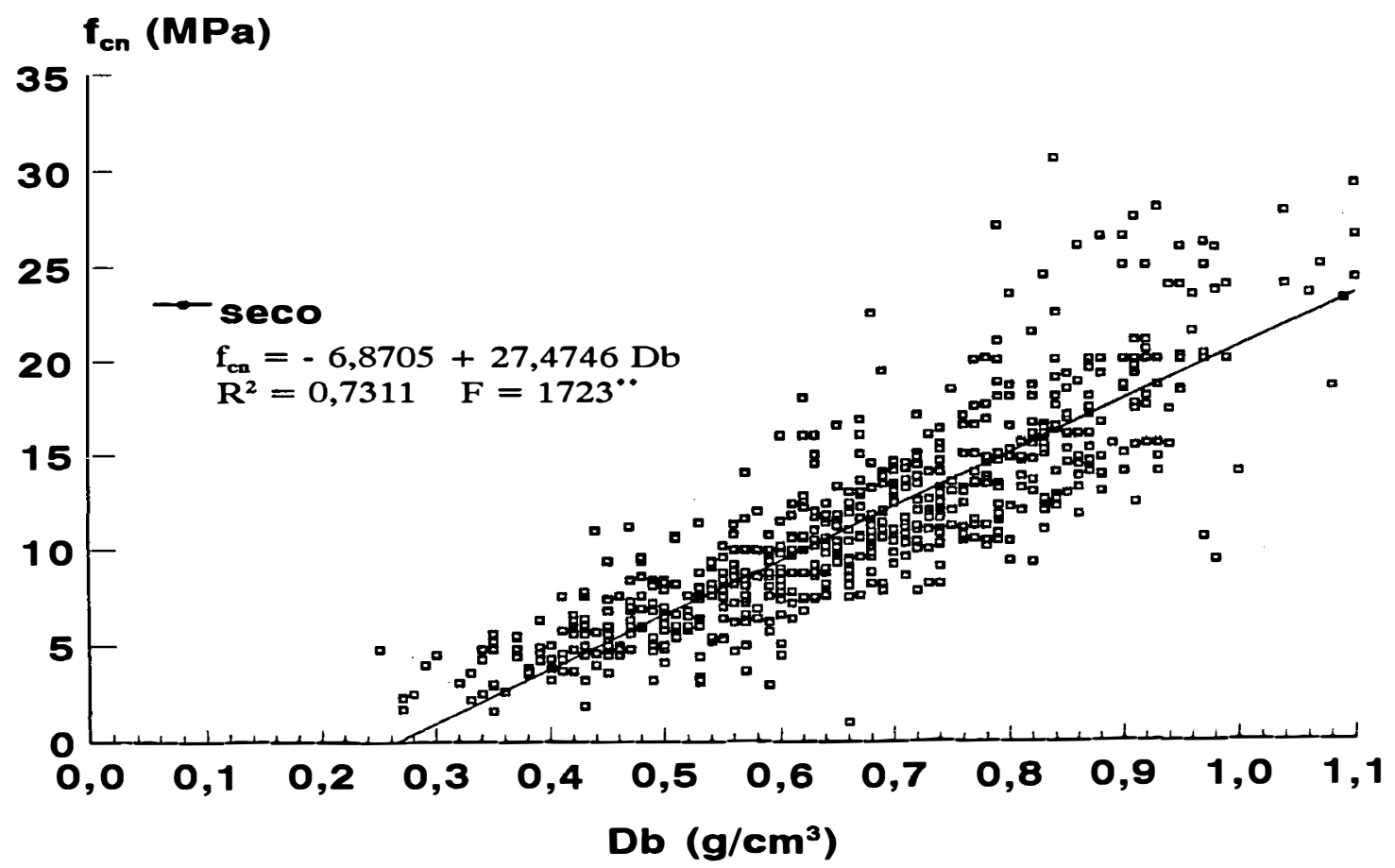

Figura 9. Relação entre módulo de resistência no limite de proporcionalidade $\left(f_{c n}\right)$ à compressão normal às fibras na condição seca e densidade básica (valores individuais reunindo todas as regiōes) 


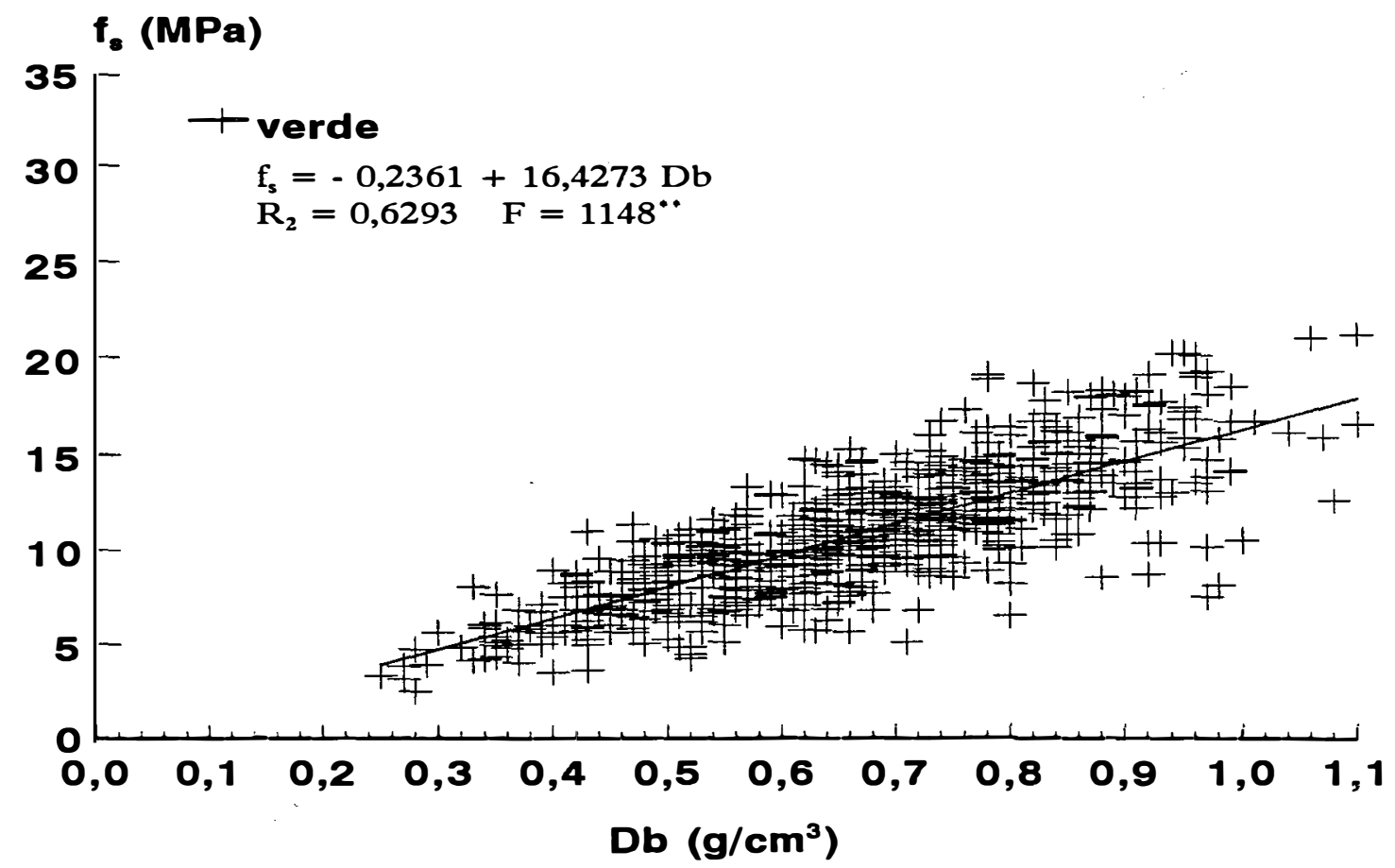

Figura 10. Relação entre tensão no limite de resistência ( $f_{g}$ ) ao cisalhamento paralelo às fibras na condiçẵo verde e densidade básica (valores individuais reunindo todas as regiōes)

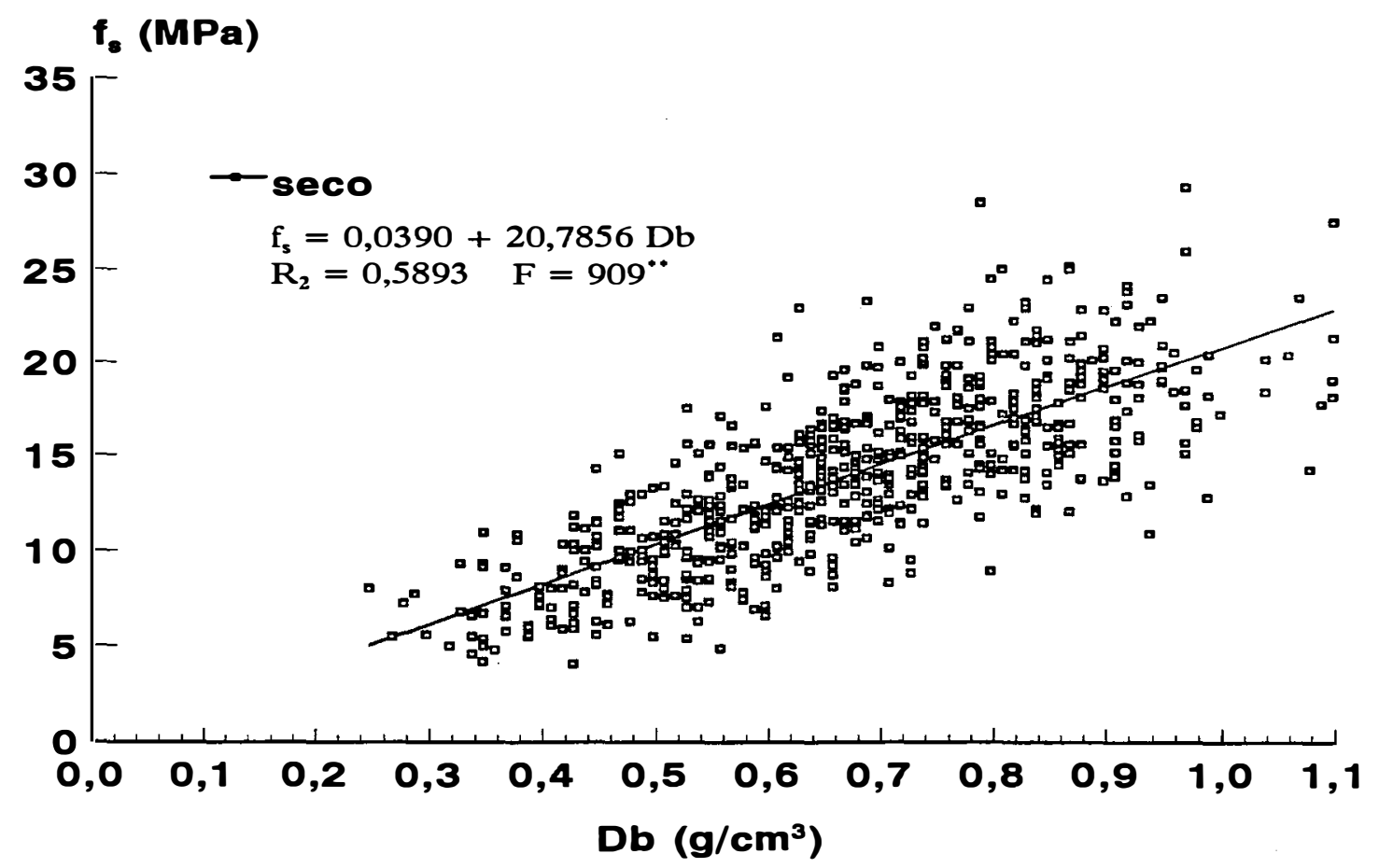

Figura 11. Relação entre tensão no limite de resistência $\left(f_{s}\right)$ ao cisalhamento paralelo às fibras na condição seca e densidade básica (valores individuais reunindo todas as regiōes) 
Admite-se que devido à rigorosa inspeção realizada nas madeiras do Amapá ensaiadas na condição seca, onde todas as amostras que apresentavam pequenas trincas superficiais foram eliminadas, este procedimento pode ter contribuído para melhorar as associaçōes entre densidade básica e propriedades de resistência.

Nas relaçōes entre as retraçōes tangencial, radial e volumétrica e com a densidade básica, observa-se que todos os valores dos coeficientes de determinação, tanto em cada região como no global, são inferiores àqueles obtidos entre propriedades mecânicas e densidade básica.

Mesmo na região do Amapá que apresentou os maiores coeficientes de determinação, verifica-se que os valores são equivalentes à metade dos valores obtidos entre propriedades mecânicas e densidade básica.

Apesar do teste $F$ das análises de variâncias das regressōes entre as retraçōes e a densidade básica terem sido significantes mesmo ao nível de $1 \%$, constata-se que 0 maior valor do coeficiente de determinação foi obtido na relação entre a retração radial $(\mathrm{Rr})$ com a densidade básica para as madeiras do Amapá. O modelo consegue explicar somente 37\% da variação total da retração radial. Por outro lado, o modelo global consegue explicar apenas $22 \%$

Os menores valores dos coeficientes de determinação, foram entre retração tangencial (Rt) e densidade básica, principalmente nas regiōes de Balbina e 
Curuá-Una. Deve ser evidenciado que em Balbina, o teste $\mathrm{F}$ não apresentou significância a 1\% de probabilidade.

CHIMELO (1980), estudando 44 espécies da Estação Experimental de Curuá-Una, obteve valores similares. o autor admite que a densidade básica tem muito pouca influência sobre a retração e ressalta ainda que o alto teor de extrativos presentes em algumas espécies de madeiras tropicais, afeta a relação entre retração e densidade básica, tendo em vista que os extrativos podem agir como repelentes à água e também como agentes de enchimento da parede celular, protegendo certas regiōes da parede contra a penetração da água ou vapor de água. Portanto, pode-se deduzir que tais substâncias reduzem a retração da madeira quando submetida à secagem.

Mediante os resultados obtidos e visando tornar evidente que a associação entre retração e densidade básica é fraca, foram elaboradas as Figuras 12, 13 e 14, que mostram respectivamente os gráficos de dispersão entre a retração tangencial, radial e volumétrica, com a densidade básica . 


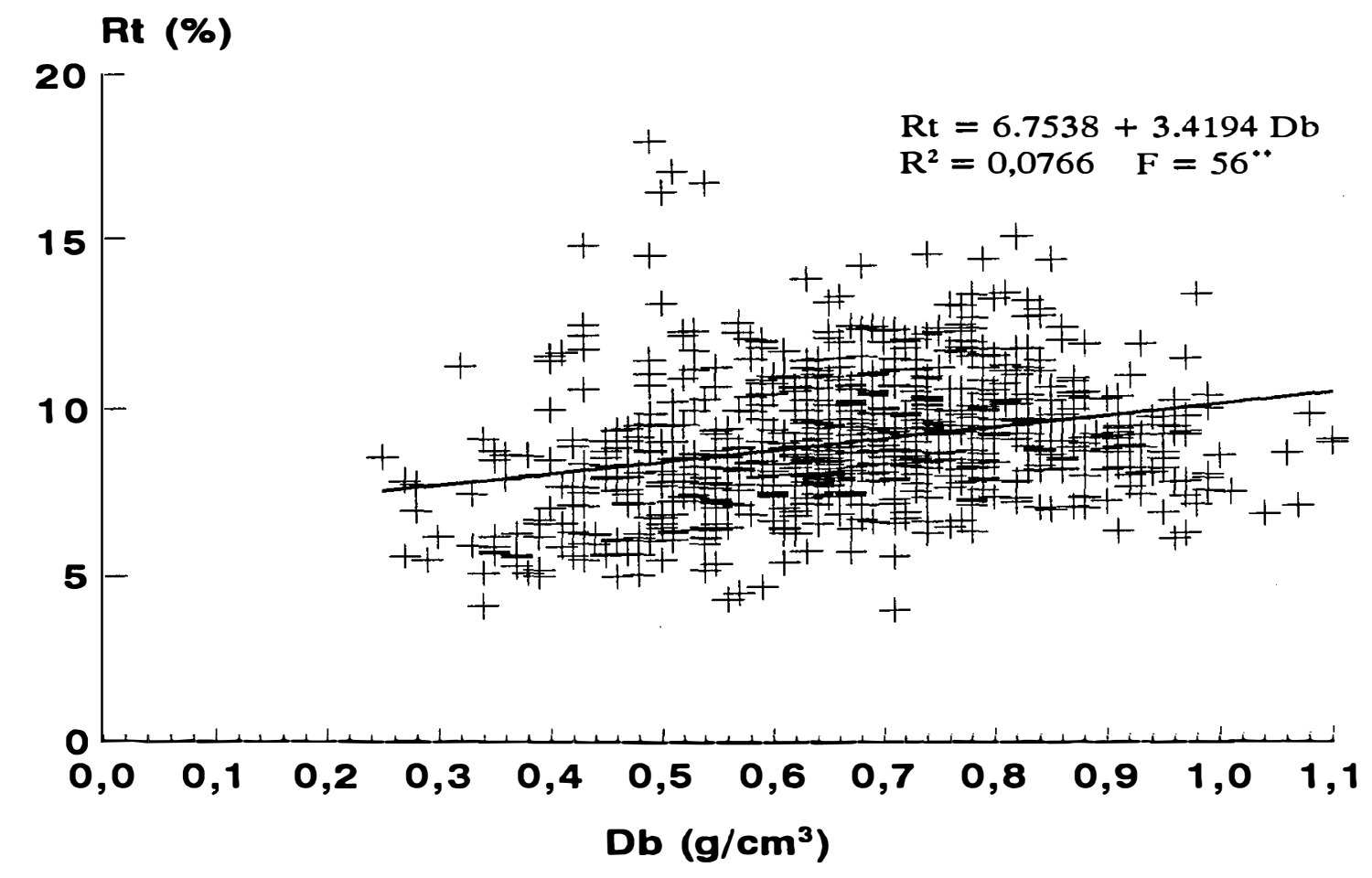

Figura 12. Relação entre retração tangencial (Rt) e densidade básica (valores individuais reunindo todas as regiōes)

Rr (\%)

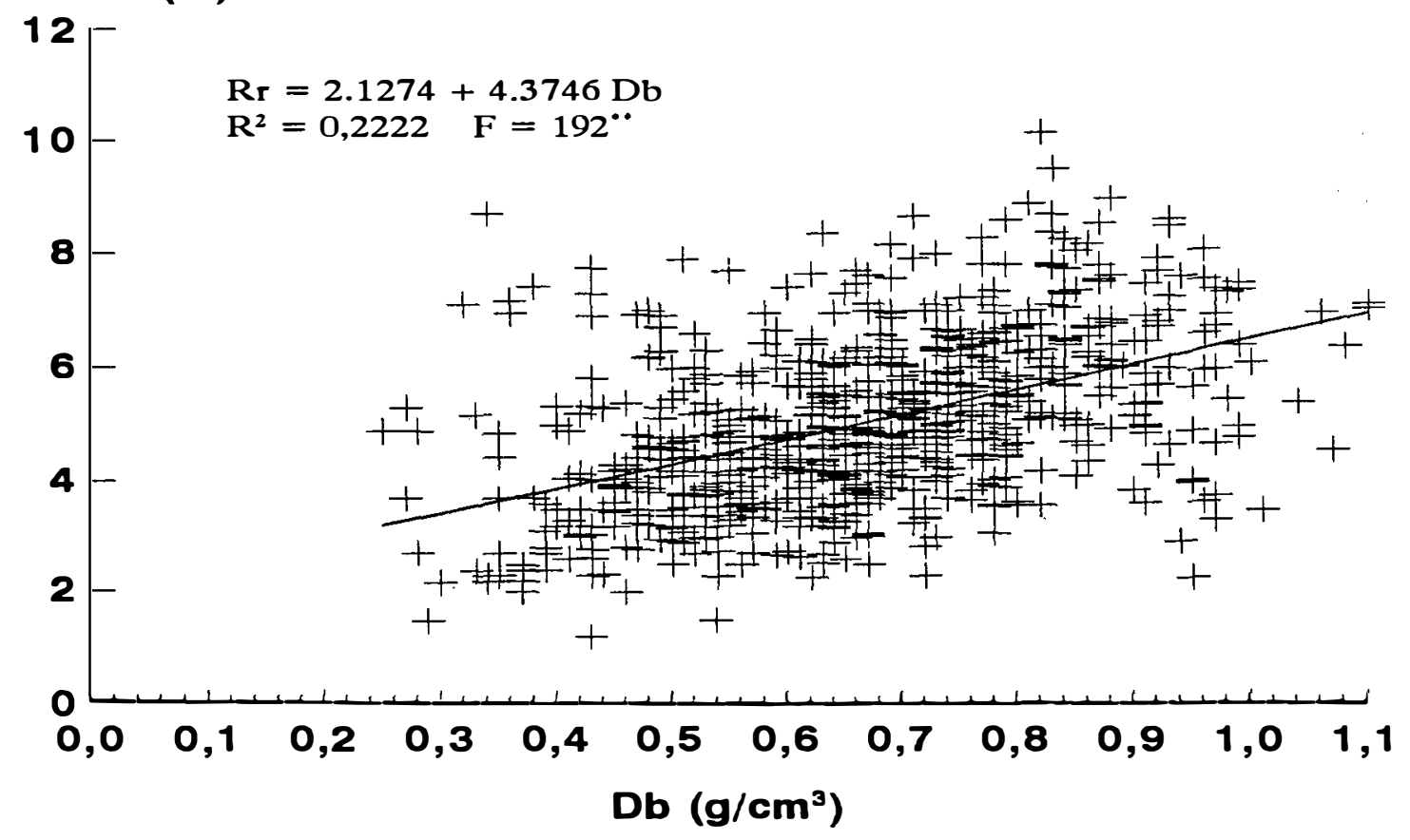

Figura 13. Relação entre retração radial ( $R r)$ e densidade básica (valores individuais reunindo todas as regiōes) 
Rv (\%)

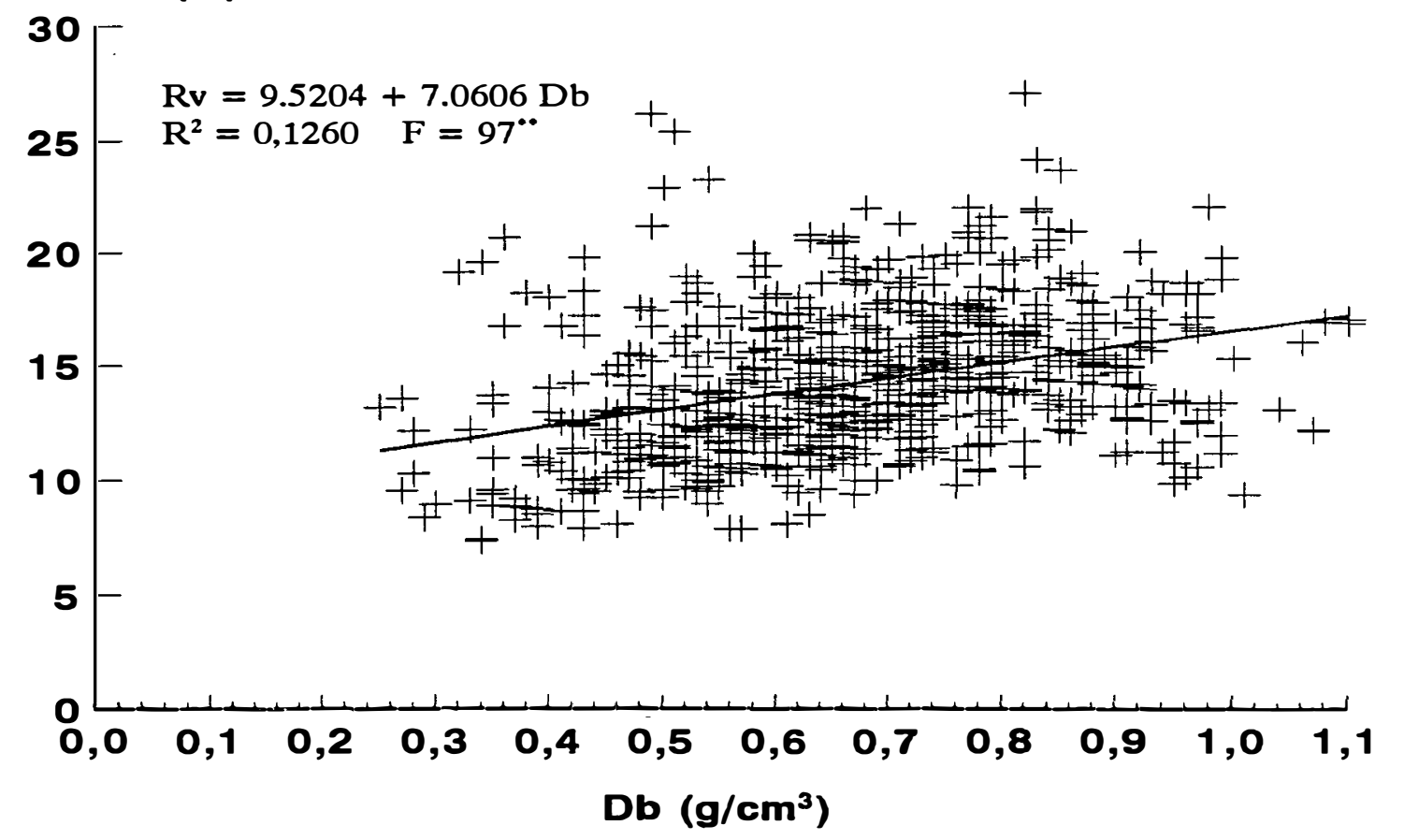

Figura 14. Relação entre retração volumétrica (Rv) e densidade básica (Db) (valores individuais reunindo todas as regiōes)

\subsection{Agrupamento de espécies}

De acordo com os intervalos de classes de densidade mostrados na Figura 15, foram obtidos oito grupos de densidade dentro da variação de $0,25 \mathrm{~g} / \mathrm{cm}^{3}$ a $1,14 \mathrm{~g} / \mathrm{cm}^{3}$.

Dentre todos os grupos, o 1 foi 0 que apresentou a menor frequência de espécies. Enquanto a maior concentração de espécies ocorreu no grupo 5. Conforme a Figura 15, observa-se que a maioria das espécies arbóreas da Amazônia apresenta densidade que varia de $0,55 \mathrm{~g} / \mathrm{cm}^{3}$ a 0,84 $\mathrm{g} / \mathrm{cm}^{3}$, abrangendo os grupos 4 a 6 . 


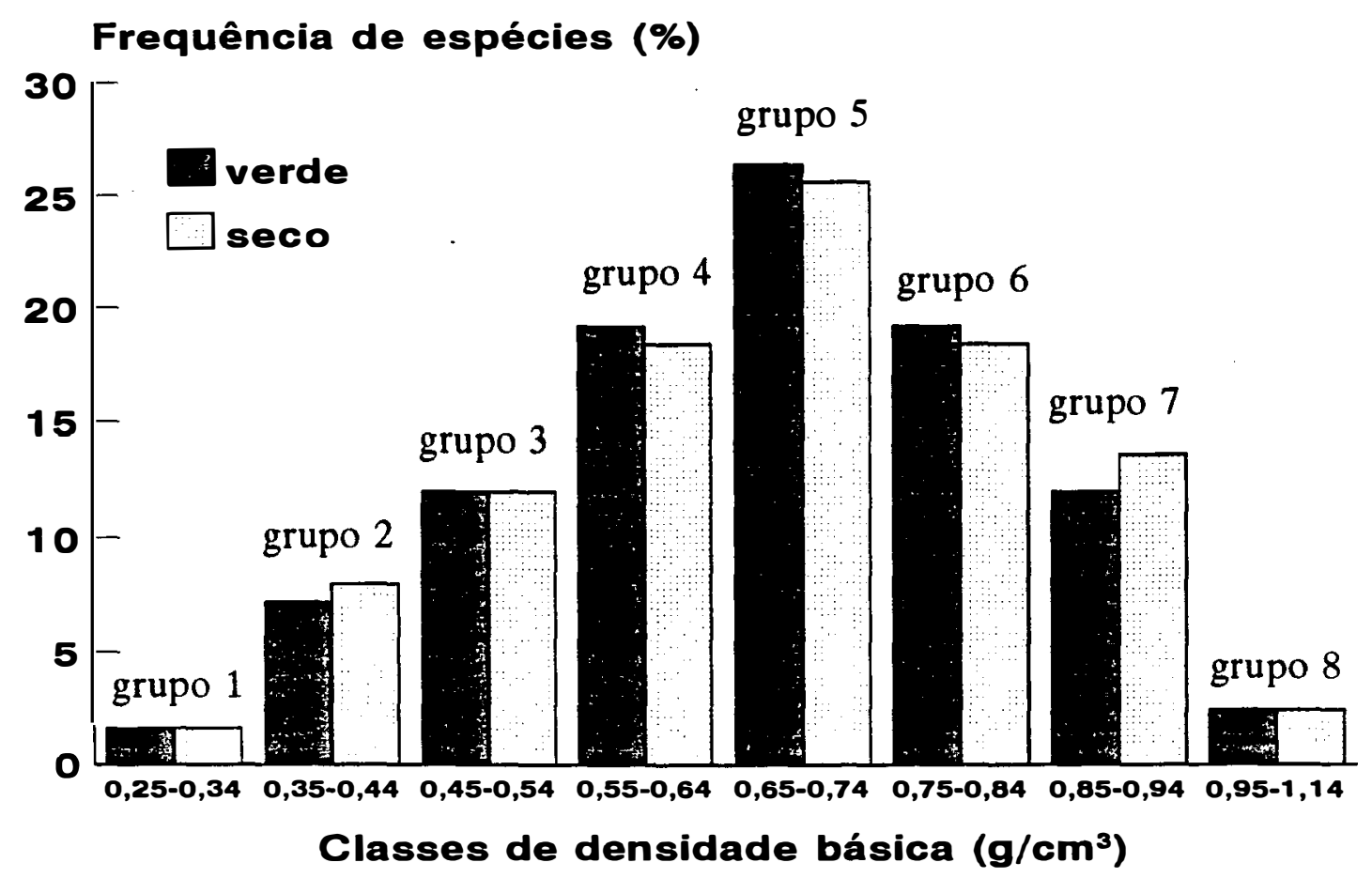

Figura 15. Frequências de espécies arbóreas amazônicas por intervalos de classes de densidade básica

A frequência de espécies com densidade variando de $0,25 \mathrm{~g} / \mathrm{cm}^{3}$ a $0,34 \mathrm{~g} / \mathrm{cm}^{3}$ e de $0,95 \mathrm{~g} / \mathrm{cm}^{3}$ a 1,14 $\mathrm{g} / \mathrm{cm}^{3}$ é muito baixa na floresta amazônica.

Existe a possibilidade de reduzir-se o número de grupos, todavia, preferiu-se mantê-los porque em caso de redução, aumentar-se-ia a variabilidade dentro de cada grupo e prejudicar-se-ia a segurança das estruturas de madeira.

As espécies que compõem cada grupo, encontramse na Tabela 13 . 
Tabela 13. Relação das espécies contidas nos grupos

\begin{tabular}{|c|c|c|}
\hline $\begin{array}{c}\text { Nome } \\
\text { cientifico }\end{array}$ & $\begin{array}{l}\text { grupo } \\
\text { verde }\end{array}$ & $\begin{array}{c}\text { grupo seco } \\
\text { ( } 12 \% \text { de umidade) }\end{array}$ \\
\hline Aldina heterophylla & 5 & 5 \\
\hline Alexa imperatricis & 4 & 4 \\
\hline Alexa grandiflora & 4 & 4 \\
\hline Anacardium spruceanum & 2 & 2 \\
\hline Andira parviflora & 5 & 5 \\
\hline Aniba canelilla & 7 & 7 \\
\hline Aspidosperma obscurinervium & 6 & 7 \\
\hline Astronium gracile & 5 & 5 \\
\hline Astronium lecointei & 6 & 6 \\
\hline Astronium ulei & 4 & 4 \\
\hline Bertholletia excelsa & 4 & 5 \\
\hline Bowdichia nitida & 7 & 7 \\
\hline Brosimum acutifolium & 4 & 4 \\
\hline Brosimum alicastrum & 5 & 5 \\
\hline Brosimum rubescens & 6 & 6 \\
\hline Buchenavia oxycarpa & 6 & 6 \\
\hline Carapa guianensis & 4 & 4 \\
\hline Cariniana integrifolia & 3 & 3 \\
\hline Cassia scleroxylon & 8 & 8 \\
\hline Cedrelinga catenaeformis & 3 & 3 \\
\hline clarisia racemosa & 4 & 4 \\
\hline Copaifera reticulata & 4 & 4 \\
\hline Cordia Bicolor & 2 & 2 \\
\hline Cordia goeldiana & 3 & 3 \\
\hline Corythophora rimosa & 7 & 7 \\
\hline Couratari guianensis & 3 & 3 \\
\hline Couratari oblongifolia & 3 & 3 \\
\hline Couratari stellata & 4 & 4 \\
\hline Dialium guianense & 7 & 7 \\
\hline Didymopanax morototoni & 2 & 2 \\
\hline Dinizia excelsa & 6 & 6 \\
\hline Diploon venezuelana & 7 & 7 \\
\hline Dipteryx odorata & 7 & 7 \\
\hline Dipteryx polyphylla & 6 & 6 \\
\hline Drypetes variabilis & 5 & 5 \\
\hline Endopleura uchi & 6 & 6 \\
\hline Enterolobium schomburgkii & 5 & 5 \\
\hline Eperua sp. & 6 & 6 \\
\hline Erisma uncinatum & 3 & 3 \\
\hline Eschweilera amara & 5 & 5 \\
\hline Eschweilera odora & 7 & 7 \\
\hline Eschweilera sagotiana & 6 & 6 \\
\hline Eschweilera sp. & 6 & 6 \\
\hline
\end{tabular}


continuação

\begin{tabular}{|c|c|c|}
\hline Granchetella gongrijpii & 5 & 5 \\
\hline Glycydendron amazonicum & 5 & 5 \\
\hline Goupia glabra & 5 & 5 \\
\hline Guatteria olivacea & 3 & 3 \\
\hline Guarea trichilioides & 5 & 5 \\
\hline Hymenaea courbaril & 6 & 5 \\
\hline Hymenaea parviflora & 7 & 7 \\
\hline Hymenolobium excelsum & 5 & 4 \\
\hline Hymenolobium modestum & 5 & 5 \\
\hline Hymenolobium pulcherrimum & 5 & 5 \\
\hline Inga alba & 4 & 4 \\
\hline Inga paraensis & 6 & 6 \\
\hline Iryanthera grandis & 5 & 5 \\
\hline Iryanthera tricornis & 5 & 5 \\
\hline Jacaranda copaia & 1 & 1 \\
\hline Joanesia heveoides & 2 & 2 \\
\hline Laetia procera & 5 & 5 \\
\hline Lecythis pisonis & 6 & 7 \\
\hline Lecythis poiteaui & 6 & 6 \\
\hline Licania octandra & 6 & 6 \\
\hline Licaria aritu & 6 & 6 \\
\hline Licaria canela & 8 & 8 \\
\hline Licaria rigida & 5 & 6 \\
\hline Lueheopsis duckeana & 4 & 4 \\
\hline Malouetia duckei & 4 & 4 \\
\hline Manilkara amazonica & 6 & 6 \\
\hline Manilkara huberi & 7 & 7 \\
\hline Maquira sclerophylla & 4 & 4 \\
\hline Mezilaurus itauba & 5 & 5 \\
\hline Micropholis venulosa & 4 & 4 \\
\hline Nectandra rubra & 3 & 3 \\
\hline Nemaluma anomala & 6 & 6 \\
\hline Ocotea neesiana & 3 & 3 \\
\hline Ocotea sp. & 4 & 4 \\
\hline Onychopetalum amazonicum & 4 & 4 \\
\hline ormosia paraensis & 5 & 5 \\
\hline Parkia nitida & 2 & 2 \\
\hline Parkia paraensis & 3 & 3 \\
\hline Parkia pendula & 3 & 3 \\
\hline Parkia ulei & 2 & 2 \\
\hline Parinari montana & 5 & 5 \\
\hline Peltogyne paradoxo & 7 & 7 \\
\hline Piptadenia suaveolens & 5 & 5 \\
\hline Pithecelobium racemosum & 6 & 6 \\
\hline Planchonella pachycarpa & 5 & 6 \\
\hline Pouteria caimito & 7 & 7 \\
\hline Pouteria guianensis & 7 & 7 \\
\hline
\end{tabular}


continuação

\begin{tabular}{|c|c|c|}
\hline Protium Heptaphyllum & 3 & 3 \\
\hline Protium sp. & 6 & 5 \\
\hline Protium tenuifolium & 5 & 4 \\
\hline Qualea albiflora & 4 & 4 \\
\hline Qualea brevipedicellata & 5 & 5 \\
\hline Qualea cf. lancifolia & 4 & 4 \\
\hline Qualea paraensis & 5 & 5 \\
\hline Rollinia exsucca & 3 & 3 \\
\hline Roupala montana & 6 & 6 \\
\hline Sacoglottis guianensis & 6 & 6 \\
\hline Sandwithiodoxa egregia & 5 & 6 \\
\hline sclerolobium chrysophyllum & 4 & 4 \\
\hline Sclerolobium paraense & 5 & 5 \\
\hline Sclerolobium poeppigianum & 5 & 5 \\
\hline Sclerolobium sp. & 2 & 2 \\
\hline Scleronema micranthum & 4 & 4 \\
\hline Simaruba amara & 1 & 1 \\
\hline sterculia pilosa & 2 & 2 \\
\hline sterculia speciosa & 2 & 2 \\
\hline Swartzia panacoco & 8 & 8 \\
\hline Symphonia globulifera & 4 & 4 \\
\hline Tabebuia serratifolia & 7 & 7 \\
\hline Tachigalia myrmecophilla & 4 & 5 \\
\hline Tetragastris altissima & 5 & 5 \\
\hline Tetragastris panamensis & 6 & 6 \\
\hline Thyrsodium guianensis & 5 & 5 \\
\hline Trattinickia cf. burserifolia & 3 & 2 \\
\hline Trichilia lecointei & 7 & 7 \\
\hline Vantanea parviflora & 7 & 7 \\
\hline Vatairea paraensis & 6 & 6 \\
\hline Vatairea sericea & 5 & 5 \\
\hline Vataireopsis sp. & 5 & 5 \\
\hline Vochysia guianensis & 4 & 4 \\
\hline Vochysia melinonii & 3 & 3 \\
\hline Xylopia nitida & 4 & 3 \\
\hline
\end{tabular}

\subsection{Ajuste para a distribuição dos dados}

De acordo com a técnica empregada (gráfico QQ), admite-se que as distribuições amostral e teórica, representam as distribuições observadas das variáveis $\mathrm{Db}, \mathrm{E}_{\mathrm{f}}$, 
$f_{f}, f_{c}, f_{c n} e f_{s} e$ a distribuição de Weibull estimada respectivamente, tanto para os grupos de espécies, quanto no global cujas estimativas se encontram no Anexo 2.

\subsection{Teste de normalidade dos dados observados}

Os resultados dos teste de normalidade, apresentaram valores da estatística $A^{2 *}$ de Anderson - Darling para a densidade básica igual $a=2,043$ e para o módulo de ruptura à flexão estática igual a =3,111. o valor tabelado dessa estatistica, conforme Tabela A-6 (SHAPIRO, 1990), para $\alpha=0,05$, é de 0,752 . Portanto, há evidências, ao nível de 5\% de significância, de que a densidade básica e o módulo de ruptura à flexão estática não seguem distribuição normal.

o teste de normalidade foi feito apenas para essas duas variáveis porque, para o desenvolvimento da teoria empregando a função Weibull visando quantificar as probabilidades de segurança das estruturas, foi realizado somente com as citadas variáveis.

\subsection{Distribuição Weibull para a densidade básica $e$ o módulo de ruptura à flexão estática das madeiras amazônicas nas condições verde e seca}

Mediante os resultados obtidos no item anterior, onde, constatou-se que as variáveis densidade 
básica e módulo de ruptura à flexão estática $\left(f_{f}\right)$ seguem uma distribuição normal e, considerando ainda que dentre todas as propriedades físicas e mecânicas da madeira, a densidade básica é a propriedade mais pura, admite-se que as demais propriedades mecânicas também não apresentam distribuição normal.

Nas Figuras 16 a 19 estão mostradas as distribuiçōes obtidas para a densidade básica conjuntamente com os valores observados.

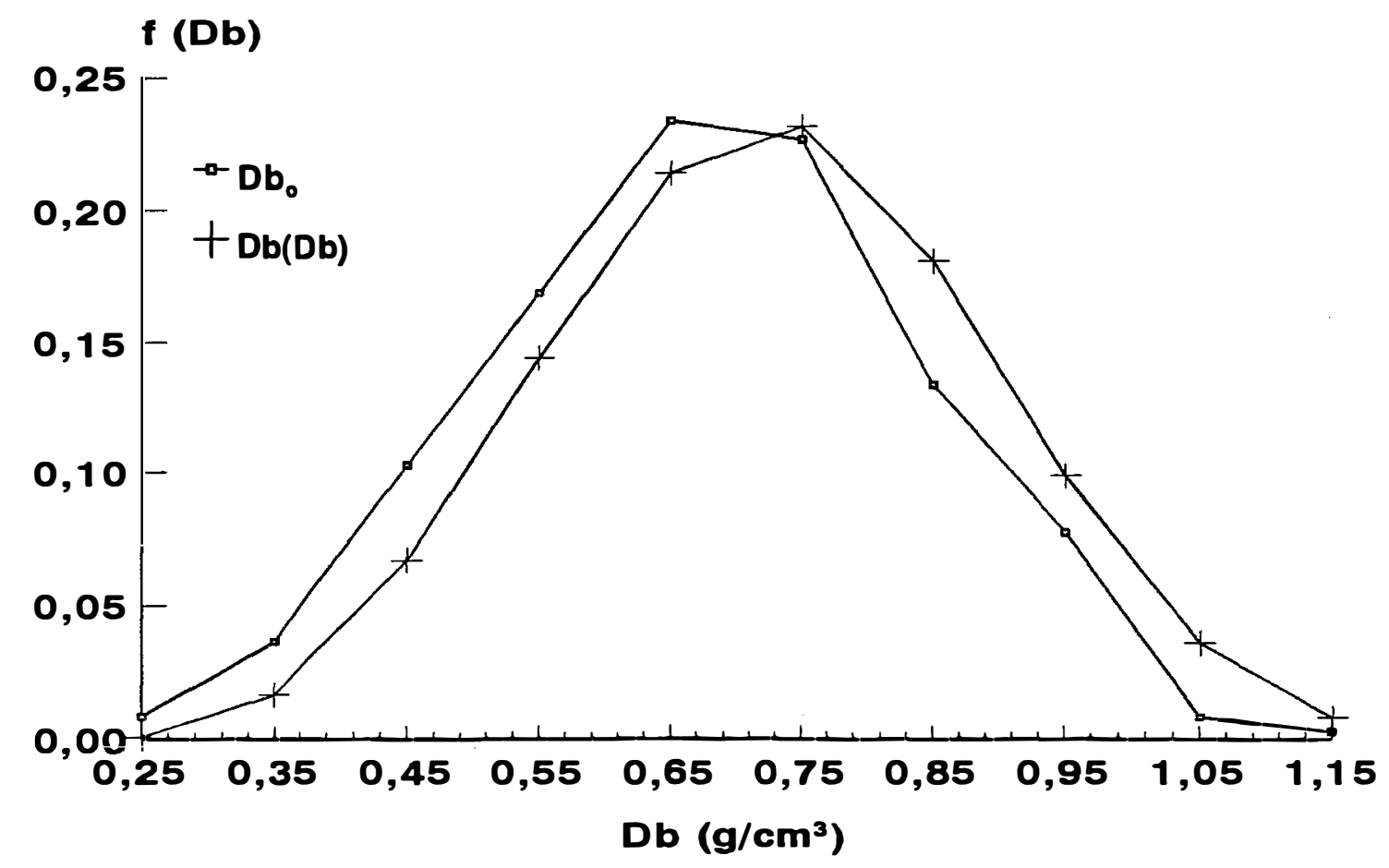

Figura 16. f.d.p. ajustada aos dados observados de Db das madeiras da floresta amazônica estudadas na condição verde 


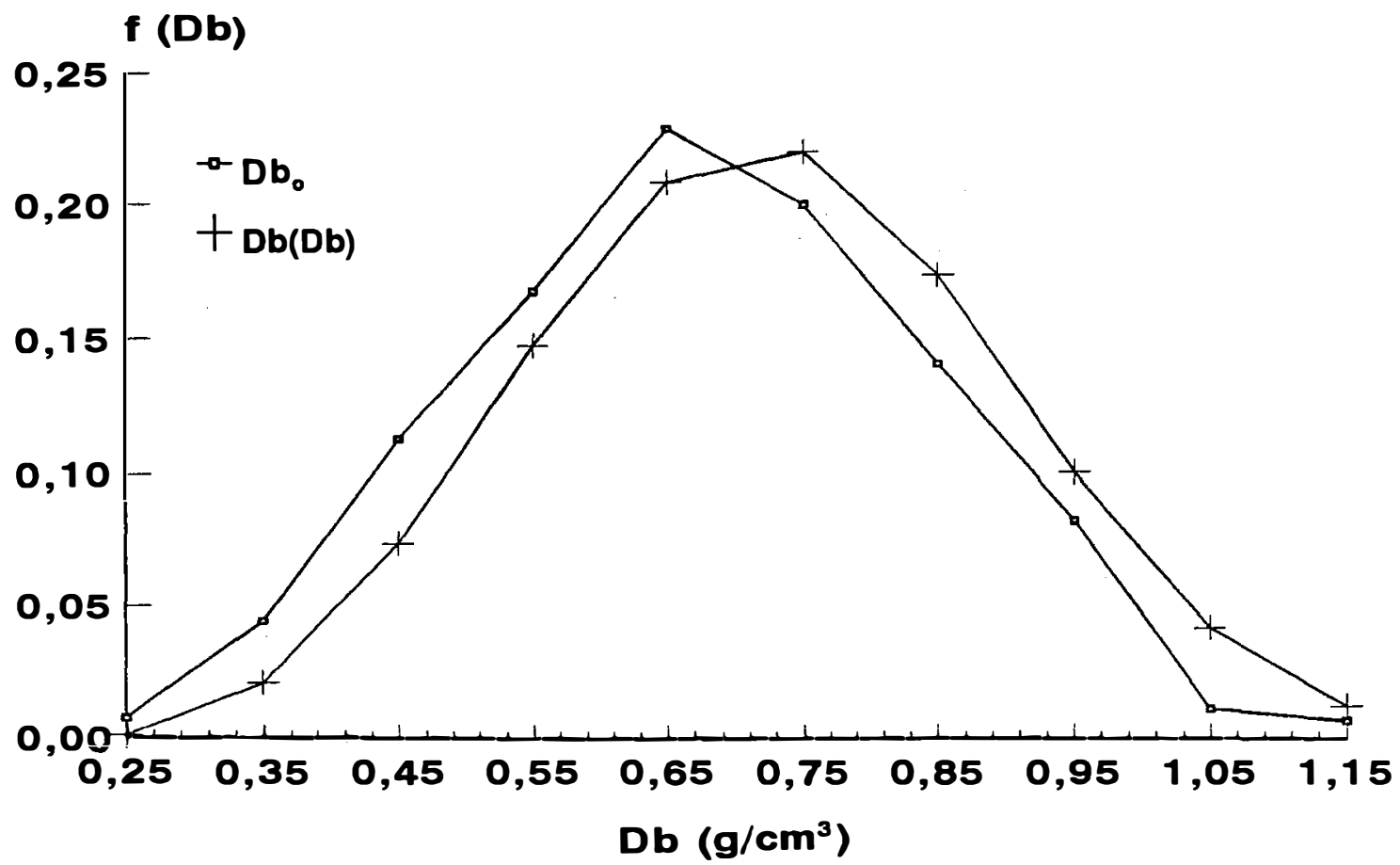

Figura 17. f.d.p. ajustada aos dados observados de Db das madeiras da floresta amazônica estudadas na condição seca

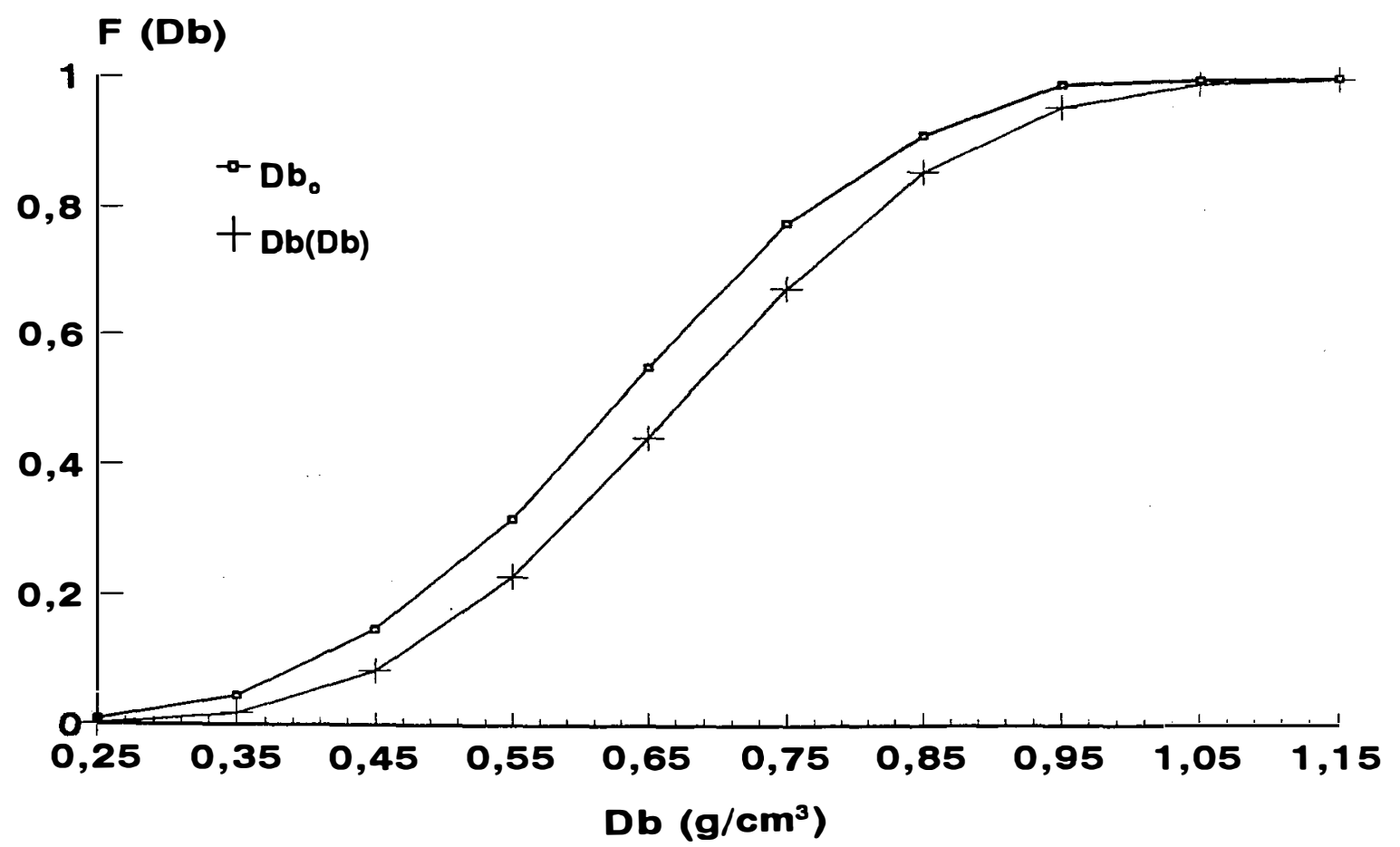

Figura 18. F.d.a. ajustada aos dados observados de Db das madeiras da floresta amazônica estudadas na condição verde 


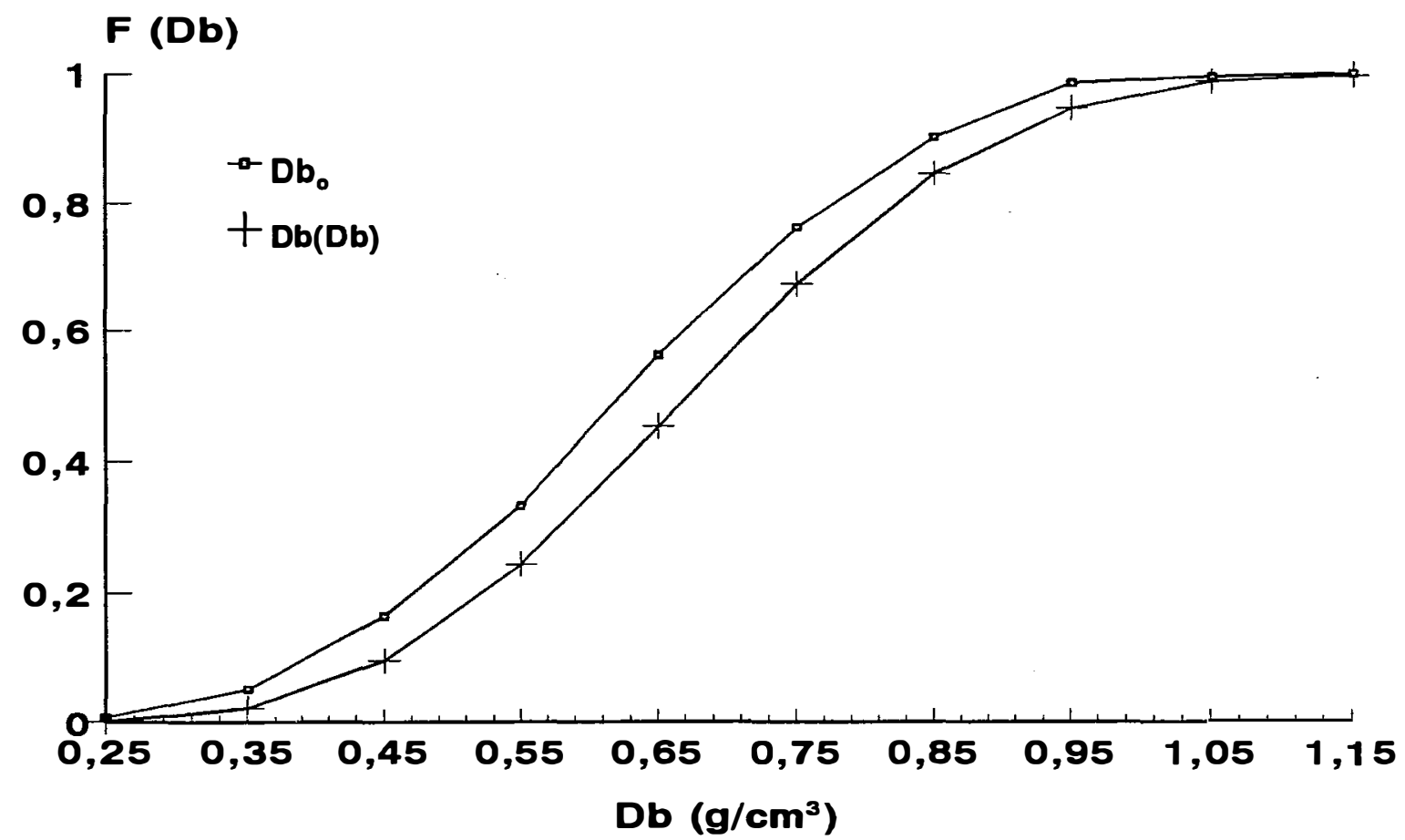

Figura 19. F.d.a. ajustada aos dados observados de Db das madeiras da floresta amazônica estudadas na condição seca

Como era de se esperar, pode-se observar na Tabela 14 que as estimitivas dos parâmetros de posição (a), escala (b) e forma (c) das distribuições da densidade básica estimadas $\left(\mathrm{Db}_{e}\right)$ determinadas a partir da madeira na condição verde, são idênticas àquelas obtidas da madeira na condição seca. Pequenas variações devidas a erros experimentais e a pequenas alterações no número de amostras são observadas. 
Tabela 14. Estimativas dos parâmetros a, $\mathbf{b}$ e c, da distribuição Weibull feitas em função da densidade básica observada das madeiras amazônicas estudadas nas condiçōes verde e seca

\begin{tabular}{crr}
\hline \hline Parâmetros & $\mathrm{Db}$ (condição verde) & Db (condição seca) \\
\hline \hline $\mathrm{a}$ & 0,190000 & 0,190000 \\
$\mathrm{~b}$ & 0,540974 & 0,541285 \\
$\mathrm{C}$ & 3,312490 & 3,131890 \\
$\mathrm{~N}$ & 710 & 656 \\
\hline
\end{tabular}

Nas Figuras 20 a 23 estão plotados em cada uma, a distribuição dos valores do módulo de ruptura à flexão estática observados $\left(f_{f o}\right)$ e duas distribuiçōes estimadas. Uma delas foi obtida diretamente dos dados observados e a outra é a própria distribuição da densidade básica aplicada aos valores do módulo de ruptura à flexão estática, $\left(f_{f}\right)$ em função da densidade básica (Db) da Equação 9 . 


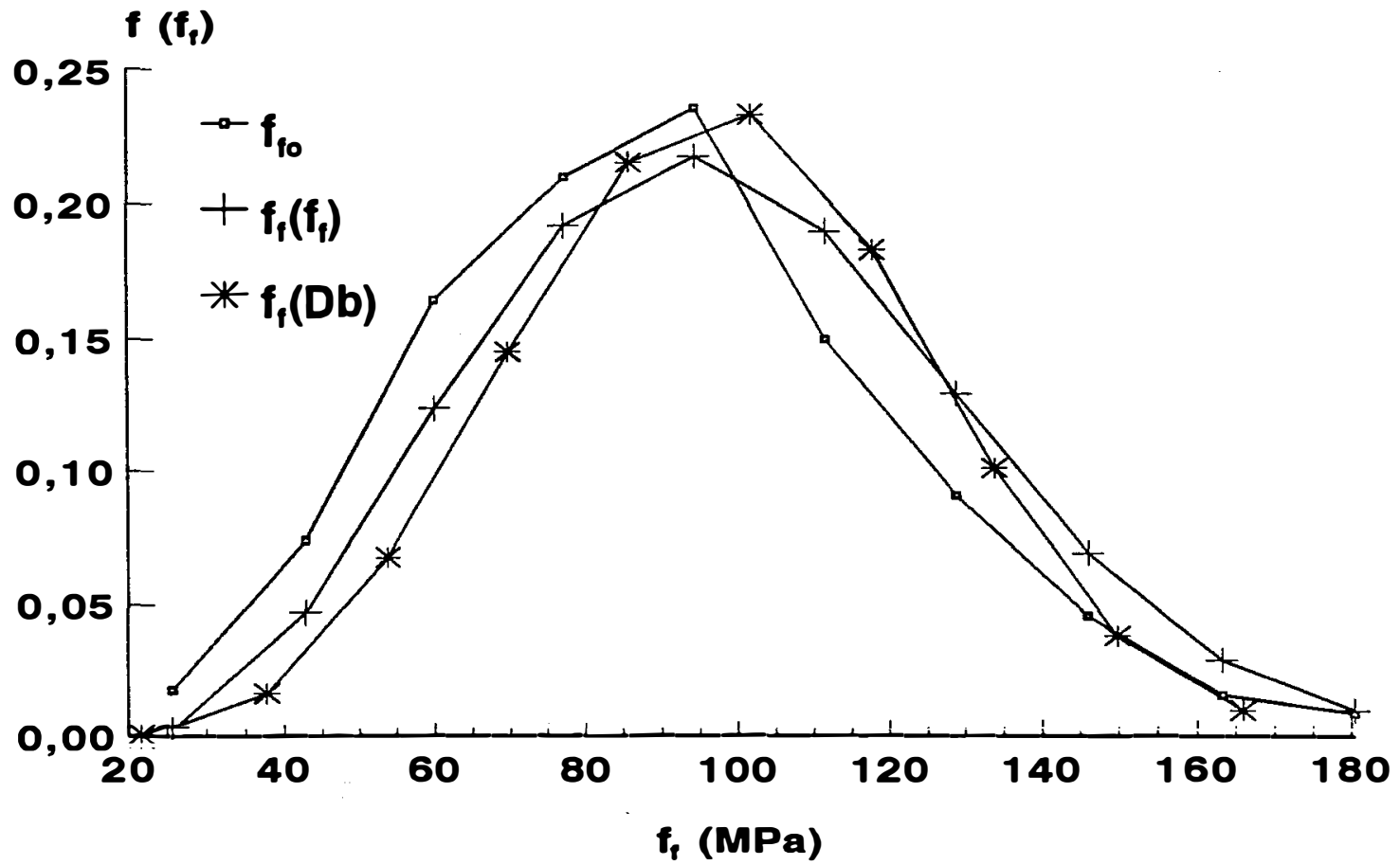

Figura 20. f.d.p. ajustada aos dados observados do $f_{f} e$ aos dados do $f_{f}$ estimados através dos valores da $\mathrm{Db}$ das madeiras da floresta amazônica estudadas na condição verde

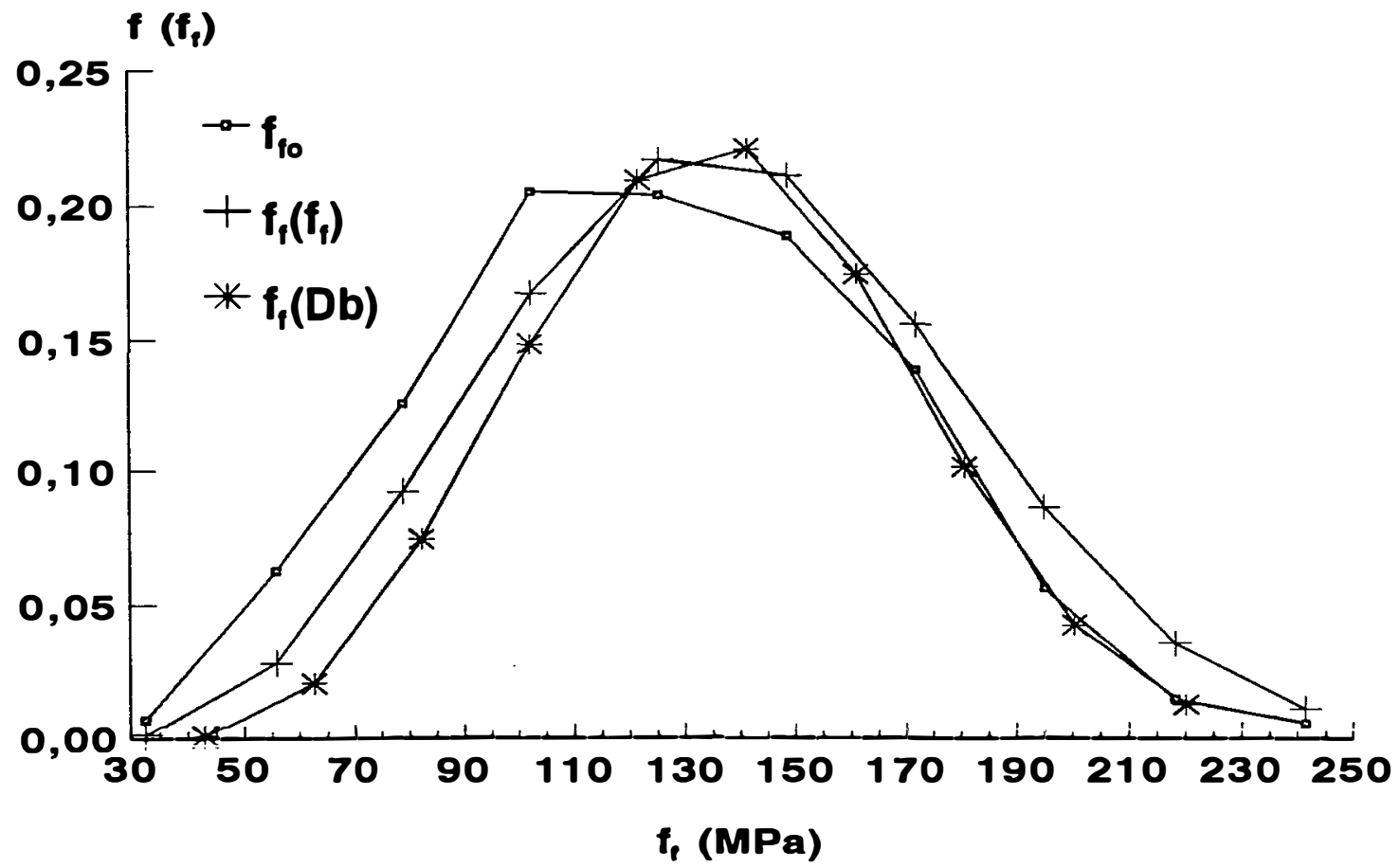

Figura 21. f.d.p. ajustada aos dados observados do $f_{f} e$ aos dados do $f_{f}$ estimados através dos valores da $\mathrm{Db}$ das madeiras da floresta amazônica estudadas na condição seca 


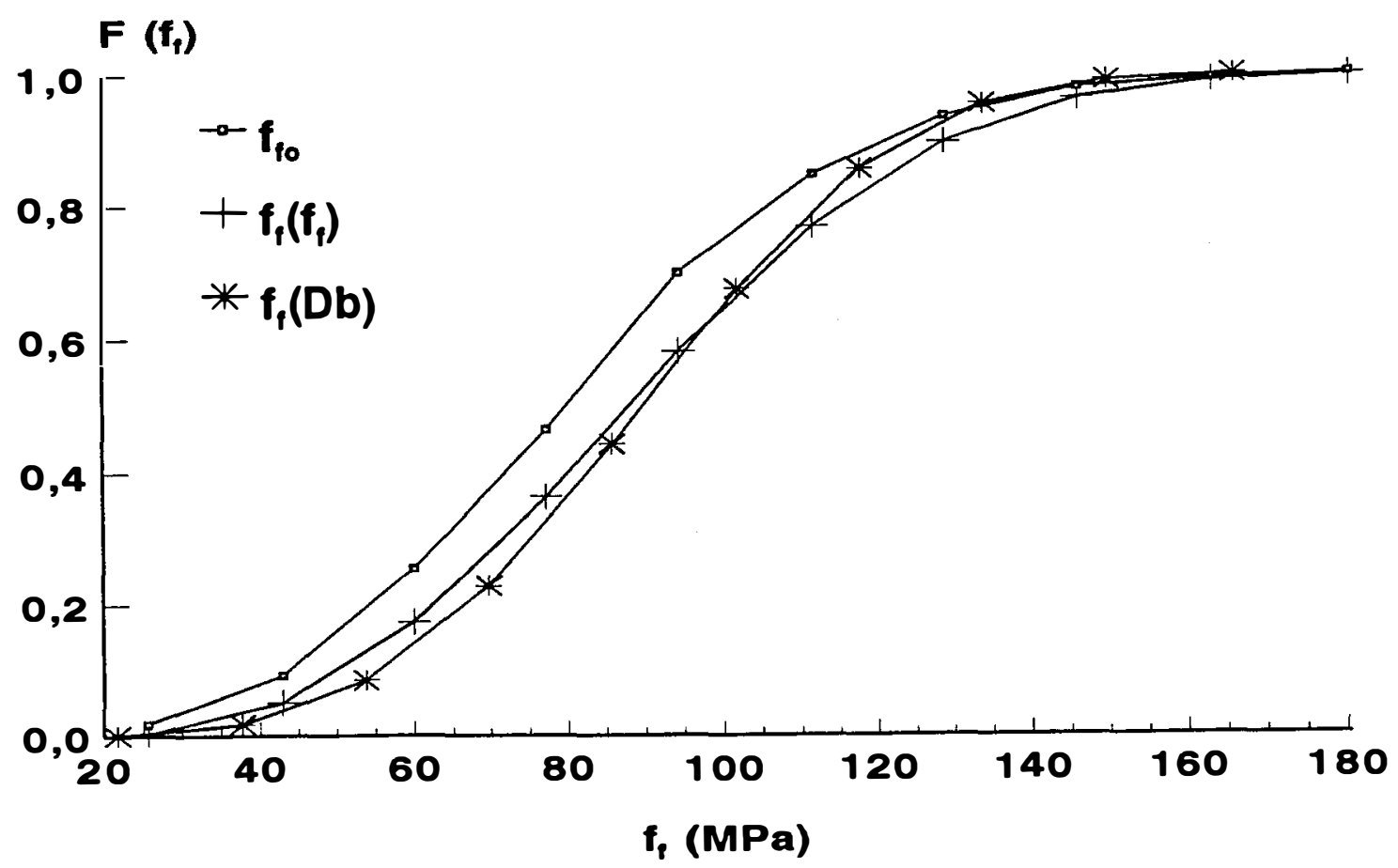

Figura 22. F.d.a. ajustada aos dados observados do $f_{f} e$ aos dados do $f_{f}$ estimados através dos valores da $\mathrm{Db}$ das madeiras da floresta amazônica estudadas na condição verde

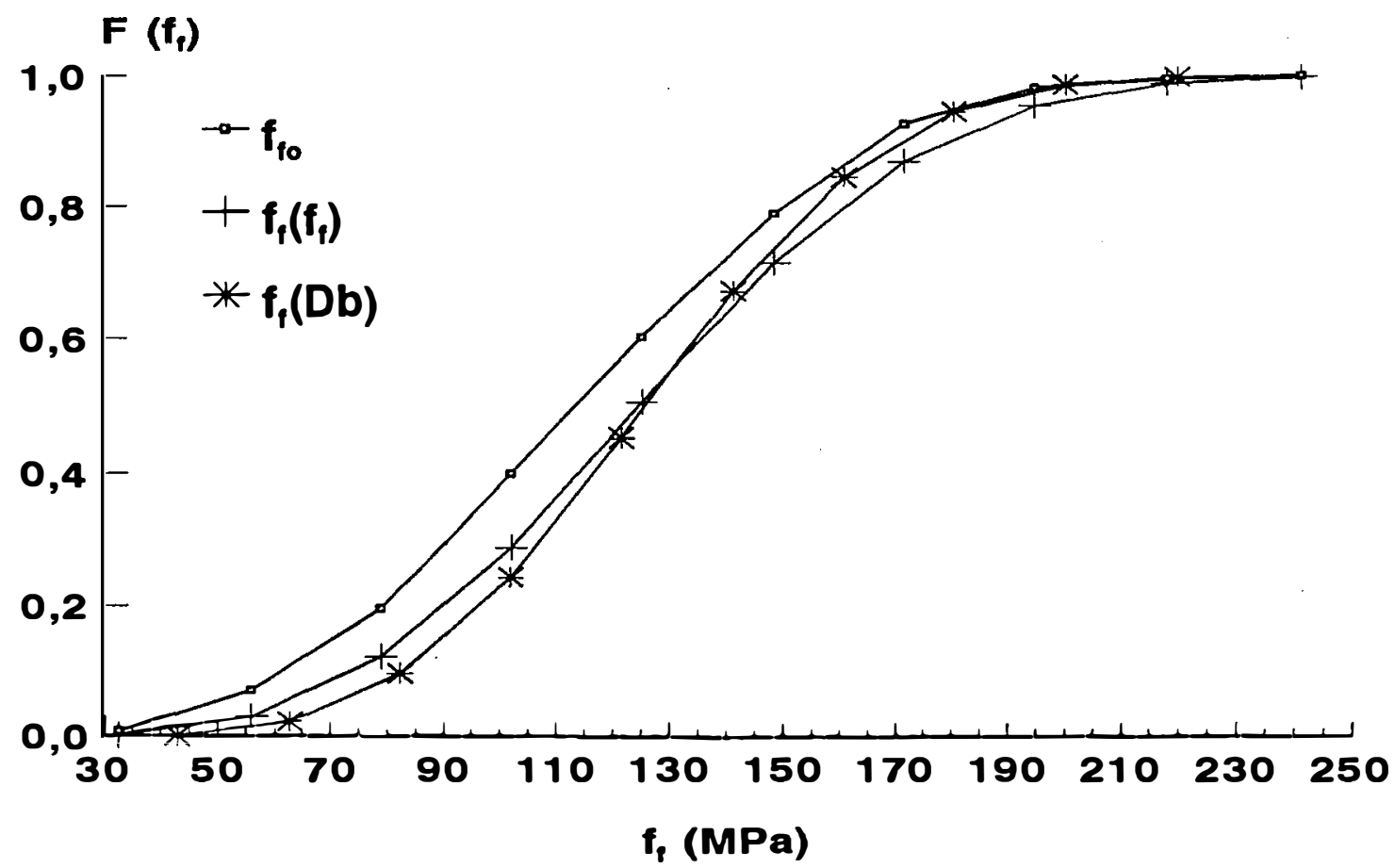

Figura 23. F.d.a. ajustada aos dados observados do $f_{f} e$ aos dados do $f_{f}$ estimados através dos valores da $\mathrm{Db}$ das madeiras da floresta amazônica estudadas na condição seca 
Observa-se que as distribuiçōes do módulo de ruptura à flexão estática obtidas na condição seca têm praticamente a mesma conformação daquelas obtidas na condição verde, estando entretanto, transladadas para a direita em função da superioridade da resistência da madeira seca em relação à madeira verde.

Através das equaçōes 5 e 6 , os valores estimados dos parâmetros b e c das distribuiçōes Weibull, possibilitaram a obtenção das frequências de densidade básica para as frequências de densidade probabilistica (f.d.p.) e acumulada (F.d.a.), nas condiçōes verde e seca, conforme Anexo 6.

4.7. Densidade básica da madeira como um estimador de propriedades mecânicas

Tendo sido constatado através da análise da variância da regressão, que as propriedades mecânicas da madeira estão diretamente relacionadas com a densidade básica, tanto para a madeira na condição verde quanto seca, torna-se possivel estimar as propriedades mecânicas de qualquer espécie da Amazônia, utilizando somente os valores de densidade básica, a partir das Equaçōes 7 a 16, abaixo.

$$
\begin{aligned}
& f\left(E_{f} \text { verde }\right)=f(2507,9+14217 D b)=f(D b) \\
& f\left(E_{f} \text { seca }\right)=f(4173,1+14094 D b)=f(D b)
\end{aligned}
$$




$$
\begin{aligned}
& \mathrm{f}\left(\mathrm{f}_{\mathrm{f}} \text { verde }\right)=\mathrm{f}(-18,3766+160,21 \mathrm{Db})=\mathrm{f}(\mathrm{Db}) \\
& \mathrm{f}\left(\mathrm{f}_{\mathrm{f}} \text { seca }\right)=\mathrm{f}(-6,1749+196,73 \mathrm{Db})=\mathrm{f}(\mathrm{Db}) \\
& \mathrm{f}\left(\mathrm{f}_{\mathrm{c}} \text { verde }\right)=\mathrm{f}(-14,5784+88,7035 \mathrm{Db})=\mathrm{f}(\mathrm{Db}) \\
& \mathrm{f}\left(\mathrm{f}_{\mathrm{c}} \text { seca }\right)=\mathrm{f}(1,4446+98,452 \mathrm{Db})=\mathrm{f}(\mathrm{Db}) \\
& \mathrm{f}\left(\mathrm{f}_{\mathrm{cn}} \text { verde }\right)=\mathrm{f}(-8,7750+26,0218 \mathrm{Db})=\mathrm{f}(\mathrm{Db}) \\
& \mathrm{f}\left(\mathrm{f}_{\mathrm{cn}} \text { seca }\right)=\mathrm{f}(-6,8705+27,4746 \mathrm{Db})=\mathrm{f}(\mathrm{Db}) \\
& \mathrm{f}\left(\mathrm{f}_{\mathrm{s}} \text { verde }\right)=\mathrm{f}(-0,2361+16,4273 \mathrm{Db})=\mathrm{f}(\mathrm{Db}) \\
& \mathrm{f}\left(\mathrm{f}_{\mathrm{s}} \text { seca }\right)=\mathrm{f}(0,0390+20,7856 \mathrm{Db})=\mathrm{f}(\mathrm{Db})
\end{aligned}
$$

Diante dos resultados obtidos, desenvolveu-se uma teoria que permite, através de densidade básica, predizer a probabilidade de segurança de uma estrutura de madeira, da mesma forma com que se pode predizer a segurança das estruturas através da distribuição da propriedade mecânica desejada. Porém, o mais importante desta teoria, é a sua aplicaçāo no sentido inverso, tendo em vista que a mesma permite predizer a densidade básica necessária para se obter uma determinada segurança desejada para uma estrutura.

Entretanto, a adoçāo de uma determinada segurança, que seja razoável para a estrutura, ainda é uma dificuldade a ser vencida.

\subsection{Distribuiçōes Weibull para grupos de espécies}

O emprego dessa distribuiçāo para grupos de espécies, ficou restrita a apenas uma propriedade mecânica, 
isto é, o módulo de ruptura à flexão estática $\left(f_{f}\right)$. Tendo em vista que objetivou-se quantificar a segurança das estruturas de madeira, foram desenvolvidas somente as distribuiçōes de frequência de densidade acumulada (F.d.a.).

Cada grupo de espécie é composto de três distribuições, onde, $f_{f o}$ representa a frequência dos dados observados, $f_{f}\left(f_{f}\right)$ reflete a frequência dos valores estimados em função dos dados observados e $f_{f}(D b)$ representa a frequência dos dados do módulo de ruptura estimados em função da densidade básica, conforme Figuras 24 a 27.

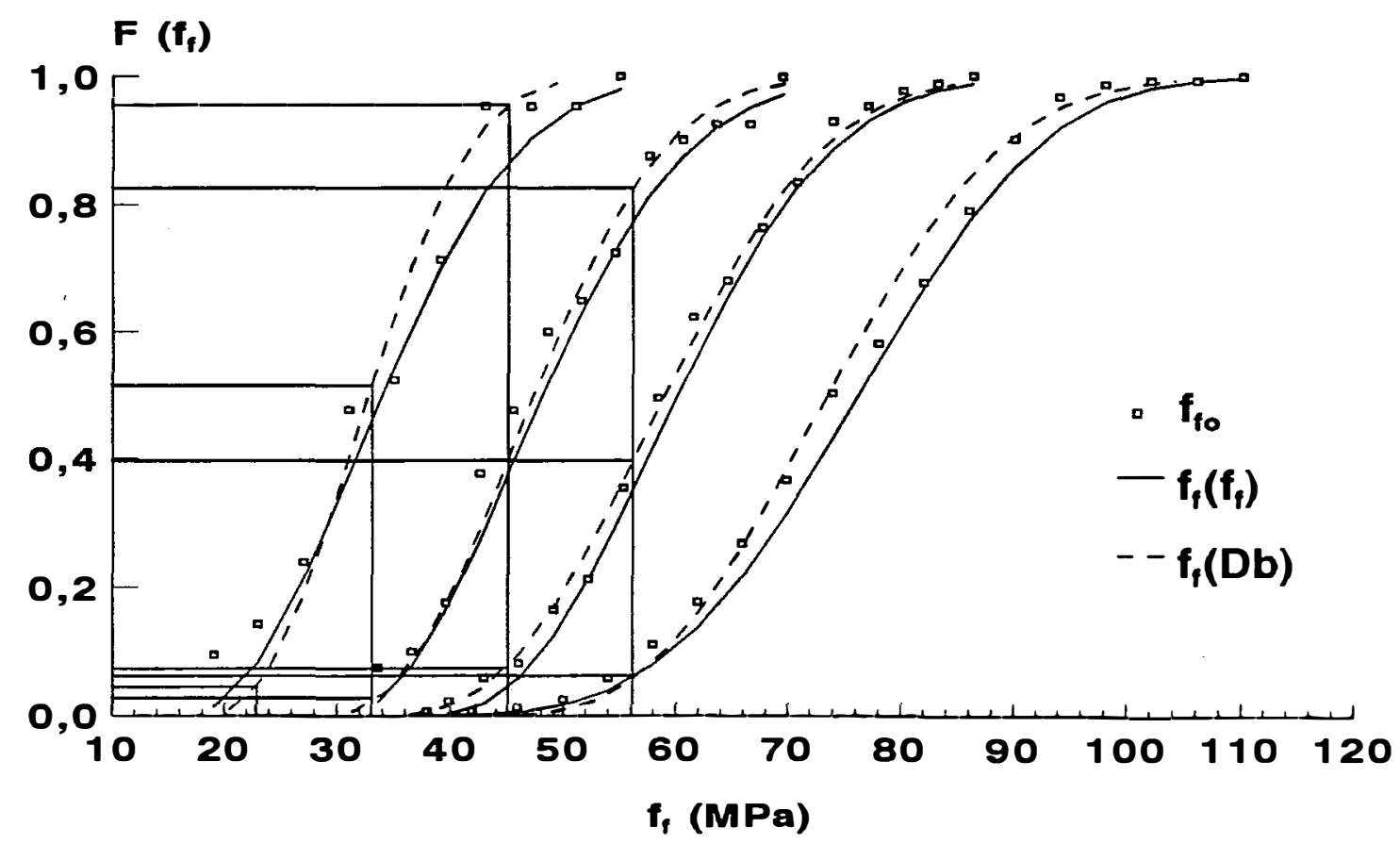

Figura 24. F.d.a. ajustada aos dados observados do $f_{f} e$ aos dados do $f_{f}$ estimados através dos valores observados da $\mathrm{Db}$ nos grupos de espécies 1 a 4 das madeiras amazônicas estudadas na condição verde 
$\left(f_{\mathbf{f}}\right)$

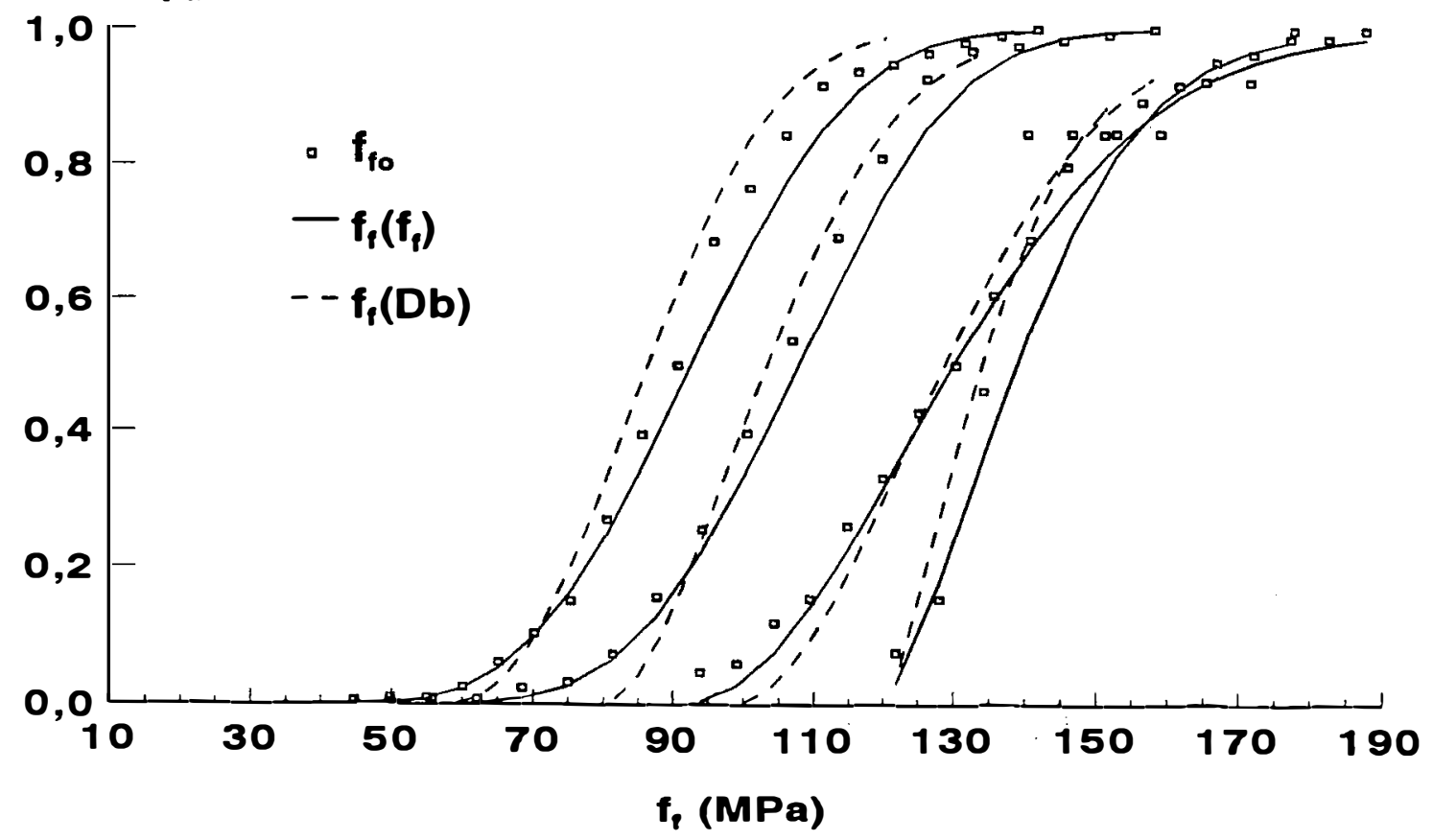

Figura 25. F.d.a. ajustada aos dados observados do $f_{f} e$ aos dados do $f_{f}$ estimados através dos valores observados da $\mathrm{Db}$ nos grupos de espécies 5 a 8 das madeiras amazônicas estudadas na condição verde

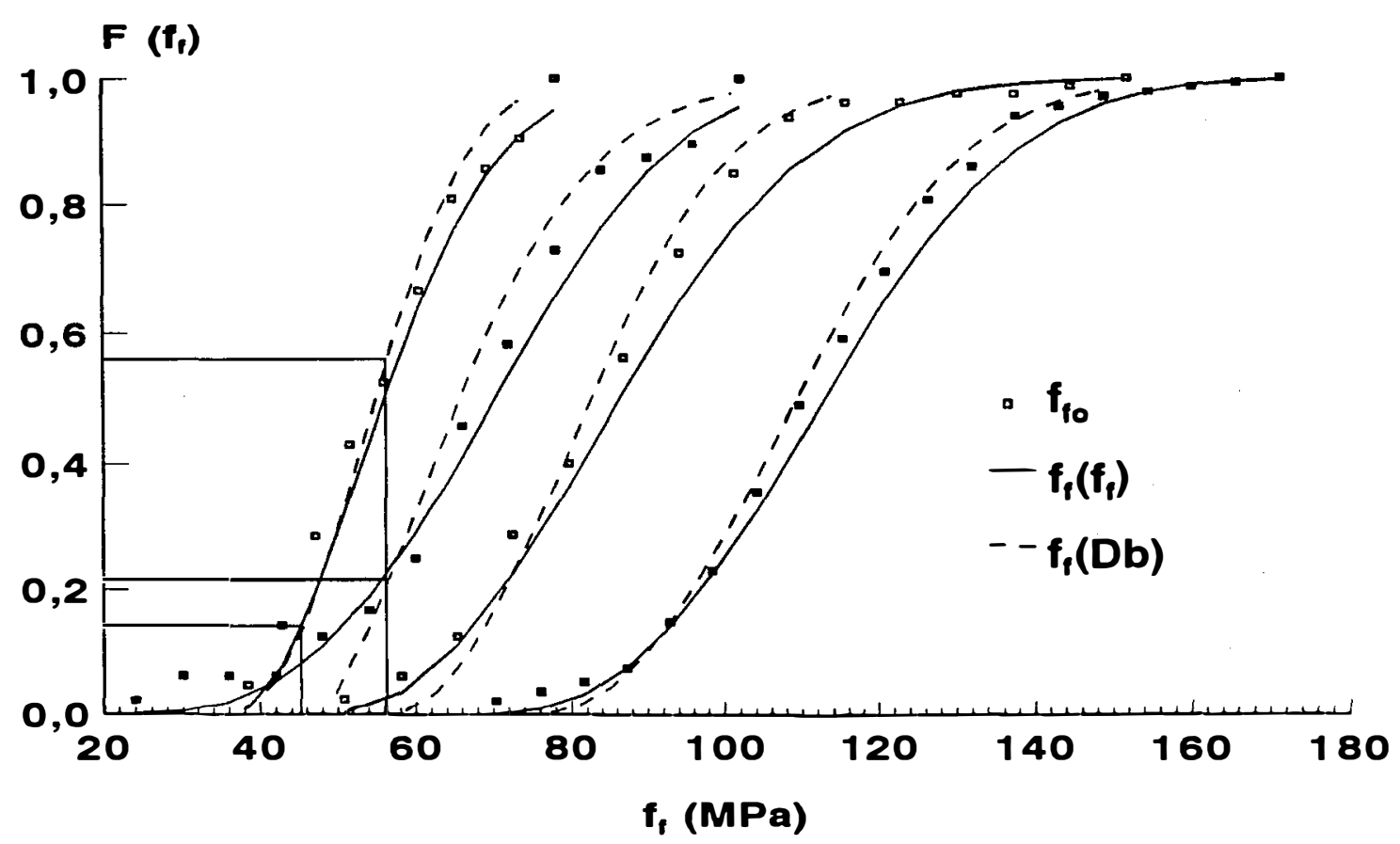

Figura 26. F.d.a. ajustada aos dados observados do $f_{f} e$ aos dados do $f_{f}$ estimados através dos valores observados da $\mathrm{Db}$ nos grupos de espécies 1 a 4 das madeiras amazônicas estudadas na condição seca 
$F\left(f_{p}\right)$

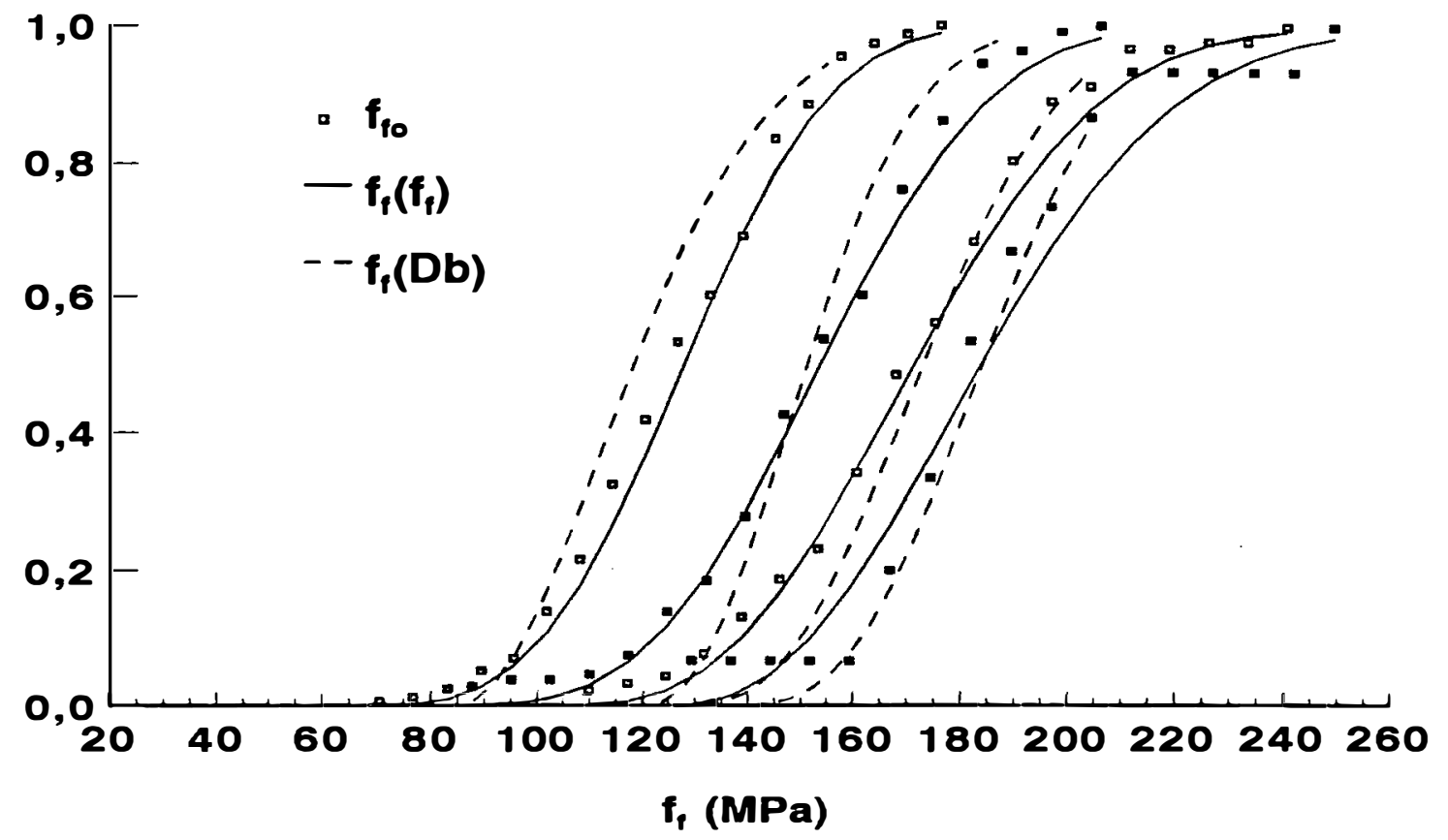

Figura 27. F.d.a. ajustada aos dados observados do $f_{f} e$ aos dados do $f_{f}$ estimados através dos valores observados da Db nos grupos de espécies 5 a 8 das madeiras amazônicas estudadas na condição seca

Para um ajuste satisfatório das curvas, foi necessário adotar um processo iterativo na estimativa dos parâmetros a, b e c, da distribuiçōes em cada grupo, pois cada um apresenta uma situação diferente.

Os ajustes foram feitos somente com o módulo de ruptura à flexão estática em função da densidade básica, correspondentes às curvas $f_{f}(D b)$ nos gráficos.

Observa-se na Figura 25, que nos grupos 5, 6 e 7 na condição verde, os ajustes não estão tão bons quanto nos demais grupos. Na condição seca, tal situação ocorre também nos grupos 5 a 8, conforme mostra a Figura 22 .

Verificou-se que é possível melhorar os 
ajustes nesses grupos, através de pequenas alterações, por tentativas, nos parâmetros $\mathbf{a}, \mathbf{b} \mathbf{e} \mathbf{c}$, mas preferiu-se dar maior importância ao objetivo principal que é o desenvolvimento da teoria que possibilita quantificar a segurança das estruturas baseando-se somente na variabilidade do módulo de ruptura à flexão estática determinado na condição verde ou seca, dentro dos grupos formados, isto é, através do $f_{f}(D b)$ e do $f_{f}\left(f_{f}\right)$, como será visto no item 4.9..

\subsection{Probabilidades de segurança das estruturas baseadas nos grupos de espécies}

o desenvolvimento desta teoria possibilita

quantificar a segurança das estruturas, baseada nas características dos grupos de espécies, tanto na condição verde como seca. Adotou-se a função Weibull, a qual foi comparada com a distribuição normal, e ainda com a determinação da norma brasileira, conforme será demonstrado a seguir.

Supondo-se que em quatro estruturas de madeira $A, B, C$ e D, em que a ordem sequencial dos esforços solicitantes $\left(\sigma_{f}\right)$, fossem respectivamente $22,90 \mathrm{MPa}, 33,00$ $\mathrm{MPa}, 45,00 \mathrm{MPa}$ e $56,20 \mathrm{MPa}$. Qual seria a segurança de cada uma dessas estruturas, se fossem usadas madeiras dos diversos grupos formados, nas condições verde e seca?

Para a execução dos cálculos tomou-se os 
valores dos parâmetros a, b e c estimados para a distribuição Weibull e os valores dos módulos de ruptura máximo ( $f_{\text {fmax }}$ ), médio $\left(f_{f m}\right)$ e mínimo $\left(f_{f m i n}\right)$ e os desvios padrão dos dados observados dos grupos de espécies 1, 2, 3 e 4, nas condições verde e seca, os quais estão contidos nos Anexos 2, 3 e 4 . Fixando $0 \sigma_{f}$ em $22,90 \mathrm{MPa}$, obtém-se através da Equação 4 da função Weibull, as probabilidades do $f_{f}(\mathrm{Db})$ e do $f_{f}\left(f_{f}\right)$, para qualquer grupo que se queira.

No caso do grupo 1, por exemplo, a distribuição $f_{f}(D b)$, para madeira verde tém-se:

$$
F(22,9)=1-e^{-\left(\frac{22,90-18,07}{17,00}\right)^{2,46}}=0,0442
$$

Este percentual obtido de $4,42 \%$, refere-se à probabilidade que tem o grupo 1 , na condição verde, de apresentar valores de resistência entre o valor mínimo estimado de $18,07 \mathrm{MPa}$ e o valor do esforço solicitante de $22,90 \mathrm{MPa}$.

Para determinar-se a segurança da estrutura $A$, utilizando aleatoriamente, espécies do grupo 1, calcula-se a probabilidade daquelas espécies apresentarem valores de resistência entre $22,90 \mathrm{MPa}$ e 56,20 MPa que é o valor máximo observado do grupo, conforme mostrado no Anexo 3. Então,

$$
F(56,20)=1-e^{-\left(\frac{56,20-18,07}{17.00} \cdot\right)^{2,46}}=0,9993
$$


Pela diferença entre $F(56,20)$ e $F(22,90)$, obtém-se a probabilidade de segurança (P) da estrutura A.

$$
P=F(56,20)-F(22,90)=0,9993-0,0442=0,9551
$$

Portanto, a segurança máxima da estrutura A, se executada utilizando-se aleatoriamente espécies do grupo 1 na condição verde, é de $95,51 \%$.

Analogamente, calcula-se a segurança através do $f_{f}\left(f_{f}\right)$ que fornece uma segurança de $90,33 \%$.

Admitindo-se distribuição normal dos valores do $f_{f}$ dentro do grupo 1 como permitem as conclusōes de Rocco LAHR (1990), a segurança da estrutura A, é obtida a partir dos valores de $u_{i}$ calculados através das Equações 17a e 17b.

$$
\begin{aligned}
& u_{1}=\frac{f_{f m i n}-f_{f m}}{s} \\
& u_{2}=\frac{\sigma_{f}-f_{f m}}{S}
\end{aligned}
$$

onde:

$$
\begin{array}{r}
u_{i}=\text { número de desvios padrão expresso pela diferença } \\
\text { entre um determinado valor de resistência e a média } \\
\text { Substituindo-se os valores nas Equações acima, }
\end{array}
$$

obtêm-se:

$$
\psi_{1}=\frac{17,80-35,17}{9,30}=-1,87
$$




$$
u_{2}-\frac{22,90-35,17}{9,30}=-1,32
$$

Pela simetria da distribuição normal, têm-se:

$$
\begin{aligned}
& \mathrm{P}\left(-1,87 \leq \mathrm{u}_{1} \leq 0\right)=\mathrm{P}\left(0 \leq \mathrm{u}_{1} \leq 1,87\right) \\
& \mathrm{P}\left(-1,32 \leq \mathrm{u}_{2} \leq 0\right)=\mathrm{P}\left(0 \leq \mathrm{u}_{2} \leq 1,32\right)
\end{aligned}
$$

Recorrendo à Tabela B1 de (SANTOS, 1977),

obtêm-se:

$$
\begin{aligned}
& P\left(-u_{1}\right)=0,9693 \\
& P\left(-u_{2}\right)=0,9066
\end{aligned}
$$

Pela diferença entre $P\left(-u_{1}\right)-P\left(-u_{2}\right)$, obtém-se a probabilidade de ruína $(\mathrm{Pr})$, onde:

$$
\operatorname{Pr}=P\left(-u_{1}\right)-P\left(-u_{2}\right)=0,9693-0,9066=0,0627
$$

Através da diferença entre a segurança máxima $(1,0)$ e a probabilidade de ruína, determina-se a segurança de estruturas com espécies do grupo 1 , para $\sigma_{f}=22,90 \mathrm{MPa} e$ para o caso de madeira verde.

Então,

$$
P_{s}=1,0-0,0627=0,9373
$$

Porém, deve ser ressaltado que este procedimento só é válido quando $\sigma_{f}<f_{f m}$. No caso inverso, a segurança é calculada simplesmente pela diferença entre P($\left.u_{1}\right)$ e $P\left(u_{2}\right)$, ou seja, $P_{s}=P\left(-u_{1}\right)-P\left(u_{2}\right)$.

Esta probabilidade de segurança de $93,73 \%$, é ligeiramente inferior àquela de $95,51 \%$ calculada através do $f_{f}(D b)$ e ligeiramente superior àquela de $90,33 \%$ obtida 
através da $f_{f}\left(f_{f}\right)$, ambas estimadas pela função Weibull.

A norma brasileira recomenda que a resistência

de cálculo $\left(\bar{f}_{f}\right)$ a ser usada nos cálculos das estruturas

deve ser 0,15 do módulo de ruptura à flexão estática, ou seja, $0,15 f_{f} \geq \sigma_{f}$

Então,

$$
f_{f}=\frac{22,90}{0,15}=152,67 \mathrm{MPa}
$$

Verifica-se que $f_{f}=152,67 \mathrm{MPa}$ é 6,67 vezes maior que o valor do $\sigma_{f}(22,90 \mathrm{MPa})$ e 4,34 vezes maior que o valor do $\mathrm{f}_{\mathrm{fm}}(35,17 \mathrm{MPa})$. Portanto, pode-se constatar no Anexo 3, que na condição verde, nenhum dos 8 grupos adotados, apresenta valores de $f_{f m} \geq 152,67 \mathrm{MPa}$. Consequentemente, não seria encontrada nenhuma espécie de madeira da Amazônia que pudesse satisfazer as exigências da norma brasileira, no que se refere a um esforço solicitante de $\sigma_{f}=22,90 \mathrm{MPa}$.

Caso houvesse um grupo ou uma espécie que apresentasse $f_{f m}=152,67 \mathrm{MPa} e$, como comprova ROCCO LAHR (1991), um CV $=20 \%$ obtido de uma distribuição normal de $f_{f}$, então a segurança desta estrutura seria.

$$
\operatorname{se} \frac{20 \times 152,67}{100}=30,53
$$


onde:

$$
u_{i}=-\frac{22,9-152,67}{30,53}=-4,25
$$

Através do programa SAS obteve-se

$$
P_{8}(-4,25)=99,9989311
$$

que é a segurança de uma estrutura de madeira construída de acordo com a NB-11.

De forma análoga poder-se-ia obter a segurança da mesma estrutura utilizando-se as mesmas madeiras do grupo 1, na condição seca.

Entretanto, verifica-se que

$$
\begin{aligned}
& F(22,90)-1-e^{-\left(\frac{22,90-35,04}{23,20}\right)^{2,40}}-0, \text { pela } f_{f}(D b) \\
& F(22,90)=1-e^{-\left(-\frac{22,90-36,10}{24,05}\right)^{1,97}}-0, \text { pela } f_{f}\left(f_{f}\right)
\end{aligned}
$$

Isto significa que na condição seca, a função Weibull apresenta $100 \%$ de segurança, porque $\sigma_{f}=22,90 \mathrm{MPa}$ é menor do que o valor mínimo do $f_{f}$ estimado para as espécies do grupo $1, a=35,04 \mathrm{MPa}$. Portanto, qualquer madeira do grupo 1, seca à $12 \%$ de umidade, oferecerá segurança máxima para a estrutura A. Porém, na condição verde, somente a partir do grupo 2 é alcançada esta segurança, tanto para $f_{f}(D b)$ quanto para $f_{f}\left(f_{f}\right)$, cujos valores mínimos estimados 
são maiores do que $\sigma_{f}$, conforme anexos 2 e 4 .

Admitindo-se também distribuição normal dos dados de $f_{f}$ obtidos da madeira seca dentro do grupo 1, a segurança calculada, como anteriormente, será de $96,59 \%$ contra $93,73 \%$ obtida para madeira verde.

Para o caso de um esforço solicitante de 33,00 MPa (estrutura B), obtem-se, através das funçōes Weibull ajustadas, e também pela distribuição normal, as seguintes probabilidades.

a) $\mathrm{Na}$ condição verde

$\left.a_{1}\right)$ Através da distribuição Weibull

\begin{tabular}{c|ccl}
\hline Função & Grupo 1 & Grupo 2 & Grupo 3 \\
\hline$f_{f}(D b)$ & $P_{s}=48,29 \%$ & $P_{s}=97,27 \%$ & $P_{s}=100 \%$ \\
$f_{f}\left(f_{f}\right)$ & $P_{s}=52,33 \%$ & $P_{s}=96,21 \%$ & $P_{s}=100 \%$ \\
\hline
\end{tabular}

$a_{2}$ ) Através da distribuição normal

\begin{tabular}{c|ccc}
\hline Função & Grupo 1 & Grupo 2 & Grupo 3 \\
\hline normal & $\mathrm{P}_{\mathrm{s}}=62,17 \%$ & $\mathrm{P}_{\mathrm{s}}=99,33 \%$ & $\mathrm{P}_{\mathrm{s}}=99,00 \%$ \\
\hline
\end{tabular}

Pela norma brasileira, a espécie a ser utilizada para suportar um $\sigma_{f}=33,00 \mathrm{MPa}$, deveria ter a seguinte média de resistência à flexão.

$$
f_{f}=\frac{33,00}{0,15}=220,00 \mathrm{MPa}
$$


Observa-se que através da função Weibull, a partir do grupo 3, têm-se $100 \%$ de segurança. Através da normal, verifica-se que a segurança oferecida pelas espécies do grupo 2 é ligeiramente superior à do grupo 3. Este fato, é explicado pelos respectivos desvios padrão.

b) Na condição seca

$b_{1}$ ) Através da função Weibull

\begin{tabular}{c|ccc}
\hline Função & Grupo 1 & Grupo 2 & Grupo 3 \\
\hline$f_{f}(D b)$ & $P_{s}=100 \%$ & $P_{s}=100 \%$ & $P_{s}=100 \%$ \\
$f_{f}\left(f_{f}\right)$ & $P_{s}=100 \%$ & $P_{s}=100 \%$ & $P_{s}=100 \%$ \\
\hline
\end{tabular}

$b_{2}$ ) Através da distribuição normal

\begin{tabular}{c|ccc}
\hline Função & Grupo 1 & Grupo 2 & Grupo 3 \\
\hline normal & $P_{\mathbf{s}}=98,33 \%$ & $P_{s}=99,39 \%$ & $P_{s}=99,25 \%$ \\
\hline
\end{tabular}

Observa-se que já a partir do grupo 1, a estrutura $B$, se construída com madeira seca, tem $100 \%$ de probabilidade de resistir ao esforço solicitante de 33,00 MPa. Pela normal, observa-se também que no grupo 1 se alcança - patamar de segurança máxima.

No caso da estrutura $C$, as probabilidades de segurança na condição verde, são: 
a) Através da função Weibull.

\begin{tabular}{l|cll}
\hline Função & Grupo 1 & Grupo 2 & Grupo 3 \\
\hline$f_{f}(\mathrm{Db})$ & $\mathrm{P}_{s}=4,43 \%$ & $\mathrm{P}_{s}=59,61 \%$ & $\mathrm{P}_{s}=91,49 \%$ \\
$f_{f}\left(f_{f}\right)$ & $\mathrm{P}_{s}=11,80 \%$ & $\mathrm{P}_{s}=60,52 \%$ & $\mathrm{P}_{\mathrm{s}}=98,95 \%$ \\
\hline
\end{tabular}

b) Através da distribuição normal

\begin{tabular}{c|ccc}
\hline Função & Grupo 1 & Grupo 2 & Grupo 3 \\
\hline normal & $\mathrm{P}_{\mathrm{s}}=1,78 \%$ & $\mathrm{P}_{\mathrm{s}}=70,82 \%$ & $\mathrm{P}_{\mathrm{s}}=99,72 \%$ \\
\hline
\end{tabular}

c) Pela norma brasileira

$$
f_{f}=\frac{45,00}{0,15}=300 \mathrm{MPa}
$$

$0 f_{f}=300,00 \mathrm{MPa}$ é 6,67 vezes maior do que $\sigma_{f}=45,00 \mathrm{MPa} e 2,24$ vezes maior do que $0 \mathrm{f}_{\mathrm{fm}}$ do melhor grupo (grupo 8).

Na condição seca, as probabilidades de segurança na estrutura $C$, são:

a) Através da função Weibull

\begin{tabular}{c|cll}
\hline Função & Grupo 1 & Grupo 2 & Grupo 3 \\
\hline $\mathrm{f}_{f}(\mathrm{Db})$ & $\mathrm{P}_{\mathrm{s}}=86,88 \%$ & $\mathrm{P}_{\mathbf{s}}=100 \%$ & $\mathrm{P}_{\mathbf{s}}=100 \%$ \\
$\mathrm{f}_{\mathrm{f}}\left(\mathrm{f}_{\mathrm{f}}\right)$ & $\mathrm{P}_{\mathbf{s}}=80,07 \%$ & $\mathrm{P}_{\mathbf{s}}=88,69 \%$ & $\mathrm{P}_{\mathrm{s}}=100 \%$ \\
\hline
\end{tabular}


b) Através da distribuição normal

\begin{tabular}{c|ccc}
\hline Função & Grupo 1 & Grupo 2 & Grupo 3 \\
\cline { 1 - 4 } normal & $\mathrm{P}_{\mathbf{s}}=82,69 \%$ & $\mathrm{P}_{\mathrm{s}}=90,77 \%$ & $\mathrm{P}_{\mathbf{s}}=99,33 \%$ \\
\hline
\end{tabular}

Observa-se que através do $f_{f}(D b)$, a partir do grupo 2 , a estrutura C apresenta $100 \%$ de segurança, enquanto, que através do $f_{f}\left(f_{f}\right)$ a segurança máxima é alcançada somente a partir do grupo 3. Pela normal os percentuais aproximam-se dos obtidos pela Weibull.

$\mathrm{Na}$ estrutura $\mathrm{D}$, cujo $\sigma_{f}=56,20 \mathrm{MPa}$, as probabilidades de segurança na condição verde são:

a) Através da função Weibull.

\begin{tabular}{c|lll}
\hline Função & Grupo 1 & Grupo 2 & Grupo 3 \\
\cline { 2 - 4 }$f_{f}(D b)$ & $P_{s}=0$ & $P_{s}=16,92 \%$ & $P_{s}=59,41 \%$ \\
$f_{f}\left(f_{f}\right)$ & $P_{s}=0$ & $P_{s}=20,01 \%$ & $P_{s}=63,74 \%$ \\
\hline
\end{tabular}

b) Através da distribuição normal

\begin{tabular}{c|ccc}
\hline Função & Grupo 1 & Grupo 2 & Grupo 3 \\
\hline normal & $\mathrm{P}_{\mathbf{s}}=1,88 \%$ & $\mathrm{P}_{\mathbf{s}}=19,70 \%$ & $\mathrm{P}_{\mathbf{s}}=69,04 \%$ \\
\hline
\end{tabular}

c) Pela norma brasileira

$$
f_{f}=\frac{56,20}{0,15}=374,67 \mathrm{MPa}
$$


O valor do $f_{f}=374,67 \mathrm{MPa}$ é 6,67 vezes maior que o esforço solicitante e 2,80 vezes superior ao $f_{f m}$ do melhor grupo.

$\mathrm{Na}$ condição seca, as probabilidades de segurança são:

a) Através da função Weibull

\begin{tabular}{c|ccc}
\hline Função & Grupo 1 & Grupo 2 & Grupo 3 \\
\hline$f_{f}(D b)$ & $P_{s}=44,04 \%$ & $P_{s}=77,98 \%$ & $P_{s}=97,59 \%$ \\
$f_{f}\left(f_{f}\right)$ & $P_{s}=45,59 \%$ & $P_{s}=74,19 \%$ & $P_{s}=88,78 \%$ \\
\hline
\end{tabular}

b) Através da distribuição normal

\begin{tabular}{c|ccc}
\hline Função & Grupo 1 & Grupo 2 & Grupo 3 \\
\hline normal & $\mathrm{P}_{\mathbf{s}}=58,37 \%$ & $\mathrm{P}_{\mathbf{s}}=77,35 \%$ & $\mathrm{P}_{\mathbf{s}}=97,51 \%$ \\
\hline
\end{tabular}

Tendo em vista que não foi conseguida a segurança máxima nem no grupo 3 para $\sigma_{f}=56,20 \mathrm{MPa}$, procurar-se-á encontrá-la no grupo 4 .

Conforme observaçōes nos anexos 2,3 e 4, verifica-se que na condição verde o $\sigma_{f}=56,20 \mathrm{MPa}$ é maior do que o valor mínimo estimado do grupo, portanto, o grupo 4 não oferece segurança máxima para a estrutura D. Buscou-se então nesse mesmo grupo, a madeira seca, e neste caso as probabilidades de segurança são: 
a) Através da Weibull

para $f_{f}(D b)$

$$
P_{s}=100 \%
$$

$\operatorname{para} f_{f}\left(f_{f}\right)$

$$
P_{s}=100 \%
$$

b) Através da distribuição normal

$$
P_{s}=99,43 \%
$$

Portanto, na condição seca obtém-se através da

Weibull, segurança máxima. Porém deve ser ressaltado que não existe segurança máxima, pois sempre existe alguma probabilidade de insucesso.

Comparando as distribuiçōes Weibull com a normal e ainda com a norma brasileira, pode-se admitir que as probabilidades de segurança obtidas pela Weibull aproximam-se dos resultados gerados pela distribuição normal. Porém, a Weibull é mais geral, facilmente ajustada aos dados observados e ainda de utilização mais prática, ou seja, dispensa o uso de tabelas para quantificar as probabilidades envolvidas.

A Norma Brasileira não quantifica a segurança, apenas especifica o valor de resistência média que a espécie deve ter em relação a um determinado esforço solicitante na estrutura. Conforme foi constatado nos resultados obtidos pela Weibull e pela normal, pode-se afirmar que a resistência exigida pela norma brasileira é exageradamente elevada, 
tornando portanto, as estruturas anti-econômicas, porém com elevadíssimo grau de segurança.

A partir dos resultados obtidos com os grupos $1,2,3$ e 4 nas condiçōes verde e seca, pode-se constatar que as formas de aumentar a segurança das estruturas de madeira, para um determinado esforço solicitante, e sem aumentar a seção transversal das peças são:

- Utilizar a madeira seca, pois as probabilidades de segurança obtidas com as espécies dos grupos nessa condição de umidade são, de uma maneira geral, aumentadas e às vezes acentuadamente.

- Retirar do grupo a(s) espécie(s) que apresenta(m) alta variabilidade, pois dessa maneira, poder-se-á diminuir o desvio padrão sem prejuízo da resistência média. Caso esta(s) espécie(s) seja(m) colocada(s) num grupo inferior ter-se-á, neste grupo, um aumento na resistência média e se o desvio padrão não aumentar, proporcionalmente, então este grupo também terá segurança majorada.

Pode-se observar nas Figuras 24 a 27 , de uma forma expedita, a frequência de valores de resistência abaixo e acima dos esforços solicitantes utilizados nos cálculos anteriores. Pode-se também determinar, de imediato a segurança da estrutura, dentro de cada grupo que se queira, a partir do esforço solicitante desejado.

No caso de um esforço solicitante de 45,00 MPa, por exemplo, traça-se na Figura 24 uma linha vertical no 
ponto 45 do eixo x. O ponto de interseção dessa vertical com a curva da distribuição Weibull do grupo, fornece a probabilidade de ocorrências de valores de resistência inferiores a 45 .

Para o grupo 2 pode-se observar, por exemplo, que esta interseção se dá no ponto 0,4.

Isto significa que existem $40 \%$ de valores de resistência inferiores a $45 \mathrm{MPa}$ e a segurança é dada, logicamente por $1-0,4$, ou seja, $60 \%$.

4.10. Cálculo da segurança desejada através da variabilidade da densidade básica

Supondo uma segurança desejada de 95,51\%, para uma estrutura cujo esforço solicitante seja $\sigma_{f}=22,90 \mathrm{MPa}$. É possível saber-se qual seria, dentro de cada grupo em uma dada condição de umidade, a densidade básica necessária para atenderem-se a estas necessidades.

Substituindo $\circ$ valor de $\sigma_{f}=22,90 \mathrm{MPa}$ na Equação 9, obtém-se a densidade básica correspondente ao referido esforço solicitante.

Então,

$22,90=-18,3766+160,21^{\prime} \mathrm{Db}_{\mathrm{s}}$ 
Donde,

$$
D b_{s}=\frac{22,90+18,3766}{160,21}=0,26 \mathrm{~g} / \mathrm{cm}^{3}
$$

Como visto anteriormente, a segurança de uma estrutura sujeita a um esforço solicitante $\sigma_{f}$, através da distribuição Weibull é calculada por

$$
P_{s}=1-e^{-\left(\frac{f_{f^{-a}}}{b}\right) c_{-}\left[1-e^{-\left(\frac{a f^{-a}}{b}\right) c}\right]}
$$

A hipótese adotada neste trabalho é a de que esta Equação (19) pode ser, sem prejuízo da segurança substituída por

$$
P_{s}=1-e^{-\left(\frac{D b-a}{b}\right)^{c}}-\left[1-e^{-\left(\frac{D b_{s}-a}{b}\right)^{c}}\right]
$$

Isolando a variável Db tém-se

$$
D b-b e^{\frac{1}{c} \ln \left\{-\ln \left[-P_{a}+e^{-\left(\frac{D b_{s}-a}{b}\right)^{c}}\right]\right\}}+a
$$

Esta Db é, portanto, aquela necessária para atender a segurança especificada.

Tomando-se por exemplo os parâmetros $a=0,24$, $\mathrm{b}=0,11$ e $\mathrm{c}=2,46$ da distribuição Weibull para o grupo 1 apresentados no Anexo 2 e $\mathrm{Db}_{\mathrm{s}}=0,26 \mathrm{~g} / \mathrm{cm}^{3} \mathrm{calculada}$ pela 
Equação (18) e substituindo-os na Equação (21), obtém-se

$$
D b=0,11 e^{\frac{1}{2.46} \ln \left(-\ln \left[-0,9551+e^{-\left(\frac{0.26-0,24,2.46}{0,21}\right)}\right]\right.}+0,24=0,42
$$

$A$ esta $\mathrm{Db}=0,42 \mathrm{~g} / \mathrm{cm}^{3}$ corresponde um $\mathrm{f}_{\mathrm{f}}=$ 48,91 MPa, o qual pode ser tomado como um valor aleatório. Portanto,

$$
F(48,91)=1-e^{-\left(\frac{48,91-18,07}{17}\right)^{2,46}}=0,9868
$$

$$
F(22,90)=1-e^{-\left(\frac{22,90-18,07}{17}\right)^{2,46}}
$$

$$
P_{s}=F(48,91)-F(22,90)=0,9868-0,0442=0,9426
$$

Observa-se que a probabilidade de segurança $\left(P_{s}\right)$ obtida, é ligeiramente inferior à segurança especificada inicialmente. Entretanto, deve ser ressaltado que essa diferença deve-se ao fato de que os ajustes de $\mathrm{Db}(\mathrm{Db})$ e do $f_{f}(D b)$, foram efetuados independentemente um do outro, isto é, sobre conjuntos de dados completamente diferentes.

Depreende-se portanto, que a Equação 9 e a distribuição Weibull para Db são suficientes para se estimar a segurança de uma estrutura construída com madeiras amazônicas.

Nas Figuras 28 e 29 , estão apresentadas as 
distribuiçōes Weibull para a densidade básica observada e para a densidade básica estimada, para os grupos de espécies 1 a 8 , na condição verde. Através destas duas figuras, podese obter de forma expedita, a probabilidade de segurança em uma estrutura, para qualquer um dos grupos de espécies, conforme foi mostrado no item 4.9., porém, deve-se ter a densidade básica calculada correspondente ao esforço solicitante na estrutura.

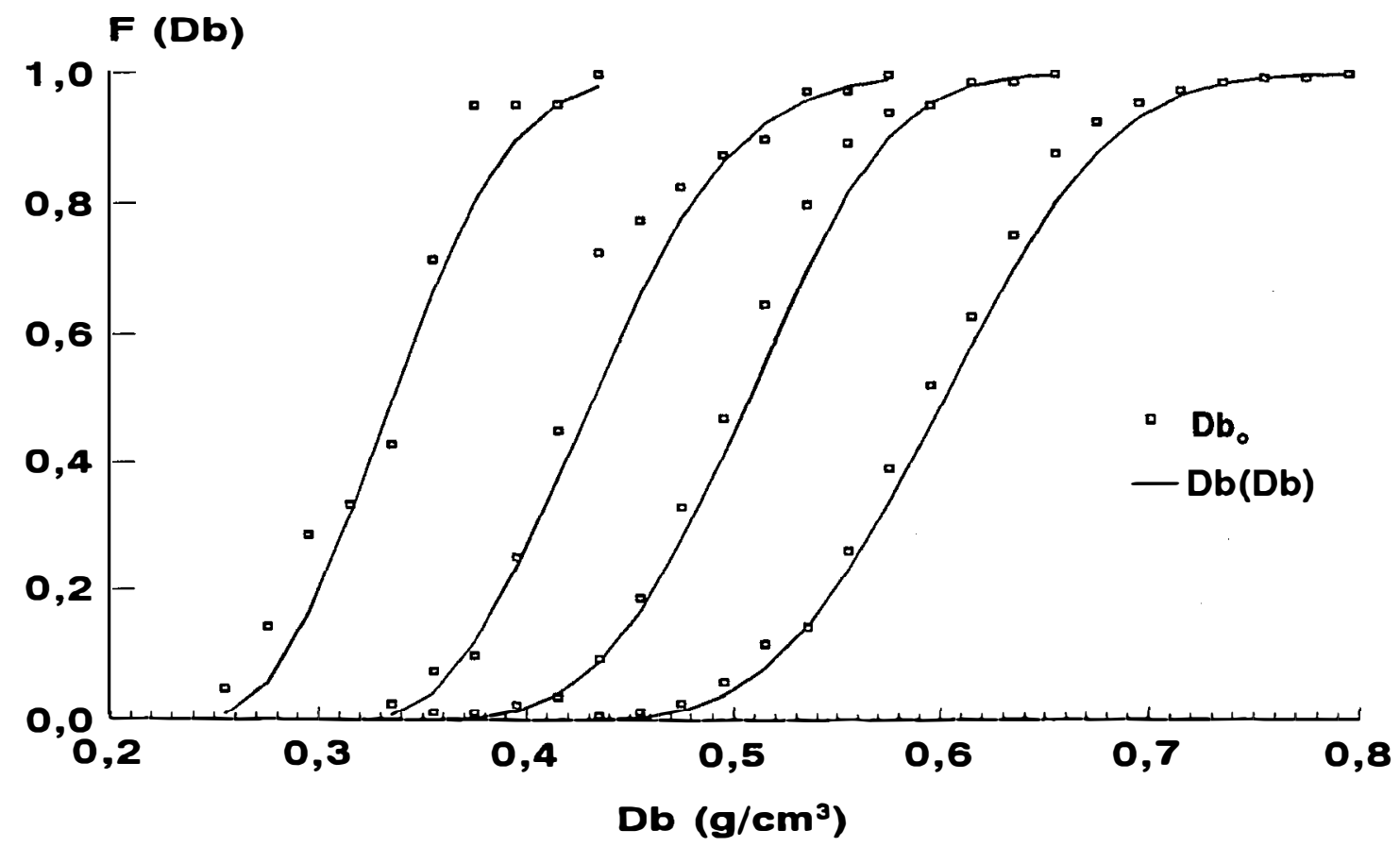

Figura 28. F.d.a. ajustada aos dados observados de Db para os grupos de espécies 1 a 4 das madeiras da floresta amazônica 


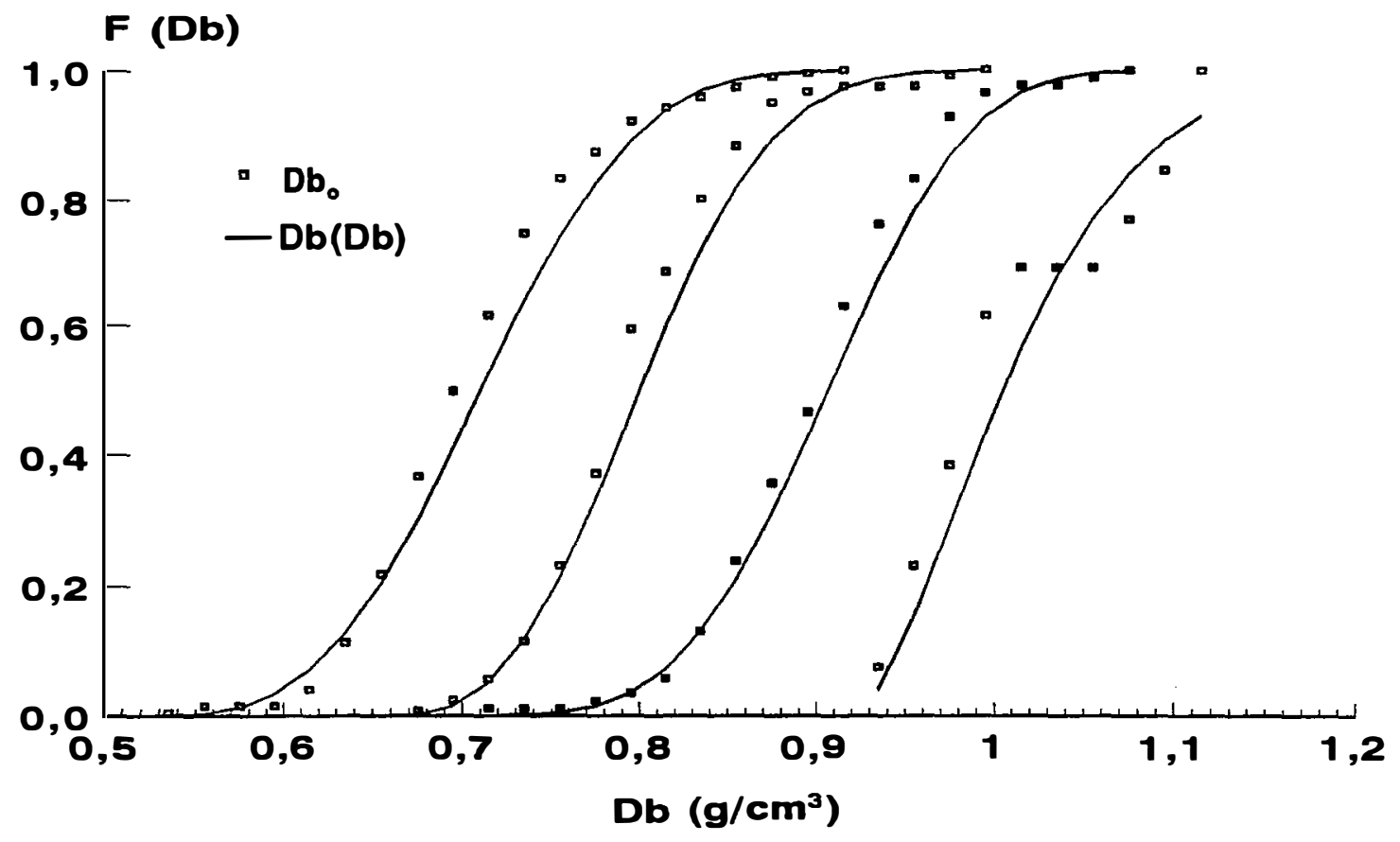

Figura 29. F.d.a. ajustada aos dados observados de Db para os grupos de espécies 5 a 8 das madeiras da floresta amazônica 


\section{COMCLUSĀo}

De acordo com os resultados obtidos neste trabalho, conclui-se que:

- Os coeficientes de variação obtidos para as diversas propriedades da madeira praticamente não variam entre regiōes e são da mesma ordem de grandeza que aqueles encontrados para a floresta amazônica como um todo. A partir desta constatação, pode-se admitir que a amostragem conseguiu captar toda a amplitude de variação das propriedades físicas e mecânicas das madeiras da região amazônica ;

- A maioria das variabilidades das propriedades mecânicas das madeiras estudadas na condição seca à $12 \%$ de umidade, são menores do que as variabilidades dessas propriedades determinadas na condição verde;

- Não se deve afirmar de imediato, que as retraçōes variam com a densidade básica da madeira. Os resultados mostram que várias espécies com densidades médias e altas, 
apresentam retração inferior ou equivalente à algumas espécies de densidades mais baixas;

- Devido aos baixos coeficientes de correlação entre as retrações e a densidade básica, admite-se que as mesmas têm maior associação com a anatomia e os extrativos da madeira do que com a densidade básica;

- As relações entre as propriedades mecânicas e densidade básica, demonstram bons níveis de correlação, podendo-se afirmar que as mesmas são diretamente relacionadas;

- As equações obtidas das relações entre propriedades mecânicas e densidade básica, permitem estimar os valores daquelas propriedades de qualquer espécie de madeira amazônica, tanto na condição verde quanto seca, através da densidade básica.

- A distribuição Weibull mostrou-se apropriada para estimar a distribuição dos valores de densidade básica e de propriedades mecânicas representadas pelo módulo de ruptura à flexão estática das madeiras amazônicas, tanto na condição verde quanto seca à $12 \%$ de umidade;

- Através da distribuição Weibull, pode-se estimar a segurança das estruturas de madeira, podendo-se até 
estabelecerem-se níveis desejáveis de segurança nas estruturas, de acordo com as exigências do proprietário ou do engenheiro responsável pela obra;

- A teoria desenvolvida neste trabalho possibilita que a estimativa da segurança desejada em uma estrutura, seja calculada sem necessitar dos valores de propriedades mecânicas, tendo em vista que, por intermédio da função Weibull, pode-se estimar qual o valor da densidade que a madeira deverá ter para satisfazer a estimativa de segurança esperada;

- o agrupamento de espécies para uso em estruturas de madeira, com base nas classes de densidade, possibilita maior aproveitamento de madeira por hectare;

- Tendo-se em vista que a frequência da maioria das espécies comercialmente desejáveis, é muito baixa por unidade de área, os grupos de espécies formados minimizam as limitações do baixo aproveitamento das madeiras da Amazônia .

- Os resultados mostram que os níveis de segurança nas estruturas de madeira, adotados pela norma brasileira são exageradamente altos. Isto, tem limitado significativamente a utilização de um grande número de espécies para 
usos estruturais;

- Além dos resultados alcançados, este trabalho poderá ainda contribuir no que concerne à redução de custos, tempo e volume de madeira para a obtenção de propriedades mecânicas com o objetivo de utilizá-las nos cálculos das estruturas de madeira, pois, através da densidade básica, pode-se estimar os valores daquelas propriedades para qualquer espécie. 


\section{RERERÊNCIAS BIBLIOGRÁFICAS}

ARGANBRIGHT, D. G. Influence of extractives on bending strength of redwood (Sequoia sempervirens). Wood and Fiber, Madison, 2(4) 367-372, 1971 .

ASSOCIAÇÃO BRASILEIRA DE NORMAS TÉCNICAS. Cálculo e execução de estruturas de madeira. ABNT / NB-11. Rio de Janeiro, 1972 .

BAtista, J. L. F. A função Weibull como modelo para a distribuição de diâmetros de espécies arbóreas tropicais. Piracicaba, 1989. 116 p. (Mestrado - Escola Superior de Agricultura "Luiz de Queiroz" / USP).

BURGER, L. M. \& RICHTER, H. G. Anatomia da madeira. São Paulo. Nobel S.A., 1991. 154 p. 
CHAFE, S. C. Collapse volumetric shrinkage, specific gravity and extractives in Eucalyptus and other species; part 2 the influence of wood extratives. Wood Science and Technology. New York, 21:27-41, 1987.

CHIMELO, J. P. Development of a probability-based computerization system for identification and for property prediction of selected tropical hardwoods. Blacksburg, 1980. 202p. (Thesis PhD - Virginia Polytechnic Institute and state University).

CHOONG, E. T. Effect of extractives on shrinkage and other hidroscopic properties of the southern pines. Wood and Fiber, Madison, 1:124-133, 1969.

\& ACHMADI, S. S. Effect of extractives on moisture sorption and shrinkage in tropical woods. Wood and Fiber Science, Madison, $23(2): 185-196$, abr. 1991.

COMISION PANAMERICANA DE NORMAS TÉCNICAS. Maderas: Selección y colección de muestras. COPANT, no 458, abr. 1972 .

Maderas :

Método de determinación del peso especifico aparente. COPANT, ne 30:1-004, jun. 1971. 
Maderas:

Método de determinación del la contracción. COPANT, ne 462 , abr. 1972 .

- Maderas:

Método de determinación de flexión estática. COPANT, ne 30:1-006, jun. 1972 .

- Maderas:

Método de determinación de la compresión paralela al grano. COPANT, ne 30:1-008, jun. 1971.

- Maderas:

Método de determinación de la compresión perpendicular al grano. COPANT, ne 466, abr. 1972 .

- Maderas :

Método de determinación del cisallamento paralelo al grano. COPANT, ne 463, 1971 .

DIAZ, M. P.; DO COUTO, H. T.; CORRENTE, J. E. Simulation of binomial data and transformation for the analysis of variance. Biometries Bulletin. 9: $\mathrm{n}$ \% 2, 19-20. Alexandria, VA, USA, 1992. 
FINDLAY, W. P. K. Timber properties and uses. Granada Publishing Limited. London, 1975, 224 p.

FOELKEL, C. E. B.; BARRICHELO, L. E. G.; MILANEZ, A. F. Estudo comparativo de madeiras de Eucalyptus saligna, Eucalyptus paniculata, Eucalyptus citriodora, Eucalyptus imaculata e Eucalyptus tereticornis para produção de celulose sulfato. Piracicaba, IPEF, (10):17-37, 1974.

GARCIA, J. N. \& QUIRINO, W. F. Influência dos extrativos solúveis em água na resistência à compressão paralela da madeira de ipê (Tabebuia sp). 19 Congresso Florestal Panamericano. 79 Congresso Florestal Brasileiro. ANAIS. Curitiba, setembro de 1993. 2 V. 647-650 p.

JANKOWSKY, I. P. Influência da densidade básica e do teor de extrativos na umidade de equilíbrio da madeira. Piracicaba, 1979. 94 p. (Mestrado - Escola Superior de Agricultura "Luiz de Queiróz" / USP) .

JOHNSON, J. W. Relations among modeli of elasticity and ruptura: seasoned and unseasoned coast-type douglas fir and seasoned western hembock. Symposium Nondestructive Testing of Wood, 2. PROCEEDINGS, apr. 1965. 
KOLlmanN, F. F. P. \& CôTÉ, W. A. Jr. Principles of wood Science and Tecnology. Solid Wood. Berlim, Heildeberg, New York. Spring-Verlag, 1968. 592 p. 1 V.

KNOWLES, O. H. Perpectiva das oportunidades de investimentos no desenvolvimento da indústria florestal da Amazônia Brasileira. Belém, SUDAM, APC, DD, 1971. 85 p.

LOUREIRO, A. A.; SILVA, M. F.; ALENCAR, J. C. Essências. madeireiras da amazônia. Manaus. INPA/CNPq, 1977. 315 p. 1 V.

Mc GULLAGH, P. \& NELDER, J. A. Generalized Linear Models. 2 ed. Londres, Chapman and Hall, 1969, 511 p.

NASCIMENTO, C. C. Variabilidade da densidade básica e de propriedades mecânicas de madeiras da Amazônia. Piracicaba, 1993. 129 p. (Mestrado - Escola Superior de Agricultura "Luiz de Queiroz" / USP).

PANDOLFO, C. A. Floresta amazônica brasileira. Enfoque econômico - ecológico. Belém, SUDAM, 1978, 118 p.

- Considerações sobre a questão ecológica da Amazônia Brasileira, Belém, SUDAM, 1990, 64 p. 
PANSHIN, A. J. \& ZEEUW, C. Textbook of technology. 3. ed. New York. Mc Graw-Hill Book Co., 1970. 705 p. 1 V.

PAULA, E. V. C. M.; CABRAL, M. T. F. D.; NASCIMENTO, C. C.; ROCHA, J. S. Propriedades mecânicas de trinta e nove espécies de madeiras do Amazonas. II Encontro Brasileiro em Madeiras e em Estruturas de Madeira. ANAIS. São Carlos, 1986. $1 \mathrm{~V}$.

PEREIRA, J. A. As relações da estrutura anatômica do lenho com as propriedades físicas e mecânicas e os usos das madeiras. 19 Conferência de Anatomistas de Madeira. Belém, $(s / d)$.

ROCCO LAHR, F. A. Considerações a respeito da variabilidade de propriedades de resistência e de elasticidade da madeira. Tese de livre docência. São Carlos, EESC/USP, 161 p, 1990.

ROCHA, J. S.; PAULA, E. V. C. M.; SIQUEIRA, M. L. Flexão estática em amostras pequenas livres de defeitos. Acta Amazonica. Manaus, 18(1/2):147-162, mar/jun. 1988.

SANTOS, L. M. Cálculo de concreto armado segundo a NB-1/76 e o CEB/72. São Paulo, Edgard Blucher, 1977. 409 p. 
SHAPIRO, S. How to teste normality and other distributional assumptions. American society for Quality control. Wisconsin, 1990. $92 \mathrm{p}$.

SLOOTEN, H. J. VAN DER; LISBOA, C. D. J.; SOBRAL FILHO, M. ; PASTORE JUNIOR, F. Espéies florestais da Amazônia Características, propriedades e dados de engenharia da madeira. PRODEPEF. Série Técnica ne 6, Brasília, 1976, $90 \mathrm{p}$.

STAAM, A. J. Wood and cellulose science. New York. Ronald Press, 1964. 549 p.

STEPHENS, M. A. EDF statistics for goodness of fit and some comparasions. Am. Stat. As. Jour. 69:(347) 730-737. 1974.

TARKOW, H. \& KRUEGER, J. Distribution of hot-water soluble material in cell walls and cavities of redwood. Forest Products Journal, Madison, 1961, 11(5):228-229.

U. S. FOREST PRODUCTS LABORATORY. Wood handbook: Wood as un engeneering material. Madison, 1974. $1 \mathrm{~V}$.

WILSON, T. R. C. ; CARLSON, T. A.; LUXFORD, R. F. The effect of partial seasoning on the strength of wood. Madison, USDA, (1024), 1960 . 
A N E X O 1

valores médios, coeficientes de variação, desvios padrão e número de amostras da densidade básica, retraçōes tangencial, radial e volumétrica e propriedades de resistência (nas condiçōes verde e seca à $12 \%$ de umidade) das espécies do Amapá, Balbina, Curuá-Una e Tapajós. 
Espécies originárias da região do Amapá

\begin{tabular}{|c|c|c|c|c|c|c|c|c|c|c|}
\hline $\begin{array}{c}\text { Nome } \\
\text { Cientifico }\end{array}$ & & $\mathrm{Db}$ & Rt & $\mathrm{Rr}$ & Rv & $E_{f}$ & $f_{f}$ & $f_{c}$ & $f_{c n}$ & $f_{s}$ \\
\hline $\begin{array}{l}\text { Alexa } \\
\text { imperatricis }\end{array}$ & $\begin{array}{l}\mu(v) \\
\mu(12 \%) \\
\text { CV (V) } \\
\text { CV }(12 \%) \\
\text { s (V) } \\
\text { S (12\%) } \\
N(v) \\
N(12 \%)\end{array}$ & $\begin{array}{r}0,56 \\
0,57 \\
8,660 \\
4,691 \\
0,048 \\
0,027 \\
6 \\
5\end{array}$ & $\begin{array}{r}9,40 \\
9,68 \\
17,403 \\
17,262 \\
1,636 \\
1,670 \\
6 \\
5\end{array}$ & $\begin{array}{r}4,39 \\
4,38 \\
24,996 \\
28,000 \\
1,098 \\
1,228 \\
6 \\
5\end{array}$ & $\begin{array}{r}15,25 \\
15,67 \\
17,450 \\
17,465 \\
2,661 \\
2,737 \\
6 \\
5\end{array}$ & $\begin{array}{r}8433 \\
10340 \\
17,211 \\
9,266 \\
1451,4 \\
958,12 \\
6 \\
5\end{array}$ & $\begin{array}{r}60,57 \\
85,98 \\
25,820 \\
9,729 \\
15,638 \\
8,365 \\
6 \\
5\end{array}$ & $\begin{array}{r}33.65 \\
48,04 \\
7,325 \\
5,021 \\
2,465 \\
2,412 \\
6 \\
5\end{array}$ & $\begin{array}{r}7.03 \\
8,74 \\
25,524 \\
8,470 \\
1,795 \\
0,740 \\
6 \\
5\end{array}$ & $\begin{array}{r}8.92 \\
11,92 \\
21,413 \\
19,344 \\
1,909 \\
2,306 \\
6 \\
5\end{array}$ \\
\hline$\frac{\text { Couratari }}{\text { guianensis }}$ & $\begin{array}{l}\mu(v) \\
\mu(12 \%) \\
\text { CV }(v) \\
\text { CV }(12 \%) \\
s(v) \\
S(12 \%) \\
N(v) \\
N(12 \%)\end{array}$ & $\begin{array}{r}0,50 \\
0,50 \\
4,809 \\
4,809 \\
0,024 \\
0,024 \\
4 \\
4\end{array}$ & $\begin{array}{r}8,63 \\
8,63 \\
8,194 \\
8,194 \\
0,707 \\
0,707 \\
4 \\
4\end{array}$ & $\begin{array}{r}6,39 \\
6,39 \\
10,767 \\
10,767 \\
0,688 \\
0,688 \\
4 \\
4\end{array}$ & $\begin{array}{r}16,12 \\
16,12 \\
6,061 \\
6,061 \\
0,977 \\
0,977 \\
4 \\
4\end{array}$ & $\begin{array}{r}6600 \\
9850 \\
8,481 \\
11,561 \\
559,76 \\
1138,7 \\
4 \\
4\end{array}$ & $\begin{array}{r}45,05 \\
85,83 \\
12,392 \\
10,053 \\
5,582 \\
8,628 \\
4 \\
4\end{array}$ & $\begin{array}{r}27,43 \\
47,95 \\
13,876 \\
9,346 \\
3,806 \\
4,481 \\
4 \\
4\end{array}$ & $\begin{array}{r}4,95 \\
8,20 \\
19,897 \\
29,336 \\
0,985 \\
2,406 \\
4 \\
4\end{array}$ & $\begin{array}{r}9,28 \\
12,15 \\
14,178 \\
17,530 \\
1,315 \\
2,130 \\
4 \\
4\end{array}$ \\
\hline Eperua sp & $\begin{array}{l}\mu(V) \\
\mu(12 \%) \\
\text { CV }(v) \\
\text { CV }(12 \%) \\
\text { S (V) } \\
\text { S }(12 \%) \\
N(v) \\
N(12 \%)\end{array}$ & $\begin{array}{r}0,78 \\
0,78 \\
4,931 \\
6,784 \\
0,038 \\
0,053 \\
6 \\
3\end{array}$ & $\begin{array}{r}10,08 \\
9,50 \\
9,302 \\
10,112 \\
0,937 \\
0,960 \\
6 \\
3\end{array}$ & $\begin{array}{r}4,06 \\
3,53 \\
22,532 \\
19,279 \\
0,915 \\
0,681 \\
6 \\
3\end{array}$ & $\begin{array}{r}14,88 \\
13,56 \\
12,004 \\
9,565 \\
1,787 \\
1,297 \\
6 \\
3\end{array}$ & $\begin{array}{r}12817 \\
14167 \\
11,440 \\
6,559 \\
1466,2 \\
929,16 \\
6 \\
3\end{array}$ & $\begin{array}{r}88,53 \\
149,97 \\
22,589 \\
13,936 \\
19,999 \\
20,899 \\
6 \\
3\end{array}$ & $\begin{array}{r}55,32 \\
72,43 \\
13,044 \\
12,375 \\
7,216 \\
8,963 \\
6 \\
3\end{array}$ & $\begin{array}{r}14,72 \\
15,20 \\
6,746 \\
21,176 \\
0,993 \\
3,219 \\
6 \\
3\end{array}$ & $\begin{array}{r}11,32 \\
14,93 \\
5,819 \\
5,1114 \\
0,659 \\
0,764 \\
6 \\
3\end{array}$ \\
\hline$\frac{\text { Lecythis }}{\text { poi teaui }}$ & $\begin{array}{l}\mu(v) \\
\mu(12 \%) \\
\text { CV }(v) \\
\text { CV }(12 \%) \\
\text { s }(v) \\
\text { S }(12 \%) \\
N(v) \\
N(12 \%)\end{array}$ & $\begin{array}{r}0,81 \\
0,81 \\
4,701 \\
4,701 \\
0,038 \\
0,038 \\
5 \\
5\end{array}$ & $\begin{array}{r}13,48 \\
13,48 \\
9,669 \\
9,669 \\
1,304 \\
1,304 \\
5 \\
5\end{array}$ & $\begin{array}{r}8,27 \\
8,27 \\
13,894 \\
13,894 \\
1,149 \\
1,149 \\
5 \\
5\end{array}$ & $\begin{array}{r}23,00 \\
23,00 \\
11,105 \\
11,105 \\
2,554 \\
2,554 \\
5 \\
5\end{array}$ & $\begin{array}{r}13520 \\
14680 \\
4,719 \\
4,992 \\
637,97 \\
732,80 \\
5 \\
5\end{array}$ & $\begin{array}{r}116,14 \\
168,20 \\
7,810 \\
10,962 \\
9,071 \\
18,438 \\
5 \\
5\end{array}$ & $\begin{array}{r}50,18 \\
79,18 \\
16,196 \\
12,279 \\
8,127 \\
9,722 \\
5 \\
5\end{array}$ & $\begin{array}{r}17,16 \\
15,30 \\
24,860 \\
12,783 \\
4,266 \\
1,956 \\
5 \\
5\end{array}$ & $\begin{array}{r}16,08 \\
16,60 \\
10,080 \\
16,170 \\
1,621 \\
2,684 \\
5 \\
5\end{array}$ \\
\hline $\begin{array}{l}\text { Mani lkara } \\
\text { amazonica }\end{array}$ & $\begin{array}{l}\mu(v) \\
\mu(12 \%) \\
C V(V) \\
C V(12 \%) \\
s(V) \\
S(12 \%) \\
N(v) \\
N(12 \%)\end{array}$ & $\begin{array}{r}0,84 \\
0,84 \\
1,380 \\
1,380 \\
0,012 \\
0,012 \\
3 \\
3\end{array}$ & $\begin{array}{r}11,01 \\
11,01 \\
14,316 \\
14,316 \\
1,577 \\
1,577 \\
3 \\
3\end{array}$ & $\begin{array}{r}7,42 \\
7,42 \\
4,839 \\
4,839 \\
0,359 \\
0,359 \\
3 \\
3\end{array}$ & $\begin{array}{r}19,50 \\
19,50 \\
10,997 \\
10,997 \\
2,144 \\
2,144 \\
3 \\
3\end{array}$ & $\begin{array}{r}12267 \\
12500 \\
6,640 \\
4,996 \\
814,45 \\
624,50 \\
3 \\
3\end{array}$ & $\begin{array}{r}108,43 \\
130,10 \\
31,178 \\
8,435 \\
33,807 \\
10,974 \\
3 \\
3\end{array}$ & $\begin{array}{r}55,90 \\
79,57 \\
3,180 \\
19,729 \\
1,778 \\
15,698 \\
3 \\
3\end{array}$ & $\begin{array}{r}16,03 \\
16,20 \\
18,880 \\
4,048 \\
3,027 \\
0,656 \\
3 \\
3\end{array}$ & $\begin{array}{r}12,30 \\
14,80 \\
7,756 \\
6,446 \\
0,954 \\
0,954 \\
3 \\
3\end{array}$ \\
\hline$\frac{\text { Parinari }}{\text { montana }}$ & $\begin{array}{l}\mu(v) \\
\mu(12 \%) \\
C V(v) \\
C V(12 \%) \\
s(v) \\
\text { S }(12 \%) \\
N(v) \\
N(12 \%)\end{array}$ & $\begin{array}{r}0,70 \\
0,69 \\
3,689 \\
2,899 \\
0,026 \\
0,020 \\
4 \\
3\end{array}$ & $\begin{array}{r}11,31 \\
11,06 \\
5,500 \\
4,024 \\
0,622 \\
0,445 \\
4 \\
3\end{array}$ & $\begin{array}{r}7,49 \\
7,76 \\
11,774 \\
10,937 \\
0,882 \\
0,849 \\
4 \\
3\end{array}$ & $\begin{array}{r}19,97 \\
20,01 \\
4,658 \\
5,660 \\
0,930 \\
1,133 \\
4 \\
3\end{array}$ & $\begin{array}{r}11600 \\
13767 \\
7,806 \\
4,837 \\
905,54 \\
665,83 \\
4 \\
3\end{array}$ & $\begin{array}{r}85,63 \\
134,07 \\
19,436 \\
12,386 \\
16,642 \\
16,606 \\
4 \\
3\end{array}$ & $\begin{array}{r}43,85 \\
81,67 \\
10,688 \\
14,249 \\
4,687 \\
11,636 \\
4 \\
3\end{array}$ & $\begin{array}{r}7,45 \\
11,23 \\
21,067 \\
4,207 \\
1,570 \\
0,473 \\
4 \\
3\end{array}$ & $\begin{array}{r}11,45 \\
15,17 \\
3,229 \\
8,297 \\
0,370 \\
1,258 \\
4 \\
3\end{array}$ \\
\hline $\begin{array}{l}\mu \\
C V \\
S \\
N \\
v \\
(12 \%)\end{array}$ & $\begin{array}{l}\text { - média da den } \\
\text { - coeficiente } \\
\text { - desvio padrãa } \\
\text { - tamanho da a } \\
\text { - madeiras est } \\
\text { - madeiras à }\end{array}$ & idade & $\begin{array}{l}\text { Jásica, } \\
\text { ção }\end{array}$ & -atrac̃̃a & Drome & dados & & mecâni & & \\
\hline
\end{tabular}


continuação

\begin{tabular}{|c|c|c|c|c|c|c|c|c|c|c|}
\hline$\frac{\text { Parkia }}{\text { nitida }}$ & $\begin{array}{l}\mu(v) \\
\mu(12 \%) \\
\text { CV }(v) \\
\text { CV }(12 \%) \\
s(v) \\
S(12 \%) \\
N(v) \\
N(12 \%)\end{array}$ & $\begin{array}{r}0,41 \\
0,41 \\
4,453 \\
4,453 \\
0,018 \\
0,018 \\
4 \\
4\end{array}$ & $\begin{array}{r}7,14 \\
7,14 \\
12,529 \\
12,529 \\
0,894 \\
0,894 \\
4 \\
4\end{array}$ & $\begin{array}{r}3,03 \\
3,03 \\
5,978 \\
5,978 \\
0,181 \\
0,181 \\
4 \\
4\end{array}$ & $\begin{array}{r}10,96 \\
10,96 \\
8,990 \\
8,990 \\
0,985 \\
0,985 \\
4 \\
4\end{array}$ & $\begin{array}{r}7125 \\
5850 \\
13,817 \\
11,034 \\
984,46 \\
645,50 \\
4 \\
4\end{array}$ & $\begin{array}{r}50,20 \\
40,00 \\
13,633 \\
44,289 \\
6,844 \\
17,716 \\
4 \\
4\end{array}$ & $\begin{array}{r}24,33 \\
28,23 \\
5,161 \\
11,925 \\
1,255 \\
3,366 \\
4 \\
4\end{array}$ & $\begin{array}{r}4,43 \\
5,18 \\
11,129 \\
23,581 \\
0,492 \\
1,220 \\
4 \\
4\end{array}$ & $\begin{array}{r}6,85 \\
6,90 \\
16,191 \\
17,907 \\
1,109 \\
1,236 \\
4 \\
4\end{array}$ \\
\hline $\begin{array}{l}\text { Pel togyne } \\
\text { paradoxo }\end{array}$ & $\begin{array}{l}\mu(v) \\
\mu(12 \%) \\
\text { CV }(v) \\
\text { CV }(12 \%) \\
s(v) \\
\text { s }(12 \%) \\
N(v) \\
N(12 \%)\end{array}$ & $\begin{array}{r}0,89 \\
0,89 \\
4,051 \\
4,051 \\
0,036 \\
0,036 \\
3 \\
3\end{array}$ & $\begin{array}{r}8,39 \\
8,39 \\
11,272 \\
11,272 \\
0,946 \\
0,946 \\
3 \\
3\end{array}$ & $\begin{array}{r}6,70 \\
6,70 \\
5,757 \\
5,757 \\
0,386 \\
0,386 \\
3 \\
3\end{array}$ & $\begin{array}{r}15,87 \\
15,87 \\
6,948 \\
6,948 \\
1,103 \\
1,103 \\
3 \\
3\end{array}$ & $\begin{array}{r}15100 \\
17000 \\
1,147 \\
2,564 \\
173,21 \\
435,89 \\
3 \\
3\end{array}$ & $\begin{array}{r}164,73 \\
184,80 \\
12,925 \\
9,316 \\
21,292 \\
17,217 \\
3 \\
3\end{array}$ & $\begin{array}{r}85,07 \\
106,50 \\
3,755 \\
3,209 \\
3,194 \\
3,418 \\
3 \\
3\end{array}$ & $\begin{array}{r}26,17 \\
26,83 \\
15,911 \\
3,879 \\
4,163 \\
1,041 \\
3 \\
3\end{array}$ & $\begin{array}{r}15,73 \\
15,97 \\
7,767 \\
13,496 \\
1,222 \\
2,155 \\
3 \\
3\end{array}$ \\
\hline$\frac{\text { Protium }}{\text { tenuifolium }}$ & $\begin{array}{l}\mu(v) \\
\mu(12 \%) \\
\text { CV }(v) \\
\text { CV }(12 \%) \\
s(v) \\
\text { s }(12 \%) \\
N(v) \\
N(12 \%)\end{array}$ & $\begin{array}{r}0,68 \\
0,67 \\
7,115 \\
6,764 \\
0,049 \\
0,045 \\
4 \\
3\end{array}$ & $\begin{array}{r}9,12 \\
9,30 \\
7,642 \\
7,714 \\
0,697 \\
0,718 \\
4 \\
3\end{array}$ & $\begin{array}{r}5,55 \\
5,93 \\
19,805 \\
16,316 \\
1,098 \\
0,967 \\
4 \\
3\end{array}$ & $\begin{array}{r}15,73 \\
16,38 \\
13,858 \\
13,114 \\
2,180 \\
2,148 \\
4 \\
3\end{array}$ & $\begin{array}{r}10700 \\
12267 \\
16,701 \\
7,029 \\
1787,0 \\
862,17 \\
4 \\
3\end{array}$ & $\begin{array}{r}80,53 \\
113,07 \\
11,155 \\
4,979 \\
8,982 \\
5,630 \\
4 \\
3\end{array}$ & $\begin{array}{r}38,53 \\
62,57 \\
5,692 \\
16,199 \\
2,193 \\
10,135 \\
4 \\
3\end{array}$ & $\begin{array}{r}8,58 \\
12,00 \\
27,239 \\
17,638 \\
2,336 \\
2,117 \\
4 \\
3\end{array}$ & $\begin{array}{r}11,45 \\
13,83 \\
5,815 \\
35,106 \\
0,666 \\
4,856 \\
4 \\
3\end{array}$ \\
\hline$\frac{\text { Parkia }}{\text { ulei. }}$ & $\begin{array}{l}\mu(v) \\
\mu(12 \%) \\
C V(V) \\
\text { CV }(12 \%) \\
s(v) \\
S(12 \%) \\
N(v) \\
N(12 \%)\end{array}$ & $\begin{array}{r}0,44 \\
0,44 \\
8,042 \\
8,042 \\
0,035 \\
0,035 \\
3 \\
3\end{array}$ & $\begin{array}{r}7,34 \\
7,34 \\
15,268 \\
15,268 \\
1,121 \\
1,121 \\
3 \\
3\end{array}$ & $\begin{array}{r}2,87 \\
2,87 \\
20,909 \\
20,909 \\
0,600 \\
0,600 \\
3 \\
3\end{array}$ & $\begin{array}{r}11,18 \\
11,18 \\
14,180 \\
14,180 \\
1,585 \\
1,585 \\
3 \\
3\end{array}$ & $\begin{array}{r}7367 \\
7867 \\
18,530 \\
1,942 \\
1365,0 \\
152,75 \\
3 \\
3\end{array}$ & $\begin{array}{r}56,23 \\
60,10 \\
23,708 \\
24,946 \\
13,332 \\
14,992 \\
3 \\
3\end{array}$ & $\begin{array}{r}22,77 \\
33,73 \\
6,232 \\
14,063 \\
1,419 \\
4,744 \\
3 \\
3\end{array}$ & $\begin{array}{r}4,53 \\
4,80 \\
13,478 \\
4,167 \\
0,611 \\
0,200 \\
3 \\
3\end{array}$ & $\begin{array}{r}9,27 \\
9,43 \\
3,469 \\
21,342 \\
0,321 \\
2,013 \\
3 \\
3\end{array}$ \\
\hline$\frac{\text { Sacoglottis }}{\text { guianensis }}$ & $\begin{array}{l}\mu(v) \\
\mu(12 \%) \\
C V(v) \\
C V(12 \%) \\
s(v) \\
S(12 \%) \\
N(v) \\
N(12 \%)\end{array}$ & $\begin{array}{r}0,76 \\
0,78 \\
9,201 \\
8,504 \\
0,070 \\
0,066 \\
3 \\
4\end{array}$ & $\begin{array}{r}11,43 \\
11,29 \\
20,442 \\
17,055 \\
2,336 \\
1,926 \\
3 \\
4\end{array}$ & $\begin{array}{r}8,10 \\
8,20 \\
15,050 \\
12,376 \\
1,219 \\
1,014 \\
3 \\
4\end{array}$ & $\begin{array}{r}20,79 \\
20,78 \\
16,043 \\
13,108 \\
3,336 \\
2,724 \\
3 \\
4\end{array}$ & $\begin{array}{r}12567 \\
12975 \\
4,383 \\
7,768 \\
550,76 \\
1007,9 \\
3 \\
4\end{array}$ & $\begin{array}{r}109,60 \\
134,00 \\
5,379 \\
8,217 \\
5,895 \\
11,011 \\
3 \\
4\end{array}$ & $\begin{array}{r}50,60 \\
66,00 \\
6,030 \\
9,519 \\
3,051 \\
6,283 \\
3 \\
4\end{array}$ & $\begin{array}{r}8,33 \\
11,13 \\
3,464 \\
5,655 \\
0,289 \\
0,629 \\
3 \\
4\end{array}$ & $\begin{array}{r}13,43 \\
16,43 \\
3,009 \\
5,363 \\
0,404 \\
0,881 \\
3 \\
4\end{array}$ \\
\hline $\begin{array}{l}\text { Eschwei lera } \\
\text { sagotiana }\end{array}$ & $\begin{array}{l}\mu(v) \\
\mu(12 \%) \\
C V(V) \\
C V(12 \%) \\
s(v) \\
\text { S }(12 \%) \\
N(v) \\
N(12 \%)\end{array}$ & $\begin{array}{r}0,79 \\
0,79 \\
5,518 \\
5,518 \\
0,044 \\
0,044 \\
3 \\
3\end{array}$ & $\begin{array}{r}11,07 \\
11,07 \\
18,802 \\
18,802 \\
2,082 \\
2,082 \\
3 \\
3\end{array}$ & $\begin{array}{r}6,29 \\
6,29 \\
17,382 \\
17,382 \\
1,094 \\
1,094 \\
3 \\
3\end{array}$ & $\begin{array}{r}18,14 \\
18,14 \\
12,774 \\
12,774 \\
2,317 \\
2,317 \\
3 \\
3\end{array}$ & $\begin{array}{r}11833 \\
14133 \\
8,796 \\
5,719 \\
1040,8 \\
808,29 \\
3 \\
3\end{array}$ & $\begin{array}{r}101,57 \\
144,50 \\
19,122 \\
2,161 \\
19,422 \\
3,122 \\
3 \\
3\end{array}$ & $\begin{array}{r}59,83 \\
78,27 \\
8,790 \\
2,684 \\
5,260 \\
2,101 \\
3 \\
3\end{array}$ & $\begin{array}{r}17,33 \\
19,00 \\
7,259 \\
16,007 \\
1,258 \\
3,041 \\
3 \\
3\end{array}$ & $\begin{array}{r}11,17 \\
20,07 \\
6,721 \\
4,789 \\
0,751 \\
0,961 \\
3 \\
3\end{array}$ \\
\hline$\frac{\text { Sclerolobium }}{\text { sp. }}$ & $\begin{array}{l}\mu(v) \\
\mu(12 \%) \\
C V(V) \\
\text { CV }(12 \%) \\
S(V) \\
S(12 \%) \\
N(v) \\
N(12 \%)\end{array}$ & $\begin{array}{r}0,42 \\
0,42 \\
2,381 \\
2,381 \\
0,010 \\
0,010 \\
3 \\
3\end{array}$ & $\begin{array}{r}6,97 \\
6,97 \\
16,959 \\
16,959 \\
1,182 \\
1,182 \\
3 \\
3\end{array}$ & $\begin{array}{r}3,72 \\
3,72 \\
15,536 \\
15,536 \\
0,577 \\
0,577 \\
3 \\
3\end{array}$ & $\begin{array}{r}11,52 \\
11,52 \\
14,501 \\
14,501 \\
1,670 \\
1,670 \\
3 \\
3\end{array}$ & $\begin{array}{r}6700 \\
8166 \\
14,394 \\
11,766 \\
964,37 \\
960,90 \\
3 \\
3\end{array}$ & $\begin{array}{r}45,10 \\
69,47 \\
2,983 \\
10,719 \\
1,345 \\
7,446 \\
3 \\
3\end{array}$ & $\begin{array}{r}21,63 \\
41,50 \\
7,166 \\
17,142 \\
1,550 \\
7,114 \\
3 \\
3\end{array}$ & $\begin{array}{r}3,90 \\
6,87 \\
9,245 \\
9,363 \\
0,361 \\
0,643 \\
3 \\
3\end{array}$ & $\begin{array}{r}8,10 \\
9,60 \\
6,874 \\
17,053 \\
0,557 \\
1,637 \\
3 \\
3\end{array}$ \\
\hline
\end{tabular}


continuação

\begin{tabular}{|c|c|c|c|c|c|c|c|c|c|c|}
\hline $\begin{array}{l}\text { Thyrsodium } \\
\text { guianensis }\end{array}$ & $\begin{array}{l}\mu(v) \\
\mu(12 \%) \\
\text { CV }(v) \\
\text { CV }(12 \%) \\
s(v) \\
\text { s }(12 \%) \\
N(v) \\
N(12 \%)\end{array}$ & $\begin{array}{r}0,65 \\
0,65 \\
4,676 \\
4,676 \\
0,031 \\
0,031 \\
3 \\
3\end{array}$ & $\begin{array}{r}11,49 \\
11,49 \\
7,926 \\
7,926 \\
0,910 \\
0,910 \\
3 \\
3\end{array}$ & $\begin{array}{r}6,08 \\
6,08 \\
23,090 \\
23,090 \\
1,404 \\
1,404 \\
3 \\
3\end{array}$ & $\begin{array}{r}18,66 \\
18,66 \\
10,436 \\
10,436 \\
1,947 \\
1,947 \\
3 \\
3\end{array}$ & $\begin{array}{r}10033 \\
11833 \\
18,115 \\
7,187 \\
1817,5 \\
850,49 \\
3 \\
3\end{array}$ & $\begin{array}{r}64,73 \\
96,23 \\
0,089 \\
9,041 \\
0,058 \\
8,700 \\
3 \\
3\end{array}$ & $\begin{array}{r}32,77 \\
55,77 \\
9,127 \\
6,580 \\
2,991 \\
3,669 \\
3 \\
3\end{array}$ & $\begin{array}{r}5,60 \\
7,73 \\
12,877 \\
5,226 \\
0,721 \\
0,404 \\
3 \\
3\end{array}$ & $\begin{array}{r}11,83 \\
18,03 \\
17,097 \\
9,800 \\
2,023 \\
1,767 \\
3 \\
3\end{array}$ \\
\hline$\frac{\text { Tetragastris }}{\text { panamens is }}$ & $\begin{array}{l}\mu(v) \\
\mu(12 \%) \\
\text { CV }(v) \\
\text { CV }(12 \%) \\
S(v) \\
\text { S }(12 \%) \\
N(v) \\
N(12 \%)\end{array}$ & $\begin{array}{r}0,76 \\
0,75 \\
3,045 \\
2,880 \\
0,023 \\
0,022 \\
5 \\
4\end{array}$ & $\begin{array}{r}10,48 \\
10,01 \\
10,864 \\
4,472 \\
1,139 \\
0,447 \\
5 \\
4\end{array}$ & $\begin{array}{r}6,06 \\
5,92 \\
12,286 \\
13,202 \\
0,744 \\
0,781 \\
5 \\
4\end{array}$ & $\begin{array}{r}17,29 \\
16,60 \\
9,427 \\
3,715 \\
1,629 \\
0,617 \\
5 \\
4\end{array}$ & $\begin{array}{r}11080 \\
13050 \\
9,169 \\
6,981 \\
1015,9 \\
911,04 \\
5 \\
4\end{array}$ & $\begin{array}{r}86,92 \\
134,12 \\
16,619 \\
7,633 \\
14,445 \\
10,238 \\
5 \\
4\end{array}$ & $\begin{array}{r}48,52 \\
74,83 \\
12,130 \\
6,075 \\
5,885 \\
4,546 \\
5 \\
4\end{array}$ & $\begin{array}{r}12,54 \\
14,00 \\
17,810 \\
8,748 \\
2,233 \\
1,225 \\
5 \\
4\end{array}$ & $\begin{array}{r}12,64 \\
17,58 \\
9,731 \\
16,539 \\
1,230 \\
2,907 \\
5 \\
4\end{array}$ \\
\hline$\frac{\text { Vochysia }}{\text { guianens is }}$ & $\begin{array}{l}\mu(V) \\
\mu(12 \%) \\
\text { CV }(V) \\
\text { CV }(12 \%) \\
s(v) \\
\text { s }(12 \%) \\
N(v) \\
N(12 \%)\end{array}$ & $\begin{array}{r}0,59 \\
0,60 \\
14,610 \\
16,415 \\
0,086 \\
0,098 \\
5 \\
3\end{array}$ & $\begin{array}{r}14,12 \\
13,43 \\
12,675 \\
12,831 \\
1,790 \\
1,723 \\
5 \\
3\end{array}$ & $\begin{array}{r}5,81 \\
5,82 \\
8,565 \\
11,495 \\
0,497 \\
0,669 \\
5 \\
3\end{array}$ & $\begin{array}{r}20,87 \\
20,28 \\
9,785 \\
11,744 \\
2,042 \\
2,381 \\
5 \\
3\end{array}$ & $\begin{array}{r}9700 \\
13033 \\
10,738 \\
3,194 \\
1041,6 \\
416,33 \\
5 \\
3\end{array}$ & $\begin{array}{r}62,54 \\
97,70 \\
13,940 \\
2,381 \\
8,718 \\
2,326 \\
5 \\
3\end{array}$ & $\begin{array}{r}32,70 \\
53,27 \\
15,151 \\
24,765 \\
4,954 \\
13,191 \\
5 \\
3\end{array}$ & $\begin{array}{r}6,18 \\
8,13 \\
27,327 \\
8 \quad 8, \\
1,689 \\
0,651 \\
5 \\
3\end{array}$ & $\begin{array}{r}7,80 \\
10,37 \\
14,334 \\
317 \\
1,118 \\
0,862 \\
5 \\
3\end{array}$ \\
\hline$\frac{\text { Alexa }}{\text { grandi flora }}$ & $\begin{array}{l}\mu(v) \\
\mu(12 \%) \\
\text { CV }(v) \\
\text { CV }(12 \%) \\
s(v) \\
\text { s }(12 \%) \\
N(v) \\
N(12 \%)\end{array}$ & $\begin{array}{r}0,53 \\
0,52 \\
8,168 \\
8,889 \\
0,043 \\
0,046 \\
4 \\
5\end{array}$ & $\begin{array}{r}15,96 \\
15,56 \\
16,737 \\
15,544 \\
2,671 \\
2,419 \\
4 \\
5\end{array}$ & $\begin{array}{r}6,21 \\
6,62 \\
23,572 \\
25,992 \\
1,464 \\
1,721 \\
4 \\
5\end{array}$ & $\begin{array}{r}23,07 \\
23,30 \\
17,312 \\
17,650 \\
3,994 \\
4,112 \\
4 \\
5\end{array}$ & $\begin{array}{r}7625 \\
10320 \\
21,373 \\
10,264 \\
1629,7 \\
1059,2 \\
4 \\
5\end{array}$ & $\begin{array}{r}57,50 \\
87,28 \\
13,969 \\
20,026 \\
8,032 \\
17,479 \\
4 \\
5\end{array}$ & $\begin{array}{r}29,78 \\
51,74 \\
9,762 \\
6,693 \\
2,907 \\
3,463 \\
4 \\
5\end{array}$ & $\begin{array}{r}9,40 \\
9,08 \\
5,955 \\
12,615 \\
0,560 \\
1,145 \\
4 \\
5\end{array}$ & $\begin{array}{r}8,85 \\
12,30 \\
11,905 \\
19,521 \\
1,054 \\
2,401 \\
4 \\
5\end{array}$ \\
\hline
\end{tabular}


Espécies originárias da região de Balbina

\begin{tabular}{|c|c|c|c|c|c|c|c|c|c|c|}
\hline $\begin{array}{c}\text { Nome } \\
\text { Cient ífico }\end{array}$ & & Db & Rt & $\mathbf{R r}$ & Rv & $E_{f}$ & $f_{f}$ & $f_{c}$ & $f_{c n}$ & $f_{s}$ \\
\hline$\frac{\text { Aldina }}{\text { heterophylla }}$ & $\begin{array}{l}\mu(v) \\
\mu(12 \%) \\
C V(v) \\
C V(12 \%) \\
s(v) \\
S(12 \%) \\
N(v) \\
N(12 \%)\end{array}$ & $\begin{array}{r}0,73 \\
0,71 \\
6,953 \\
4,970 \\
0,051 \\
0,035 \\
4 \\
3\end{array}$ & $\begin{array}{r}7,17 \\
6,79 \\
16,577 \\
16,522 \\
1,188 \\
1,121 \\
4 \\
3\end{array}$ & $\begin{array}{r}4,63 \\
4,39 \\
15,502 \\
15,253 \\
0,717 \\
0,670 \\
4 \\
3\end{array}$ & $\begin{array}{r}12,39 \\
11,70 \\
16,636 \\
16,011 \\
2,061 \\
1,873 \\
4 \\
3\end{array}$ & $\begin{array}{r}9825 \\
10733 \\
27,416 \\
9,786 \\
2693,7 \\
1050,4 \\
4 \\
3\end{array}$ & $\begin{array}{r}76,15 \\
116,73 \\
33,119 \\
26,324 \\
25,220 \\
30,729 \\
4 \\
3\end{array}$ & $\begin{array}{r}43,05 \\
61,87 \\
20,912 \\
13,203 \\
9,002 \\
8,168 \\
4 \\
3\end{array}$ & $\begin{array}{r}9,55 \\
15,27 \\
7,906 \\
6,086 \\
0,755 \\
0,929 \\
4 \\
3\end{array}$ & $\begin{array}{r}12,83 \\
14,53 \\
10,792 \\
7,357 \\
1,384 \\
1,069 \\
4 \\
3\end{array}$ \\
\hline $\begin{array}{l}\text { Aspidosperma } \\
\text { obscurinervium }\end{array}$ & $\begin{array}{l}\mu(v) \\
\mu(12 \%) \\
\text { CV }(v) \\
\text { CV }(12 \%) \\
s(v) \\
S(12 \%) \\
N(v) \\
N(12 \%)\end{array}$ & $\begin{array}{r}0,88 \\
0,88 \\
12,112 \\
12,112 \\
0,107 \\
0,107 \\
4 \\
4\end{array}$ & $\begin{array}{r}12,09 \\
12,09 \\
7,300 \\
7,300 \\
0,883 \\
0,883 \\
4 \\
4\end{array}$ & $\begin{array}{r}7,77 \\
7,77 \\
7,598 \\
7,598 \\
0,590 \\
0,590 \\
4 \\
4\end{array}$ & $\begin{array}{r}20,68 \\
20,68 \\
8,453 \\
8,453 \\
1,748 \\
1,748 \\
4 \\
4\end{array}$ & $\begin{array}{r}13825 \\
15275 \\
22,109 \\
8,078 \\
3056,6 \\
1233,9 \\
4 \\
4\end{array}$ & $\begin{array}{r}96,30 \\
139,17 \\
12,309 \\
17,798 \\
11,853 \\
24,770 \\
4 \\
4\end{array}$ & $\begin{array}{r}53,53 \\
77,03 \\
15,612 \\
12,840 \\
8,356 \\
9,890 \\
4 \\
4\end{array}$ & $\begin{array}{r}8,33 \\
10,95 \\
19,254 \\
11,370 \\
1,603 \\
1,245 \\
4 \\
4\end{array}$ & $\begin{array}{r}11,05 \\
16,63 \\
35,271 \\
6,277 \\
3,897 \\
1,044 \\
4 \\
4\end{array}$ \\
\hline$\frac{\text { Andira }}{\text { Parviflora }}$ & $\begin{array}{l}\mu(v) \\
\mu(12 \%) \\
C V(v) \\
C V(12 \%) \\
S(v) \\
S(12 \%) \\
N(v) \\
N(12 \%)\end{array}$ & $\begin{array}{r}0,67 \\
0,66 \\
5,335 \\
5,830 \\
0,036 \\
0,039 \\
5 \\
4\end{array}$ & $\begin{array}{r}9,21 \\
9,13 \\
3,184 \\
5,072 \\
0,293 \\
0,463 \\
5 \\
4\end{array}$ & $\begin{array}{r}4,84 \\
5,28 \\
7,659 \\
21,843 \\
0,371 \\
1,152 \\
5 \\
4\end{array}$ & $\begin{array}{r}14,76 \\
15,17 \\
4,581 \\
8,259 \\
0,676 \\
1,252 \\
5 \\
4\end{array}$ & $\begin{array}{r}10820 \\
11350 \\
13,126 \\
9,393 \\
1420,2 \\
1066,1 \\
5 \\
4\end{array}$ & $\begin{array}{r}86,74 \\
98,08 \\
14,367 \\
21,132 \\
12,462 \\
20,725 \\
5 \\
4\end{array}$ & $\begin{array}{r}38,80 \\
70,08 \\
33,105 \\
9,177 \\
12,845 \\
6,431 \\
5 \\
4\end{array}$ & $\begin{array}{r}9,28 \\
12,63 \\
15,361 \\
8,342 \\
1,425 \\
1,053 \\
5 \\
4\end{array}$ & $\begin{array}{r}10,26 \\
13,98 \\
5,276 \\
12,330 \\
0,541 \\
1,723 \\
5 \\
4\end{array}$ \\
\hline $\begin{array}{l}\text { Buchenavia } \\
\text { oxycarpa }\end{array}$ & $\begin{array}{l}\mu(v) \\
\mu(12 \%) \\
\text { CV }(v) \\
\text { CV }(12 \%) \\
s(v) \\
\text { S }(12 \%) \\
N(v) \\
N(12 \%)\end{array}$ & $\begin{array}{r}0,79 \\
0,79 \\
5,168 \\
6,329 \\
0,041 \\
0,050 \\
4 \\
3\end{array}$ & $\begin{array}{r}9,11 \\
9,49 \\
10,613 \\
7,599 \\
0,967 \\
0,721 \\
4 \\
3\end{array}$ & $\begin{array}{r}5,17 \\
5,40 \\
17,543 \\
17,650 \\
0,907 \\
0,953 \\
4 \\
3\end{array}$ & $\begin{array}{r}14,96 \\
15,59 \\
11,793 \\
9,557 \\
1,764 \\
1,490 \\
4 \\
3\end{array}$ & $\begin{array}{r}11975 \\
12767 \\
4,887 \\
7,924 \\
585,23 \\
1011,6 \\
4 \\
3\end{array}$ & $\begin{array}{r}103,62 \\
142,37 \\
2,203 \\
16,806 \\
2,282 \\
23,926 \\
4 \\
3\end{array}$ & $\begin{array}{r}52,60 \\
81,30 \\
10,404 \\
3,643 \\
5,472 \\
2,961 \\
4 \\
3\end{array}$ & $\begin{array}{r}12,30 \\
16,83 \\
20,589 \\
21,894 \\
2,532 \\
3,686 \\
4 \\
3\end{array}$ & $\begin{array}{r}10,00 \\
16,73 \\
2,944 \\
24,642 \\
0,294 \\
4,124 \\
4 \\
3\end{array}$ \\
\hline$\frac{\text { Brosimum }}{\text { rubescens }}$ & $\begin{array}{l}\mu(v) \\
\mu(12 \%) \\
\text { CV }(v) \\
\text { CV }(12 \%) \\
s(v) \\
\text { S }(12 \%) \\
N(v) \\
N(12 \%)\end{array}$ & $\begin{array}{r}0,79 \\
0,85 \\
15,555 \\
18,947 \\
0,123 \\
0,160 \\
5 \\
3\end{array}$ & $\begin{array}{r}8,65 \\
8,01 \\
19,417 \\
22,337 \\
1,679 \\
1,788 \\
5 \\
3\end{array}$ & $\begin{array}{r}5,99 \\
5,30 \\
22,775 \\
24,264 \\
1,364 \\
1,285 \\
5 \\
3\end{array}$ & $\begin{array}{r}15,34 \\
13,98 \\
20,681 \\
23,225 \\
3,173 \\
3,246 \\
5 \\
3\end{array}$ & $\begin{array}{r}14100 \\
13233 \\
20,079 \\
19,667 \\
2831,1 \\
2602,6 \\
5 \\
3\end{array}$ & $\begin{array}{r}111,36 \\
130,10 \\
24,744 \\
32,532 \\
27,554 \\
42,325 \\
5 \\
3\end{array}$ & $\begin{array}{r}55,82 \\
67,07 \\
28,208 \\
18,719 \\
15,746 \\
12,554 \\
5 \\
3\end{array}$ & $\begin{array}{r}14,14 \\
13,90 \\
46,114 \\
4,718 \\
6,521 \\
0,656 \\
5 \\
3\end{array}$ & $\begin{array}{r}12,96 \\
15,27 \\
32,254 \\
12,084 \\
4,180 \\
1,845 \\
5 \\
3\end{array}$ \\
\hline $\begin{array}{l}\text { Carapa } \\
\text { guianensis }\end{array}$ & $\begin{array}{l}\mu(v) \\
\mu(12 \%) \\
C V(v) \\
C V(12 \%) \\
S(v) \\
S(12 \%) \\
N(v) \\
N(12 \%)\end{array}$ & $\begin{array}{r}0,45 \\
0,44 \\
7,747 \\
4,877 \\
0,035 \\
0,021 \\
3 \\
2\end{array}$ & $\begin{array}{r}8,37 \\
7,76 \\
14,458 \\
10,752 \\
1,210 \\
0,834 \\
3 \\
2\end{array}$ & $\begin{array}{r}4,03 \\
3,74 \\
13,854 \\
8,519 \\
0,558 \\
0,318 \\
3 \\
2\end{array}$ & $\begin{array}{r}13,05 \\
11,98 \\
15,551 \\
9,389 \\
2,030 \\
1,124 \\
3 \\
2\end{array}$ & $\begin{array}{r}8500 \\
10300 \\
8,151 \\
6,865 \\
692,82 \\
707,11 \\
3 \\
2\end{array}$ & $\begin{array}{r}59,67 \\
88,15 \\
8,323 \\
8,904 \\
4,966 \\
7,849 \\
3 \\
2\end{array}$ & $\begin{array}{r}28,17 \\
51,75 \\
5,341 \\
2,596 \\
1,504 \\
1,344 \\
3 \\
2\end{array}$ & $\begin{array}{r}5,13 \\
5,75 \\
18,412 \\
13,527 \\
0,945 \\
0,778 \\
3 \\
2\end{array}$ & $\begin{array}{r}8,73 \\
9,45 \\
20,041 \\
15,713 \\
1,750 \\
1,485 \\
3 \\
2\end{array}$ \\
\hline
\end{tabular}


continuação

\begin{tabular}{|c|c|c|c|c|c|c|c|c|c|c|}
\hline $\begin{array}{l}\text { Cedrel inga } \\
\text { catenaeformis } \\
\end{array}$ & $\begin{array}{l}\mu(v) \\
\mu(12 \%) \\
\text { CV }(v) \\
\text { CV }(12 \%) \\
s(v) \\
S(12 \%) \\
N(v) \\
N(12 \%)\end{array}$ & $\begin{array}{r}0,47 \\
0,47 \\
5,054 \\
3,918 \\
0,024 \\
0,018 \\
4 \\
6\end{array}$ & $\begin{array}{r}7,95 \\
7,55 \\
20,654 \\
18,700 \\
1,641 \\
1,412 \\
4 \\
6\end{array}$ & $\begin{array}{r}3,59 \\
3,67 \\
12,761 \\
10,371 \\
0,458 \\
0,380 \\
4 \\
6\end{array}$ & $\begin{array}{r}12,31 \\
11,92 \\
15,340 \\
13,289 \\
1,888 \\
1,584 \\
4 \\
6\end{array}$ & $\begin{array}{r}7000 \\
8200 \\
11,606 \\
5,874 \\
812,40 \\
481,66 \\
4 \\
6\end{array}$ & $\begin{array}{r}52,65 \\
79,48 \\
3,781 \\
6,111 \\
1,991 \\
4,857 \\
4 \\
6\end{array}$ & $\begin{array}{r}24,50 \\
38,98 \\
8,005 \\
6,844 \\
1,961 \\
2,668 \\
4 \\
6\end{array}$ & $\begin{array}{r}6,58 \\
7,57 \\
28,164 \\
15,014 \\
1,852 \\
1,136 \\
4 \\
6\end{array}$ & $\begin{array}{r}8,60 \\
12,63 \\
18,238 \\
9,455 \\
1,568 \\
1,194 \\
4 \\
6\end{array}$ \\
\hline $\begin{array}{l}\text { Cariniana } \\
\text { integrifol ia }\end{array}$ & $\begin{array}{l}\mu(v) \\
\mu(12 \%) \\
C V(V) \\
\text { CV }(12 \%) \\
s(v) \\
S(12 \%) \\
N(v) \\
N(12 \%)\end{array}$ & $\begin{array}{r}0,50 \\
0,50 \\
3,499 \\
3,499 \\
0,017 \\
0,017 \\
4 \\
4\end{array}$ & $\begin{array}{r}5,81 \\
5,81 \\
10,091 \\
10,091 \\
0,587 \\
0,587 \\
4 \\
4\end{array}$ & $\begin{array}{r}4,24 \\
4,24 \\
8,089 \\
8,089 \\
0,343 \\
0,343 \\
4 \\
4\end{array}$ & $\begin{array}{r}10,64 \\
10,64 \\
7,689 \\
7,689 \\
0,818 \\
0,818 \\
4 \\
4\end{array}$ & $\begin{array}{r}8500 \\
9900 \\
11,078 \\
16,761 \\
941,63 \\
1659,3 \\
4 \\
4\end{array}$ & $\begin{array}{r}55,33 \\
81,58 \\
13,368 \\
17,998 \\
7,396 \\
14,682 \\
4 \\
4\end{array}$ & $\begin{array}{r}27,23 \\
46,08 \\
7,903 \\
4,453 \\
2,152 \\
2,052 \\
4 \\
4\end{array}$ & $\begin{array}{r}4,93 \\
8,18 \\
14,955 \\
27,919 \\
0,737 \\
2,282 \\
4 \\
4\end{array}$ & $\begin{array}{r}6,18 \\
8,00 \\
23,961 \\
16,040 \\
1,480 \\
1,283 \\
4 \\
4\end{array}$ \\
\hline $\begin{array}{l}\text { Clarisia } \\
\text { racemosa }\end{array}$ & $\begin{array}{l}\mu(v) \\
\mu(12 \%) \\
\text { CV }(v) \\
\text { CV }(12 \%) \\
S \quad(v) \\
S(12 \%) \\
N(v) \\
N(12 \%)\end{array}$ & $\begin{array}{r}0,61 \\
0,60 \\
12,244 \\
17,361 \\
0,075 \\
0,104 \\
8 \\
5\end{array}$ & $\begin{array}{r}6,58 \\
5,91 \\
21,297 \\
21,852 \\
1,401 \\
1,291 \\
8 \\
5\end{array}$ & $\begin{array}{r}3,21 \\
3,00 \\
16,895 \\
19,541 \\
0,543 \\
0,586 \\
8 \\
5\end{array}$ & $\begin{array}{r}10,57 \\
9,22 \\
14,949 \\
19,945 \\
1,580 \\
1,839 \\
8 \\
5\end{array}$ & $\begin{array}{r}10038 \\
10300 \\
15,452 \\
14,740 \\
1551,0 \\
1518,2 \\
8 \\
5\end{array}$ & $\begin{array}{r}85,16 \\
105,68 \\
15,837 \\
19,528 \\
13,487 \\
20,637 \\
8 \\
5\end{array}$ & $\begin{array}{r}47,34 \\
69,20 \\
19,263 \\
25,661 \\
9,119 \\
17,757 \\
8 \\
5\end{array}$ & $\begin{array}{r}12,53 \\
12,20 \\
21,161 \\
15,498 \\
2,650 \\
1,891 \\
8 \\
5\end{array}$ & $\begin{array}{r}10,64 \\
12,26 \\
16,328 \\
11,428 \\
1,737 \\
1,401 \\
8 \\
5\end{array}$ \\
\hline $\begin{array}{l}\text { Corythophora } \\
\text { rimosa }\end{array}$ & $\begin{array}{l}\mu(v) \\
\mu(12 \%) \\
\text { CV }(v) \\
\text { CV }(12 \%) \\
S(v) \\
\text { S }(12 \%) \\
N(v) \\
N(12 \%)\end{array}$ & $\begin{array}{r}0,85 \\
0,85 \\
1,804 \\
1,804 \\
0,015 \\
0,015 \\
3 \\
3\end{array}$ & $\begin{array}{r}11,24 \\
11,24 \\
10,822 \\
10,822 \\
1,216 \\
1,216 \\
3 \\
3\end{array}$ & $\begin{array}{r}7,19 \\
7,19 \\
30,089 \\
30,089 \\
2,163 \\
2,163 \\
3 \\
3\end{array}$ & $\begin{array}{r}19,42 \\
19,42 \\
18,762 \\
18,762 \\
3,643 \\
3,643 \\
3 \\
3\end{array}$ & $\begin{array}{r}13867 \\
14000 \\
18,671 \\
4,684 \\
2589,1 \\
655,74 \\
3 \\
3\end{array}$ & $\begin{array}{r}114,10 \\
158,57 \\
8,731 \\
3,628 \\
9,962 \\
5,754 \\
3 \\
3\end{array}$ & $\begin{array}{r}49,17 \\
77,30 \\
14,645 \\
9,834 \\
7,200 \\
7,602 \\
3 \\
3\end{array}$ & $\begin{array}{r}11,93 \\
14,70 \\
10,808 \\
2,965 \\
1,290 \\
0,436 \\
3 \\
3\end{array}$ & $\begin{array}{r}12,37 \\
16,23 \\
11,921 \\
19,503 \\
1,474 \\
3,166 \\
3 \\
3\end{array}$ \\
\hline $\begin{array}{l}\text { Curatari } \\
\text { stellata }\end{array}$ & $\begin{array}{l}\mu(v) \\
\mu(12 \%) \\
C V(v) \\
C V(12 \%) \\
s \quad(v) \\
s(12 \%) \\
N(v) \\
N(12 \%)\end{array}$ & $\begin{array}{r}0,60 \\
0,60 \\
7,345 \\
7,345 \\
0,044 \\
0,044 \\
4 \\
4\end{array}$ & $\begin{array}{r}8,69 \\
8,69 \\
20,309 \\
20,309 \\
1,764 \\
1,764 \\
4 \\
4\end{array}$ & $\begin{array}{r}6,35 \\
6,35 \\
28,559 \\
28,559 \\
1,812 \\
1,812 \\
4 \\
4\end{array}$ & $\begin{array}{r}15,70 \\
15,69 \\
23,535 \\
23,561 \\
3,694 \\
3,697 \\
4 \\
4\end{array}$ & $\begin{array}{r}11075 \\
12975 \\
21,986 \\
6,961 \\
2435,0 \\
903,23 \\
4 \\
4\end{array}$ & $\begin{array}{r}81,93 \\
131,37 \\
13,109 \\
9,954 \\
10,740 \\
13,078 \\
4 \\
4\end{array}$ & $\begin{array}{r}37,875 \\
64,375 \\
20,289 \\
3,373 \\
7,684 \\
2,172 \\
4 \\
4\end{array}$ & $\begin{array}{r}7,400 \\
9,425 \\
16,806 \\
8,416 \\
1,244 \\
0,793 \\
4 \\
4\end{array}$ & $\begin{array}{r}11,58 \\
13,38 \\
10,936 \\
9,601 \\
1,266 \\
1,284 \\
4 \\
4\end{array}$ \\
\hline $\begin{array}{l}\text { Dipteryx } \\
\text { odorata }\end{array}$ & $\begin{array}{l}\mu(v) \\
\mu(12 \%) \\
C V(v) \\
\text { CV }(12 \%) \\
\text { s }(v) \\
\text { S }(12 \%) \\
N(v) \\
N(12 \%)\end{array}$ & $\begin{array}{r}0,97 \\
0,96 \\
5,552 \\
6,842 \\
0,054 \\
0,066 \\
6 \\
4\end{array}$ & $\begin{array}{r}8,22 \\
7,80 \\
12,207 \\
11,745 \\
1,004 \\
0,916 \\
6 \\
4\end{array}$ & $\begin{array}{r}5,90 \\
5,68 \\
9,435 \\
9,228 \\
0,556 \\
0,524 \\
6 \\
4\end{array}$ & $\begin{array}{r}14,74 \\
14,06 \\
9,764 \\
7,863 \\
1,439 \\
1,106 \\
6 \\
4\end{array}$ & $\begin{array}{r}15817 \\
16075 \\
8,608 \\
13,932 \\
1361,5 \\
2239,6 \\
6 \\
4\end{array}$ & $\begin{array}{r}134,13 \\
181,98 \\
9,662 \\
10,709 \\
12,960 \\
19,487 \\
6 \\
4\end{array}$ & $\begin{array}{r}83,07 \\
98,25 \\
5,735 \\
3,251 \\
4,764 \\
3,194 \\
6 \\
4\end{array}$ & $\begin{array}{r}24,55 \\
26,93 \\
7,166 \\
3,271 \\
1,759 \\
0,881 \\
6 \\
4\end{array}$ & $\begin{array}{r}16,17 \\
17,18 \\
19,108 \\
12,527 \\
3,089 \\
2,152 \\
6 \\
4\end{array}$ \\
\hline $\begin{array}{l}\text { Dipteryx } \\
\text { polyphyl la }\end{array}$ & $\begin{array}{l}\mu(v) \\
\mu(12 \%) \\
C V(v) \\
C V(12 \%) \\
s(v) \\
\text { s }(12 \%) \\
N(v) \\
N(12 \%)\end{array}$ & $\begin{array}{r}0,85 \\
0,85 \\
6,299 \\
6,299 \\
0,053 \\
0,053 \\
4 \\
4\end{array}$ & $\begin{array}{r}6,71 \\
6,71 \\
5,999 \\
5,999 \\
0,402 \\
0,402 \\
4 \\
4\end{array}$ & $\begin{array}{r}4,75 \\
4,75 \\
10,429 \\
10,429 \\
0,495 \\
0,495 \\
4 \\
4\end{array}$ & $\begin{array}{r}11,72 \\
11,72 \\
9,895 \\
9,895 \\
1,160 \\
1,160 \\
4 \\
4\end{array}$ & $\begin{array}{r}14375 \\
14850 \\
14,067 \\
19,185 \\
2022,2 \\
2849,0 \\
4 \\
4\end{array}$ & $\begin{array}{r}133,12 \\
168,80 \\
13,040 \\
11,693 \\
17,359 \\
19,738 \\
4 \\
4\end{array}$ & $\begin{array}{r}73,55 \\
87,98 \\
16,145 \\
22,876 \\
11,874 \\
20,125 \\
4 \\
4\end{array}$ & $\begin{array}{r}19,00 \\
18,93 \\
13,418 \\
7,185 \\
2,550 \\
1,360 \\
4 \\
4\end{array}$ & $\begin{array}{r}13,90 \\
13,53 \\
11,114 \\
6,314 \\
1,545 \\
0,854 \\
4 \\
4\end{array}$ \\
\hline
\end{tabular}


continuação

\begin{tabular}{|c|c|c|c|c|c|c|c|c|c|c|}
\hline $\begin{array}{l}\text { Eschwei lera } \\
\text { odora }\end{array}$ & $\begin{array}{l}\mu(v) \\
\mu(12 \%) \\
\text { CV }(v) \\
\text { CV }(12 \%) \\
s(v) \\
\text { s }(12 \%) \\
N(v) \\
N(12 \%)\end{array}$ & $\begin{array}{r}0,90 \\
0,90 \\
3,382 \\
3,382 \\
0,031 \\
0,031 \\
3 \\
3\end{array}$ & $\begin{array}{r}10,06 \\
10,06 \\
6,972 \\
6,972 \\
0,701 \\
0,701 \\
3 \\
3\end{array}$ & $\begin{array}{r}7,54 \\
7,54 \\
14,331 \\
14,331 \\
1,080 \\
1,080 \\
3 \\
3\end{array}$ & $\begin{array}{r}18,65 \\
18,65 \\
2,952 \\
2,952 \\
0,551 \\
0,551 \\
3 \\
3\end{array}$ & $\begin{array}{r}14467 \\
14667 \\
25,136 \\
3,363 \\
3636,4 \\
493,29 \\
3 \\
3\end{array}$ & $\begin{array}{r}106,00 \\
144,67 \\
12,068 \\
18,598 \\
12,792 \\
26,905 \\
3 \\
3\end{array}$ & $\begin{array}{r}52,87 \\
68,90 \\
20,478 \\
12,700 \\
10,826 \\
8,750 \\
3 \\
3\end{array}$ & $\begin{array}{r}15,90 \\
18,67 \\
33,083 \\
15,231 \\
5,260 \\
2,843 \\
3 \\
3\end{array}$ & $\begin{array}{r}13,03 \\
14,77 \\
6,249 \\
15,087 \\
0,814 \\
2,228 \\
3\end{array}$ \\
\hline $\begin{array}{l}\text { Enterolobium } \\
\text { schomburgkii }\end{array}$ & $\begin{array}{l}\mu(v) \\
\mu(12 \%) \\
C V(V) \\
C V(12 \%) \\
s(v) \\
\text { S }(12 \%) \\
N(v) \\
N(12 \%)\end{array}$ & $\begin{array}{r}0,69 \\
0,69 \\
7,911 \\
7,911 \\
0,054 \\
0,054 \\
4 \\
4\end{array}$ & $\begin{array}{r}9,63 \\
9,63 \\
11,141 \\
11,141 \\
1,073 \\
1,073 \\
4 \\
4\end{array}$ & $\begin{array}{r}4,38 \\
4,38 \\
12,919 \\
12,919 \\
0,566 \\
0,566 \\
4 \\
4\end{array}$ & $\begin{array}{r}14,88 \\
14,88 \\
9,580 \\
9,580 \\
1,426 \\
1,426 \\
4 \\
4\end{array}$ & $\begin{array}{r}12325 \\
12575 \\
8,519 \\
9,462 \\
1050,0 \\
1189,9 \\
4 \\
4\end{array}$ & $\begin{array}{r}82,58 \\
126,22 \\
19,239 \\
11,552 \\
15,887 \\
14,581 \\
4 \\
4\end{array}$ & $\begin{array}{r}43,70 \\
64,50 \\
18,865 \\
15,370 \\
8,244 \\
9,914 \\
4 \\
4\end{array}$ & $\begin{array}{r}8,60 \\
11,45 \\
11,550 \\
10,222 \\
0,993 \\
1,170 \\
4 \\
4\end{array}$ & $\begin{array}{r}11,93 \\
15,23 \\
20,918 \\
20,883 \\
2,494 \\
3,179 \\
4 \\
4\end{array}$ \\
\hline $\begin{array}{l}\text { Erisma } \\
\text { uncinatum }\end{array}$ & $\begin{array}{l}\mu(v) \\
\mu(12 \%) \\
C V(V) \\
\text { CV }(12 \%) \\
S(v) \\
\text { S }(12 \%) \\
N(v) \\
N(12 \%)\end{array}$ & $\begin{array}{r}0,55 \\
0,55 \\
6,471 \\
6,471 \\
0,036 \\
0,036 \\
4 \\
4\end{array}$ & $\begin{array}{r}9,91 \\
9,91 \\
17,585 \\
17,585 \\
1,743 \\
1,743 \\
4 \\
4\end{array}$ & $\begin{array}{r}3,94 \\
3,94 \\
22,220 \\
22,220 \\
0,875 \\
0,875 \\
4 \\
4\end{array}$ & $\begin{array}{r}14,54 \\
14,54 \\
19,157 \\
19,157 \\
2,785 \\
2,785 \\
4 \\
4\end{array}$ & $\begin{array}{r}7975 \\
8825 \\
16,835 \\
12,833 \\
1342,6 \\
1132,5 \\
4 \\
4\end{array}$ & $\begin{array}{r}54,33 \\
64,03 \\
25,550 \\
21,782 \\
13,880 \\
13,946 \\
4 \\
4\end{array}$ & $\begin{array}{r}21,15 \\
41,15 \\
14,406 \\
13,650 \\
3,047 \\
5,617 \\
4 \\
4\end{array}$ & $\begin{array}{r}4,30 \\
6,65 \\
6,005 \\
11,872 \\
0,258 \\
0,790 \\
4 \\
4\end{array}$ & $\begin{array}{r}6,05 \\
7,73 \\
24,976 \\
19,240 \\
1,511 \\
1,486 \\
4 \\
4\end{array}$ \\
\hline $\begin{array}{l}\text { Goupia } \\
\text { glabra }\end{array}$ & $\begin{array}{l}\mu(v) \\
\mu(12 \%) \\
C V(v) \\
C V(12 \%) \\
S(v) \\
\text { s }(12 \%) \\
N(v) \\
N(12 \%)\end{array}$ & $\begin{array}{r}0,71 \\
0,68 \\
6,037 \\
8,598 \\
0,043 \\
0,058 \\
8 \\
8\end{array}$ & $\begin{array}{r}9,99 \\
9,39 \\
14,131 \\
8,404 \\
1,412 \\
0,789 \\
8 \\
8\end{array}$ & $\begin{array}{r}5,75 \\
5,28 \\
7,433 \\
14,680 \\
0,427 \\
0,776 \\
8 \\
8\end{array}$ & $\begin{array}{r}16,51 \\
15,49 \\
12,256 \\
9,366 \\
2,023 \\
1,451 \\
8 \\
8\end{array}$ & $\begin{array}{r}11375 \\
12275 \\
10,907 \\
9,448 \\
1240,7 \\
1159,7 \\
8 \\
8\end{array}$ & $\begin{array}{r}91,38 \\
114,76 \\
10,984 \\
21,398 \\
10,036 \\
24,557 \\
8 \\
8\end{array}$ & $\begin{array}{r}46,58 \\
65,26 \\
16,815 \\
14,975 \\
7,832 \\
9,773 \\
8 \\
8\end{array}$ & $\begin{array}{r}9,75 \\
12,94 \\
28,333 \\
24,731 \\
2,763 \\
3,200 \\
8 \\
8\end{array}$ & $\begin{array}{r}12,03 \\
14,64 \\
14,694 \\
22,194 \\
1,767 \\
3,249 \\
8 \\
8\end{array}$ \\
\hline $\begin{array}{l}\text { Guarea } \\
\text { trichíl ioides }\end{array}$ & $\begin{array}{l}\mu(v) \\
\mu(12 \%) \\
\text { CV }(v) \\
\text { CV }(12 \%) \\
S(v) \\
\text { S }(12 \%) \\
N(v) \\
N(12 \%)\end{array}$ & $\begin{array}{r}0,69 \\
0,69 \\
6,648 \\
5,797 \\
0,046 \\
0,040 \\
5 \\
3\end{array}$ & $\begin{array}{r}10,67 \\
11,16 \\
11,798 \\
13,195 \\
1,259 \\
1,472 \\
5 \\
3\end{array}$ & $\begin{array}{r}6,75 \\
6,56 \\
19,173 \\
23,252 \\
1,295 \\
1,525 \\
5 \\
3\end{array}$ & $\begin{array}{r}16,44 \\
16,44 \\
9,749 \\
11,212 \\
1,603 \\
1,843 \\
5 \\
3\end{array}$ & $\begin{array}{r}12080 \\
13867 \\
24,823 \\
13,536 \\
2998,7 \\
1877,1 \\
5 \\
3\end{array}$ & $\begin{array}{r}81,68 \\
122,57 \\
10,685 \\
16,731 \\
8,727 \\
20,507 \\
5 \\
3\end{array}$ & $\begin{array}{r}39,98 \\
62,33 \\
13,121 \\
10,083 \\
5,246 \\
6,285 \\
5 \\
3\end{array}$ & $\begin{array}{r}10,52 \\
12,97 \\
13,683 \\
8,027 \\
1,439 \\
1,041 \\
5 \\
3\end{array}$ & $\begin{array}{r}9,88 \\
11,47 \\
5,788 \\
18,650 \\
0,572 \\
2,139 \\
5 \\
3\end{array}$ \\
\hline $\begin{array}{l}\text { Hymenolobium } \\
\text { excelsum }\end{array}$ & $\begin{array}{l}\mu(v) \\
\mu(12 \%) \\
\text { CV }(v) \\
\text { CV }(12 \%) \\
S(v) \\
\text { S }(12 \%) \\
N(v) \\
N(12 \%)\end{array}$ & $\begin{array}{r}0,65 \\
0,64 \\
2,685 \\
3,341 \\
0,017 \\
0,021 \\
4 \\
2\end{array}$ & $\begin{array}{r}9,29 \\
9,23 \\
18,716 \\
14,180 \\
1,738 \\
1,308 \\
4 \\
2\end{array}$ & $\begin{array}{r}5,67 \\
5,36 \\
22,564 \\
4,485 \\
1,279 \\
0,240 \\
4 \\
2\end{array}$ & $\begin{array}{r}15,74 \\
15,41 \\
19,936 \\
8,859 \\
3,138 \\
1,365 \\
4 \\
2\end{array}$ & $\begin{array}{r}12700 \\
13550 \\
8,208 \\
8,871 \\
1042,4 \\
1202,1 \\
4 \\
2\end{array}$ & $\begin{array}{r}89,35 \\
133,35 \\
9,071 \\
7,159 \\
8,105 \\
9,546 \\
4 \\
2\end{array}$ & $\begin{array}{r}47,55 \\
75,30 \\
13,264 \\
3,944 \\
6,307 \\
2,970 \\
4 \\
2\end{array}$ & $\begin{array}{r}8,08 \\
11,00 \\
35,076 \\
20,570 \\
2,832 \\
2,263 \\
4 \\
2\end{array}$ & $\begin{array}{r}10,80 \\
13,70 \\
22,718 \\
13,420 \\
2,454 \\
1,838 \\
4 \\
2\end{array}$ \\
\hline $\begin{array}{l}\text { Hymenol obium } \\
\text { pulcherrimum }\end{array}$ & $\begin{array}{l}\mu(v) \\
\mu(12 \%) \\
\text { CV }(v) \\
\text { CV }(12 \%) \\
s(v) \\
\text { S }(12 \%) \\
N(v) \\
N(12 \%)\end{array}$ & $\begin{array}{r}0,67 \\
0,68 \\
10,096 \\
14,029 \\
0,068 \\
0,095 \\
5 \\
3\end{array}$ & $\begin{array}{r}8,81 \\
8,29 \\
15,795 \\
18,956 \\
1,392 \\
1,571 \\
5 \\
3\end{array}$ & $\begin{array}{r}5,75 \\
5,69 \\
4,556 \\
4,759 \\
0,262 \\
0,271 \\
5 \\
3\end{array}$ & $\begin{array}{r}15,35 \\
14,76 \\
10,468 \\
11,641 \\
1,607 \\
1,719 \\
5 \\
3\end{array}$ & $\begin{array}{r}10560 \\
12300 \\
4,948 \\
6,946 \\
522,49 \\
854,40 \\
5 \\
3\end{array}$ & $\begin{array}{r}88,88 \\
131,17 \\
15,347 \\
4,513 \\
13,641 \\
5,920 \\
5 \\
3\end{array}$ & $\begin{array}{r}47,54 \\
63,47 \\
5,462 \\
2,056 \\
2,597 \\
1,305 \\
5 \\
3\end{array}$ & $\begin{array}{r}8,82 \\
15,23 \\
11,956 \\
21,133 \\
1,055 \\
3,219 \\
5 \\
3\end{array}$ & $\begin{array}{r}11,18 \\
12,63 \\
13,644 \\
5,560 \\
1,525 \\
0,702 \\
5 \\
3\end{array}$ \\
\hline
\end{tabular}


continuação

\begin{tabular}{|c|c|c|c|c|c|c|c|c|c|c|}
\hline$\frac{\text { Iryanthera }}{\text { tricornis }}$ & $\begin{array}{l}\mu(v) \\
\mu(12 \%) \\
C V(v) \\
C V(12 \%) \\
s(v) \\
S(12 \%) \\
N(v) \\
N(12 \%)\end{array}$ & $\begin{array}{r}0,69 \\
0,69 \\
10,701 \\
10,701 \\
0,074 \\
0,074 \\
4 \\
4\end{array}$ & $\begin{array}{r}9,84 \\
9,84 \\
9,443 \\
9,443 \\
0,929 \\
0,929 \\
4 \\
4\end{array}$ & $\begin{array}{r}5,20 \\
5,20 \\
13,136 \\
13,136 \\
0,683 \\
0,683 \\
4 \\
4\end{array}$ & $\begin{array}{r}15,78 \\
15,78 \\
8,684 \\
8,684 \\
1,371 \\
1,371 \\
4 \\
4\end{array}$ & $\begin{array}{r}11900 \\
13200 \\
9,943 \\
6,517 \\
1183,2 \\
860,23 \\
4 \\
4\end{array}$ & $\begin{array}{r}91,60 \\
118,60 \\
28,492 \\
5,993 \\
26,099 \\
7,107 \\
4 \\
4\end{array}$ & $\begin{array}{r}37,58 \\
61,35 \\
11,271 \\
7,383 \\
4,235 \\
4,530 \\
4 \\
4\end{array}$ & $\begin{array}{r}8,00 \\
10,68 \\
64,840 \\
13,797 \\
5,187 \\
1,473 \\
4 \\
4\end{array}$ & $\begin{array}{r}7,80 \\
12,95 \\
36,638 \\
14,495 \\
2,858 \\
1,877 \\
4 \\
4\end{array}$ \\
\hline $\begin{array}{l}\text { Jacaranda } \\
\text { copaia }\end{array}$ & $\begin{array}{l}\mu(v) \\
\mu(12 \%) \\
\text { CV }(v) \\
\text { CV }(12 \%) \\
S(v) \\
S(12 \%) \\
N(v) \\
N(12 \%)\end{array}$ & $\begin{array}{r}0,34 \\
0,34 \\
4,986 \\
4,409 \\
0,017 \\
0,015 \\
4 \\
5\end{array}$ & $\begin{array}{r}9,47 \\
9,15 \\
13,048 \\
14,130 \\
1,236 \\
1,292 \\
4 \\
5\end{array}$ & $\begin{array}{r}6,86 \\
6,54 \\
25,823 \\
25,724 \\
1,770 \\
1,683 \\
4 \\
5\end{array}$ & $\begin{array}{r}17,29 \\
16,62 \\
15,678 \\
16,769 \\
2,710 \\
2,786 \\
4 \\
5\end{array}$ & $\begin{array}{r}7425 \\
8460 \\
16,618 \\
14,754 \\
1233,9 \\
1248,2 \\
4 \\
5\end{array}$ & $\begin{array}{r}25,30 \\
49,94 \\
34,230 \\
8,671 \\
8,660 \\
4,330 \\
4 \\
5\end{array}$ & $\begin{array}{r}16,55 \\
28,98 \\
1,157 \\
5,672 \\
0,191 \\
1,644 \\
4 \\
5\end{array}$ & $\begin{array}{r}2,93 \\
2,56 \\
46,406 \\
23,209 \\
1,357 \\
0,594 \\
4 \\
5\end{array}$ & $\begin{array}{r}4,68 \\
5,18 \\
6,848 \\
10,068 \\
0,320 \\
0,522 \\
4 \\
5\end{array}$ \\
\hline$\frac{\text { Licaria }}{\text { aritu }}$ & $\begin{array}{l}\mu(v) \\
\mu(12 \%) \\
\text { CV }(v) \\
\text { CV }(12 \%) \\
s(v) \\
s(12 \%) \\
N(v) \\
N(12 \%)\end{array}$ & $\begin{array}{r}0,80 \\
0,80 \\
2,613 \\
2,613 \\
0,021 \\
0,021 \\
3 \\
3\end{array}$ & $\begin{array}{r}11,16 \\
11,16 \\
8,410 \\
8,410 \\
0,938 \\
0,938 \\
3 \\
3\end{array}$ & $\begin{array}{r}5,61 \\
5,61 \\
7,272 \\
7,272 \\
0,408 \\
0,408 \\
3 \\
3\end{array}$ & $\begin{array}{r}16,34 \\
16,34 \\
5,063 \\
5,063 \\
0,827 \\
0,827 \\
3 \\
3\end{array}$ & $\begin{array}{r}14967 \\
15767 \\
7,915 \\
0,969 \\
1184,6 \\
152,75 \\
3 \\
3\end{array}$ & $\begin{array}{r}109,17 \\
162,10 \\
18,775 \\
9,232 \\
20,496 \\
14,964 \\
3 \\
3\end{array}$ & $\begin{array}{r}58,53 \\
89,07 \\
14,448 \\
3,255 \\
8,457 \\
2,899 \\
3 \\
3\end{array}$ & $\begin{array}{r}14,17 \\
19,03 \\
26,956 \\
12,392 \\
3,819 \\
2,359 \\
3 \\
3\end{array}$ & $\begin{array}{r}15,30 \\
17,30 \\
18,750 \\
9,861 \\
2,869 \\
1,706 \\
3 \\
3\end{array}$ \\
\hline$\frac{\text { Licaria }}{\text { canela }}$ & $\begin{array}{l}\mu(v) \\
\mu(12 \%) \\
\text { CV }(v) \\
\text { CV }(12 \%) \\
s(v) \\
\text { s }(12 \%) \\
N(v) \\
N(12 \%)\end{array}$ & $\begin{array}{r}1,05 \\
1,06 \\
8,176 \\
7,384 \\
0,085 \\
0,078 \\
4 \\
5\end{array}$ & $\begin{array}{r}8,78 \\
8,86 \\
4,405 \\
4,292 \\
0,387 \\
0,380 \\
4 \\
5\end{array}$ & $\begin{array}{r}6,95 \\
6,95 \\
2,487 \\
2,154 \\
0,173 \\
0,150 \\
4 \\
5\end{array}$ & $\begin{array}{r}16,50 \\
16,47 \\
3,763 \\
3,304 \\
0,621 \\
0,544 \\
4 \\
5\end{array}$ & $\begin{array}{r}16900 \\
18340 \\
10,727 \\
11,519 \\
1812,9 \\
2112,6 \\
4 \\
5\end{array}$ & $\begin{array}{r}157,28 \\
189,78 \\
12,406 \\
24,328 \\
19,511 \\
46,170 \\
4 \\
5\end{array}$ & $\begin{array}{r}90,18 \\
125,66 \\
17,838 \\
9,854 \\
16,086 \\
12,383 \\
4 \\
5\end{array}$ & $\begin{array}{r}22,60 \\
23,26 \\
35,989 \\
19,507 \\
8,133 \\
4,537 \\
4 \\
5\end{array}$ & $\begin{array}{r}18,63 \\
18,42 \\
14,127 \\
17,735 \\
2,631 \\
3,267 \\
4 \\
5\end{array}$ \\
\hline $\begin{array}{l}\text { Mani lkara } \\
\text { huberi. }\end{array}$ & $\begin{array}{l}\mu(v) \\
\mu(12 \%) \\
C V(V) \\
\text { CV }(12 \%) \\
\text { s }(v) \\
\text { s }(12 \%) \\
N(v) \\
N(12 \%)\end{array}$ & $\begin{array}{r}0,92 \\
0,93 \\
3,550 \\
2,474 \\
0,033 \\
0,023 \\
4 \\
3\end{array}$ & $\begin{array}{r}9,09 \\
9,75 \\
17,679 \\
11,311 \\
1,606 \\
1,103 \\
4 \\
3\end{array}$ & $\begin{array}{r}7,52 \\
7,90 \\
10,164 \\
2,434 \\
0,765 \\
0,192 \\
4 \\
3\end{array}$ & $\begin{array}{r}17,74 \\
18,60 \\
11,463 \\
7,159 \\
2,033 \\
1,331 \\
4 \\
3\end{array}$ & $\begin{array}{r}13200 \\
17133 \\
12,662 \\
14,133 \\
1671,3 \\
2421,4 \\
4 \\
3\end{array}$ & $\begin{array}{r}137,80 \\
155,93 \\
8,454 \\
12,904 \\
11,649 \\
20,122 \\
4 \\
3\end{array}$ & $\begin{array}{r}72,43 \\
86,13 \\
3,712 \\
3,907 \\
2,689 \\
3,365 \\
4 \\
3\end{array}$ & $\begin{array}{r}20,68 \\
20,17 \\
16,863 \\
9,387 \\
3,487 \\
1,893 \\
4 \\
3\end{array}$ & $\begin{array}{r}14,40 \\
22,67 \\
30,556 \\
8,198 \\
4,400 \\
1,858 \\
4 \\
3\end{array}$ \\
\hline$\frac{\text { Mezi laurus }}{\text { itauba }}$ & $\begin{array}{l}\mu(v) \\
\mu(12 \%) \\
C V(V) \\
C V(12 \%) \\
s(v) \\
S(12 \%) \\
N(v) \\
N(12 \%)\end{array}$ & $\begin{array}{r}0,70 \\
0,70 \\
11,492 \\
13,093 \\
0,080 \\
0,092 \\
4 \\
3\end{array}$ & $\begin{array}{r}8,65 \\
7,55 \\
28,377 \\
14,746 \\
2,455 \\
1,114 \\
4 \\
3\end{array}$ & $\begin{array}{r}3,61 \\
3,01 \\
46,029 \\
23,069 \\
1,661 \\
0,695 \\
4 \\
3\end{array}$ & $\begin{array}{r}12,96 \\
11,75 \\
32,035 \\
16,931 \\
4,153 \\
1,990 \\
4 \\
3\end{array}$ & $\begin{array}{r}9125 \\
14300 \\
21,276 \\
30,936 \\
1941,4 \\
4423,8 \\
4 \\
3\end{array}$ & $\begin{array}{r}64,85 \\
105,07 \\
23,140 \\
23,425 \\
15,006 \\
24,611 \\
4 \\
3\end{array}$ & $\begin{array}{r}33,75 \\
48,87 \\
21,977 \\
26,910 \\
7,417 \\
13,150 \\
4 \\
3\end{array}$ & $\begin{array}{r}10,75 \\
11,47 \\
16,317 \\
8,243 \\
1,754 \\
0,945 \\
4 \\
3\end{array}$ & $\begin{array}{r}7,85 \\
11,73 \\
21,731 \\
26,135 \\
1,706 \\
3,066 \\
4 \\
3\end{array}$ \\
\hline $\begin{array}{l}\text { Nectandra } \\
\text { rubra }\end{array}$ & $\begin{array}{l}\mu(v) \\
\mu(12 \%) \\
\text { CV }(v) \\
\text { CV }(12 \%) \\
\text { s }(v) \\
\text { s }(12 \%) \\
N(v) \\
N(12 \%)\end{array}$ & $\begin{array}{r}0,52 \\
0,52 \\
3,331 \\
3,331 \\
0,017 \\
0,017 \\
3 \\
3\end{array}$ & $\begin{array}{r}9,21 \\
9,21 \\
29,416 \\
29,416 \\
2,708 \\
2,708 \\
3 \\
3\end{array}$ & $\begin{array}{r}3,08 \\
3,08 \\
20,325 \\
20,325 \\
0,626 \\
0,626 \\
3 \\
3\end{array}$ & $\begin{array}{r}12,75 \\
12,75 \\
27,009 \\
27,009 \\
3,443 \\
3,443 \\
3 \\
3\end{array}$ & $\begin{array}{r}7233 \\
9767 \\
20,799 \\
5,254 \\
1504,4 \\
513,16 \\
3 \\
3\end{array}$ & $\begin{array}{r}57,73 \\
74,57 \\
17,155 \\
12,184 \\
9,904 \\
9,085 \\
3 \\
3\end{array}$ & $\begin{array}{r}31,47 \\
44,20 \\
26,707 \\
20,744 \\
8,404 \\
9,169 \\
3 \\
3\end{array}$ & $\begin{array}{r}4,47 \\
4,37 \\
16,803 \\
42,372 \\
0,751 \\
1,850 \\
3 \\
3\end{array}$ & $\begin{array}{r}6,33 \\
8,27 \\
11,090 \\
6,879 \\
0,702 \\
0,569 \\
3 \\
3\end{array}$ \\
\hline
\end{tabular}


continuação

\begin{tabular}{|c|c|c|c|c|c|c|c|c|c|c|}
\hline$\frac{\text { Pouteria }}{\text { guianensis }}$ & $\begin{array}{l}\mu(v) \\
\mu(12 \%) \\
C V(v) \\
C V(12 \%) \\
s(v) \\
S(12 \%) \\
N(v) \\
N(12 \%)\end{array}$ & $\begin{array}{r}0,92 \\
0,93 \\
8,897 \\
7,306 \\
0,082 \\
0,068 \\
3 \\
4\end{array}$ & $\begin{array}{r}9,33 \\
9,40 \\
10,857 \\
8,912 \\
1,013 \\
0,837 \\
3 \\
4\end{array}$ & $\begin{array}{r}7,64 \\
7,54 \\
2,247 \\
3,277 \\
0,172 \\
0,247 \\
3 \\
4\end{array}$ & $\begin{array}{r}17,95 \\
17,86 \\
6,052 \\
5,059 \\
1,086 \\
0,904 \\
3 \\
4\end{array}$ & $\begin{array}{r}14200 \\
16050 \\
12,279 \\
8,084 \\
1743,6 \\
1297,4 \\
3 \\
4\end{array}$ & $\begin{array}{r}127,87 \\
165,97 \\
6,805 \\
8,237 \\
8,702 \\
13,672 \\
3 \\
4\end{array}$ & $\begin{array}{r}68,967 \\
94,550 \\
20,816 \\
13,045 \\
14,356 \\
12,334 \\
3 \\
4\end{array}$ & $\begin{array}{r}18,800 \\
20,325 \\
6,976 \\
21,041 \\
1,311 \\
4,277 \\
3 \\
4\end{array}$ & $\begin{array}{r}13,967 \\
13,500 \\
16,426 \\
16,902 \\
2,294 \\
2,282 \\
3\end{array}$ \\
\hline $\begin{array}{l}\text { Pithece lobium } \\
\text { racemosum }\end{array}$ & $\begin{array}{l}\mu(v) \\
\mu(12 \%) \\
C V(V) \\
C V(12 \%) \\
s(V) \\
\text { s }(12 \%) \\
N(v) \\
N(12 \%)\end{array}$ & $\begin{array}{r}0,78 \\
0,84 \\
3,240 \\
7,204 \\
0,025 \\
0,060 \\
3 \\
3\end{array}$ & $\begin{array}{r}12,47 \\
12,05 \\
7,234 \\
13,187 \\
0,902 \\
1,590 \\
3 \\
3\end{array}$ & $\begin{array}{r}6,43 \\
6,78 \\
8,503 \\
11,839 \\
0,547 \\
0,803 \\
3 \\
3\end{array}$ & $\begin{array}{r}19,85 \\
19,43 \\
7,158 \\
10,664 \\
1,421 \\
2,072 \\
3 \\
3\end{array}$ & $\begin{array}{r}11700 \\
13800 \\
3,082 \\
10,222 \\
360,56 \\
1410,7 \\
3 \\
3\end{array}$ & $\begin{array}{r}84,60 \\
126,13 \\
11,227 \\
35,191 \\
9,498 \\
44,388 \\
3 \\
3\end{array}$ & $\begin{array}{r}54,93 \\
80,53 \\
5,333 \\
31,356 \\
2,930 \\
25,252 \\
3 \\
3\end{array}$ & $\begin{array}{r}12,70 \\
15,33 \\
33,304 \\
6,788 \\
4,230 \\
1,041 \\
3 \\
3\end{array}$ & $\begin{array}{r}11,23 \\
19,37 \\
17,812 \\
20,938 \\
2,001 \\
4,055 \\
3 \\
3\end{array}$ \\
\hline $\begin{array}{l}\text { Qualea } \\
\text { paraens is }\end{array}$ & $\begin{array}{l}\mu(v) \\
\mu(12 \%) \\
C V(v) \\
C V(12 \%) \\
s(v) \\
s(12 \%) \\
N(v) \\
N(12 \%)\end{array}$ & $\begin{array}{r}0,69 \\
0,69 \\
6,063 \\
5,917 \\
0,042 \\
0,041 \\
5 \\
4\end{array}$ & $\begin{array}{r}11,66 \\
11,69 \\
16,024 \\
15,870 \\
1,868 \\
1,855 \\
5 \\
4\end{array}$ & $\begin{array}{r}5,85 \\
6,39 \\
10,695 \\
3,399 \\
0,626 \\
0,217 \\
5 \\
4\end{array}$ & $\begin{array}{r}18,43 \\
19,12 \\
12,884 \\
9,511 \\
2,374 \\
1,818 \\
5 \\
4\end{array}$ & $\begin{array}{r}11680 \\
11750 \\
6,245 \\
17,723 \\
729,38 \\
2082,5 \\
5 \\
4\end{array}$ & $\begin{array}{r}80,44 \\
100,62 \\
14,066 \\
16,524 \\
11,315 \\
16,628 \\
5 \\
4\end{array}$ & $\begin{array}{r}47,50 \\
57,98 \\
23,057 \\
19,918 \\
10,952 \\
11,547 \\
5 \\
4\end{array}$ & $\begin{array}{r}10,32 \\
8,93 \\
12,604 \\
17,295 \\
1,301 \\
1,544 \\
5 \\
4\end{array}$ & $\begin{array}{r}10,20 \\
12,78 \\
16,867 \\
8,018 \\
1,720 \\
1,024 \\
5 \\
4\end{array}$ \\
\hline$\frac{\text { Simaruba }}{\text { amara }}$ & $\begin{array}{l}\mu(v) \\
\mu(12 \%) \\
C V(V) \\
C V(12 \%) \\
s(V) \\
s(12 \%) \\
N(v) \\
N(12 \%)\end{array}$ & $\begin{array}{r}0,35 \\
0,35 \\
8,204 \\
8,204 \\
0,029 \\
0,029 \\
6 \\
6\end{array}$ & $\begin{array}{r}5,91 \\
5,91 \\
5,031 \\
5,031 \\
0,297 \\
0,297 \\
6 \\
6\end{array}$ & $\begin{array}{r}2,29 \\
2,29 \\
7,525 \\
7,525 \\
0,172 \\
0,172 \\
6 \\
6\end{array}$ & $\begin{array}{r}8,89 \\
8,89 \\
3,775 \\
3,775 \\
0,335 \\
0,335 \\
6 \\
6\end{array}$ & $\begin{array}{r}6816 \\
7450 \\
16,941 \\
9,670 \\
1154,8 \\
720,42 \\
6 \\
6\end{array}$ & $\begin{array}{r}39,97 \\
56,18 \\
8,626 \\
28,349 \\
3,448 \\
15,927 \\
6 \\
6\end{array}$ & $\begin{array}{r}17,98 \\
31,30 \\
12,271 \\
12,577 \\
2,207 \\
3,936 \\
6 \\
6\end{array}$ & $\begin{array}{r}2,32 \\
4,42 \\
23,392 \\
26,108 \\
0,542 \\
1,153 \\
6 \\
6\end{array}$ & $\begin{array}{r}5,80 \\
7,88 \\
21,562 \\
26,039 \\
1,251 \\
2,053 \\
6 \\
6\end{array}$ \\
\hline $\begin{array}{l}\text { Scleronema } \\
\text { micranthum }\end{array}$ & $\begin{array}{l}\mu(v) \\
\mu(12 \%) \\
\text { CV }(v) \\
\text { CV }(12 \%) \\
S(v) \\
S(12 \%) \\
N(v) \\
N(12 \%)\end{array}$ & $\begin{array}{r}0,59 \\
0,59 \\
1,904 \\
2,259 \\
0,011 \\
0,013 \\
8 \\
5\end{array}$ & $\begin{array}{r}10,64 \\
10,91 \\
8,151 \\
9,412 \\
0,867 \\
1,027 \\
8 \\
5\end{array}$ & $\begin{array}{r}5,00 \\
5,32 \\
21,873 \\
24,331 \\
1,093 \\
1,294 \\
8 \\
5\end{array}$ & $\begin{array}{r}16,52 \\
17,17 \\
11,778 \\
13,109 \\
1,945 \\
2,250 \\
8 \\
5\end{array}$ & $\begin{array}{r}10900 \\
11860 \\
7,224 \\
10,808 \\
787,40 \\
1281,8 \\
8 \\
5\end{array}$ & $\begin{array}{r}78,78 \\
94,58 \\
10,995 \\
13,900 \\
8,662 \\
13,147 \\
8 \\
5\end{array}$ & $\begin{array}{r}39,53 \\
62,10 \\
12,772 \\
7,834 \\
5,048 \\
4,865 \\
8 \\
5\end{array}$ & $\begin{array}{r}5,54 \\
7,64 \\
12,397 \\
14,505 \\
0,686 \\
1,108 \\
8 \\
5\end{array}$ & $\begin{array}{r}8,85 \\
9,38 \\
8,058 \\
12,304 \\
0,713 \\
1,154 \\
8 \\
5\end{array}$ \\
\hline$\frac{\text { Swartzia }}{\text { panacoco }}$ & $\begin{array}{l}\mu(v) \\
\mu(12 \%) \\
C V(v) \\
C V(12 \%) \\
s(v) \\
s(12 \%) \\
N(v) \\
N(12 \%)\end{array}$ & $\begin{array}{r}1,00 \\
0,99 \\
5,239 \\
14,417 \\
0,053 \\
0,142 \\
4 \\
4\end{array}$ & $\begin{array}{r}9,86 \\
9,73 \\
4,454 \\
3,333 \\
0,439 \\
0,324 \\
4 \\
4\end{array}$ & $\begin{array}{r}6,65 \\
6,71 \\
9,172 \\
4,247 \\
0,610 \\
0,285 \\
4 \\
4\end{array}$ & $\begin{array}{r}17,66 \\
17,19 \\
8,289 \\
1,376 \\
1,464 \\
0,236 \\
4 \\
4\end{array}$ & $\begin{array}{r}16525 \\
16300 \\
7,450 \\
7,102 \\
1231,2 \\
1157,6 \\
4 \\
4\end{array}$ & $\begin{array}{r}137,37 \\
184,43 \\
2,695 \\
7,919 \\
3,703 \\
14,604 \\
4 \\
4\end{array}$ & $\begin{array}{r}74,80 \\
107,80 \\
2,599 \\
10,456 \\
1,944 \\
11,271 \\
4 \\
4\end{array}$ & $\begin{array}{r}23,90 \\
25,25 \\
6,400 \\
18,504 \\
1,530 \\
4,672 \\
4 \\
4\end{array}$ & $\begin{array}{r}12,80 \\
19,10 \\
16,175 \\
30,912 \\
2,070 \\
5,904 \\
4 \\
4\end{array}$ \\
\hline$\frac{\text { Tabebuia }}{\text { serratifol ia }}$ & $\begin{array}{l}\mu(v) \\
\mu(12 \%) \\
C V(v) \\
C V(12 \%) \\
s(v) \\
S(12 \%) \\
N(v) \\
N(12 \%)\end{array}$ & $\begin{array}{r}0,90 \\
0,90 \\
8,364 \\
8,364 \\
0,075 \\
0,075 \\
4 \\
4\end{array}$ & $\begin{array}{r}10,36 \\
10,36 \\
8,730 \\
8,730 \\
0,905 \\
0,905 \\
4 \\
4\end{array}$ & $\begin{array}{r}7,59 \\
7,59 \\
8,954 \\
8,954 \\
0,680 \\
0,680 \\
4 \\
4\end{array}$ & $\begin{array}{r}18,88 \\
18,88 \\
8,267 \\
8,267 \\
1,561 \\
1,561 \\
4 \\
4\end{array}$ & $\begin{array}{r}14775 \\
16925 \\
6,063 \\
3,177 \\
895,82 \\
537,74 \\
4 \\
4\end{array}$ & $\begin{array}{r}167,22 \\
204,62 \\
6,292 \\
13,030 \\
10,522 \\
26,662 \\
4 \\
4\end{array}$ & $\begin{array}{r}80,00 \\
102,05 \\
18,510 \\
8,281 \\
14,808 \\
8,451 \\
4 \\
4\end{array}$ & $\begin{array}{r}20,13 \\
24,70 \\
17,258 \\
17,253 \\
3,473 \\
4,261 \\
4 \\
4\end{array}$ & $\begin{array}{r}17,50 \\
18,88 \\
7,421 \\
3,629 \\
1,299 \\
0,685 \\
4 \\
4\end{array}$ \\
\hline
\end{tabular}


continuação

\begin{tabular}{llrrrrrrrrr}
\hline Vataireopsis & $\mu(v)$ & 0,69 & 9,12 & 5,68 & 15,54 & 12940 & 107,38 & 61,82 & 9,72 & 11,80 \\
sp. & $\mu(12 \%)$ & 0,68 & 8,97 & 5,65 & 15,19 & 12775 & 138,00 & 70,18 & 15,28 & 13,20 \\
& CV (v) & 7,476 & 8,643 & 10,712 & 8,743 & 10,951 & 4,614 & 11,049 & 2,761 & 14,703 \\
& CV (12\%) & 7,845 & 9,341 & 11,373 & 9,544 & 7,518 & 10,580 & 17,447 & 7,566 & 9,603 \\
& S (v) & 0,051 & 0,788 & 0,608 & 1,358 & 1417,0 & 4,954 & 6,831 & 0,268 & 1,735 \\
& S (12\%) & 0,053 & 0,838 & 0,643 & 1,450 & 960,47 & 14,601 & 12,243 & 1,156 & 1,268 \\
& N (v) & 5 & 5 & 5 & 5 & 5 & 5 & 5 & 5 & 5 \\
& N (12\%) & 4 & 4 & 4 & 4 & 4 & 4 & 4 & 4 & 4 \\
\hline
\end{tabular}


Espécies originárias da região de Curuá-Una

\begin{tabular}{|c|c|c|c|c|c|c|c|c|c|c|}
\hline $\begin{array}{c}\text { Nome } \\
\text { Cientifico }\end{array}$ & & $\mathrm{Db}$ & Rt & $\mathrm{Rr}$ & RV & $E_{f}$ & $f_{f}$ & $f_{c}$ & $f_{\text {cn }}$ & $f_{s}$ \\
\hline $\begin{array}{l}\text { Aniba } \\
\text { canetilla }\end{array}$ & $\begin{array}{l}\mu(v) \\
\mu(12 \%) \\
C V(v) \\
C V(12 \%) \\
s(v) \\
S(12 \%) \\
N(v) \\
N(12 \%)\end{array}$ & $\begin{array}{r}0,94 \\
0,94 \\
8,018 \\
8,926 \\
0,075 \\
0,084 \\
6 \\
5\end{array}$ & $\begin{array}{r}8,26 \\
8,34 \\
10,965 \\
11,806 \\
0,905 \\
0,985 \\
6 \\
5\end{array}$ & $\begin{array}{r}6,27 \\
6,34 \\
16,823 \\
18,424 \\
1,055 \\
1,167 \\
6 \\
5\end{array}$ & $\begin{array}{r}13,70 \\
14,20 \\
10,008 \\
16,403 \\
1,371 \\
2,329 \\
6 \\
5\end{array}$ & $\begin{array}{r}16750 \\
18460 \\
7,981 \\
2,317 \\
1336,8 \\
427,78 \\
6 \\
5\end{array}$ & $\begin{array}{r}147,82 \\
186,66 \\
10,696 \\
7,020 \\
15,811 \\
13,104 \\
6 \\
5\end{array}$ & $\begin{array}{r}75,82 \\
97,82 \\
16,056 \\
6,073 \\
12,173 \\
5,941 \\
6 \\
5\end{array}$ & $\begin{array}{r}15,47 \\
20,60 \\
14,781 \\
12,659 \\
2,286 \\
2,608 \\
6 \\
5\end{array}$ & $\begin{array}{r}14,85 \\
18,52 \\
16,087 \\
17,581 \\
2,389 \\
3,256 \\
6 \\
5\end{array}$ \\
\hline$\frac{\text { Astronium }}{\text { gracile }}$ & $\begin{array}{l}\mu(v) \\
\mu(12 \%) \\
C V(v) \\
C V(12 \%) \\
S(v) \\
S(12 \%) \\
N(v) \\
N(12 \%)\end{array}$ & $\begin{array}{r}0,73 \\
0,73 \\
17,436 \\
17,436 \\
0,127 \\
0,127 \\
2 \\
2\end{array}$ & $\begin{array}{r}8,04 \\
8,04 \\
13,641 \\
13,641 \\
1,096 \\
1,096 \\
2 \\
2\end{array}$ & $\begin{array}{r}5,27 \\
5,27 \\
45,529 \\
45,529 \\
2,397 \\
2,397 \\
2 \\
2\end{array}$ & $\begin{array}{r}11,95 \\
11,95 \\
15,976 \\
15,976 \\
1,909 \\
1,909 \\
2 \\
2\end{array}$ & $\begin{array}{r}13800 \\
16250 \\
7,174 \\
5,657 \\
989,95 \\
919,24 \\
2 \\
2\end{array}$ & $\begin{array}{r}90,55 \\
133,25 \\
2,265 \\
5,254 \\
2,051 \\
7,000 \\
2 \\
2\end{array}$ & $\begin{array}{r}49,00 \\
71,50 \\
2,020 \\
3,560 \\
0,990 \\
2,546 \\
2 \\
2\end{array}$ & $\begin{array}{r}7,70 \\
9,95 \\
34,896 \\
9,239 \\
2,687 \\
0,919 \\
2 \\
2\end{array}$ & $\begin{array}{r}11,30 \\
17,05 \\
21,276 \\
4,562 \\
2,404 \\
0,778 \\
2 \\
2\end{array}$ \\
\hline $\begin{array}{l}\text { Astronium } \\
\text { lecointei } \\
\end{array}$ & $\begin{array}{l}\mu(v) \\
\mu(12 \%) \\
C V(v) \\
C V(12 \%) \\
s(v) \\
S(12 \%) \\
N(v) \\
N(12 \%)\end{array}$ & $\begin{array}{r}0,79 \\
0,82 \\
7,145 \\
4,878 \\
0,056 \\
0,040 \\
5 \\
3\end{array}$ & $\begin{array}{r}6,89 \\
7,93 \\
27,018 \\
12,559 \\
1,861 \\
0,996 \\
5 \\
3\end{array}$ & $\begin{array}{r}4,63 \\
4,96 \\
24,870 \\
27,509 \\
1,152 \\
1,365 \\
5 \\
3\end{array}$ & $\begin{array}{r}12,05 \\
12,23 \\
8,060 \\
9,004 \\
0,971 \\
1,102 \\
4 \\
3\end{array}$ & $\begin{array}{r}13180 \\
15433 \\
10,682 \\
4,949 \\
1407,8 \\
763,76 \\
5 \\
3\end{array}$ & $\begin{array}{r}104,24 \\
135,47 \\
22,173 \\
29,037 \\
23,113 \\
39,336 \\
5 \\
3\end{array}$ & $\begin{array}{r}52,30 \\
84,53 \\
17,549 \\
9,643 \\
9,178 \\
8,151 \\
5 \\
3\end{array}$ & $\begin{array}{r}9,86 \\
14,70 \\
18,123 \\
0,680 \\
1,787 \\
0,100 \\
5 \\
3\end{array}$ & $\begin{array}{r}13,66 \\
17,57 \\
10,976 \\
5,925 \\
1,499 \\
1,041 \\
5 \\
3\end{array}$ \\
\hline$\frac{\text { Astronium }}{\text { ulei. }}$ & $\begin{array}{l}\mu(v) \\
\mu(12 \%) \\
C V(v) \\
C V(12 \%) \\
S(v) \\
S(12 \%) \\
N(v) \\
N(12 \%)\end{array}$ & $\begin{array}{r}0,71 \\
0,71 \\
15,935 \\
15,935 \\
0,113 \\
0,113 \\
2 \\
2\end{array}$ & $\begin{array}{r}8,07 \\
8,07 \\
7,886 \\
7,886 \\
0,636 \\
0,636 \\
2 \\
2\end{array}$ & $\begin{array}{r}4,28 \\
4,28 \\
12,405 \\
12,405 \\
0,530 \\
0,530 \\
2 \\
2\end{array}$ & $\begin{array}{r}12,25 \\
12,25 \\
7,504 \\
7,504 \\
0,919 \\
0,919 \\
2 \\
2\end{array}$ & $\begin{array}{r}13200 \\
13350 \\
0 \\
13,242 \\
0 \\
1767,8 \\
2 \\
2\end{array}$ & $\begin{array}{r}89,20 \\
110,95 \\
21,403 \\
13,957 \\
19,092 \\
15,486 \\
2 \\
2\end{array}$ & $\begin{array}{r}45,85 \\
81,00 \\
5,706 \\
4,889 \\
2,616 \\
3,960 \\
2 \\
2\end{array}$ & $\begin{array}{r}6,10 \\
15,00 \\
11,592 \\
0 \\
0,707 \\
0 \\
2 \\
2\end{array}$ & $\begin{array}{r}14,70 \\
20,85 \\
0,962 \\
13,905 \\
0,141 \\
2,899 \\
2 \\
2\end{array}$ \\
\hline$\frac{\text { Brosimum }}{\text { al icastrum }}$ & $\begin{array}{l}\mu(v) \\
\mu(12 \%) \\
C V(v) \\
C V(12 \%) \\
s(v) \\
S(12 \%) \\
N(v) \\
N(12 \%)\end{array}$ & $\begin{array}{r}0,72 \\
0,72 \\
4,945 \\
4,945 \\
0,035 \\
0,035 \\
2 \\
2\end{array}$ & $\begin{array}{r}8,93 \\
8,93 \\
8,477 \\
8,477 \\
0,757 \\
0,757 \\
2 \\
2\end{array}$ & $\begin{array}{r}5,56 \\
5,56 \\
0,127 \\
0,127 \\
0,007 \\
0,007 \\
2 \\
2\end{array}$ & $\begin{array}{r}16,65 \\
16,65 \\
16,563 \\
16,563 \\
2,758 \\
2,758 \\
2 \\
2\end{array}$ & $\begin{array}{r}13700 \\
16300 \\
1,032 \\
9,544 \\
141,42 \\
1555,6 \\
2 \\
2\end{array}$ & $\begin{array}{r}97,05 \\
155,65 \\
3,133 \\
7,587 \\
3,041 \\
11,809 \\
2 \\
2\end{array}$ & $\begin{array}{r}44,50 \\
87,85 \\
5,403 \\
0,080 \\
2,404 \\
0,071 \\
2 \\
2\end{array}$ & $\begin{array}{r}6,45 \\
11,40 \\
23,022 \\
9,924 \\
1,485 \\
1,131 \\
2 \\
2\end{array}$ & $\begin{array}{r}11,05 \\
15,10 \\
26,237 \\
1,873 \\
2,899 \\
0,283 \\
2 \\
2\end{array}$ \\
\hline$\frac{\text { Bowdichia }}{\text { nitida }}$ & $\begin{array}{l}\mu(v) \\
\mu(12 \%) \\
C V(v) \\
C V(12 \%) \\
s(v) \\
S(12 \%) \\
N(v) \\
N(12 \%)\end{array}$ & $\begin{array}{r}0,84 \\
0,87 \\
8,031 \\
1,991 \\
0,068 \\
0,017 \\
6 \\
7\end{array}$ & $\begin{array}{r}8,75 \\
9,13 \\
19,791 \\
10,943 \\
1,732 \\
0,999 \\
6 \\
7\end{array}$ & $\begin{array}{r}6,14 \\
6,30 \\
14,683 \\
11,331 \\
0,902 \\
0,713 \\
6 \\
7\end{array}$ & $\begin{array}{r}14,82 \\
14,74 \\
15,021 \\
9,921 \\
2,226 \\
1,463 \\
6 \\
7\end{array}$ & $\begin{array}{r}16500 \\
18200 \\
8,866 \\
5,145 \\
1462,9 \\
936,30 \\
6 \\
7\end{array}$ & $\begin{array}{r}128,93 \\
190,74 \\
19,493 \\
9,664 \\
25,134 \\
18,433 \\
6 \\
7\end{array}$ & $\begin{array}{r}70,38 \\
93,90 \\
11,945 \\
7,998 \\
8,407 \\
7,510 \\
6 \\
7\end{array}$ & $\begin{array}{r}10,67 \\
16,59 \\
13,761 \\
15,499 \\
1,468 \\
2,571 \\
6 \\
7\end{array}$ & $\begin{array}{r}13,60 \\
19,31 \\
16,083 \\
12,866 \\
2,187 \\
2,485 \\
6 \\
7\end{array}$ \\
\hline
\end{tabular}


continuação

\begin{tabular}{|c|c|c|c|c|c|c|c|c|c|c|}
\hline $\begin{array}{l}\text { Couratari } \\
\text { oblongifol ia }\end{array}$ & $\begin{array}{l}\mu(v) \\
\mu(12 \%) \\
C V(V) \\
C V(12 \%) \\
S(v) \\
S(12 \%) \\
N(v) \\
N(12 \%)\end{array}$ & $\begin{array}{r}0,52 \\
0,48 \\
9,944 \\
6,063 \\
0,052 \\
0,029 \\
6 \\
7\end{array}$ & $\begin{array}{r}6,48 \\
6,58 \\
12,159 \\
8,432 \\
0,787 \\
0,554 \\
6 \\
7\end{array}$ & $\begin{array}{r}4,10 \\
4,16 \\
18,132 \\
17,950 \\
0,744 \\
0,746 \\
6 \\
7\end{array}$ & $\begin{array}{r}11,03 \\
10,64 \\
6,871 \\
5,788 \\
0,758 \\
0,616 \\
6 \\
7\end{array}$ & $\begin{array}{r}10533 \\
10657 \\
14,026 \\
7,640 \\
1477,4 \\
814,16 \\
6 \\
7\end{array}$ & $\begin{array}{r}68,67 \\
80,54 \\
15,646 \\
26,192 \\
10,744 \\
21,096 \\
6 \\
7\end{array}$ & $\begin{array}{r}31,60 \\
45,47 \\
18,557 \\
15,779 \\
5,864 \\
7,175 \\
6 \\
7\end{array}$ & $\begin{array}{r}4,60 \\
6,60 \\
17,227 \\
19,639 \\
0,792 \\
1,296 \\
6 \\
7\end{array}$ & $\begin{array}{r}8,75 \\
9,83 \\
18,636 \\
15,405 \\
1,631 \\
1,514 \\
6 \\
7\end{array}$ \\
\hline$\frac{\text { Clarisia }}{\text { racemosa }}$ & $\begin{array}{l}\mu(v) \\
\mu(12 \%) \\
\text { CV }(v) \\
\text { CV }(12 \%) \\
S(v) \\
\text { S }(12 \%) \\
N(v) \\
N(12 \%)\end{array}$ & $\begin{array}{r}0,60 \\
0,60 \\
8,847 \\
12,298 \\
0,053 \\
0,074 \\
5 \\
8\end{array}$ & $\begin{array}{r}6,21 \\
6,14 \\
7,124 \\
14,898 \\
0,442 \\
0,914 \\
5 \\
8\end{array}$ & $\begin{array}{r}3,17 \\
3,00 \\
10,816 \\
14,257 \\
0,343 \\
0,428 \\
5 \\
8\end{array}$ & $\begin{array}{r}9,52 \\
9,77 \\
9,079 \\
9,686 \\
0,864 \\
0,946 \\
5 \\
7\end{array}$ & $\begin{array}{r}11100 \\
12388 \\
3,927 \\
5,986 \\
435,89 \\
741,50 \\
5 \\
8\end{array}$ & $\begin{array}{r}87,86 \\
113,12 \\
12,972 \\
12,624 \\
11,397 \\
14,281 \\
5 \\
8\end{array}$ & $\begin{array}{r}47,30 \\
66,78 \\
8,237 \\
14,726 \\
3,896 \\
9,834 \\
5 \\
8\end{array}$ & $\begin{array}{r}7,58 \\
9,44 \\
18,432 \\
10,952 \\
1,397 \\
1,034 \\
5 \\
8\end{array}$ & $\begin{array}{r}10,40 \\
12,25 \\
8,627 \\
17,101 \\
0,897 \\
2,095 \\
5 \\
8\end{array}$ \\
\hline $\begin{array}{l}\text { Cassia } \\
\text { scleroxylon }\end{array}$ & $\begin{array}{l}\mu(v) \\
\mu(12 \%) \\
\text { CV }(v) \\
\text { CV }(12 \%) \\
\text { S (V) } \\
\text { S }(12 \%) \\
N(v) \\
N(12 \%)\end{array}$ & $\begin{array}{r}0,98 \\
1,00 \\
2,744 \\
5,447 \\
0,027 \\
0,055 \\
5 \\
6\end{array}$ & $\begin{array}{r}7,78 \\
7,74 \\
8,688 \\
10,333 \\
0,676 \\
0,800 \\
5 \\
6\end{array}$ & $\begin{array}{r}4,25 \\
4,52 \\
14,557 \\
22,443 \\
0,618 \\
1,014 \\
5 \\
6\end{array}$ & $\begin{array}{r}10,84 \\
11,47 \\
10,490 \\
7,248 \\
1,137 \\
0,831 \\
5 \\
6\end{array}$ & $\begin{array}{r}15460 \\
17150 \\
7,662 \\
12,800 \\
1184,5 \\
2195,2 \\
5 \\
6\end{array}$ & $\begin{array}{r}130,78 \\
185,38 \\
6,523 \\
9,244 \\
8,531 \\
17,136 \\
5 \\
6\end{array}$ & $\begin{array}{r}78,22 \\
97,38 \\
10,289 \\
6,437 \\
8,048 \\
6,268 \\
5 \\
6\end{array}$ & $\begin{array}{r}19,96 \\
21,90 \\
30,101 \\
9,273 \\
6,008 \\
2,031 \\
5 \\
6\end{array}$ & $\begin{array}{r}16,96 \\
19,88 \\
13,957 \\
10,353 \\
2,367 \\
2,059 \\
5 \\
6\end{array}$ \\
\hline$\frac{\text { Dinizia }}{\text { excelsa }}$ & $\begin{array}{l}\mu(v) \\
\mu(12 \%) \\
\text { CV }(v) \\
\text { CV }(12 \%) \\
\text { S }(v) \\
\text { S }(12 \%) \\
N(v) \\
N(12 \%)\end{array}$ & $\begin{array}{r}0,81 \\
0,84 \\
6,665 \\
6,682 \\
0,054 \\
0,056 \\
8 \\
9\end{array}$ & $\begin{array}{r}9,38 \\
9,61 \\
7,191 \\
7,476 \\
0,674 \\
0,719 \\
8 \\
9\end{array}$ & $\begin{array}{r}5,57 \\
5,51 \\
19,317 \\
15,936 \\
1,077 \\
0,878 \\
8 \\
9\end{array}$ & $\begin{array}{r}14,34 \\
14,71 \\
10,351 \\
9,317 \\
1,484 \\
1,371 \\
8 \\
9\end{array}$ & $\begin{array}{r}16013 \\
17167 \\
15,097 \\
8,492 \\
2417,5 \\
1457,7 \\
8 \\
9\end{array}$ & $\begin{array}{r}118,30 \\
160,00 \\
7,366 \\
15,189 \\
8,714 \\
24,303 \\
8 \\
9\end{array}$ & $\begin{array}{r}61,66 \\
86,24 \\
9,759 \\
13,199 \\
6,018 \\
11,383 \\
8 \\
9\end{array}$ & $\begin{array}{r}10,30 \\
14,60 \\
19,666 \\
16,410 \\
2,026 \\
2,396 \\
8 \\
9\end{array}$ & $\begin{array}{r}12,86 \\
17,73 \\
12,285 \\
16,334 \\
1,580 \\
2,897 \\
8 \\
9\end{array}$ \\
\hline $\begin{array}{l}\text { Dial ium } \\
\text { guianense }\end{array}$ & $\begin{array}{l}\mu(v) \\
\mu(12 \%) \\
\text { CV }(v) \\
\text { CV }(12 \%) \\
\text { S }(v) \\
\text { S }(12 \%) \\
N(v) \\
N(12 \%)\end{array}$ & $\begin{array}{r}0,90 \\
0,92 \\
8,422 \\
4,936 \\
0,076 \\
0,046 \\
5 \\
5\end{array}$ & $\begin{array}{r}8,70 \\
8,08 \\
19,490 \\
14,808 \\
1,696 \\
1,197 \\
5 \\
5\end{array}$ & $\begin{array}{r}4,73 \\
4,63 \\
18,624 \\
18,933 \\
0,881 \\
0,877 \\
5 \\
5\end{array}$ & $\begin{array}{r}13,46 \\
12,96 \\
8,046 \\
3,843 \\
1,083 \\
0,498 \\
5 \\
5\end{array}$ & $\begin{array}{r}15660 \\
17980 \\
10,062 \\
3,999 \\
1575,8 \\
719,03 \\
5 \\
5\end{array}$ & $\begin{array}{r}144,32 \\
203,00 \\
19,021 \\
14,137 \\
27,451 \\
28,697 \\
5 \\
5\end{array}$ & $\begin{array}{r}66,52 \\
99,58 \\
24,187 \\
7,413 \\
16,089 \\
7,382 \\
5 \\
5\end{array}$ & $\begin{array}{r}15,42 \\
22,60 \\
13,230 \\
16,662 \\
2,040 \\
3,766 \\
5 \\
5\end{array}$ & $\begin{array}{r}14,66 \\
23,76 \\
19,115 \\
15,758 \\
2,802 \\
3,744 \\
5 \\
5\end{array}$ \\
\hline $\begin{array}{l}\text { Didymopanax } \\
\text { morototoni }\end{array}$ & $\begin{array}{l}\mu(v) \\
\mu(12 \%) \\
C V(V) \\
C V(12 \%) \\
S(V) \\
S(12 \%) \\
N(v) \\
N(12 \%)\end{array}$ & $\begin{array}{r}0,41 \\
0,40 \\
14,756 \\
12,457 \\
0,060 \\
0,050 \\
8 \\
8\end{array}$ & $\begin{array}{r}9,27 \\
9,24 \\
16,070 \\
14,424 \\
1,490 \\
1,333 \\
8 \\
7\end{array}$ & $\begin{array}{r}6,28 \\
6,39 \\
17,614 \\
21,543 \\
1,106 \\
1,377 \\
8 \\
7\end{array}$ & $\begin{array}{r}16,21 \\
16,03 \\
17,930 \\
12,979 \\
2,907 \\
2,081 \\
8 \\
6\end{array}$ & $\begin{array}{r}9250 \\
11475 \\
16,426 \\
11,531 \\
1519,4 \\
1323,1 \\
8 \\
8\end{array}$ & $\begin{array}{r}40,19 \\
75,35 \\
14,440 \\
17,792 \\
5,803 \\
13,406 \\
8 \\
8\end{array}$ & $\begin{array}{r}17,85 \\
41,79 \\
17,563 \\
19,398 \\
3,135 \\
8,106 \\
8 \\
8\end{array}$ & $\begin{array}{r}2,04 \\
4,40 \\
22,096 \\
19,551 \\
0,450 \\
0,860 \\
8 \\
8\end{array}$ & $\begin{array}{r}6,38 \\
10,48 \\
12,928 \\
9,039 \\
0,824 \\
0,947 \\
8 \\
8\end{array}$ \\
\hline $\begin{array}{l}\text { Dipteryx } \\
\text { odorata }\end{array}$ & $\begin{array}{l}\mu(v) \\
\mu(12 \%) \\
C V(V) \\
C V(12 \%) \\
s(v) \\
\text { S }(12 \%) \\
N(V) \\
N(12 \%)\end{array}$ & $\begin{array}{r}0,91 \\
0,91 \\
4,927 \\
3,584 \\
0,045 \\
0,033 \\
8 \\
7\end{array}$ & $\begin{array}{r}8,72 \\
8,61 \\
9,268 \\
8,620 \\
0,808 \\
0,742 \\
8 \\
7\end{array}$ & $\begin{array}{r}5,59 \\
5,48 \\
10,584 \\
9,888 \\
0,591 \\
0,541 \\
8 \\
7\end{array}$ & $\begin{array}{r}13,81 \\
13,88 \\
6,999 \\
7,491 \\
0,967 \\
1,040 \\
7 \\
6\end{array}$ & $\begin{array}{r}17850 \\
17571 \\
18,922 \\
8,146 \\
3377,7 \\
1431,4 \\
8 \\
7\end{array}$ & $\begin{array}{r}139,65 \\
172,83 \\
8,304 \\
18,274 \\
11,596 \\
31,582 \\
8 \\
7\end{array}$ & $\begin{array}{r}71,11 \\
97,31 \\
9,276 \\
12,550 \\
6,596 \\
12,213 \\
8 \\
7\end{array}$ & $\begin{array}{r}16,48 \\
20,40 \\
21,725 \\
10,298 \\
3,579 \\
2,101 \\
8 \\
7\end{array}$ & $\begin{array}{r}16,85 \\
20,57 \\
10,550 \\
18,824 \\
1,778 \\
3,872 \\
8 \\
7\end{array}$ \\
\hline
\end{tabular}


continuação

\begin{tabular}{|c|c|c|c|c|c|c|c|c|c|c|}
\hline $\begin{array}{l}\text { Drypetes } \\
\text { variabi lis }\end{array}$ & $\begin{array}{l}\mu(v) \\
\mu(12 \%) \\
C V(v) \\
C V(12 \%) \\
s(v) \\
s(12 \%) \\
N(v) \\
N(12 \%)\end{array}$ & $\begin{array}{r}0,71 \\
0,69 \\
4,564 \\
4,501 \\
0,032 \\
0,031 \\
5 \\
5\end{array}$ & $\begin{array}{r}10,90 \\
10,95 \\
4,516 \\
14,887 \\
0,492 \\
1,630 \\
5 \\
5\end{array}$ & $\begin{array}{r}5,39 \\
5,62 \\
18,483 \\
15,536 \\
0,997 \\
0,873 \\
5 \\
5\end{array}$ & $\begin{array}{r}16,00 \\
16,12 \\
5,913 \\
10,811 \\
0,946 \\
1,743 \\
5 \\
5\end{array}$ & $\begin{array}{r}13280 \\
15800 \\
11,300 \\
13,193 \\
1500,7 \\
2084,5 \\
5 \\
5\end{array}$ & $\begin{array}{r}94,50 \\
141,54 \\
13,001 \\
17,272 \\
12,286 \\
24,447 \\
5 \\
5\end{array}$ & $\begin{array}{r}42,92 \\
71,88 \\
11,518 \\
17,055 \\
4,943 \\
12,259 \\
5 \\
5\end{array}$ & $\begin{array}{r}7,64 \\
11,56 \\
16,598 \\
10,118 \\
1,268 \\
1,170 \\
5 \\
5\end{array}$ & $\begin{array}{r}11,32 \\
15,54 \\
9,944 \\
18,295 \\
1,126 \\
2,843 \\
5 \\
5\end{array}$ \\
\hline $\begin{array}{l}\text { Diploon } \\
\text { venezuel ana }\end{array}$ & $\begin{array}{l}\mu(v) \\
\mu(12 \%) \\
C V(v) \\
C V(12 \%) \\
s(v) \\
S s(12 \%) \\
N(v) \\
N(12 \%)\end{array}$ & $\begin{array}{r}0,89 \\
0,89 \\
6,804 \\
6,804 \\
0,061 \\
0,061 \\
4 \\
4\end{array}$ & $\begin{array}{r}9,99 \\
9,99 \\
13,049 \\
13,049 \\
1,304 \\
1,304 \\
4 \\
4\end{array}$ & $\begin{array}{r}7,23 \\
7,23 \\
11,695 \\
11,695 \\
0,845 \\
0,845 \\
4 \\
4\end{array}$ & $\begin{array}{r}16,13 \\
16,13 \\
3,734 \\
3,734 \\
0,602 \\
0,602 \\
4 \\
4\end{array}$ & $\begin{array}{r}15150 \\
18350 \\
16,396 \\
7,209 \\
2483,9 \\
1322,9 \\
4 \\
4\end{array}$ & $\begin{array}{r}124,75 \\
189,65 \\
11,207 \\
8,762 \\
13,981 \\
16,617 \\
4 \\
4\end{array}$ & $\begin{array}{r}58,20 \\
101,20 \\
19,661 \\
7,386 \\
11,443 \\
7,475 \\
4 \\
4\end{array}$ & $\begin{array}{r}16,25 \\
19,10 \\
24,766 \\
19,604 \\
4,025 \\
3,744 \\
4 \\
4\end{array}$ & $\begin{array}{r}13,05 \\
20,33 \\
17,965 \\
20,685 \\
2,344 \\
4,204 \\
4 \\
4\end{array}$ \\
\hline $\begin{array}{l}\text { Eschwei lera } \\
\text { amara }\end{array}$ & $\begin{array}{l}\mu(v) \\
\mu(12 \%) \\
C V(v) \\
C V(12 \%) \\
S(v) \\
S(12 \%) \\
N(v) \\
N(12 \%)\end{array}$ & $\begin{array}{r}0,74 \\
0,75 \\
9,293 \\
9,725 \\
0,069 \\
0,073 \\
7 \\
6\end{array}$ & $\begin{array}{r}10,14 \\
10,35 \\
14,283 \\
14,256 \\
1,449 \\
1,475 \\
7 \\
6\end{array}$ & $\begin{array}{r}4,94 \\
5,02 \\
20,158 \\
21,244 \\
0,995 \\
1,065 \\
7 \\
6\end{array}$ & $\begin{array}{r}14,93 \\
15,10 \\
12,572 \\
13,212 \\
1,877 \\
1,995 \\
7 \\
6\end{array}$ & $\begin{array}{r}12729 \\
14983 \\
12,370 \\
6,005 \\
1574,5 \\
899,81 \\
7 \\
6\end{array}$ & $\begin{array}{r}97,90 \\
142,00 \\
8,464 \\
13,111 \\
8,287 \\
18,617 \\
7 \\
6\end{array}$ & $\begin{array}{r}50,09 \\
67,85 \\
13,433 \\
8,111 \\
6,728 \\
5,503 \\
7 \\
6\end{array}$ & $\begin{array}{r}9,27 \\
12,00 \\
27,770 \\
19,090 \\
2,575 \\
2,291 \\
7 \\
6\end{array}$ & $\begin{array}{r}11,81 \\
14,38 \\
14,040 \\
12,921 \\
1,659 \\
1,858 \\
7 \\
6\end{array}$ \\
\hline $\begin{array}{l}\text { Enterol obium } \\
\text { schomburgkii }\end{array}$ & $\begin{array}{l}\mu(v) \\
\mu(12 \%) \\
C V(v) \\
C V(12 \%) \\
s(v) \\
S(12 \%) \\
N(v) \\
N(12 \%)\end{array}$ & $\begin{array}{r}0,80 \\
0,80 \\
7,896 \\
6,913 \\
0,063 \\
0,055 \\
5 \\
3\end{array}$ & $\begin{array}{r}9,20 \\
9,40 \\
6,924 \\
8,343 \\
0,637 \\
0,784 \\
5 \\
3\end{array}$ & $\begin{array}{r}4,33 \\
4,38 \\
15,977 \\
19,120 \\
0,691 \\
0,837 \\
4 \\
3\end{array}$ & $\begin{array}{r}13,48 \\
13,73 \\
10,879 \\
12,235 \\
1,466 \\
1,680 \\
4 \\
3\end{array}$ & $\begin{array}{r}13920 \\
16533 \\
14,682 \\
13,610 \\
2043,8 \\
2250,2 \\
5 \\
3\end{array}$ & $\begin{array}{r}110,12 \\
166,03 \\
14,510 \\
8,360 \\
15,978 \\
13,880 \\
5 \\
3\end{array}$ & $\begin{array}{r}58,10 \\
81,50 \\
6,940 \\
8,956 \\
4,032 \\
7,299 \\
5 \\
3\end{array}$ & $\begin{array}{r}14,38 \\
15,23 \\
10,710 \\
16,792 \\
1,540 \\
2,558 \\
5 \\
3\end{array}$ & $\begin{array}{r}15,48 \\
19,43 \\
13,218 \\
14,890 \\
2,046 \\
2,894 \\
5 \\
3\end{array}$ \\
\hline $\begin{array}{l}\text { Endopl eura } \\
\text { uchi. }\end{array}$ & $\begin{array}{l}\mu(v) \\
\mu(12 \%) \\
C V(v) \\
C V(12 \%) \\
S(v) \\
S(12 \%) \\
N(v) \\
N(12 \%)\end{array}$ & $\begin{array}{r}0,79 \\
0,80 \\
4,759 \\
4,422 \\
0,038 \\
0,035 \\
7 \\
6\end{array}$ & $\begin{array}{r}9,64 \\
9,83 \\
5,643 \\
2,064 \\
0,544 \\
0,203 \\
7 \\
6\end{array}$ & $\begin{array}{r}6,76 \\
6,68 \\
9,557 \\
10,035 \\
0,646 \\
0,671 \\
7 \\
6\end{array}$ & $\begin{array}{r}16,03 \\
16,22 \\
5,031 \\
4,581 \\
0,807 \\
0,743 \\
6 \\
5\end{array}$ & $\begin{array}{r}15114 \\
16333 \\
3,978 \\
5,526 \\
601,19 \\
902,59 \\
7 \\
6\end{array}$ & $\begin{array}{r}121,10 \\
165,27 \\
7,194 \\
8,504 \\
8,712 \\
14,055 \\
7 \\
6\end{array}$ & $\begin{array}{r}57,71 \\
78,63 \\
8,034 \\
8,508 \\
4,637 \\
6,690 \\
7 \\
6\end{array}$ & $\begin{array}{r}8,23 \\
13,87 \\
18,993 \\
11,308 \\
1,563 \\
1,568 \\
7 \\
6\end{array}$ & $\begin{array}{r}14,24 \\
19,12 \\
5,526 \\
15,618 \\
0,787 \\
2,986 \\
7 \\
6\end{array}$ \\
\hline $\begin{array}{l}\text { Erisma } \\
\text { uncinatum }\end{array}$ & $\begin{array}{l}\mu(v) \\
\mu(12 \%) \\
C V(V) \\
C V(12 \%) \\
s(v) \\
s(12 \%) \\
N(v) \\
N(12 \%)\end{array}$ & $\begin{array}{r}0,47 \\
0,47 \\
10,017 \\
9,850 \\
0,047 \\
0,047 \\
8 \\
5\end{array}$ & $\begin{array}{r}9,97 \\
9,87 \\
16,490 \\
20,355 \\
1,643 \\
2,009 \\
8 \\
5\end{array}$ & $\begin{array}{r}4,23 \\
4,16 \\
16,951 \\
20,003 \\
0,717 \\
0,833 \\
7 \\
5\end{array}$ & $\begin{array}{r}13,62 \\
13,20 \\
11,324 \\
13,267 \\
1,542 \\
1,751 \\
6 \\
4\end{array}$ & $\begin{array}{r}9725 \\
11180 \\
13,143 \\
19,611 \\
1278,1 \\
2192,5 \\
8 \\
5\end{array}$ & $\begin{array}{r}62,58 \\
88,48 \\
13,817 \\
18,043 \\
8,646 \\
15,964 \\
8 \\
5\end{array}$ & $\begin{array}{r}27,91 \\
50,52 \\
20,398 \\
7,379 \\
5,693 \\
3,728 \\
8 \\
5\end{array}$ & $\begin{array}{r}2,83 \\
5,36 \\
26,608 \\
8,908 \\
0,752 \\
0,477 \\
8 \\
5\end{array}$ & $\begin{array}{r}7,09 \\
8,10 \\
21,297 \\
14,477 \\
1,509 \\
1,173 \\
8 \\
5\end{array}$ \\
\hline $\begin{array}{l}\text { Eschwei lera } \\
\text { sp. }\end{array}$ & $\begin{array}{l}\mu(v) \\
\mu(12 \%) \\
C V(v) \\
C V(12 \%) \\
s(v) \\
S(12 \%) \\
N(v) \\
N(12 \%)\end{array}$ & $\begin{array}{r}0,81 \\
0,81 \\
1,746 \\
1,746 \\
0,014 \\
0,014 \\
2 \\
2\end{array}$ & $\begin{array}{r}10,67 \\
10,67 \\
4,973 \\
4,973 \\
0,530 \\
0,530 \\
2 \\
2\end{array}$ & $\begin{array}{r}6,05 \\
6,05 \\
11,814 \\
11,814 \\
0,714 \\
0,714 \\
2 \\
2\end{array}$ & $\begin{array}{r}16,10 \\
16,10 \\
6,149 \\
6,149 \\
0,990 \\
0,990 \\
2 \\
2\end{array}$ & $\begin{array}{r}15950 \\
19250 \\
9,310 \\
1,837 \\
1484,9 \\
353,55 \\
2 \\
2\end{array}$ & $\begin{array}{r}120,35 \\
171,50 \\
7,932 \\
4,123 \\
9,546 \\
7,071 \\
2 \\
2\end{array}$ & $\begin{array}{r}58,10 \\
88,10 \\
11,440 \\
2,889 \\
6,647 \\
2,546 \\
2 \\
2\end{array}$ & $\begin{array}{r}10,70 \\
18,30 \\
9,252 \\
2,318 \\
0,990 \\
0,424 \\
2 \\
2\end{array}$ & $\begin{array}{r}12,05 \\
20,85 \\
0,587 \\
2,374 \\
0,071 \\
0,495 \\
2 \\
2\end{array}$ \\
\hline
\end{tabular}


continuação

\begin{tabular}{|c|c|c|c|c|c|c|c|c|c|c|}
\hline$\frac{\text { Franchetel la }}{\text { gongrijpi i }}$ & $\begin{array}{l}\mu(v) \\
\mu(12 \%) \\
\text { CV }(v) \\
\text { CV }(12 \%) \\
\text { s }(v) \\
\text { S }(12 \%) \\
N(v) \\
N(12 \%)\end{array}$ & $\begin{array}{r}0,72 \\
0,72 \\
2,778 \\
2,778 \\
0,020 \\
0,020 \\
3 \\
3\end{array}$ & $\begin{array}{r}10,07 \\
10,07 \\
2,683 \\
2,683 \\
0,270 \\
0,270 \\
3 \\
3\end{array}$ & $\begin{array}{r}4,48 \\
4,48 \\
21,878 \\
21,878 \\
0,979 \\
0,979 \\
3 \\
3\end{array}$ & $\begin{array}{r}14,97 \\
14,97 \\
4,347 \\
4,347 \\
0,651 \\
0,651 \\
3 \\
3\end{array}$ & $\begin{array}{r}13367 \\
15633 \\
3,766 \\
14,786 \\
503,32 \\
2311,6 \\
3 \\
3\end{array}$ & $\begin{array}{r}100,97 \\
147,27 \\
5,279 \\
6,553 \\
5,330 \\
9,650 \\
3 \\
3\end{array}$ & $\begin{array}{r}43,10 \\
77,03 \\
15,273 \\
12,442 \\
6,583 \\
9,585 \\
3 \\
3\end{array}$ & $\begin{array}{r}9,50 \\
12,77 \\
23,795 \\
18,038 \\
2,261 \\
2,303 \\
3 \\
3\end{array}$ & $\begin{array}{r}11,90 \\
17,97 \\
11,765 \\
16,144 \\
1,400 \\
2,901 \\
3 \\
3\end{array}$ \\
\hline $\begin{array}{l}\text { Glycydendron } \\
\text { amazonicum }\end{array}$ & $\begin{array}{l}\mu(v) \\
\mu(12 \%) \\
\text { CV }(v) \\
\text { CV }(12 \%) \\
s(v) \\
\text { S }(12 \%) \\
N(v) \\
N(12 \%)\end{array}$ & $\begin{array}{r}0,68 \\
0,68 \\
6,840 \\
10,306 \\
0,046 \\
0,069 \\
8 \\
7\end{array}$ & $\begin{array}{r}7,63 \\
7,69 \\
7,727 \\
7,960 \\
0,590 \\
0,612 \\
8 \\
7\end{array}$ & $\begin{array}{r}4,93 \\
4,83 \\
16,087 \\
21,884 \\
0,792 \\
1,057 \\
8 \\
7\end{array}$ & $\begin{array}{r}12,30 \\
12,17 \\
8,199 \\
9,022 \\
1,009 \\
1,098 \\
8 \\
7\end{array}$ & $\begin{array}{r}12525 \\
15257 \\
12,751 \\
8,735 \\
1597,1 \\
1332,7 \\
8 \\
7\end{array}$ & $\begin{array}{r}81,38 \\
128,09 \\
17,191 \\
12,482 \\
13,989 \\
15,988 \\
8 \\
7\end{array}$ & $\begin{array}{r}42,75 \\
67,76 \\
9,385 \\
16,914 \\
4,012 \\
11,460 \\
8 \\
7\end{array}$ & $\begin{array}{r}5,63 \\
9,73 \\
18,615 \\
15,115 \\
1,047 \\
1,471 \\
8 \\
7\end{array}$ & $\begin{array}{r}9,59 \\
13,74 \\
16,420 \\
11,527 \\
1,574 \\
1,584 \\
8 \\
7\end{array}$ \\
\hline$\frac{\text { Goupia }}{\text { glabra }}$ & $\begin{array}{l}\mu(v) \\
\mu(12 \%) \\
\text { CV }(v) \\
\text { CV }(12 \%) \\
\text { s }(v) \\
\text { S }(12 \%) \\
N(v) \\
N(12 \%)\end{array}$ & $\begin{array}{r}0,70 \\
0,70 \\
4,566 \\
3,882 \\
0,032 \\
0,027 \\
6 \\
5\end{array}$ & $\begin{array}{r}8,07 \\
8,52 \\
7,437 \\
9,731 \\
0,600 \\
0,829 \\
6 \\
5\end{array}$ & $\begin{array}{r}4,50 \\
4,54 \\
11,543 \\
9,088 \\
0,519 \\
0,412 \\
6 \\
5\end{array}$ & $\begin{array}{r}12,52 \\
13,20 \\
6,596 \\
5,276 \\
0,826 \\
0,696 \\
6 \\
5\end{array}$ & $\begin{array}{r}11433 \\
14640 \\
11,704 \\
7,722 \\
1338,2 \\
1130,5 \\
6 \\
5\end{array}$ & $\begin{array}{r}89,98 \\
131,88 \\
12,491 \\
14,698 \\
11,240 \\
19,384 \\
6 \\
5\end{array}$ & $\begin{array}{r}47,70 \\
78,30 \\
10,900 \\
24,829 \\
5,199 \\
19,441 \\
6 \\
5\end{array}$ & $\begin{array}{r}8,93 \\
15,18 \\
7,581 \\
27,958 \\
0,677 \\
4,244 \\
6 \\
5\end{array}$ & $\begin{array}{r}11,95 \\
15,10 \\
11,628 \\
13,962 \\
1,390 \\
2,108 \\
6 \\
5\end{array}$ \\
\hline$\frac{\text { Guatteria }}{\text { olivacea }}$ & $\begin{array}{l}\mu(v) \\
\mu(12 \%) \\
C V(V) \\
C V(12 \%) \\
S(v) \\
S(12 \%) \\
N(v) \\
N(12 \%)\end{array}$ & $\begin{array}{r}0,51 \\
0,51 \\
5,546 \\
5,546 \\
0,028 \\
0,028 \\
2 \\
2\end{array}$ & $\begin{array}{r}9,30 \\
9,30 \\
9,124 \\
9,124 \\
0,849 \\
0,849 \\
2 \\
2\end{array}$ & $\begin{array}{r}4,40 \\
4,40 \\
6,750 \\
6,750 \\
0,297 \\
0,297 \\
2 \\
2\end{array}$ & $\begin{array}{r}13,05 \\
13,05 \\
0,542 \\
0,542 \\
0,071 \\
0,071 \\
2 \\
2\end{array}$ & $\begin{array}{r}10150 \\
12450 \\
4,877 \\
7,383 \\
494,97 \\
919,24 \\
2 \\
2\end{array}$ & $\begin{array}{r}57,45 \\
100,20 \\
5,046 \\
5,222 \\
2,899 \\
5,233 \\
2 \\
2\end{array}$ & $\begin{array}{r}26,40 \\
52,40 \\
1,071 \\
7,017 \\
0,283 \\
3,677 \\
2 \\
2\end{array}$ & $\begin{array}{r}3,40 \\
6,00 \\
49,913 \\
65,997 \\
1,697 \\
3,960 \\
2 \\
2\end{array}$ & $\begin{array}{r}8,25 \\
8,90 \\
6,00 \\
14,301 \\
0,495 \\
1,273 \\
2 \\
2\end{array}$ \\
\hline $\begin{array}{l}\text { Hymenaea } \\
\text { courbar il }\end{array}$ & $\begin{array}{l}\mu(v) \\
\mu(12 \%) \\
\text { CV }(v) \\
\text { CV }(12 \%) \\
s(v) \\
\text { s }(12 \%) \\
N(v) \\
N(12 \%)\end{array}$ & $\begin{array}{r}0,78 \\
0,73 \\
7,345 \\
6,827 \\
0,057 \\
0,049 \\
6 \\
2\end{array}$ & $\begin{array}{r}7,92 \\
6,59 \\
15,968 \\
1,825 \\
1,265 \\
0,120 \\
5 \\
2\end{array}$ & $\begin{array}{r}3,71 \\
3,24 \\
17,221 \\
26,189 \\
0,638 \\
0,849 \\
5 \\
2\end{array}$ & $\begin{array}{r}10,94 \\
10,40 \\
7,718 \\
8,159 \\
0,844 \\
0,849 \\
5 \\
2\end{array}$ & $\begin{array}{r}14517 \\
15750 \\
9,399 \\
4,939 \\
1364,4 \\
777,82 \\
6 \\
2\end{array}$ & $\begin{array}{r}111,88 \\
151,05 \\
12,485 \\
7,818 \\
13,968 \\
11,809 \\
6 \\
2\end{array}$ & $\begin{array}{r}59,53 \\
77,65 \\
6,380 \\
2,459 \\
3,798 \\
1,909 \\
6 \\
2\end{array}$ & $\begin{array}{r}10,60 \\
13,50 \\
15,023 \\
3,143 \\
1,592 \\
0,424 \\
6 \\
2\end{array}$ & $\begin{array}{r}15,35 \\
18,20 \\
13,794 \\
9,324 \\
2,117 \\
1,697 \\
6 \\
2\end{array}$ \\
\hline $\begin{array}{l}\text { Hymenol obium } \\
\text { modestum }\end{array}$ & $\begin{array}{l}\mu(v) \\
\mu(12 \%) \\
C V(V) \\
\text { CV }(12 \%) \\
\text { s }(v) \\
\text { s }(12 \%) \\
N(v) \\
N(12 \%)\end{array}$ & $\begin{array}{r}0,65 \\
0,65 \\
11,045 \\
11,045 \\
0,072 \\
0,072 \\
9 \\
9\end{array}$ & $\begin{array}{r}7,65 \\
7,55 \\
8,479 \\
8,547 \\
0,649 \\
0,645 \\
7 \\
6\end{array}$ & $\begin{array}{r}4,43 \\
4,40 \\
14,877 \\
16,274 \\
0,659 \\
0,716 \\
7 \\
6\end{array}$ & $\begin{array}{r}12,80 \\
12,72 \\
7,092 \\
7,791 \\
0,908 \\
0,991 \\
6 \\
5\end{array}$ & $\begin{array}{r}12644 \\
13400 \\
16,866 \\
11,811 \\
2132,6 \\
1582,7 \\
9 \\
9\end{array}$ & $\begin{array}{r}93,68 \\
120,94 \\
16,883 \\
15,660 \\
15,815 \\
18,940 \\
9 \\
9\end{array}$ & $\begin{array}{r}44,93 \\
61,90 \\
18,190 \\
11,918 \\
8,173 \\
7,377 \\
9 \\
9\end{array}$ & $\begin{array}{r}6,99 \\
10,71 \\
13,258 \\
6,058 \\
0,927 \\
0,649 \\
9 \\
9\end{array}$ & $\begin{array}{r}11,51 \\
14,04 \\
10,626 \\
17,193 \\
1,223 \\
2,415 \\
9 \\
9\end{array}$ \\
\hline $\begin{array}{l}\text { Hymenaea } \\
\text { parviflora }\end{array}$ & $\begin{array}{l}\mu(v) \\
\mu(12 \%) \\
\text { CV }(v) \\
\text { CV }(12 \%) \\
s \quad(v) \\
\text { s }(12 \%) \\
N(v) \\
N(12 \%)\end{array}$ & $\begin{array}{r}0,90 \\
0,89 \\
9,802 \\
11,076 \\
0,088 \\
0,098 \\
4 \\
5\end{array}$ & $\begin{array}{r}8,76 \\
9,59 \\
10,937 \\
10,729 \\
0,958 \\
1,029 \\
3 \\
4\end{array}$ & $\begin{array}{r}3,18 \\
4,10 \\
34,214 \\
21,196 \\
1,089 \\
0,868 \\
3 \\
4\end{array}$ & $\begin{array}{r}12,00 \\
13,45 \\
13,869 \\
10,902 \\
1,664 \\
1,466 \\
3 \\
4\end{array}$ & $\begin{array}{r}15500 \\
17500 \\
9,093 \\
10,428 \\
1409,5 \\
1824,8 \\
4 \\
5\end{array}$ & $\begin{array}{r}129,15 \\
171,06 \\
17,057 \\
11,164 \\
22,029 \\
19,097 \\
4 \\
5\end{array}$ & $\begin{array}{r}64,50 \\
90,80 \\
17,045 \\
13,148 \\
10,994 \\
11,938 \\
4 \\
5\end{array}$ & $\begin{array}{r}17,65 \\
19,48 \\
15,547 \\
15,483 \\
2,744 \\
3,016 \\
4 \\
5\end{array}$ & $\begin{array}{r}16,63 \\
22,44 \\
14,988 \\
15,930 \\
2,492 \\
3,575 \\
4 \\
5\end{array}$ \\
\hline
\end{tabular}


continuação

\begin{tabular}{|c|c|c|c|c|c|c|c|c|c|c|}
\hline$\frac{\text { Inga }}{\text { alba }}$ & $\begin{array}{l}\mu(v) \\
\mu(12 \%) \\
\text { CV }(v) \\
\text { CV }(12 \%) \\
s(v) \\
S(12 \%) \\
N(v) \\
N(12 \%)\end{array}$ & $\begin{array}{r}0,60 \\
0,63 \\
10,622 \\
13,587 \\
0,064 \\
0,085 \\
7 \\
8\end{array}$ & $\begin{array}{r}9,40 \\
9,91 \\
9,476 \\
10,158 \\
0,890 \\
1,007 \\
7 \\
8\end{array}$ & $\begin{array}{r}3,90 \\
3,99 \\
16,247 \\
15,775 \\
0,634 \\
0,629 \\
7 \\
8\end{array}$ & $\begin{array}{r}12,94 \\
13,65 \\
10,916 \\
12,500 \\
1,413 \\
1,706 \\
7 \\
8\end{array}$ & $\begin{array}{r}11486 \\
14275 \\
13,898 \\
13,873 \\
1596,3 \\
1980,4 \\
7 \\
8\end{array}$ & $\begin{array}{r}78,50 \\
128,56 \\
13,876 \\
15,907 \\
10,893 \\
20,450 \\
7 \\
8\end{array}$ & $\begin{array}{r}36,41 \\
62,33 \\
12,844 \\
13,880 \\
4,677 \\
8,651 \\
7 \\
8\end{array}$ & $\begin{array}{r}5,80 \\
8,73 \\
21,511 \\
18,620 \\
1,248 \\
1,625 \\
7 \\
8\end{array}$ & $\begin{array}{r}11,29 \\
14,93 \\
16,382 \\
12,832 \\
1,849 \\
1,915 \\
7 \\
8\end{array}$ \\
\hline Inga & $\begin{array}{l}\mu(v) \\
\mu(12 \%) \\
\text { CV (v) } \\
\text { CV }(12 \%) \\
S(v) \\
S(12 \%) \\
N(v) \\
N(12 \%)\end{array}$ & $\begin{array}{r}0,82 \\
0,82 \\
1,725 \\
1,725 \\
0,014 \\
0,014 \\
2 \\
2\end{array}$ & $\begin{array}{r}10,74 \\
10,74 \\
6,653 \\
6,653 \\
0,714 \\
0,714 \\
2 \\
2\end{array}$ & $\begin{array}{r}5,26 \\
5,26 \\
4,033 \\
4,033 \\
0,212 \\
0,212 \\
2 \\
2\end{array}$ & $\begin{array}{r}15,95 \\
15,95 \\
3,103 \\
3,103 \\
0,495 \\
0,495 \\
2 \\
2\end{array}$ & $\begin{array}{r}14550 \\
18300 \\
3,402 \\
4,637 \\
494,97 \\
848,53 \\
2 \\
2\end{array}$ & $\begin{array}{r}121,40 \\
186,60 \\
3,844 \\
8,337 \\
4,667 \\
15,556 \\
2 \\
2\end{array}$ & $\begin{array}{r}52,00 \\
85,00 \\
11,694 \\
0,499 \\
6,081 \\
0,424 \\
2 \\
2\end{array}$ & $\begin{array}{r}9,60 \\
14,70 \\
26,517 \\
14,431 \\
2,546 \\
2,121 \\
2 \\
2\end{array}$ & $\begin{array}{r}15,30 \\
21,75 \\
15,713 \\
8,128 \\
2,404 \\
1,768 \\
2 \\
2\end{array}$ \\
\hline $\begin{array}{l}\text { Lueheopsis } \\
\text { duckeana }\end{array}$ & $\begin{array}{l}\mu(v) \\
\mu(12 \%) \\
C V(v) \\
C V(12 \%) \\
S(v) \\
S(12 \%) \\
N(v) \\
N(12 \%)\end{array}$ & $\begin{array}{r}0,62 \\
0,61 \\
5,040 \\
5,086 \\
0,031 \\
0,031 \\
9 \\
9\end{array}$ & $\begin{array}{r}9,51 \\
9,32 \\
14,370 \\
14,220 \\
1,367 \\
1,326 \\
9 \\
8\end{array}$ & $\begin{array}{r}4,58 \\
4,56 \\
18,100 \\
19,383 \\
0,829 \\
0,884 \\
9 \\
8\end{array}$ & $\begin{array}{r}13,58 \\
13,36 \\
14,142 \\
14,467 \\
1,920 \\
1,933 \\
9 \\
8\end{array}$ & $\begin{array}{r}12478 \\
14378 \\
8,210 \\
5,097 \\
1024,4 \\
732,76 \\
9 \\
9\end{array}$ & $\begin{array}{r}82,50 \\
125,29 \\
11,218 \\
8,444 \\
9,255 \\
10,579 \\
9 \\
9\end{array}$ & $\begin{array}{r}35,06 \\
64,02 \\
12,079 \\
4,880 \\
4,234 \\
3,124 \\
9 \\
9\end{array}$ & $\begin{array}{r}5,83 \\
9,73 \\
22,515 \\
11,555 \\
1,313 \\
1,125 \\
9 \\
9\end{array}$ & $\begin{array}{r}9,13 \\
13,23 \\
13,139 \\
15,061 \\
1,200 \\
1,993 \\
9 \\
9\end{array}$ \\
\hline$\frac{\text { Licania }}{\text { octandra }}$ & $\begin{array}{l}\mu(v) \\
\mu(12 \%) \\
C V(V) \\
C V(12 \%) \\
S(v) \\
S(12 \%) \\
N(v) \\
N(12 \%)\end{array}$ & $\begin{array}{r}0,78 \\
0,82 \\
5,439 \\
1,725 \\
0,042 \\
0,014 \\
2 \\
2\end{array}$ & $\begin{array}{c}12,87 \\
13,45 \\
6,431 \\
\cdots \\
0,827 \\
-- \\
2 \\
1\end{array}$ & $\begin{array}{c}6,02 \\
6,30 \\
6,701 \\
\ldots \\
0,403 \\
\ldots \\
2 \\
1\end{array}$ & $\begin{array}{r}18,00 \\
17,75 \\
2,357 \\
4,382 \\
0,424 \\
0,778 \\
2 \\
2\end{array}$ & $\begin{array}{r}14050 \\
18050 \\
5,536 \\
10,577 \\
777,82 \\
1909,2 \\
2 \\
2\end{array}$ & $\begin{array}{r}89,35 \\
175,80 \\
4,986 \\
6,114 \\
4,455 \\
10,748 \\
2 \\
2\end{array}$ & $\begin{array}{r}37,65 \\
87,20 \\
27,233 \\
3,730 \\
10,253 \\
3,253 \\
2 \\
2\end{array}$ & $\begin{array}{r}5,50 \\
12,20 \\
12,856 \\
2,318 \\
0,707 \\
0,283 \\
2 \\
2\end{array}$ & $\begin{array}{r}9,70 \\
17,15 \\
18,953 \\
1,237 \\
1,838 \\
0,212 \\
2 \\
2\end{array}$ \\
\hline$\frac{\text { Licaria }}{\text { rigida }}$ & $\begin{array}{l}\mu(v) \\
\mu(12 \%) \\
C V(v) \\
C V(12 \%) \\
s(v) \\
S(12 \%) \\
N(v) \\
N(12 \%)\end{array}$ & $\begin{array}{r}0,73 \\
0,74 \\
5,078 \\
4,810 \\
0,037 \\
0,035 \\
6 \\
7\end{array}$ & $\begin{array}{r}9,14 \\
9,17 \\
10,714 \\
9,782 \\
0,980 \\
0,897 \\
6 \\
7\end{array}$ & $\begin{array}{r}5,26 \\
5,15 \\
21,297 \\
20,679 \\
1,121 \\
1,065 \\
6 \\
7\end{array}$ & $\begin{array}{r}13,50 \\
13,50 \\
4,485 \\
4,485 \\
0,606 \\
0,606 \\
4 \\
4\end{array}$ & $\begin{array}{r}14133 \\
17514 \\
6,737 \\
6,118 \\
952,19 \\
1071,5 \\
6 \\
7\end{array}$ & $\begin{array}{r}99,43 \\
163,70 \\
6,908 \\
7,753 \\
6,869 \\
12,692 \\
6 \\
7\end{array}$ & $\begin{array}{r}53,38 \\
84,97 \\
14,807 \\
10,804 \\
7,905 \\
9,181 \\
6 \\
7\end{array}$ & $\begin{array}{r}6,30 \\
13,09 \\
27,730 \\
10,473 \\
1,747 \\
1,370 \\
6 \\
7\end{array}$ & $\begin{array}{r}12,25 \\
17,61 \\
10,802 \\
12,948 \\
1,323 \\
2,281 \\
6 \\
7\end{array}$ \\
\hline$\frac{\text { Lecythis }}{\text { pisonis }}$ & $\begin{array}{l}\mu(v) \\
\mu(12 \%) \\
C V(v) \\
C V(12 \%) \\
s(v) \\
S(12 \%) \\
N(v) \\
N(12 \%)\end{array}$ & $\begin{array}{r}0,81 \\
0,85 \\
7,685 \\
7,594 \\
0,063 \\
0,064 \\
6 \\
9\end{array}$ & $\begin{array}{r}8,44 \\
8,59 \\
14,714 \\
16,684 \\
1,241 \\
1,434 \\
6 \\
9\end{array}$ & $\begin{array}{r}5,45 \\
5,37 \\
15,374 \\
18,230 \\
0,837 \\
0,979 \\
6 \\
9\end{array}$ & $\begin{array}{r}13,82 \\
14,18 \\
15,288 \\
12,817 \\
2,112 \\
1,817 \\
6 \\
9\end{array}$ & $\begin{array}{r}14850 \\
15611 \\
13,897 \\
9,654 \\
2063,7 \\
1507,0 \\
6 \\
9\end{array}$ & $\begin{array}{r}115,08 \\
158,56 \\
13,911 \\
10,079 \\
16,009 \\
15,981 \\
6 \\
9\end{array}$ & $\begin{array}{r}50,63 \\
75,02 \\
17,514 \\
13,785 \\
8,868 \\
10,342 \\
6 \\
9\end{array}$ & $\begin{array}{r}11,87 \\
14,88 \\
28,436 \\
11,191 \\
3,374 \\
1,665 \\
6 \\
9\end{array}$ & $\begin{array}{r}14,45 \\
17,90 \\
15,355 \\
13,437 \\
2,219 \\
2,405 \\
6 \\
9\end{array}$ \\
\hline $\begin{array}{l}\text { Manilkara } \\
\text { amazonica }\end{array}$ & $\begin{array}{l}\mu(v) \\
\mu(12 \%) \\
C V(v) \\
C V(12 \%) \\
s(v) \\
s(12 \%) \\
N(v) \\
N(12 \%)\end{array}$ & $\begin{array}{r}0,83 \\
0,83 \\
4,283 \\
4,919 \\
0,036 \\
0,041 \\
5 \\
4\end{array}$ & $\begin{array}{r}8,34 \\
8,35 \\
6,631 \\
7,653 \\
0,553 \\
0,639 \\
5 \\
4\end{array}$ & $\begin{array}{r}5,92 \\
5,92 \\
9,733 \\
11,252 \\
0,577 \\
0,666 \\
5 \\
4\end{array}$ & $\begin{array}{r}13,80 \\
13,83 \\
2,943 \\
3,360 \\
0,406 \\
0,465 \\
5 \\
4\end{array}$ & $\begin{array}{r}12580 \\
13800 \\
8,056 \\
4,915 \\
1013,4 \\
678,23 \\
5 \\
4\end{array}$ & $\begin{array}{r}108,08 \\
128,45 \\
6,520 \\
5,355 \\
7,047 \\
6,878 \\
5 \\
4\end{array}$ & $\begin{array}{r}53,90 \\
64,88 \\
8,198 \\
5,234 \\
4,419 \\
3,395 \\
5 \\
4\end{array}$ & $\begin{array}{r}12,72 \\
15,95 \\
22,990 \\
9,292 \\
2,924 \\
1,482 \\
5 \\
4\end{array}$ & $\begin{array}{r}12,86 \\
16,25 \\
13,385 \\
8,911 \\
1,721 \\
1,448 \\
5 \\
4\end{array}$ \\
\hline
\end{tabular}


continuação

\begin{tabular}{|c|c|c|c|c|c|c|c|c|c|c|}
\hline$\frac{\text { Maloutia }}{\text { duckei. }}$ & $\begin{array}{l}\mu(v) \\
\mu(12 \%) \\
C V(V) \\
C V(12 \%) \\
s(V) \\
s(12 \%) \\
N(V) \\
N(12 \%)\end{array}$ & $\begin{array}{r}0,57 \\
0,57 \\
2,026 \\
2,026 \\
0,012 \\
0,012 \\
4 \\
4\end{array}$ & $\begin{array}{r}9,18 \\
9,18 \\
9,379 \\
9,379 \\
0,861 \\
0,861 \\
4 \\
4\end{array}$ & $\begin{array}{r}3,91 \\
3,91 \\
11,871 \\
11,871 \\
0,464 \\
0,464 \\
4 \\
4\end{array}$ & $\begin{array}{r}12,75 \\
12,75 \\
13,471 \\
13,471 \\
1,718 \\
1,718 \\
4 \\
4\end{array}$ & $\begin{array}{r}10875 \\
12900 \\
5,536 \\
7,829 \\
602,08 \\
1010,0 \\
4 \\
4\end{array}$ & $\begin{array}{r}70,55 \\
118,28 \\
10,327 \\
4,948 \\
7,285 \\
5,852 \\
4 \\
4\end{array}$ & $\begin{array}{r}32,20 \\
61,88 \\
13,006 \\
5,486 \\
4,188 \\
3,394 \\
4 \\
4\end{array}$ & $\begin{array}{r}4,25 \\
9,18 \\
11,284 \\
6,562 \\
0,480 \\
0,602 \\
4 \\
4\end{array}$ & $\begin{array}{r}8,60 \\
14,88 \\
20,648 \\
13,760 \\
1,776 \\
2,047 \\
4 \\
4\end{array}$ \\
\hline $\begin{array}{l}\text { Microphol is } \\
\text { venulosa }\end{array}$ & $\begin{array}{l}\mu(v) \\
\mu(12 \%) \\
C V(V) \\
C V(12 \%) \\
s(v) \\
s(12 \%) \\
N(v) \\
N(12 \%)\end{array}$ & $\begin{array}{r}0,67 \\
0,67 \\
9,570 \\
9,570 \\
0,064 \\
0,064 \\
2 \\
2\end{array}$ & $\begin{array}{r}9,670 \\
9,670 \\
15,210 \\
15,210 \\
1,471 \\
1,471 \\
2 \\
2\end{array}$ & $\begin{array}{r}4,715 \\
4,715 \\
21,146 \\
21,146 \\
0,997 \\
0,997 \\
2 \\
2\end{array}$ & $\begin{array}{r}14,00 \\
14,00 \\
9,091 \\
9,091 \\
1,273 \\
1,273 \\
2 \\
2\end{array}$ & $\begin{array}{r}12950 \\
14150 \\
14,743 \\
4,497 \\
1909,2 \\
636,40 \\
2 \\
2\end{array}$ & $\begin{array}{r}80,40 \\
133,35 \\
26,385 \\
40,247 \\
21,213 \\
53,669 \\
2 \\
2\end{array}$ & $\begin{array}{r}41,25 \\
66,150 \\
18,685 \\
15,072 \\
7,707 \\
9,970 \\
2 \\
2\end{array}$ & $\begin{array}{r}6,60 \\
10,150 \\
21,427 \\
2,090 \\
1,414 \\
0,212 \\
2 \\
2\end{array}$ & $\begin{array}{r}10,75 \\
14,700 \\
21,707 \\
7,696 \\
2,333 \\
1,131 \\
2 \\
2\end{array}$ \\
\hline $\begin{array}{l}\text { Nema luma } \\
\text { anomala }\end{array}$ & $\begin{array}{l}\mu(v) \\
\mu(12 \%) \\
C V(v) \\
C V(12 \%) \\
s(v) \\
\text { s }(12 \%) \\
N(v) \\
N(12 \%)\end{array}$ & $\begin{array}{r}0,75 \\
0,75 \\
4,065 \\
4,286 \\
0,031 \\
0,032 \\
8 \\
7\end{array}$ & $\begin{array}{r}9,37 \\
9,37 \\
5,204 \\
5,616 \\
0,487 \\
0,526 \\
8 \\
7\end{array}$ & $\begin{array}{r}6,32 \\
6,37 \\
11,694 \\
12,359 \\
0,739 \\
0,787 \\
8 \\
7\end{array}$ & $\begin{array}{r}15,18 \\
15,16 \\
8,334 \\
9,005 \\
1,265 \\
1,365 \\
8 \\
7\end{array}$ & $\begin{array}{r}14088 \\
16214 \\
10,967 \\
4,607 \\
1545,0 \\
747,06 \\
8 \\
7\end{array}$ & $\begin{array}{r}112,54 \\
163,39 \\
8,071 \\
5,374 \\
9,083 \\
8,780 \\
8 \\
7\end{array}$ & $\begin{array}{r}54,13 \\
84,47 \\
10,778 \\
6,421 \\
5,833 \\
5,424 \\
8 \\
7\end{array}$ & $\begin{array}{r}8,53 \\
14,34 \\
17,643 \\
13,099 \\
1,504 \\
1,879 \\
8 \\
7\end{array}$ & $\begin{array}{r}11,89 \\
19,30 \\
14,977 \\
7,085 \\
1,780 \\
1,367 \\
8 \\
7\end{array}$ \\
\hline $\begin{array}{l}\text { Onychopetalum } \\
\text { amazonicum }\end{array}$ & $\begin{array}{l}\mu(v) \\
\mu(12 \%) \\
C V(V) \\
C V(12 \%) \\
s(v) \\
s \quad(12 \%) \\
N(v) \\
N(12 \%)\end{array}$ & $\begin{array}{r}0,56 \\
0,57 \\
5,051 \\
5,263 \\
0,028 \\
0,030 \\
2 \\
3\end{array}$ & $\begin{array}{r}8,39 \\
8,11 \\
1,011 \\
9,948 \\
0,085 \\
0,807 \\
2 \\
3\end{array}$ & $\begin{array}{r}5,01 \\
4,93 \\
4,380 \\
23,685 \\
0,219 \\
1,167 \\
2 \\
3\end{array}$ & $\begin{array}{r}14,65 \\
13,40 \\
9,171 \\
5,923 \\
1,344 \\
0,794 \\
2 \\
3\end{array}$ & $\begin{array}{r}14400 \\
14167 \\
10,803 \\
10,016 \\
1555,6 \\
1418,9 \\
2 \\
3\end{array}$ & $\begin{array}{r}79,60 \\
114,43 \\
2,132 \\
7,931 \\
1,697 \\
9,075 \\
2 \\
3\end{array}$ & $\begin{array}{r}41,30 \\
61,70 \\
5,479 \\
12,655 \\
2,263 \\
7,808 \\
2 \\
3\end{array}$ & $\begin{array}{r}3,80 \\
5,90 \\
29,773 \\
22,034 \\
1,131 \\
1,300 \\
2 \\
3\end{array}$ & $\begin{array}{r}7,00 \\
9,77 \\
8,081 \\
23,221 \\
0,566 \\
2,268 \\
2 \\
3\end{array}$ \\
\hline $\begin{array}{l}\text { Ocotea } \\
\text { neesiana }\end{array}$ & $\begin{array}{l}\mu(v) \\
\mu(12 \%) \\
\text { CV }(v) \\
\text { CV }(12 \%) \\
s \quad(v) \\
\text { s }(12 \%) \\
N(v) \\
N(12 \%)\end{array}$ & $\begin{array}{r}0,55 \\
0,55 \\
5,143 \\
5,143 \\
0,028 \\
0,028 \\
2 \\
2\end{array}$ & $\begin{array}{r}7,68 \\
7,68 \\
0,829 \\
0,829 \\
0,064 \\
0,064 \\
2 \\
2\end{array}$ & $\begin{array}{r}4,10 \\
4,22 \\
25,383 \\
20,634 \\
1,039 \\
0,870 \\
2 \\
2\end{array}$ & $\begin{array}{r}10,25 \\
10,25 \\
3,449 \\
3,449 \\
0,354 \\
0,354 \\
2 \\
2\end{array}$ & $\begin{array}{r}10600 \\
12050 \\
1,334 \\
0,587 \\
141,42 \\
70,711 \\
2 \\
2\end{array}$ & $\begin{array}{r}71,60 \\
110,10 \\
0,593 \\
1,798 \\
0,424 \\
1,980 \\
2 \\
2\end{array}$ & $\begin{array}{r}36,75 \\
61,15 \\
4,810 \\
3,585 \\
1,768 \\
2,192 \\
2 \\
2\end{array}$ & $\begin{array}{r}4,60 \\
7,30 \\
24,595 \\
1,937 \\
1,131 \\
0,141 \\
2 \\
2\end{array}$ & $\begin{array}{r}10,30 \\
12,65 \\
13,730 \\
9,503 \\
1,414 \\
1,202 \\
2 \\
2\end{array}$ \\
\hline$\frac{\text { Ormosia }}{\text { paraensis }}$ & $\begin{array}{l}\mu(v) \\
\mu(12 \%) \\
C V(v) \\
C V(12 \%) \\
s(v) \\
s(12 \%) \\
N(v) \\
N(12 \%)\end{array}$ & $\begin{array}{r}0,67 \\
0,67 \\
3,731 \\
3,530 \\
0,025 \\
0,024 \\
9 \\
9\end{array}$ & $\begin{array}{r}10,47 \\
10,16 \\
11,624 \\
13,458 \\
1,217 \\
1,368 \\
9 \\
9\end{array}$ & $\begin{array}{r}4,71 \\
4,71 \\
21,097 \\
18,201 \\
0,995 \\
0,857 \\
9 \\
9\end{array}$ & $\begin{array}{r}14,70 \\
14,68 \\
13,056 \\
13,423 \\
1,919 \\
1,970 \\
7 \\
9\end{array}$ & $\begin{array}{r}12922 \\
15122 \\
10,826 \\
8,370 \\
1398,9 \\
1265,7 \\
9 \\
9\end{array}$ & $\begin{array}{r}86,96 \\
125,78 \\
10,218 \\
12,330 \\
8,885 \\
15,508 \\
9 \\
9\end{array}$ & $\begin{array}{r}46,13 \\
70,23 \\
7,443 \\
6,237 \\
3,434 \\
4,381 \\
9 \\
9\end{array}$ & $\begin{array}{r}7,86 \\
10,73 \\
28,980 \\
15,252 \\
2,277 \\
1,637 \\
9 \\
9\end{array}$ & $\begin{array}{r}9,59 \\
13,14 \\
12,156 \\
13,153 \\
1,166 \\
1,808 \\
9 \\
9\end{array}$ \\
\hline$\frac{\text { Ocotea }}{\text { sp. }}$ & $\begin{array}{l}\mu(v) \\
\mu(12 \%) \\
\text { CV }(v) \\
\text { CV }(12 \%) \\
s(v) \\
s(12 \%) \\
N(v) \\
N(12 \%)\end{array}$ & $\begin{array}{r}0,62 \\
0,65 \\
12,236 \\
10,779 \\
0,076 \\
0,070 \\
5 \\
4\end{array}$ & $\begin{array}{r}7,59 \\
7,66 \\
10,383 \\
11,622 \\
0,788 \\
0,891 \\
5 \\
4\end{array}$ & $\begin{array}{r}3,59 \\
3,74 \\
17,952 \\
17,219 \\
0,644 \\
0,643 \\
5 \\
4\end{array}$ & $\begin{array}{r}11,10 \\
11,38 \\
7,697 \\
6,022 \\
0,854 \\
0,685 \\
5 \\
4\end{array}$ & $\begin{array}{r}13180 \\
14525 \\
7,226 \\
10,264 \\
952,37 \\
1490,8 \\
5 \\
4\end{array}$ & $\begin{array}{r}82,16 \\
127,40 \\
10,150 \\
13,705 \\
8,339 \\
17,460 \\
5 \\
4\end{array}$ & $\begin{array}{r}43,50 \\
67,73 \\
11,743 \\
13,374 \\
5,108 \\
9,058 \\
5 \\
4\end{array}$ & $\begin{array}{r}6,64 \\
9,95 \\
12,309 \\
15,075 \\
0,817 \\
1,500 \\
5 \\
4\end{array}$ & $\begin{array}{r}10,12 \\
12,28 \\
18,780 \\
15,900 \\
1,901 \\
1,952 \\
5 \\
4\end{array}$ \\
\hline
\end{tabular}


continuação

\begin{tabular}{|c|c|c|c|c|c|c|c|c|c|c|}
\hline$\frac{\text { Pouteria }}{\text { caimito }}$ & $\begin{array}{l}\mu(v) \\
\mu(12 \%) \\
\text { CV }(v) \\
\text { CV }(12 \%) \\
s(v) \\
\text { s }(12 \%) \\
N(v) \\
N(12 \%)\end{array}$ & $\begin{array}{r}0,88 \\
0,89 \\
4,684 \\
5,001 \\
0,041 \\
0,044 \\
10 \\
7\end{array}$ & $\begin{array}{r}9,42 \\
9,53 \\
8,213 \\
8,950 \\
0,774 \\
0,853 \\
9 \\
7\end{array}$ & $\begin{array}{r}5,39 \\
5,26 \\
16,971 \\
16,455 \\
0,915 \\
0,865 \\
9 \\
7\end{array}$ & $\begin{array}{r}14,47 \\
14,67 \\
9,424 \\
10,656 \\
1,363 \\
1,563 \\
6 \\
6\end{array}$ & $\begin{array}{r}16300 \\
17986 \\
4,201 \\
7,252 \\
684,75 \\
1304,4 \\
10 \\
7\end{array}$ & $\begin{array}{r}133,31 \\
171,27 \\
7,086 \\
7,888 \\
9,447 \\
13,510 \\
10 \\
7\end{array}$ & $\begin{array}{r}66,39 \\
87,09 \\
6,267 \\
7,144 \\
4,161 \\
6,221 \\
10 \\
7\end{array}$ & $\begin{array}{r}14,00 \\
16,06 \\
17,330 \\
16,504 \\
2,426 \\
2,650 \\
10 \\
7\end{array}$ & $\begin{array}{r}14,62 \\
16,74 \\
11,052 \\
12,220 \\
1,616 \\
2,046 \\
10 \\
7\end{array}$ \\
\hline$\frac{\text { Parkia }}{\text { paraensis }}$ & $\begin{array}{l}\mu(v) \\
\mu(12 \%) \\
C V(V) \\
C V(12 \%) \\
s(V) \\
s(12 \%) \\
N(v) \\
N(12 \%)\end{array}$ & $\begin{array}{r}0,45 \\
0,45 \\
5,634 \\
4,607 \\
0,025 \\
0,021 \\
3 \\
4\end{array}$ & $\begin{array}{r}8,03 \\
7,78 \\
4,083 \\
7,349 \\
0,328 \\
0,572 \\
3 \\
4\end{array}$ & $\begin{array}{r}4,02 \\
3,67 \\
2,658 \\
19,402 \\
0,107 \\
0,712 \\
3 \\
4\end{array}$ & $\begin{array}{r}12,03 \\
11,53 \\
4,725 \\
9,698 \\
0,569 \\
1,118 \\
3 \\
4\end{array}$ & $\begin{array}{r}10200 \\
11450 \\
9,352 \\
17,328 \\
953,94 \\
1984,1 \\
3 \\
4\end{array}$ & $\begin{array}{r}60,00 \\
82,20 \\
7,213 \\
14,804 \\
4,328 \\
12,169 \\
3 \\
4\end{array}$ & $\begin{array}{r}26,60 \\
42,75 \\
19,018 \\
4,938 \\
5,059 \\
2,111 \\
3 \\
4\end{array}$ & $\begin{array}{r}3,57 \\
5,00 \\
21,044 \\
28,237 \\
0,751 \\
1,412 \\
3 \\
4\end{array}$ & $\begin{array}{r}8,33 \\
0,88 \\
23,062 \\
13,163 \\
1,922 \\
1,431 \\
3\end{array}$ \\
\hline$\frac{\text { Parkia }}{\text { pendula }}$ & $\begin{array}{l}\mu(v) \\
\mu(12 \%) \\
C V(V) \\
C V(12 \%) \\
s(V) \\
S(12 \%) \\
N(v) \\
N(12 \%)\end{array}$ & $\begin{array}{r}0,50 \\
0,49 \\
12,544 \\
7,788 \\
0,062 \\
0,038 \\
10 \\
7\end{array}$ & $\begin{array}{r}7,66 \\
7,50 \\
12,632 \\
13,110 \\
0,968 \\
0,983 \\
10 \\
7\end{array}$ & $\begin{array}{r}3,74 \\
3,94 \\
30,867 \\
34,361 \\
1,155 \\
1,353 \\
10 \\
7\end{array}$ & $\begin{array}{r}10,46 \\
10,52 \\
7,713 \\
9,459 \\
0,806 \\
0,995 \\
9 \\
6\end{array}$ & $\begin{array}{r}9910 \\
12157 \\
12,141 \\
14,270 \\
1203,2 \\
1734,8 \\
10 \\
7\end{array}$ & $\begin{array}{r}65,85 \\
84,87 \\
16,652 \\
23,317 \\
10,965 \\
19,790 \\
10 \\
7\end{array}$ & $\begin{array}{r}31,28 \\
48,67 \\
14,310 \\
12,635 \\
4,476 \\
6,150 \\
10 \\
7\end{array}$ & $\begin{array}{r}4,34 \\
6,80 \\
21,040 \\
21,412 \\
0,913 \\
1,456 \\
10 \\
7\end{array}$ & $\begin{array}{r}9,56 \\
11,37 \\
16,897 \\
9,894 \\
1,615 \\
1,125 \\
10\end{array}$ \\
\hline$\frac{\text { Planchonel la }}{\text { pachycarpa }}$ & $\begin{array}{l}\mu(v) \\
\mu(12 \%) \\
C V(V) \\
C V(12 \%) \\
S(V) \\
S \quad(12 \%) \\
N(v) \\
N(12 \%)\end{array}$ & $\begin{array}{r}0,75 \\
0,75 \\
4,583 \\
4,580 \\
0,034 \\
0,034 \\
8 \\
8\end{array}$ & $\begin{array}{r}12,21 \\
12,77 \\
11,956 \\
14,243 \\
1,460 \\
1,819 \\
8 \\
8\end{array}$ & $\begin{array}{r}6,31 \\
6,48 \\
6,883 \\
9,976 \\
0,434 \\
0,647 \\
8 \\
8\end{array}$ & $\begin{array}{r}17,45 \\
17,53 \\
4,901 \\
5,089 \\
0,855 \\
0,892 \\
8 \\
7\end{array}$ & $\begin{array}{r}15800 \\
17325 \\
11,841 \\
8,179 \\
1870,8 \\
1417,0 \\
8 \\
8\end{array}$ & $\begin{array}{r}116,00 \\
168,86 \\
13,176 \\
10,381 \\
15,284 \\
17,530 \\
8 \\
8\end{array}$ & $\begin{array}{r}55,31 \\
84,43 \\
8,022 \\
9,614 \\
4,437 \\
8,117 \\
8 \\
8\end{array}$ & $\begin{array}{r}6,80 \\
11,39 \\
11,895 \\
11,092 \\
0,809 \\
1,263 \\
8 \\
8\end{array}$ & $\begin{array}{r}11,43 \\
17,49 \\
11,591 \\
8,798 \\
1,324 \\
1,538 \\
8 \\
8\end{array}$ \\
\hline $\begin{array}{l}\text { Piptadenia } \\
\text { suaveolens }\end{array}$ & $\begin{array}{l}\mu(V) \\
\mu(12 \%) \\
C V(V) \\
C V(12 \%) \\
s(V) \\
\text { s }(12 \%) \\
N(v) \\
N(12 \%)\end{array}$ & $\begin{array}{r}0,76 \\
0,75 \\
9,580 \\
10,232 \\
0,073 \\
0,077 \\
8 \\
5\end{array}$ & $\begin{array}{r}8,35 \\
8,59 \\
10,385 \\
5,925 \\
0,867 \\
0,509 \\
8 \\
5\end{array}$ & $\begin{array}{r}5,29 \\
5,38 \\
14,272 \\
11,486 \\
0,755 \\
0,618 \\
7 \\
5\end{array}$ & $\begin{array}{r}13,16 \\
13,64 \\
13,060 \\
9,003 \\
1,718 \\
1,228 \\
7 \\
5\end{array}$ & $\begin{array}{r}13775 \\
15900 \\
7,205 \\
5,031 \\
992,47 \\
800,00 \\
8 \\
5\end{array}$ & $\begin{array}{r}111,74 \\
146,54 \\
12,144 \\
8,689 \\
13,569 \\
12,733 \\
8 \\
5\end{array}$ & $\begin{array}{r}55,90 \\
77,34 \\
9,560 \\
6,357 \\
5,344 \\
4,917 \\
8 \\
5\end{array}$ & $\begin{array}{r}9,16 \\
13,64 \\
25,840 \\
18,588 \\
2,368 \\
2,535 \\
8 \\
5\end{array}$ & $\begin{array}{r}14,60 \\
15,12 \\
12,209 \\
12,100 \\
1,782 \\
1,829 \\
8 \\
5\end{array}$ \\
\hline$\frac{\text { Protium }}{\text { tenuifol ium }}$ & $\begin{array}{l}\mu(v) \\
\mu(12 \%) \\
C V(V) \\
C V(12 \%) \\
s(v) \\
S(12 \%) \\
N(v) \\
N(12 \%)\end{array}$ & $\begin{array}{r}0,63 \\
0,63 \\
4,762 \\
4,762 \\
0,030 \\
0,030 \\
3 \\
3\end{array}$ & $\begin{array}{r}8,36 \\
8,36 \\
8,623 \\
8,623 \\
0,721 \\
0,721 \\
3 \\
3\end{array}$ & $\begin{array}{r}4,18 \\
4,18 \\
18,832 \\
18,832 \\
0,788 \\
0,788 \\
3 \\
3\end{array}$ & $\begin{array}{r}12,00 \\
12,00 \\
7,500 \\
7,500 \\
0,900 \\
0,900 \\
3 \\
3\end{array}$ & $\begin{array}{r}11967 \\
12867 \\
5,373 \\
4,685 \\
642,91 \\
602,77 \\
3 \\
3\end{array}$ & $\begin{array}{r}87,37 \\
116,43 \\
7,852 \\
3,453 \\
6,860 \\
4,020 \\
3 \\
3\end{array}$ & $\begin{array}{r}40,07 \\
64,53 \\
6,433 \\
6,476 \\
2,577 \\
4,179 \\
3 \\
3\end{array}$ & $\begin{array}{r}7,47 \\
9,43 \\
12,658 \\
11,135 \\
0,945 \\
1,050 \\
3 \\
3\end{array}$ & $\begin{array}{r}10,30 \\
14,87 \\
9,562 \\
11,442 \\
0,985 \\
1,701 \\
3 \\
3\end{array}$ \\
\hline$\frac{\text { Protium }}{\text { sp. }}$ & $\begin{array}{l}\mu(V) \\
\mu(12 \%) \\
C V(V) \\
C V(12 \%) \\
s(V) \\
s(12 \%) \\
N(v) \\
N(12 \%)\end{array}$ & $\begin{array}{r}0,77 \\
0,74 \\
6,264 \\
1,695 \\
0,048 \\
0,013 \\
6 \\
4\end{array}$ & $\begin{array}{r}9,72 \\
9,83 \\
8,124 \\
8,897 \\
0,790 \\
0,874 \\
5 \\
4\end{array}$ & $\begin{array}{r}5,23 \\
5,32 \\
17,231 \\
19,080 \\
0,900 \\
1,014 \\
5 \\
4\end{array}$ & $\begin{array}{r}14,62 \\
14,50 \\
6,674 \\
8,966 \\
0,976 \\
1,300 \\
5 \\
3\end{array}$ & $\begin{array}{r}14317 \\
16275 \\
10,383 \\
4,796 \\
1486,5 \\
780,49 \\
6 \\
4\end{array}$ & $\begin{array}{r}111,07 \\
137,68 \\
14,036 \\
18,106 \\
15,590 \\
24,928 \\
6 \\
4\end{array}$ & $\begin{array}{r}53,32 \\
79,60 \\
17,050 \\
6,594 \\
9,091 \\
5,248 \\
6 \\
4\end{array}$ & $\begin{array}{r}9,42 \\
11,28 \\
12,264 \\
4,878 \\
1,155 \\
0,550 \\
6 \\
4\end{array}$ & $\begin{array}{r}12,37 \\
18,33 \\
5,524 \\
9,329 \\
0,683 \\
1,710 \\
6 \\
4\end{array}$ \\
\hline
\end{tabular}


continuação

\begin{tabular}{|c|c|c|c|c|c|c|c|c|c|c|}
\hline $\begin{array}{l}\text { Qualea } \\
\text { albiflora }\end{array}$ & $\begin{array}{l}\mu(v) \\
\mu(12 \%) \\
\text { CV }(v) \\
\text { CV }(12 \%) \\
S \text { S (V) } \\
\text { S }(12 \%) \\
N(v) \\
N(12 \%)\end{array}$ & $\begin{array}{r}0,57 \\
0,57 \\
8,474 \\
8,474 \\
0,048 \\
0,048 \\
4 \\
4\end{array}$ & $\begin{array}{r}9,54 \\
9,54 \\
11,984 \\
11,984 \\
1,143 \\
1,143 \\
4 \\
4\end{array}$ & $\begin{array}{r}5,28 \\
5,28 \\
9,063 \\
9,063 \\
0,479 \\
0,479 \\
4 \\
4\end{array}$ & $\begin{array}{r}14,73 \\
14,73 \\
11,923 \\
11,923 \\
1,756 \\
1,756 \\
4 \\
4\end{array}$ & $\begin{array}{r}11300 \\
13375 \\
10,644 \\
9,775 \\
1202,8 \\
1307,4 \\
4 \\
4\end{array}$ & $\begin{array}{r}67,38 \\
111,22 \\
20,596 \\
9,519 \\
13,877 \\
10,588 \\
4 \\
4\end{array}$ & $\begin{array}{r}41,60 \\
58,98 \\
11,480 \\
13,107 \\
4,776 \\
7,730 \\
4 \\
4\end{array}$ & $\begin{array}{r}4,50 \\
8,35 \\
13,818 \\
4,938 \\
0,622 \\
0,412 \\
4 \\
4\end{array}$ & $\begin{array}{r}9,93 \\
14,15 \\
6,066 \\
13,477 \\
0,602 \\
1,907 \\
4 \\
4\end{array}$ \\
\hline $\begin{array}{l}\text { Qualea } \\
\text { brevipedicel lat }\end{array}$ & $\begin{array}{l}\mu(V) \\
\text { ta } \mu(12 \%) \\
C V(V) \\
C V(12 \%) \\
S(V) \\
S(12 \%) \\
N(V) \\
N(12 \%)\end{array}$ & $\begin{array}{r}0,74 \\
0,74 \\
5,056 \\
5,056 \\
0,037 \\
0,037 \\
7 \\
4\end{array}$ & $\begin{array}{r}8,81 \\
8,60 \\
14,948 \\
13,411 \\
1,318 \\
1,154 \\
7 \\
4\end{array}$ & $\begin{array}{r}4,79 \\
4,93 \\
18,270 \\
22,450 \\
0,875 \\
1,106 \\
7 \\
4\end{array}$ & $\begin{array}{r}14,02 \\
13,75 \\
12,869 \\
16,268 \\
1,804 \\
2,237 \\
6 \\
4\end{array}$ & $\begin{array}{r}13757 \\
16075 \\
12,263 \\
6,859 \\
1687,1 \\
1102,6 \\
7 \\
4\end{array}$ & $\begin{array}{r}102,63 \\
151,73 \\
12,990 \\
11,748 \\
13,331 \\
17,824 \\
7 \\
4\end{array}$ & $\begin{array}{r}60,90 \\
79,60 \\
16,684 \\
11,530 \\
10,160 \\
9,178 \\
7 \\
4\end{array}$ & $\begin{array}{r}8,31 \\
14,45 \\
14,085 \\
21,749 \\
1,171 \\
3,143 \\
7 \\
4\end{array}$ & $\begin{array}{r}12,36 \\
13,93 \\
16,877 \\
4,518 \\
2,086 \\
0,629 \\
7 \\
4\end{array}$ \\
\hline$\frac{\text { Rollinia }}{\text { exsucca }}$ & $\begin{array}{l}\mu(v) \\
\mu(12 \%) \\
\text { CV }(v) \\
\text { CV }(12 \%) \\
\text { S }(v) \\
\text { S }(12 \%) \\
\text { N }(v) \\
N(12 \%)\end{array}$ & $\begin{array}{r}0,52 \\
0,52 \\
4,119 \\
4,119 \\
0,021 \\
0,021 \\
2 \\
2\end{array}$ & $\begin{array}{r}8,81 \\
8,81 \\
4,096 \\
4,096 \\
0,361 \\
0,361 \\
2 \\
2\end{array}$ & $\begin{array}{r}3,19 \\
3,19 \\
0,666 \\
0,666 \\
0,021 \\
0,021 \\
2 \\
2\end{array}$ & $\begin{array}{r}12,35 \\
12,35 \\
0,573 \\
0,573 \\
0,071 \\
0,071 \\
2 \\
2\end{array}$ & $\begin{array}{r}11600 \\
12000 \\
6,096 \\
3,536 \\
707,11 \\
424,26 \\
2 \\
2\end{array}$ & $\begin{array}{r}75,40 \\
91,40 \\
2,251 \\
4,951 \\
1,697 \\
4,525 \\
2 \\
2\end{array}$ & $\begin{array}{r}36,55 \\
53,30 \\
3,289 \\
5,572 \\
1,202 \\
2,970 \\
2 \\
2\end{array}$ & $\begin{array}{r}3,90 \\
6,00 \\
18,131 \\
4,714 \\
0,707 \\
0,283 \\
2 \\
2\end{array}$ & $\begin{array}{r}7,90 \\
8,55 \\
16,111 \\
14,059 \\
1,273 \\
1,202 \\
2 \\
2\end{array}$ \\
\hline $\begin{array}{l}\text { Roupala } \\
\text { montana }\end{array}$ & $\begin{array}{l}\mu(v) \\
\mu(12 \%) \\
C V(V) \\
C V(12 \%) \\
S(V) \\
S(12 \%) \\
N(v) \\
N(12 \%)\end{array}$ & $\begin{array}{r}0,77 \\
0,77 \\
2,675 \\
2,645 \\
0,021 \\
0,020 \\
8 \\
6\end{array}$ & $\begin{array}{r}12,34 \\
12,56 \\
6,058 \\
4,454 \\
0,748 \\
0,559 \\
8 \\
6\end{array}$ & $\begin{array}{r}6,27 \\
6,17 \\
9,570 \\
10,893 \\
0,600 \\
0,672 \\
8 \\
6\end{array}$ & $\begin{array}{r}17,98 \\
18,18 \\
6,299 \\
6,820 \\
1,132 \\
1,240 \\
8 \\
6\end{array}$ & $\begin{array}{r}14763 \\
18183 \\
9,634 \\
8,093 \\
1422,2 \\
1471,6 \\
8 \\
6\end{array}$ & $\begin{array}{r}99,38 \\
163,73 \\
11,260 \\
8,195 \\
11,189 \\
13,419 \\
8 \\
6\end{array}$ & $\begin{array}{r}49,68 \\
88,98 \\
6,787 \\
8,560 \\
3,371 \\
7,617 \\
8 \\
6\end{array}$ & $\begin{array}{r}8,71 \\
10,85 \\
9,592 \\
12,781 \\
0,836 \\
1,387 \\
8 \\
6\end{array}$ & $\begin{array}{r}10,89 \\
15,55 \\
13,049 \\
8,081 \\
1,421 \\
1,257 \\
8 \\
6\end{array}$ \\
\hline $\begin{array}{l}\text { Sclerolobium } \\
\text { chrysophyllum }\end{array}$ & $\begin{array}{l}\mu(v) \\
\mu(12 \%) \\
\text { CV }(v) \\
\text { CV }(12 \%) \\
\text { S }(v) \\
\text { S }(12 \%) \\
\text { N }(v) \\
N(12 \%)\end{array}$ & $\begin{array}{r}0,61 \\
0,65 \\
15,906 \\
13,152 \\
0,097 \\
0,085 \\
4 \\
3\end{array}$ & $\begin{array}{r}8,00 \\
8,03 \\
8,011 \\
9,735 \\
0,641 \\
0,781 \\
4 \\
3\end{array}$ & $\begin{array}{r}4,35 \\
4,22 \\
13,712 \\
15,617 \\
0,596 \\
0,659 \\
4 \\
3\end{array}$ & $\begin{array}{r}12,08 \\
12,13 \\
4,078 \\
4,829 \\
0,492 \\
0,586 \\
4 \\
3\end{array}$ & $\begin{array}{r}12175 \\
14167 \\
8,519 \\
7,934 \\
1037,2 \\
1124,0 \\
4 \\
3\end{array}$ & $\begin{array}{r}81,23 \\
125,97 \\
15,473 \\
5,340 \\
12,568 \\
6,726 \\
4 \\
3\end{array}$ & $\begin{array}{r}41,73 \\
63,40 \\
17,446 \\
6,442 \\
7,279 \\
4,084 \\
4 \\
3\end{array}$ & $\begin{array}{r}5,20 \\
10,00 \\
20,108 \\
18,000 \\
1,046 \\
1,800 \\
4 \\
3\end{array}$ & $\begin{array}{r}11,63 \\
15,73 \\
18,090 \\
16,868 \\
2,103 \\
2,654 \\
4 \\
3\end{array}$ \\
\hline $\begin{array}{l}\text { Sandwi thiodoxa } \\
\text { egregia }\end{array}$ & $\begin{array}{l}\mu(v) \\
\mu(12 \%) \\
C V(v) \\
C V(12 \%) \\
s(v) \\
S(12 \%) \\
N(v) \\
N(12 \%)\end{array}$ & $\begin{array}{r}0,79 \\
0,79 \\
13,314 \\
13,314 \\
0,105 \\
0,105 \\
6 \\
6\end{array}$ & $\begin{array}{r}10,50 \\
10,50 \\
12,494 \\
12,494 \\
1,311 \\
1,311 \\
6 \\
6\end{array}$ & $\begin{array}{r}6,69 \\
6,69 \\
12,943 \\
12,943 \\
0,866 \\
0,866 \\
6 \\
6\end{array}$ & $\begin{array}{r}15,33 \\
15,93 \\
14,990 \\
11,509 \\
2,298 \\
1,834 \\
6 \\
6\end{array}$ & $\begin{array}{r}14200 \\
17800 \\
13,302 \\
16,711 \\
1888,9 \\
2974,6 \\
6 \\
6\end{array}$ & $\begin{array}{r}108,18 \\
176,20 \\
21,181 \\
12,476 \\
22,914 \\
21,982 \\
6 \\
6\end{array}$ & $\begin{array}{r}57,32 \\
90,13 \\
21,313 \\
20,110 \\
12,216 \\
18,126 \\
6 \\
6\end{array}$ & $\begin{array}{r}9,22 \\
16,02 \\
19,329 \\
16,235 \\
1,781 \\
2,600 \\
6 \\
6\end{array}$ & $\begin{array}{r}12,38 \\
19,83 \\
22,527 \\
18,713 \\
2,790 \\
3,711 \\
6 \\
6\end{array}$ \\
\hline $\begin{array}{l}\text { Symohonia } \\
\text { gl obul i fera }\end{array}$ & $\begin{array}{l}\mu(v) \\
\mu(12 \%) \\
\text { CV }(v) \\
\text { CV }(12 \%) \\
\text { s }(v) \\
\text { S }(12 \%) \\
N(v) \\
N(12 \%)\end{array}$ & $\begin{array}{r}0,58 \\
0,57 \\
6,227 \\
6,314 \\
0,036 \\
0,036 \\
9 \\
8\end{array}$ & $\begin{array}{r}7,88 \\
7,88 \\
18,355 \\
18,355 \\
1,446 \\
1,446 \\
8 \\
8\end{array}$ & $\begin{array}{r}4,41 \\
4,41 \\
17,964 \\
17,964 \\
0,792 \\
0,792 \\
8 \\
8\end{array}$ & $\begin{array}{r}12,89 \\
12,89 \\
14,490 \\
14,490 \\
1,867 \\
1,867 \\
8 \\
8\end{array}$ & $\begin{array}{r}11611 \\
13925 \\
10,294 \\
8,478 \\
1195,2 \\
1180,5 \\
9 \\
8\end{array}$ & $\begin{array}{r}77,30 \\
109,20 \\
10,200 \\
14,406 \\
7,885 \\
15,731 \\
9 \\
8\end{array}$ & $\begin{array}{r}37,88 \\
61,66 \\
15,887 \\
11,900 \\
6,018 \\
7,338 \\
9 \\
8\end{array}$ & $\begin{array}{r}5,97 \\
7,44 \\
27,283 \\
13,173 \\
1,628 \\
0,980 \\
9 \\
8\end{array}$ & $\begin{array}{r}8,91 \\
10,56 \\
14,550 \\
11,178 \\
1,297 \\
1,181 \\
9 \\
8\end{array}$ \\
\hline
\end{tabular}


continuação

\begin{tabular}{|c|c|c|c|c|c|c|c|c|c|c|}
\hline $\begin{array}{l}\text { cclerolobium } \\
\text { araense }\end{array}$ & $\begin{array}{l}\mu(v) \\
\mu(12 \%) \\
\text { CV }(v) \\
\text { CV }(12 \%) \\
\text { s }(v) \\
\text { s }(12 \%) \\
\text { N }(v) \\
N(12 \%)\end{array}$ & $\begin{array}{r}0,67 \\
0,66 \\
5,915 \\
6,165 \\
0,039 \\
0,041 \\
10 \\
9\end{array}$ & $\begin{array}{r}8,38 \\
8,38 \\
6,788 \\
6,788 \\
0,569 \\
0,569 \\
9 \\
9\end{array}$ & $\begin{array}{r}4,04 \\
4,04 \\
23,566 \\
23,566 \\
0,952 \\
0,952 \\
9 \\
9\end{array}$ & $\begin{array}{r}12,363 \\
12,363 \\
8,260 \\
8,260 \\
1,021 \\
1,021 \\
8 \\
8\end{array}$ & $\begin{array}{r}12367 \\
13978 \\
8,596 \\
5,551 \\
1063,0 \\
775,85 \\
9 \\
9\end{array}$ & $\begin{array}{r}89,57 \\
128,22 \\
7,225 \\
12,339 \\
6,471 \\
15,821 \\
9 \\
9\end{array}$ & $\begin{array}{r}42,18 \\
66,00 \\
9,134 \\
10,068 \\
3,853 \\
6,645 \\
9 \\
9\end{array}$ & $\begin{array}{r}7,20 \\
10,13 \\
22,092 \\
35,962 \\
1,591 \\
3,644 \\
9 \\
9\end{array}$ & $\begin{array}{r}12,57 \\
17,72 \\
14,673 \\
9,678 \\
1,844 \\
1,715 \\
0\end{array}$ \\
\hline $\begin{array}{l}\text { clerol obium } \\
\text { oeppigianum }\end{array}$ & $\begin{array}{l}\mu(v) \\
\mu(12 \%) \\
\text { CV }(v) \\
\text { CV (12\%) } \\
\text { s (v) } \\
\text { s }(12 \%) \\
\text { N }(v) \\
\text { N }(12 \%)\end{array}$ & $\begin{array}{r}0,65 \\
0,65 \\
16,209 \\
16,209 \\
0,105 \\
0,105 \\
3 \\
3\end{array}$ & $\begin{array}{r}8,15 \\
8,15 \\
5,802 \\
5,802 \\
0,473 \\
0,473 \\
3 \\
3\end{array}$ & $\begin{array}{r}4,25 \\
4,25 \\
22,376 \\
22,376 \\
0,950 \\
0,950 \\
3 \\
3\end{array}$ & $\begin{array}{r}12,60 \\
12,60 \\
8,944 \\
8,944 \\
1,127 \\
1,127 \\
3 \\
3\end{array}$ & $\begin{array}{r}13067 \\
13933 \\
2,897 \\
6,104 \\
378,59 \\
850,49 \\
3 \\
3\end{array}$ & $\begin{array}{r}94,73 \\
131,27 \\
13,956 \\
17,793 \\
13,221 \\
23,356 \\
3 \\
3\end{array}$ & $\begin{array}{r}46,93 \\
68,97 \\
5,867 \\
13,757 \\
2,754 \\
9,488 \\
3 \\
3\end{array}$ & $\begin{array}{r}6,03 \\
10,60 \\
26,845 \\
12,373 \\
1,620 \\
1,311 \\
3 \\
3\end{array}$ & $\begin{array}{r}11,23 \\
18,10 \\
10,987 \\
19,384 \\
1,234 \\
3,509 \\
3 \\
3\end{array}$ \\
\hline$\frac{\text { terculia }}{\text { peciosa }}$ & $\begin{array}{l}\mu(v) \\
\mu(12 \%) \\
\text { CV }(v) \\
\text { CV (12\%) } \\
\text { s (v) } \\
\text { s (12\%) } \\
\text { N }(v) \\
\text { N }(12 \%)\end{array}$ & $\begin{array}{r}0,48 \\
0,46 \\
14,143 \\
19,457 \\
0,068 \\
0,089 \\
6 \\
7\end{array}$ & $\begin{array}{r}11,63 \\
9,98 \\
15,579 \\
13,580 \\
1,812 \\
1,355 \\
6 \\
7\end{array}$ & $\begin{array}{r}5,35 \\
4,58 \\
9,160 \\
24,714 \\
0,490 \\
1,132 \\
6 \\
7\end{array}$ & $\begin{array}{r}15,94 \\
15,20 \\
11,624 \\
13,199 \\
1,853 \\
2,006 \\
5 \\
5\end{array}$ & $\begin{array}{r}10730 \\
13457 \\
12,656 \\
7,087 \\
1360,5 \\
953,69 \\
6 \\
7\end{array}$ & $\begin{array}{r}57,83 \\
93,30 \\
18,307 \\
13,020 \\
10,587 \\
12,148 \\
6 \\
7\end{array}$ & $\begin{array}{r}25,90 \\
50,96 \\
14,190 \\
14,258 \\
3,675 \\
7,265 \\
6 \\
7\end{array}$ & $\begin{array}{r}2,73 \\
4,70 \\
25,206 \\
40,126 \\
0,689 \\
1,886 \\
6 \\
7\end{array}$ & $\begin{array}{r}7,42 \\
9,01 \\
17,835 \\
12,704 \\
1,323 \\
1,145 \\
6 \\
7\end{array}$ \\
\hline$\frac{\text { etragastris }}{\text { ltissima }}$ & $\begin{array}{l}\mu(v) \\
\mu(12 \%) \\
c V(v) \\
\text { CV }(12 \%) \\
\text { s }(v) \\
\text { S }(12 \%) \\
N(v) \\
\text { N }(12 \%)\end{array}$ & $\begin{array}{r}0,76 \\
0,74 \\
15,922 \\
11,754 \\
0,120 \\
0,087 \\
2 \\
3\end{array}$ & $\begin{array}{r}8,95 \\
9,01 \\
11,937 \\
8,479 \\
1,068 \\
0,764 \\
2 \\
3\end{array}$ & $\begin{array}{r}4,48 \\
4,58 \\
22,728 \\
16,169 \\
1,018 \\
0,741 \\
2 \\
3\end{array}$ & $\begin{array}{r}13,80 \\
13,00 \\
6,149 \\
11,615 \\
0,849 \\
1,510 \\
2 \\
3\end{array}$ & $\begin{array}{r}12850 \\
14600 \\
15,958 \\
11,023 \\
2050,6 \\
1609,3 \\
2 \\
3\end{array}$ & $\begin{array}{r}112,60 \\
137,30 \\
22,733 \\
17,238 \\
25,597 \\
23,668 \\
2 \\
3\end{array}$ & $\begin{array}{r}57,65 \\
77,90 \\
8,954 \\
12,549 \\
5,162 \\
9,775 \\
2 \\
3\end{array}$ & $\begin{array}{r}10,00 \\
15,53 \\
28,284 \\
6,351 \\
2,828 \\
0,987 \\
2 \\
3\end{array}$ & $\begin{array}{r}13,00 \\
18,33 \\
16,318 \\
4,542 \\
2,121 \\
0,833 \\
2 \\
3\end{array}$ \\
\hline $\begin{array}{l}\text { Trattinickia } \\
\text { burserifolia }\end{array}$ & $\begin{array}{l}\mu(v) \\
\mu(12 \%) \\
\text { CV }(v) \\
\text { CV (12\%) } \\
\text { s (v) } \\
\text { s (12\%) } \\
\text { N }(v) \\
\text { N }(12 \%)\end{array}$ & $\begin{array}{r}0,50 \\
0,50 \\
4,285 \\
4,285 \\
0,021 \\
0,021 \\
2 \\
2\end{array}$ & $\begin{array}{r}6,79 \\
6,79 \\
9,484 \\
9,484 \\
0,643 \\
0,643 \\
2 \\
2\end{array}$ & $\begin{array}{r}4,10 \\
4,10 \\
18,822 \\
18,822 \\
0,771 \\
0,771 \\
2 \\
2\end{array}$ & $\begin{array}{r}11,75 \\
11,75 \\
3,009 \\
3,009 \\
0,354 \\
0,354 \\
2 \\
2\end{array}$ & $\begin{array}{r}9900 \\
11200 \\
18,570 \\
5,051 \\
1838,5 \\
565,69 \\
2 \\
2\end{array}$ & $\begin{array}{r}51,70 \\
65,35 \\
20,516 \\
18,070 \\
10,607 \\
11,809 \\
2 \\
2\end{array}$ & $\begin{array}{r}28,05 \\
45,95 \\
16,386 \\
6,002 \\
4,596 \\
2,758 \\
2 \\
2\end{array}$ & $\begin{array}{r}3,20 \\
5,90 \\
35,355 \\
2,397 \\
1,131 \\
0,141 \\
2 \\
2\end{array}$ & $\begin{array}{r}9,40 \\
10,05 \\
3,009 \\
0,704 \\
0,283 \\
0,071 \\
2 \\
2\end{array}$ \\
\hline$\frac{\text { Trichilia }}{\text { lecointei }}$ & $\begin{array}{l}\mu(v) \\
\mu(12 \%) \\
\text { CV }(v) \\
\text { CV (12\%) } \\
\text { s (v) } \\
\text { s (12\%) } \\
\text { N }(v) \\
\text { N }(12 \%)\end{array}$ & $\begin{array}{r}0,90 \\
0,91 \\
4,843 \\
4,075 \\
0,043 \\
0,037 \\
8 \\
7\end{array}$ & $\begin{array}{r}8,22 \\
8,12 \\
9,961 \\
10,254 \\
0,819 \\
0,833 \\
8 \\
7\end{array}$ & $\begin{array}{r}4,44 \\
4,44 \\
17,615 \\
17,615 \\
0,783 \\
0,783 \\
7 \\
7\end{array}$ & $\begin{array}{r}13,17 \\
13,17 \\
14,523 \\
14,523 \\
1,913 \\
1,913 \\
7 \\
7\end{array}$ & $\begin{array}{r}13688 \\
16529 \\
11,535 \\
14,921 \\
1578,8 \\
2466,2 \\
8 \\
7\end{array}$ & $\begin{array}{r}106,74 \\
158,80 \\
10,508 \\
21,963 \\
11,216 \\
34,877 \\
8 \\
7\end{array}$ & $\begin{array}{r}55,04 \\
87,64 \\
15,345 \\
19,462 \\
8,446 \\
17,057 \\
8 \\
7\end{array}$ & $\begin{array}{r}14,01 \\
19,06 \\
15,001 \\
6,178 \\
2,102 \\
1,177 \\
8 \\
7\end{array}$ & $\begin{array}{r}15,00 \\
19,39 \\
13,127 \\
12,460 \\
1,969 \\
2,416 \\
8 \\
7\end{array}$ \\
\hline$\frac{\text { Tachigal ia cf }}{\text { myrmecophyla }}$ & $\begin{array}{l}\mu(v) \\
\mu(12 \%) \\
\text { CV }(v) \\
C v(12 \%) \\
S \text { s }(v) \\
\text { S (12\%) } \\
N(v) \\
N \quad(12 \%)\end{array}$ & $\begin{array}{r}0,59 \\
0,59 \\
3,508 \\
3,626 \\
0,021 \\
0,021 \\
3 \\
2\end{array}$ & $\begin{array}{r}7,26 \\
7,35 \\
3,077 \\
3,079 \\
0,223 \\
0,226 \\
3 \\
2\end{array}$ & $\begin{array}{r}5,13 \\
5,26 \\
10,281 \\
12,905 \\
0,528 \\
0,679 \\
3 \\
2\end{array}$ & $\begin{array}{l}11,80 \\
11,70 \\
8,601 \\
12,087 \\
1,015 \\
1,414 \\
3 \\
2\end{array}$ & $\begin{array}{r}11767 \\
13350 \\
3,218 \\
4,767 \\
378,59 \\
636,40 \\
3 \\
2\end{array}$ & $\begin{array}{l}83,80 \\
128,40 \\
2,990 \\
11,785 \\
2,506 \\
15,132 \\
3 \\
2\end{array}$ & $\begin{array}{r}41,67 \\
63,40 \\
3,909 \\
12,938 \\
1,629 \\
8,202 \\
3 \\
2\end{array}$ & $\begin{array}{r}5,53 \\
10,30 \\
14,608 \\
17,849 \\
0,808 \\
1,838 \\
3 \\
2\end{array}$ & $\begin{array}{r}12,60 \\
15,75 \\
6,496 \\
8,530 \\
0,819 \\
1,344 \\
3 \\
2\end{array}$ \\
\hline
\end{tabular}


continuação

\begin{tabular}{|c|c|c|c|c|c|c|c|c|c|c|}
\hline$\frac{\text { Tetragastris }}{\text { panamensis }}$ & $\begin{array}{l}\mu(v) \\
\mu(12 \%) \\
C V(V) \\
C V(12 \%) \\
s(v) \\
S(12 \%) \\
N(v) \\
N(12 \%)\end{array}$ & $\begin{array}{r}0,77 \\
0,76 \\
5,196 \\
5,152 \\
0,040 \\
0,039 \\
6 \\
6\end{array}$ & $\begin{array}{r}9,70 \\
10,01 \\
8,718 \\
10,715 \\
0,846 \\
1,073 \\
6 \\
6\end{array}$ & $\begin{array}{r}5,01 \\
5,06 \\
6,210 \\
6,784 \\
0,311 \\
0,343 \\
6 \\
6\end{array}$ & $\begin{array}{r}14,90 \\
15,35 \\
8,954 \\
9,015 \\
1,334 \\
1,384 \\
6 \\
6\end{array}$ & $\begin{array}{r}12567 \\
13983 \\
6,439 \\
12,979 \\
809,11 \\
1814,8 \\
6 \\
6\end{array}$ & $\begin{array}{r}98,17 \\
124,92 \\
3,822 \\
18,934 \\
3,752 \\
23,651 \\
6 \\
6\end{array}$ & $\begin{array}{r}49,07 \\
72,55 \\
6,510 \\
7,464 \\
3,194 \\
5,415 \\
6 \\
6\end{array}$ & $\begin{array}{r}11,02 \\
14,62 \\
16,722 \\
11,320 \\
1,842 \\
1,655 \\
6 \\
6\end{array}$ & $\begin{array}{r}15,25 \\
20,12 \\
12,781 \\
19,471 \\
1,949 \\
3,917 \\
6 \\
6\end{array}$ \\
\hline Vochysia & $\begin{array}{l}\mu(v) \\
\mu(12 \%) \\
C V(V) \\
C V(12 \%) \\
s(v) \\
\text { s }(12 \%) \\
N(v) \\
N(12 \%)\end{array}$ & $\begin{array}{r}0,58 \\
0,54 \\
7,315 \\
15,061 \\
0,042 \\
0,081 \\
2 \\
3\end{array}$ & $\begin{array}{r}10,19 \\
11,47 \\
10,686 \\
20,420 \\
1,089 \\
2,341 \\
2 \\
3\end{array}$ & $\begin{array}{r}5,14 \\
5,03 \\
27,678 \\
20,305 \\
1,421 \\
1,021 \\
2 \\
3\end{array}$ & $\begin{array}{r}15,35 \\
16,10 \\
17,966 \\
14,553 \\
2,758 \\
2,343 \\
2 \\
3\end{array}$ & $\begin{array}{r}11650 \\
14300 \\
15,174 \\
13,775 \\
1767,8 \\
1969,8 \\
2 \\
3\end{array}$ & $\begin{array}{r}71,40 \\
123,70 \\
1,386 \\
13,224 \\
0,990 \\
16,358 \\
2 \\
3\end{array}$ & $\begin{array}{r}32,55 \\
66,63 \\
2,390 \\
15,381 \\
0,778 \\
10,249 \\
2 \\
3\end{array}$ & $\begin{array}{r}4,25 \\
6,90 \\
11,646 \\
8,069 \\
0,495 \\
0,557 \\
2 \\
3\end{array}$ & $\begin{array}{r}7,70 \\
12,47 \\
3,673 \\
5,341 \\
0,283 \\
0,666 \\
2 \\
3\end{array}$ \\
\hline$\frac{\text { Vochysia }}{\text { melinonii }}$ & $\begin{array}{l}\mu(v) \\
\mu(12 \%) \\
C V(v) \\
C V(12 \%) \\
s(v) \\
\text { s }(12 \%) \\
N(v) \\
N(12 \%)\end{array}$ & $\begin{array}{r}0,51 \\
0,51 \\
10,375 \\
10,375 \\
0,053 \\
0,053 \\
3 \\
3\end{array}$ & $\begin{array}{r}10,87 \\
10,87 \\
16,110 \\
16,110 \\
1,741 \\
1,741 \\
3 \\
3\end{array}$ & $\begin{array}{r}4,74 \\
4,74 \\
9,583 \\
9,583 \\
0,454 \\
0,454 \\
3 \\
3\end{array}$ & $\begin{array}{r}14,13 \\
14,13 \\
3,191 \\
3,191 \\
0,451 \\
0,451 \\
3 \\
3\end{array}$ & $\begin{array}{r}9400 \\
12100 \\
6,383 \\
3,787 \\
600,00 \\
458,26 \\
3 \\
3\end{array}$ & $\begin{array}{r}56,77 \\
99,70 \\
11,225 \\
9,154 \\
6,372 \\
9,126 \\
3 \\
3\end{array}$ & $\begin{array}{r}29,27 \\
54,90 \\
4,537 \\
2,216 \\
1,328 \\
1,217 \\
3 \\
3\end{array}$ & $\begin{array}{r}3,73 \\
5,10 \\
4,092 \\
8,985 \\
0,153 \\
0,458 \\
3 \\
3\end{array}$ & $\begin{array}{r}8,63 \\
12,03 \\
6,787 \\
8,071 \\
0,586 \\
0,971 \\
3 \\
3\end{array}$ \\
\hline $\begin{array}{l}\text { Vatairea } \\
\text { paraensis }\end{array}$ & $\begin{array}{l}\mu(v) \\
\mu(12 \%) \\
C V(V) \\
\text { CV }(12 \%) \\
s(v) \\
s(12 \%) \\
N(v) \\
N(12 \%)\end{array}$ & $\begin{array}{r}0,78 \\
0,78 \\
2,737 \\
2,737 \\
0,021 \\
0,021 \\
2 \\
2\end{array}$ & $\begin{array}{r}9,88 \\
9,88 \\
10,669 \\
10,669 \\
1,054 \\
1,054 \\
2 \\
2\end{array}$ & $\begin{array}{r}4,62 \\
4,62 \\
16,701 \\
16,701 \\
0,771 \\
0,771 \\
2 \\
2\end{array}$ & $\begin{array}{r}13,35 \\
13,95 \\
11,123 \\
16,727 \\
1,485 \\
2,333 \\
2 \\
2\end{array}$ & $\begin{array}{r}15800 \\
15450 \\
8,951 \\
3,204 \\
1414,2 \\
494,97 \\
2 \\
2\end{array}$ & $\begin{array}{r}121,85 \\
151,65 \\
3,656 \\
2,938 \\
4,455 \\
4,455 \\
2 \\
2\end{array}$ & $\begin{array}{r}63,75 \\
75,05 \\
7,210 \\
2,921 \\
4,596 \\
2,192 \\
2 \\
2\end{array}$ & $\begin{array}{r}10,20 \\
12,00 \\
22,184 \\
16,499 \\
2,263 \\
1,980 \\
2 \\
2\end{array}$ & $\begin{array}{r}13,60 \\
15,20 \\
4,159 \\
13,026 \\
0,566 \\
1,980 \\
2 \\
2\end{array}$ \\
\hline$\frac{\text { Vantanea }}{\text { parviftora }}$ & $\begin{array}{l}\mu(v) \\
\mu(12 \%) \\
C V(V) \\
C V(12 \%) \\
s(v) \\
s(12 \%) \\
N(v) \\
N(12 \%)\end{array}$ & $\begin{array}{r}0,85 \\
0,85 \\
2,935 \\
2,935 \\
0,025 \\
0,025 \\
7 \\
7\end{array}$ & $\begin{array}{r}10,46 \\
10,46 \\
7,498 \\
7,498 \\
0,784 \\
0,784 \\
7 \\
7\end{array}$ & $\begin{array}{r}8,18 \\
8,18 \\
8,175 \\
8,175 \\
0,668 \\
0,668 \\
7 \\
7\end{array}$ & $\begin{array}{r}17,87 \\
17,87 \\
7,002 \\
7,002 \\
1,251 \\
1,251 \\
7 \\
7\end{array}$ & $\begin{array}{r}15386 \\
17843 \\
10,259 \\
9,477 \\
1578,4 \\
1691,0 \\
7 \\
7\end{array}$ & $\begin{array}{r}122,43 \\
172,59 \\
10,622 \\
14,993 \\
13,005 \\
25,875 \\
7 \\
7\end{array}$ & $\begin{array}{r}63,81 \\
87,44 \\
7,237 \\
10,933 \\
4,618 \\
9,560 \\
7 \\
7\end{array}$ & $\begin{array}{r}9,86 \\
15,40 \\
9,920 \\
10,840 \\
0,978 \\
1,669 \\
7 \\
7\end{array}$ & $\begin{array}{r}13,36 \\
18,39 \\
12,571 \\
15,652 \\
1,679 \\
2,878 \\
7 \\
7\end{array}$ \\
\hline$\frac{\text { Vatairea }}{\text { sericea }}$ & $\begin{array}{l}\mu(v) \\
\mu(12 \%) \\
\text { CV }(v) \\
\text { CV }(12 \%) \\
s(v) \\
S \text { S }(12 \%) \\
N(v) \\
N(12 \%)\end{array}$ & $\begin{array}{r}0,73 \\
0,73 \\
7,131 \\
6,406 \\
0,052 \\
0,047 \\
5 \\
6\end{array}$ & $\begin{array}{r}9,04 \\
8,49 \\
11,170 \\
19,148 \\
1,010 \\
1,625 \\
5 \\
6\end{array}$ & $\begin{array}{r}4,82 \\
4,53 \\
17,002 \\
22,693 \\
0,820 \\
1,028 \\
5 \\
6\end{array}$ & $\begin{array}{r}13,78 \\
13,78 \\
13,972 \\
13,972 \\
1,925 \\
1,925 \\
5 \\
5\end{array}$ & $\begin{array}{r}13780 \\
15017 \\
10,902 \\
7,312 \\
1502,3 \\
1098,0 \\
5 \\
6\end{array}$ & $\begin{array}{r}99,90 \\
137,52 \\
14,518 \\
10,232 \\
14,503 \\
14,070 \\
5 \\
6\end{array}$ & $\begin{array}{r}50,74 \\
67,68 \\
18,989 \\
10,224 \\
9,635 \\
6,920 \\
5 \\
6\end{array}$ & $\begin{array}{r}9,26 \\
12,05 \\
23,457 \\
9,385 \\
2,172 \\
1,131 \\
5 \\
6\end{array}$ & $\begin{array}{r}11,40 \\
14,87 \\
6,386 \\
11,042 \\
0,728 \\
1,642 \\
5 \\
6\end{array}$ \\
\hline$\frac{\text { xylopia }}{\text { nitida }}$ & $\begin{array}{l}\mu(V) \\
\mu(12 \%) \\
C V(V) \\
\text { CV (12\%) } \\
s(V) \\
\text { s (12\%) } \\
N(V) \\
N(12 \%)\end{array}$ & $\begin{array}{r}0,56 \\
0,56 \\
8,672 \\
10,813 \\
0,049 \\
0,061 \\
6 \\
4\end{array}$ & $\begin{array}{r}10,71 \\
10,43 \\
10,768 \\
12,451 \\
1,153 \\
1,299 \\
6 \\
4\end{array}$ & $\begin{array}{r}7,01 \\
6,92 \\
9,378 \\
10,306 \\
0,657 \\
0,713 \\
6 \\
4\end{array}$ & $\begin{array}{r}17,23 \\
16,95 \\
7,328 \\
8,967 \\
1,263 \\
1,520 \\
6 \\
4\end{array}$ & $\begin{array}{r}14700 \\
16750 \\
8,994 \\
12,074 \\
1322,1 \\
2022,4 \\
6 \\
4\end{array}$ & $\begin{array}{r}71,23 \\
128,45 \\
18,353 \\
22,142 \\
13,073 \\
28,442 \\
6 \\
4\end{array}$ & $\begin{array}{r}36,30 \\
70,08 \\
15,824 \\
13,903 \\
5,744 \\
9,743 \\
6 \\
4\end{array}$ & $\begin{array}{r}3,53 \\
6,45 \\
17,780 \\
18,147 \\
0,628 \\
1,170 \\
6 \\
4\end{array}$ & $\begin{array}{r}7,88 \\
10,30 \\
13,458 \\
16,666 \\
1,061 \\
1,717 \\
6 \\
4\end{array}$ \\
\hline
\end{tabular}


Espécies originárias da região de Tapajós

\begin{tabular}{|c|c|c|c|c|c|c|c|c|c|c|}
\hline $\begin{array}{l}\text { Nome } \\
\text { Cientifico }\end{array}$ & & Db & Rt & $\mathbf{R r}$ & RV & $E_{f}$ & $f_{f}$ & $f_{c}$ & $f_{c n}$ & $f_{s}$ \\
\hline$\frac{\text { Alexa }}{\text { grandiflora }}$ & $\begin{array}{l}\mu(v) \\
\mu(12 \%) \\
C V(v) \\
C V(12 \%) \\
s(v) \\
S(12 \%) \\
N(v) \\
N(12 \%)\end{array}$ & $\begin{array}{r}0,60 \\
0,60 \\
5,809 \\
5,809 \\
0,035 \\
0,035 \\
4 \\
4\end{array}$ & $\begin{array}{r}9,63 \\
9,63 \\
18,063 \\
18,063 \\
1,739 \\
1,739 \\
4 \\
4\end{array}$ & $\begin{array}{r}4,93 \\
4,93 \\
29,301 \\
29,301 \\
1,443 \\
1,443 \\
4 \\
4\end{array}$ & $\begin{array}{r}14,77 \\
14,77 \\
22,021 \\
22,021 \\
3,251 \\
3,251 \\
4 \\
4\end{array}$ & $\begin{array}{r}10375 \\
12750 \\
12,477 \\
15,810 \\
1294,5 \\
2015,8 \\
4 \\
4\end{array}$ & $\begin{array}{r}71,20 \\
107,62 \\
15,443 \\
10,545 \\
10,995 \\
11,349 \\
4 \\
4\end{array}$ & $\begin{array}{r}33,35 \\
54,88 \\
18,283 \\
9,600 \\
6,097 \\
5,268 \\
4 \\
4\end{array}$ & $\begin{array}{r}9,05 \\
9,60 \\
25,669 \\
17,264 \\
2,323 \\
1,657 \\
4 \\
4\end{array}$ & $\begin{array}{r}8,48 \\
10,73 \\
10,348 \\
7,277 \\
0,877 \\
0,780 \\
4 \\
4\end{array}$ \\
\hline $\begin{array}{l}\text { Anacardium } \\
\text { spruceanum }\end{array}$ & $\begin{array}{l}\mu(v) \\
\mu(12 \%) \\
C V(v) \\
C V(12 \%) \\
s(v) \\
S(12 \%) \\
N(v) \\
N(12 \%)\end{array}$ & $\begin{array}{r}0,412 \\
0,412 \\
6,950 \\
6,950 \\
0,029 \\
0,029 \\
5 \\
5\end{array}$ & $\begin{array}{r}5,78 \\
5,96 \\
11,632 \\
8,605 \\
0,672 \\
0,513 \\
5 \\
5\end{array}$ & $\begin{array}{r}2,68 \\
2,80 \\
17,382 \\
10,412 \\
0,466 \\
0,292 \\
5 \\
5\end{array}$ & $\begin{array}{r}8,86 \\
8,86 \\
10,158 \\
10,158 \\
0,900 \\
0,900 \\
5 \\
5\end{array}$ & $\begin{array}{r}8660 \\
9000 \\
9,260 \\
9,590 \\
801,87 \\
863,13 \\
5 \\
5\end{array}$ & $\begin{array}{r}48,26 \\
61,56 \\
14,360 \\
14,601 \\
6,930 \\
8,988 \\
5 \\
5\end{array}$ & $\begin{array}{r}22,66 \\
35,20 \\
15,132 \\
12,324 \\
3,429 \\
4,338 \\
5 \\
5\end{array}$ & $\begin{array}{r}2,98 \\
4,44 \\
13,296 \\
4,091 \\
0,396 \\
0,182 \\
5 \\
5\end{array}$ & $\begin{array}{r}6,54 \\
6,34 \\
11,874 \\
2,392 \\
0,777 \\
0,152 \\
5 \\
5\end{array}$ \\
\hline$\frac{\text { Brosimum }}{\text { acutifolium }}$ & $\begin{array}{l}\mu(y) \\
\mu(12 \%) \\
C V(v) \\
C V(12 \%) \\
S(v) \\
S \quad(12 \%) \\
N(v) \\
N(12 \%)\end{array}$ & $\begin{array}{r}0,56 \\
0,56 \\
9,021 \\
9,021 \\
0,050 \\
0,050 \\
10 \\
10\end{array}$ & $\begin{array}{r}8,12 \\
8,12 \\
20,930 \\
20,930 \\
1,700 \\
1,700 \\
10 \\
10\end{array}$ & $\begin{array}{r}4,72 \\
4,72 \\
14,328 \\
14,328 \\
0,676 \\
0,676 \\
10 \\
10\end{array}$ & $\begin{array}{r}12,90 \\
12,90 \\
18,266 \\
18,266 \\
2,356 \\
2,356 \\
10 \\
10\end{array}$ & $\begin{array}{r}10090 \\
12230 \\
13,528 \\
20,268 \\
1365,0 \\
2478,8 \\
10 \\
10\end{array}$ & $\begin{array}{r}66,63 \\
106,33 \\
13,936 \\
9,401 \\
9,285 \\
9,996 \\
10 \\
10\end{array}$ & $\begin{array}{r}31,41 \\
57,62 \\
12,772 \\
8,322 \\
4,012 \\
4,795 \\
10 \\
10\end{array}$ & $\begin{array}{r}4,76 \\
8,14 \\
31,508 \\
26,062 \\
1,500 \\
2,121 \\
10 \\
10\end{array}$ & $\begin{array}{r}7,23 \\
9,59 \\
20,234 \\
16,158 \\
1,463 \\
1,550 \\
10 \\
10\end{array}$ \\
\hline $\begin{array}{l}\text { Berthol letia } \\
\text { excelsa }\end{array}$ & $\begin{array}{l}\mu(v) \\
\mu(12 \%) \\
C V(v) \\
C V(12 \%) \\
s(v) \\
s(12 \%) \\
N(v) \\
N(12 \%)\end{array}$ & $\begin{array}{r}0,63 \\
0,63 \\
7,357 \\
8,391 \\
0,046 \\
0,053 \\
6 \\
5\end{array}$ & $\begin{array}{r}8,95 \\
9,68 \\
20,171 \\
17,538 \\
1,805 \\
1,698 \\
6 \\
5\end{array}$ & $\begin{array}{r}4,68 \\
4,66 \\
19,682 \\
20,448 \\
0,922 \\
0,953 \\
6 \\
5\end{array}$ & $\begin{array}{r}13,42 \\
14,10 \\
15,196 \\
13,659 \\
2,039 \\
1,925 \\
6 \\
5\end{array}$ & $\begin{array}{r}10533 \\
12840 \\
12,388 \\
4,757 \\
1304,9 \\
610,74 \\
6 \\
5\end{array}$ & $\begin{array}{r}73,53 \\
113,10 \\
15,967 \\
10,301 \\
11,741 \\
11,650 \\
6 \\
5\end{array}$ & $\begin{array}{r}35,08 \\
58,40 \\
17,393 \\
14,442 \\
6,102 \\
8,434 \\
6 \\
5\end{array}$ & $\begin{array}{r}5,90 \\
9,24 \\
28,603 \\
27,957 \\
1,688 \\
2,583 \\
6 \\
5\end{array}$ & $\begin{array}{r}7,22 \\
10,86 \\
27,789 \\
23,715 \\
2,005 \\
2,575 \\
6 \\
5\end{array}$ \\
\hline $\begin{array}{l}\text { Cordia } \\
\text { bicolor }\end{array}$ & $\begin{array}{l}\mu(v) \\
\mu(12 \%) \\
C V(v) \\
C V(12 \%) \\
s(v) \\
s(12 \%) \\
N(v) \\
N(12 \%)\end{array}$ & $\begin{array}{r}0,45 \\
0,45 \\
12,288 \\
12,288 \\
0,056 \\
0,056 \\
4 \\
4\end{array}$ & $\begin{array}{r}11,03 \\
11,03 \\
12,222 \\
12,222 \\
1,348 \\
1,348 \\
4 \\
4\end{array}$ & $\begin{array}{r}5,40 \\
5,40 \\
20,342 \\
20,342 \\
1,098 \\
1,098 \\
4 \\
4\end{array}$ & $\begin{array}{r}17,76 \\
17,76 \\
12,528 \\
12,528 \\
2,224 \\
2,224 \\
4 \\
4\end{array}$ & $\begin{array}{r}9175 \\
12375 \\
22,938 \\
10,969 \\
2104,6 \\
1357,4 \\
4 \\
4\end{array}$ & $\begin{array}{r}59,23 \\
74,23 \\
6,302 \\
18,006 \\
3,732 \\
13,365 \\
4 \\
4\end{array}$ & $\begin{array}{r}26,95 \\
51,23 \\
9,355 \\
1,961 \\
2,521 \\
1,005 \\
4 \\
4\end{array}$ & $\begin{array}{r}2,38 \\
3,88 \\
13,912 \\
14,806 \\
0,330 \\
0,574 \\
4 \\
4\end{array}$ & $\begin{array}{r}4,90 \\
7,48 \\
20,203 \\
15,993 \\
0,990 \\
1,195 \\
4 \\
4\end{array}$ \\
\hline $\begin{array}{l}\text { Cordia } \\
\text { goeldiana }\end{array}$ & $\begin{array}{l}\mu(v) \\
\mu(12 \%) \\
C V(v) \\
C V(12 \%) \\
s(v) \\
s(12 \%) \\
N(v) \\
N(12 \%)\end{array}$ & $\begin{array}{r}0,47 \\
0,51 \\
20,474 \\
21,123 \\
0,097 \\
0,107 \\
4 \\
4\end{array}$ & $\begin{array}{r}6,65 \\
6,98 \\
9,707 \\
7,530 \\
0,645 \\
0,525 \\
4 \\
4\end{array}$ & $\begin{array}{r}4,00 \\
4,40 \\
14,289 \\
14,961 \\
0,572 \\
0,658 \\
4 \\
4\end{array}$ & $\begin{array}{r}10,78 \\
11,21 \\
14,261 \\
10,116 \\
1,537 \\
1,134 \\
4 \\
4\end{array}$ & $\begin{array}{r}8700 \\
10500 \\
20,194 \\
8,968 \\
1756,9 \\
941,63 \\
4 \\
4\end{array}$ & $\begin{array}{r}69,28 \\
95,00 \\
13,628 \\
2,794 \\
9,440 \\
2,655 \\
4 \\
4\end{array}$ & $\begin{array}{r}34,00 \\
53,25 \\
22,723 \\
13,185 \\
7,726 \\
7,021 \\
4 \\
4\end{array}$ & $\begin{array}{r}3,43 \\
6,18 \\
16,581 \\
19,894 \\
0,568 \\
1,228 \\
4 \\
4\end{array}$ & $\begin{array}{r}6,83 \\
8,45 \\
18,432 \\
23,481 \\
1,258 \\
1,984 \\
4 \\
4\end{array}$ \\
\hline
\end{tabular}


continuação

\begin{tabular}{|c|c|c|c|c|c|c|c|c|c|c|}
\hline $\begin{array}{l}\text { ouratari } \\
\text { Jianensis }\end{array}$ & $\begin{array}{l}\mu(v) \\
\mu(12 \%) \\
\mathrm{CV}(v) \\
\mathrm{CV}(12 \%) \\
\mathrm{s}(v) \\
\mathrm{s}(12 \%) \\
\mathrm{N}(v) \\
\mathrm{N}(12 \%)\end{array}$ & $\begin{array}{r}0,54 \\
0,54 \\
4,689 \\
4,689 \\
0,025 \\
0,025 \\
3 \\
3\end{array}$ & $\begin{array}{r}5,47 \\
5,47 \\
24,153 \\
24,153 \\
1,320 \\
1,320 \\
3 \\
3\end{array}$ & $\begin{array}{r}2,93 \\
2,93 \\
15,372 \\
15,372 \\
0,451 \\
0,451 \\
3 \\
3\end{array}$ & $\begin{array}{r}9,59 \\
9,59 \\
21,772 \\
21,772 \\
2,089 \\
2,089 \\
3 \\
3\end{array}$ & $\begin{array}{r}9033 \\
10833 \\
4,474 \\
13,979 \\
404,15 \\
1514,4 \\
3 \\
3\end{array}$ & $\begin{array}{r}69,30 \\
105,23 \\
5,304 \\
9,218 \\
3,676 \\
9,700 \\
3 \\
3\end{array}$ & $\begin{array}{r}29,60 \\
52,43 \\
22,823 \\
21,780 \\
6,756 \\
11,420 \\
3 \\
3\end{array}$ & $\begin{array}{r}5,60 \\
8,50 \\
20,594 \\
6,113 \\
1,153 \\
0,520 \\
3 \\
3\end{array}$ & $\begin{array}{r}9,10 \\
11,17 \\
22,708 \\
13,941 \\
2,066 \\
1,557 \\
3 \\
3\end{array}$ \\
\hline $\begin{array}{l}\text { ouratari } \\
\text { blongifol ia }\end{array}$ & $\begin{array}{l}\mu(v) \\
\mu(12 \%) \\
\text { CV }(v) \\
\text { CV }(12 \%) \\
\text { S }(v) \\
\text { S }(12 \%) \\
\text { N }(v) \\
N \quad(12 \%)\end{array}$ & $\begin{array}{r}0,49 \\
0,49 \\
3,535 \\
3,535 \\
0,017 \\
0,017 \\
3 \\
3\end{array}$ & $\begin{array}{r}6,00 \\
6,00 \\
11,667 \\
11,667 \\
0,700 \\
0,700 \\
3 \\
3\end{array}$ & $\begin{array}{r}3,43 \\
3,43 \\
1,682 \\
1,682 \\
0,058 \\
0,058 \\
3 \\
3\end{array}$ & $\begin{array}{r}10,68 \\
10,66 \\
14,104 \\
14,418 \\
1,507 \\
1,536 \\
3 \\
3\end{array}$ & $\begin{array}{r}9066 \\
10633 \\
8,567 \\
4,444 \\
776,75 \\
472,58 \\
3 \\
3\end{array}$ & $\begin{array}{r}61,27 \\
94,57 \\
4,911 \\
7,056 \\
3,009 \\
6,673 \\
3 \\
3\end{array}$ & $\begin{array}{r}28,07 \\
46,77 \\
9,239 \\
12,855 \\
2,593 \\
6,012 \\
3 \\
3\end{array}$ & $\begin{array}{r}4,97 \\
6,57 \\
28,284 \\
24,286 \\
1,405 \\
1,595 \\
3 \\
3\end{array}$ & $\begin{array}{r}7,17 \\
9,33 \\
19,551 \\
7,751 \\
1,401 \\
0,723 \\
3 \\
3\end{array}$ \\
\hline$\frac{\text { Copaifera }}{\text { reticulata }}$ & $\begin{array}{l}\mu(v) \\
\mu(12 \%) \\
\text { CV }(v) \\
\text { CV }(12 \%) \\
\text { s }(v) \\
\text { s }(12 \%) \\
N \quad(v) \\
N \quad(12 \%)\end{array}$ & $\begin{array}{r}0,63 \\
0,63 \\
5,715 \\
5,715 \\
0,036 \\
0,036 \\
5 \\
5\end{array}$ & $\begin{array}{r}8,00 \\
8,00 \\
8,053 \\
8,053 \\
0,644 \\
0,644 \\
5 \\
5\end{array}$ & $\begin{array}{r}4,16 \\
4,16 \\
7,900 \\
7,900 \\
0,329 \\
0,329 \\
5 \\
5\end{array}$ & $\begin{array}{r}12,45 \\
12,45 \\
5,389 \\
5,389 \\
0,671 \\
0,671 \\
5 \\
5\end{array}$ & $\begin{array}{r}10500 \\
11420 \\
12,196 \\
21,237 \\
1280,6 \\
2425,3 \\
5 \\
5\end{array}$ & $\begin{array}{r}75,02 \\
117,18 \\
14,654 \\
14,863 \\
10,993 \\
17,417 \\
5 \\
5\end{array}$ & $\begin{array}{r}36,48 \\
50,62 \\
22,335 \\
28,087 \\
8,148 \\
14,218 \\
5 \\
5\end{array}$ & $\begin{array}{r}6,30 \\
10,26 \\
20,296 \\
17,100 \\
1,279 \\
1,754 \\
5 \\
5\end{array}$ & $\begin{array}{r}9,92 \\
11,86 \\
25,034 \\
17,833 \\
2,483 \\
2,115 \\
5\end{array}$ \\
\hline$\frac{\text { Couratari }}{\text { stellata }}$ & $\begin{array}{l}\mu(v) \\
\mu(12 \%) \\
\mathrm{CV}(v) \\
\mathrm{CV}(12 \%) \\
\mathrm{s}(v) \\
\mathrm{s}(12 \%) \\
\mathrm{N}(v) \\
\mathrm{N}(12 \%)\end{array}$ & $\begin{array}{r}0,65 \\
0,63 \\
4,166 \\
2,749 \\
0,027 \\
0,017 \\
4 \\
3\end{array}$ & $\begin{array}{r}7,75 \\
8,07 \\
10,770 \\
25,446 \\
0,835 \\
2,053 \\
4 \\
3\end{array}$ & $\begin{array}{r}5,03 \\
4,80 \\
25,140 \\
33,333 \\
1,263 \\
1,600 \\
4 \\
3\end{array}$ & $\begin{array}{r}12,35 \\
13,00 \\
17,434 \\
20,492 \\
2,153 \\
2,663 \\
4 \\
3\end{array}$ & $\begin{array}{r}13275 \\
14333 \\
8,192 \\
8,971 \\
1087,4 \\
1285,8 \\
4 \\
3\end{array}$ & $\begin{array}{r}90,03 \\
142,33 \\
5,318 \\
8,849 \\
4,788 \\
12,595 \\
4 \\
3\end{array}$ & $\begin{array}{r}42,35 \\
72,93 \\
12,053 \\
6,417 \\
5,105 \\
4,680 \\
4 \\
3\end{array}$ & $\begin{array}{r}7,48 \\
10,67 \\
17,592 \\
15,271 \\
1,315 \\
1,629 \\
4 \\
3\end{array}$ & $\begin{array}{r}10,25 \\
13,20 \\
16,719 \\
20,384 \\
1,714 \\
2,691 \\
4\end{array}$ \\
\hline $\begin{array}{l}\text { Carapa } \\
\text { guianens is }\end{array}$ & $\begin{array}{l}\mu(v) \\
\mu(12 \%) \\
C V(v) \\
C V \quad(12 \%) \\
\text { S }(v) \\
\text { S }(12 \%) \\
N \quad(v) \\
N \quad(12 \%)\end{array}$ & $\begin{array}{r}0,60 \\
0,60 \\
15,295 \\
15,295 \\
0,092 \\
0,092 \\
4 \\
4\end{array}$ & $\begin{array}{r}8,18 \\
8,18 \\
10,774 \\
10,774 \\
0,881 \\
0,881 \\
4 \\
4\end{array}$ & $\begin{array}{r}4,88 \\
4,88 \\
21,603 \\
21,603 \\
1,053 \\
1,053 \\
4 \\
4\end{array}$ & $\begin{array}{r}12,94 \\
12,94 \\
4,627 \\
4,627 \\
0,599 \\
0,599 \\
4 \\
4\end{array}$ & $\begin{array}{r}9825 \\
12425 \\
27,866 \\
8,032 \\
2737,9 \\
997,91 \\
4 \\
4\end{array}$ & $\begin{array}{r}74,00 \\
121,30 \\
22,251 \\
3,154 \\
16,466 \\
3,826 \\
4 \\
4\end{array}$ & $\begin{array}{r}38,23 \\
67,55 \\
30,086 \\
10,074 \\
11,501 \\
6,805 \\
4 \\
4\end{array}$ & $\begin{array}{r}5,55 \\
8,78 \\
30,807 \\
6,861 \\
1,710 \\
0,602 \\
4 \\
4\end{array}$ & $\begin{array}{r}9,75 \\
10,88 \\
9,820 \\
23,085 \\
0,957 \\
2,510 \\
4\end{array}$ \\
\hline $\begin{array}{l}\text { Erisma } \\
\text { uncinatum }\end{array}$ & $\begin{array}{l}\mu(v) \\
\mu(12 \%) \\
\text { CV }(v) \\
\text { CV }(12 \%) \\
\text { s }(v) \\
\text { s }(12 \%) \\
\text { N }(v) \\
\text { N }(12 \%)\end{array}$ & $\begin{array}{r}0,48 \\
0,47 \\
7,512 \\
4,255 \\
0,036 \\
0,020 \\
3 \\
3\end{array}$ & $\begin{array}{r}9,47 \\
7,90 \\
26,563 \\
7,700 \\
2,515 \\
0,608 \\
3 \\
3\end{array}$ & $\begin{array}{r}3,97 \\
3,23 \\
27,191 \\
7,783 \\
1,079 \\
0,252 \\
3 \\
3\end{array}$ & $\begin{array}{r}14,27 \\
12,52 \\
21,827 \\
4,402 \\
3,115 \\
0,551 \\
3 \\
3\end{array}$ & $\begin{array}{r}9666 \\
10800 \\
19,224 \\
4,900 \\
1858,3 \\
529,15 \\
3 \\
3\end{array}$ & $\begin{array}{r}57,40 \\
87,93 \\
3,053 \\
13,438 \\
1,752 \\
11,816 \\
3 \\
3\end{array}$ & $\begin{array}{r}28,80 \\
55,13 \\
10,434 \\
4,696 \\
3,005 \\
2,589 \\
3 \\
3\end{array}$ & $\begin{array}{r}3,27 \\
5,77 \\
6,372 \\
8,195 \\
0,208 \\
0,473 \\
3 \\
3\end{array}$ & $\begin{array}{r}5,53 \\
9,10 \\
11,619 \\
33,853 \\
0,643 \\
3,081 \\
3 \\
3\end{array}$ \\
\hline $\begin{array}{l}\text { Iryanthera } \\
\text { grandis }\end{array}$ & $\begin{array}{l}\mu(v) \\
\mu(12 \%) \\
\text { CV }(v) \\
\text { CV }(12 \%) \\
\text { s }(v) \\
\text { s }(12 \%) \\
N(v) \\
N(12 \%)\end{array}$ & $\begin{array}{r}0,65 \\
0,65 \\
7,050 \\
7,050 \\
0,046 \\
0,046 \\
3 \\
3\end{array}$ & $\begin{array}{r}8,73 \\
8,73 \\
5,648 \\
5,648 \\
0,493 \\
0,493 \\
3 \\
3\end{array}$ & $\begin{array}{r}5,10 \\
5,10 \\
18,909 \\
18,909 \\
0,964 \\
0,964 \\
3 \\
3\end{array}$ & $\begin{array}{r}13,32 \\
13,32 \\
12,476 \\
12,476 \\
1,661 \\
1,661 \\
3 \\
3\end{array}$ & $\begin{array}{r}10967 \\
12733 \\
11,546 \\
5,346 \\
1266,2 \\
680,69 \\
3 \\
3\end{array}$ & $\begin{array}{r}79,83 \\
114,30 \\
1,926 \\
4,927 \\
1,537 \\
5,631 \\
3 \\
3\end{array}$ & $\begin{array}{r}36,97 \\
63,73 \\
5,466 \\
15,500 \\
2,021 \\
9,878 \\
3 \\
3\end{array}$ & $\begin{array}{r}6,33 \\
9,53 \\
4,824 \\
16,957 \\
0,306 \\
1,617 \\
3 \\
3\end{array}$ & $\begin{array}{r}9,50 \\
11,57 \\
7,947 \\
22,617 \\
0,755 \\
2,616 \\
3 \\
3\end{array}$ \\
\hline
\end{tabular}


continuação

\begin{tabular}{|c|c|c|c|c|c|c|c|c|c|c|}
\hline $\begin{array}{l}\text { Jacaranda } \\
\text { copaia }\end{array}$ & $\begin{array}{l}\mu(v) \\
\mu(12 \%) \\
\text { CV }(v) \\
\text { CV }(12 \%) \\
s(v) \\
\text { s }(12 \%) \\
N(v) \\
N(12 \%)\end{array}$ & $\begin{array}{r}0,28 \\
0,29 \\
13,546 \\
15,560 \\
0,038 \\
0,044 \\
5 \\
4\end{array}$ & $\begin{array}{r}7,16 \\
7,00 \\
18,544 \\
21,093 \\
1,328 \\
1,476 \\
5 \\
4\end{array}$ & $\begin{array}{r}4,22 \\
4,05 \\
29,138 \\
33,341 \\
1,230 \\
1,350 \\
5 \\
4\end{array}$ & $\begin{array}{r}11,87 \\
11,80 \\
13,839 \\
16,002 \\
1,642 \\
1,888 \\
5 \\
4\end{array}$ & $\begin{array}{r}6560 \\
8725 \\
14,998 \\
7,211 \\
983,87 \\
629,15 \\
5 \\
4\end{array}$ & $\begin{array}{r}31,66 \\
55,55 \\
11,671 \\
16,422 \\
3,695 \\
9,122 \\
5 \\
4\end{array}$ & $\begin{array}{r}14,76 \\
30,23 \\
9,778 \\
12,463 \\
1,443 \\
3,767 \\
5\end{array}$ & $\begin{array}{r}1,48 \\
2,93 \\
21,044 \\
45,900 \\
0,311 \\
1,343 \\
5 \\
4\end{array}$ & $\begin{array}{r}3,84 \\
5,68 \\
17,430 \\
33,600 \\
0,669 \\
1,907 \\
5\end{array}$ \\
\hline $\begin{array}{l}\text { Joanesia } \\
\text { heveoides }\end{array}$ & $\begin{array}{l}\mu(v) \\
\mu(12 \%) \\
C V(V) \\
C V(12 \%) \\
s(v) \\
s(12 \%) \\
N(v) \\
N(12 \%)\end{array}$ & $\begin{array}{r}0,39 \\
0,39 \\
8,374 \\
8,374 \\
0,033 \\
0,033 \\
4 \\
4\end{array}$ & $\begin{array}{r}5,83 \\
5,83 \\
11,420 \\
11,420 \\
0,665 \\
0,665 \\
4 \\
4\end{array}$ & $\begin{array}{r}2,98 \\
2,98 \\
17,866 \\
17,866 \\
0,532 \\
0,532 \\
4 \\
4\end{array}$ & $\begin{array}{r}9,44 \\
9,44 \\
13,029 \\
13,029 \\
1,230 \\
1,230 \\
4 \\
4\end{array}$ & $\begin{array}{r}6700 \\
7875 \\
15,074 \\
28,421 \\
1010,0 \\
2238,1 \\
4 \\
4\end{array}$ & $\begin{array}{r}40,60 \\
58,45 \\
16,347 \\
35,244 \\
6,637 \\
20,600 \\
4 \\
4\end{array}$ & $\begin{array}{r}20,83 \\
33,53 \\
16,543 \\
10,516 \\
3,445 \\
3,526 \\
4 \\
4\end{array}$ & $\begin{array}{r}2,35 \\
4,98 \\
23,177 \\
15,075 \\
0,545 \\
0,750 \\
4 \\
4\end{array}$ & $\begin{array}{r}5,40 \\
5,83 \\
8,001 \\
18,080 \\
0,432 \\
1,053 \\
4\end{array}$ \\
\hline$\frac{\text { Laetia }}{\text { procera }}$ & $\begin{array}{l}\mu(v) \\
\mu(12 \%) \\
\text { CV }(v) \\
\text { CV }(12 \%) \\
s(v) \\
\text { s }(12 \%) \\
N(v) \\
N(12 \%)\end{array}$ & $\begin{array}{r}0,68 \\
0,68 \\
4,159 \\
4,159 \\
0,028 \\
0,028 \\
4 \\
4\end{array}$ & $\begin{array}{r}11,48 \\
11,48 \\
5,295 \\
5,295 \\
0,608 \\
0,608 \\
4 \\
4\end{array}$ & $\begin{array}{r}5,03 \\
5,03 \\
28,208 \\
28,208 \\
1,417 \\
1,417 \\
4 \\
4\end{array}$ & $\begin{array}{r}17,74 \\
18,07 \\
6,044 \\
7,184 \\
1,072 \\
1,298 \\
4 \\
4\end{array}$ & $\begin{array}{r}13775 \\
15750 \\
13,792 \\
3,458 \\
1899,8 \\
544,67 \\
4 \\
4\end{array}$ & $\begin{array}{r}79,68 \\
123,80 \\
11,190 \\
6,665 \\
8,916 \\
8,251 \\
4 \\
4\end{array}$ & $\begin{array}{r}38,68 \\
65,85 \\
17,818 \\
8,294 \\
6,891 \\
5,462 \\
4 \\
4\end{array}$ & $\begin{array}{r}6,28 \\
9,85 \\
13,420 \\
9,895 \\
0,842 \\
0,975 \\
4 \\
4\end{array}$ & $\begin{array}{r}8,75 \\
13,63 \\
20,980 \\
25,150 \\
1,836 \\
3,427 \\
4\end{array}$ \\
\hline$\frac{\text { Mezi laurus }}{\text { itaúba }}$ & $\begin{array}{l}\mu(v) \\
\mu(12 \%) \\
C V(v) \\
C V(12 \%) \\
s(v) \\
\text { s }(12 \%) \\
N(v) \\
N(12 \%)\end{array}$ & $\begin{array}{r}0,69 \\
0,68 \\
4,151 \\
6,986 \\
0,029 \\
0,048 \\
5 \\
5\end{array}$ & $\begin{array}{r}8,60 \\
8,68 \\
7,168 \\
6,638 \\
0,616 \\
0,576 \\
5 \\
5\end{array}$ & $\begin{array}{r}3,02 \\
2,82 \\
20,864 \\
24,233 \\
0,630 \\
0,683 \\
5 \\
5\end{array}$ & $\begin{array}{r}11,12 \\
11,17 \\
2,449 \\
2,599 \\
0,272 \\
0,290 \\
5 \\
5\end{array}$ & $\begin{array}{r}10680 \\
12100 \\
12,394 \\
11,057 \\
1323,6 \\
1337,9 \\
5 \\
5\end{array}$ & $\begin{array}{r}86,32 \\
114,46 \\
6,537 \\
10,315 \\
5,642 \\
11,807 \\
5 \\
5\end{array}$ & $\begin{array}{r}41,76 \\
56,64 \\
15,081 \\
13,979 \\
6,298 \\
7,918 \\
5 \\
5\end{array}$ & $\begin{array}{r}9,26 \\
10,70 \\
25,653 \\
22,508 \\
2,375 \\
2,408 \\
5 \\
5\end{array}$ & $\begin{array}{r}9,66 \\
11,60 \\
18,309 \\
25,696 \\
1,769 \\
2,981 \\
5\end{array}$ \\
\hline $\begin{array}{l}\text { Maquira } \\
\text { sclerophylla }\end{array}$ & $\begin{array}{l}\mu(v) \\
\mu(12 \%) \\
C V(V) \\
C V(12 \%) \\
s(v) \\
\text { s }(12 \%) \\
N(v) \\
N(12 \%)\end{array}$ & $\begin{array}{r}0,60 \\
0,60 \\
6,265 \\
6,265 \\
0,038 \\
0,038 \\
4 \\
4\end{array}$ & $\begin{array}{r}9,55 \\
9,55 \\
5,703 \\
5,703 \\
0,545 \\
0,545 \\
4 \\
4\end{array}$ & $\begin{array}{r}4,00 \\
4,00 \\
16,956 \\
16,956 \\
0,678 \\
0,678 \\
4 \\
4\end{array}$ & $\begin{array}{r}13,81 \\
13,81 \\
7,956 \\
7,956 \\
1,099 \\
1,099 \\
4 \\
4\end{array}$ & $\begin{array}{r}11175 \\
11050 \\
5,029 \\
9,390 \\
561,99 \\
1037,6 \\
4 \\
4\end{array}$ & $\begin{array}{r}84,70 \\
118,65 \\
14,115 \\
13,259 \\
11,955 \\
15,732 \\
4 \\
4\end{array}$ & $\begin{array}{r}39,70 \\
64,53 \\
11,420 \\
11,478 \\
4,534 \\
7,406 \\
4 \\
4\end{array}$ & $\begin{array}{r}6,15 \\
8,78 \\
20,503 \\
23,802 \\
1,261 \\
2,089 \\
4 \\
4\end{array}$ & $\begin{array}{r}10,23 \\
13,75 \\
15,553 \\
14,282 \\
1,590 \\
1,964 \\
4\end{array}$ \\
\hline $\begin{array}{l}\text { Nectandra } \\
\text { rubra }\end{array}$ & $\begin{array}{l}\mu(V) \\
\mu(12 \%) \\
\text { CV }(V) \\
\text { CV }(12 \%) \\
s(V) \\
S \text { S }(12 \%) \\
N(V) \\
N(12 \%)\end{array}$ & $\begin{array}{r}0,54 \\
0,56 \\
8,564 \\
7,429 \\
0,046 \\
0,041 \\
4 \\
4\end{array}$ & $\begin{array}{r}7,83 \\
7,75 \\
10,297 \\
10,133 \\
0,806 \\
0,785 \\
4 \\
4\end{array}$ & $\begin{array}{r}3,58 \\
3,80 \\
7,357 \\
16,782 \\
0,263 \\
0,638 \\
4 \\
4\end{array}$ & $\begin{array}{r}10,98 \\
11,21 \\
4,525 \\
7,874 \\
0,497 \\
0,882 \\
4 \\
4\end{array}$ & $\begin{array}{r}8300 \\
10925 \\
20,682 \\
12,866 \\
1716,6 \\
1405,6 \\
4 \\
4\end{array}$ & $\begin{array}{r}63,83 \\
82,20 \\
10,481 \\
20,826 \\
6,689 \\
17,119 \\
4 \\
4\end{array}$ & $\begin{array}{r}32,80 \\
53,13 \\
14,220 \\
15,887 \\
4,664 \\
8,440 \\
4 \\
4\end{array}$ & $\begin{array}{r}4,65 \\
4,88 \\
20,961 \\
18,828 \\
0,975 \\
0,918 \\
4 \\
4\end{array}$ & $\begin{array}{r}6,83 \\
7,00 \\
12,222 \\
33,907 \\
0,834 \\
2,373 \\
4 \\
4\end{array}$ \\
\hline $\begin{array}{l}\text { Omychopetalum } \\
\text { amazonicum }\end{array}$ & $\begin{array}{l}\mu(v) \\
\mu(12 \%) \\
C V(V) \\
C V(12 \%) \\
s(v) \\
s(12 \%) \\
N(v) \\
N(12 \%)\end{array}$ & $\begin{array}{r}0,62 \\
0,62 \\
7,582 \\
7,582 \\
0,047 \\
0,047 \\
3 \\
3\end{array}$ & $\begin{array}{r}8,50 \\
8,50 \\
4,706 \\
4,706 \\
0,400 \\
0,400 \\
3 \\
3\end{array}$ & $\begin{array}{r}3,27 \\
3,27 \\
9,840 \\
9,840 \\
0,321 \\
0,321 \\
3 \\
3\end{array}$ & $\begin{array}{r}12,06 \\
12,06 \\
0,817 \\
0,817 \\
0,098 \\
0,098 \\
3 \\
3\end{array}$ & $\begin{array}{r}12200 \\
12833 \\
7,819 \\
8,583 \\
953,94 \\
1101,5 \\
3 \\
3\end{array}$ & $\begin{array}{r}84,07 \\
110,30 \\
1,667 \\
5,980 \\
1,401 \\
6,596 \\
3 \\
3\end{array}$ & $\begin{array}{r}41,00 \\
63,03 \\
4,161 \\
2,822 \\
1,706 \\
1,779 \\
3 \\
3\end{array}$ & $\begin{array}{r}5,10 \\
6,47 \\
3,396 \\
37,253 \\
0,173 \\
2,409 \\
3 \\
3\end{array}$ & $\begin{array}{r}6,30 \\
9,00 \\
9,913 \\
5,092 \\
0,624 \\
0,458 \\
3 \\
3\end{array}$ \\
\hline
\end{tabular}


continuação

\begin{tabular}{|c|c|c|c|c|c|c|c|c|c|c|}
\hline$\frac{\text { Protium }}{\text { heptaphyllum }}$ & $\begin{array}{l}\mu(v) \\
\mu(12 \%) \\
\text { CV }(v) \\
\text { CV }(12 \%) \\
s \quad(v) \\
\text { S }(12 \%) \\
N(v) \\
N(12 \%)\end{array}$ & $\begin{array}{r}0,52 \\
0,52 \\
9,426 \\
9,426 \\
0,049 \\
0,049 \\
3 \\
3\end{array}$ & $\begin{array}{r}8,47 \\
8,47 \\
3,608 \\
3,608 \\
0,306 \\
0,306 \\
3 \\
3\end{array}$ & $\begin{array}{r}4,27 \\
4,27 \\
15,605 \\
15,605 \\
0,666 \\
0,666 \\
3 \\
3\end{array}$ & $\begin{array}{r}13,36 \\
13,36 \\
5,722 \\
5,722 \\
0,764 \\
0,764 \\
3 \\
3\end{array}$ & $\begin{array}{r}10133 \\
10133 \\
11,897 \\
17,552 \\
1205,5 \\
1778,6 \\
3 \\
3\end{array}$ & $\begin{array}{r}60,30 \\
91,70 \\
22,914 \\
19,645 \\
13,817 \\
18,014 \\
3 \\
3\end{array}$ & $\begin{array}{r}28,37 \\
49,20 \\
17,831 \\
14,714 \\
5,058 \\
7,239 \\
3 \\
3\end{array}$ & $\begin{array}{r}4,03 \\
6,37 \\
18,773 \\
15,889 \\
0,757 \\
1,012 \\
3 \\
3\end{array}$ & $\begin{array}{r}8,60 \\
9,60 \\
11,214 \\
15,345 \\
0,964 \\
1,473 \\
3 \\
3\end{array}$ \\
\hline$\frac{\text { Parkia }}{\text { pendula }}$ & $\begin{array}{l}\mu(v) \\
\mu(12 \%) \\
\text { CV }(v) \\
\text { CV }(12 \%) \\
s(v) \\
S(12 \%) \\
N(v) \\
N(12 \%)\end{array}$ & $\begin{array}{r}0,50 \\
0,47 \\
11,798 \\
9,750 \\
0,059 \\
0,046 \\
3 \\
3\end{array}$ & $\begin{array}{r}6,53 \\
7,00 \\
21,117 \\
19,219 \\
1,380 \\
1,345 \\
3 \\
3\end{array}$ & $\begin{array}{r}1,80 \\
2,23 \\
44,096 \\
40,132 \\
0,794 \\
0,896 \\
3 \\
3\end{array}$ & $\begin{array}{r}9,39 \\
9,44 \\
13,775 \\
14,065 \\
1,294 \\
1,328 \\
3 \\
3\end{array}$ & $\begin{array}{r}9433 \\
10133 \\
12,780 \\
9,885 \\
1205,5 \\
1001,7 \\
3 \\
3\end{array}$ & $\begin{array}{r}64,90 \\
84,30 \\
8,178 \\
19,999 \\
5,308 \\
16,859 \\
3 \\
3\end{array}$ & $\begin{array}{r}29,23 \\
44,23 \\
12,755 \\
6,068 \\
3,729 \\
2,684 \\
3 \\
3\end{array}$ & $\begin{array}{r}5,17 \\
7,30 \\
27,189 \\
9,589 \\
1,405 \\
0,700 \\
3 \\
3\end{array}$ & $\begin{array}{r}7,47 \\
8,67 \\
13,213 \\
23,572 \\
0,987 \\
2,043 \\
3 \\
3\end{array}$ \\
\hline $\begin{array}{l}\text { Piptadenia } \\
\text { suaveolens }\end{array}$ & $\begin{array}{l}\mu(v) \\
\mu(12 \%) \\
\text { CV }(v) \\
\text { CV }(12 \%) \\
\text { s }(v) \\
\text { s }(12 \%) \\
N(v) \\
N(12 \%)\end{array}$ & $\begin{array}{r}0,70 \\
0,70 \\
7,366 \\
7,366 \\
0,051 \\
0,051 \\
3 \\
3\end{array}$ & $\begin{array}{r}7,37 \\
7,93 \\
15,733 \\
8,853 \\
1,159 \\
0,702 \\
3 \\
3\end{array}$ & $\begin{array}{r}4,60 \\
4,60 \\
9,476 \\
9,476 \\
0,436 \\
0,436 \\
3 \\
3\end{array}$ & $\begin{array}{r}11,44 \\
11,38 \\
9,714 \\
8,914 \\
1,111 \\
1,014 \\
3 \\
3\end{array}$ & $\begin{array}{r}12900 \\
12967 \\
11,731 \\
10,065 \\
1513,3 \\
1305,1 \\
3 \\
3\end{array}$ & $\begin{array}{r}106,67 \\
144,80 \\
2,499 \\
17,335 \\
2,665 \\
25,101 \\
3 \\
3\end{array}$ & $\begin{array}{r}49,47 \\
67,70 \\
9,821 \\
8,076 \\
4,858 \\
5,467 \\
3 \\
3\end{array}$ & $\begin{array}{r}10,37 \\
11,67 \\
15,262 \\
24,081 \\
1,582 \\
2,810 \\
3 \\
3\end{array}$ & $\begin{array}{r}10,23 \\
12,67 \\
8,867 \\
5,257 \\
0,907 \\
0,666 \\
3 \\
3\end{array}$ \\
\hline$\frac{\text { Qualea cf. }}{\text { lancifolia }}$ & $\begin{array}{l}\mu(v) \\
\mu(12 \%) \\
C V(V) \\
\text { CV }(12 \%) \\
s(v) \\
S(12 \%) \\
N(v) \\
N(12 \%)\end{array}$ & $\begin{array}{r}0,60 \\
0,60 \\
7,071 \\
7,071 \\
0,042 \\
0,042 \\
2 \\
2\end{array}$ & $\begin{array}{r}8,75 \\
8,75 \\
15,354 \\
15,354 \\
1,344 \\
1,344 \\
2 \\
2\end{array}$ & $\begin{array}{r}3,65 \\
3,65 \\
36,808 \\
36,808 \\
1,344 \\
1,344 \\
2 \\
2\end{array}$ & $\begin{array}{r}12,71 \\
12,71 \\
16,579 \\
16,579 \\
2,107 \\
2,107 \\
2 \\
2\end{array}$ & $\begin{array}{r}11650 \\
12000 \\
6,677 \\
5,893 \\
777,82 \\
707,11 \\
2 \\
2\end{array}$ & $\begin{array}{r}65,50 \\
111,45 \\
12,523 \\
7,169 \\
8,202 \\
7,990 \\
2 \\
2\end{array}$ & $\begin{array}{r}30,90 \\
61,95 \\
0 \\
0 \\
2,625 \\
0 \\
1,626 \\
2 \\
2\end{array}$ & $\begin{array}{r}5,70 \\
7,00 \\
14,886 \\
8,081 \\
0,849 \\
0,566 \\
2 \\
2\end{array}$ & $\begin{array}{r}8,80 \\
10,45 \\
9,642 \\
29,096 \\
0,849 \\
3,041 \\
2 \\
2\end{array}$ \\
\hline$\frac{\text { Simaruba }}{\text { amara }}$ & $\begin{array}{l}\mu(v) \\
\mu(12 \%) \\
C V(V) \\
\text { CV }(12 \%) \\
s(v) \\
S(12 \%) \\
N(v) \\
N(12 \%)\end{array}$ & $\begin{array}{r}0,34 \\
0,34 \\
16,075 \\
16,075 \\
0,055 \\
0,055 \\
6 \\
6\end{array}$ & $\begin{array}{r}5,55 \\
5,55 \\
18,081 \\
18,081 \\
1,003 \\
1,003 \\
6 \\
6\end{array}$ & $\begin{array}{r}2,20 \\
2,20 \\
17,721 \\
17,721 \\
0,390 \\
0,390 \\
6 \\
6\end{array}$ & $\begin{array}{r}8,39 \\
8,39 \\
12,609 \\
12,609 \\
1,057 \\
1,057 \\
6 \\
6\end{array}$ & $\begin{array}{r}6800 \\
7750 \\
16,560 \\
10,347 \\
1126,1 \\
801,87 \\
6 \\
6\end{array}$ & $\begin{array}{r}39,87 \\
66,80 \\
29,015 \\
13,301 \\
11,567 \\
8,885 \\
6 \\
6\end{array}$ & $\begin{array}{r}21,10 \\
36,27 \\
21,370 \\
9,335 \\
4,509 \\
3,386 \\
6 \\
6\end{array}$ & $\begin{array}{r}2,40 \\
4,33 \\
42,492 \\
25,096 \\
1,020 \\
1,088 \\
6 \\
6\end{array}$ & $\begin{array}{r}4,67 \\
6,92 \\
30,415 \\
15,822 \\
1,419 \\
1,094 \\
6 \\
6\end{array}$ \\
\hline $\begin{array}{l}\text { Sclerolobium } \\
\text { aff. } \\
\text { chrysophyl lum }\end{array}$ & $\begin{array}{l}\mu(v) \\
\mu(12 \%) \\
\text { CV }(v) \\
\text { CV }(12 \%) \\
s \quad(v) \\
s(12 \%) \\
N(v) \\
N(12 \%)\end{array}$ & $\begin{array}{r}0,60 \\
0,60 \\
8,743 \\
8,743 \\
0,053 \\
0,053 \\
5 \\
5\end{array}$ & $\begin{array}{r}7,14 \\
7,14 \\
8,438 \\
8,438 \\
0,602 \\
0,602 \\
5 \\
5\end{array}$ & $\begin{array}{r}3,60 \\
3,60 \\
24,611 \\
24,611 \\
0,886 \\
0,886 \\
5 \\
5\end{array}$ & $\begin{array}{r}10,56 \\
10,56 \\
8,058 \\
8,058 \\
0,851 \\
0,851 \\
5 \\
5\end{array}$ & $\begin{array}{r}11400 \\
12740 \\
11,061 \\
14,785 \\
1261,0 \\
1883,6 \\
5 \\
5\end{array}$ & $\begin{array}{r}83,82 \\
127,62 \\
13,966 \\
19,213 \\
11,707 \\
24,520 \\
5 \\
5\end{array}$ & $\begin{array}{r}40,38 \\
60,82 \\
7,553 \\
18,062 \\
3,050 \\
10,985 \\
5 \\
5\end{array}$ & $\begin{array}{r}7,36 \\
11,72 \\
12,175 \\
25,407 \\
0,896 \\
2,978 \\
5 \\
5\end{array}$ & $\begin{array}{r}10,96 \\
13,82 \\
10,652 \\
26,121 \\
1,167 \\
3,610 \\
5 \\
5\end{array}$ \\
\hline$\frac{\text { Stercul ia }}{\text { pilosa }}$ & $\begin{array}{l}\mu(v) \\
\mu(12 \%) \\
\text { CV }(V) \\
\text { CV }(12 \%) \\
s \quad(v) \\
S(12 \%) \\
N(v) \\
N(12 \%)\end{array}$ & $\begin{array}{r}0,45 \\
0,45 \\
12,925 \\
12,925 \\
0,059 \\
0,059 \\
3 \\
3\end{array}$ & $\begin{array}{r}12,13 \\
12,13 \\
3,331 \\
3,331 \\
0,404 \\
0,404 \\
3 \\
3\end{array}$ & $\begin{array}{r}6,27 \\
6,27 \\
19,695 \\
19,695 \\
1,234 \\
1,234 \\
3 \\
3\end{array}$ & $\begin{array}{r}17,62 \\
17,62 \\
6,564 \\
6,564 \\
1,157 \\
1,157 \\
3 \\
3\end{array}$ & $\begin{array}{r}10167 \\
10667 \\
9,086 \\
10,024 \\
923,76 \\
1069,3 \\
3 \\
3\end{array}$ & $\begin{array}{r}51,47 \\
86,13 \\
10,701 \\
17,553 \\
5,508 \\
15,119 \\
3 \\
3\end{array}$ & $\begin{array}{r}21,10 \\
47,87 \\
12,185 \\
16,833 \\
2,571 \\
8,058 \\
3 \\
3\end{array}$ & $\begin{array}{r}2,30 \\
4,13 \\
39,130 \\
59,966 \\
0,900 \\
2,479 \\
3 \\
3\end{array}$ & $\begin{array}{r}4,53 \\
7,10 \\
22,205 \\
43,389 \\
1,007 \\
3,081 \\
3 \\
3\end{array}$ \\
\hline
\end{tabular}


continuação

\begin{tabular}{|c|c|c|c|c|c|c|c|c|c|c|}
\hline $\begin{array}{l}\text { Trattinickia } \\
\text { burserifolia }\end{array}$ & $\begin{array}{l}\mu(v) \\
\mu(12 \%) \\
C V(v) \\
C V(12 \%) \\
S(v) \\
S(12 \%) \\
N(v) \\
N(12 \%)\end{array}$ & $\begin{array}{r}0,44 \\
0,42 \\
8,665 \\
8,106 \\
0,038 \\
0,034 \\
5 \\
5\end{array}$ & $\begin{array}{r}6,36 \\
6,66 \\
16,401 \\
14,581 \\
1,043 \\
0,971 \\
5 \\
5\end{array}$ & $\begin{array}{r}4,52 \\
5,30 \\
17,448 \\
24,565 \\
0,789 \\
1,302 \\
5 \\
5\end{array}$ & $\begin{array}{r}10,49 \\
11,79 \\
15,655 \\
16,916 \\
1,642 \\
1,995 \\
5 \\
5\end{array}$ & $\begin{array}{r}8140 \\
9320 \\
19,782 \\
8,008 \\
1610,3 \\
746,32 \\
5 \\
5\end{array}$ & $\begin{array}{r}52,88 \\
73,84 \\
17,122 \\
13,048 \\
9,054 \\
9,635 \\
5 \\
5\end{array}$ & $\begin{array}{r}26,32 \\
43,28 \\
15,039 \\
6,450 \\
3,958 \\
2,791 \\
5 \\
5\end{array}$ & $\begin{array}{r}3,78 \\
5,46 \\
10,314 \\
8,046 \\
0,390 \\
0,439 \\
5 \\
5\end{array}$ & $\begin{array}{r}7,00 \\
7,14 \\
11,473 \\
10,273 \\
0,803 \\
0,733 \\
5 \\
5\end{array}$ \\
\hline$\frac{\text { Tachigalia }}{\text { myrmecophilla }}$ & $\begin{array}{l}\mu(v) \\
\mu(12 \%) \\
\text { CV }(v) \\
\text { CV }(12 \%) \\
S(v) \\
\text { S }(12 \%) \\
N(v) \\
N(12 \%)\end{array}$ & $\begin{array}{r}0,59 \\
0,68 \\
18,924 \\
4,266 \\
0,112 \\
0,029 \\
4 \\
3\end{array}$ & $\begin{array}{r}6,85 \\
7,23 \\
4,214 \\
4,855 \\
0,289 \\
0,351 \\
4 \\
3\end{array}$ & $\begin{array}{r}4,30 \\
4,77 \\
22,306 \\
19,036 \\
0,959 \\
0,907 \\
4 \\
3\end{array}$ & $\begin{array}{r}10,96 \\
11,77 \\
13,152 \\
8,670 \\
1,441 \\
1,021 \\
4 \\
3\end{array}$ & $\begin{array}{r}9950 \\
12200 \\
6,002 \\
9,453 \\
597,22 \\
1153,3 \\
4 \\
3\end{array}$ & $\begin{array}{r}82,33 \\
130,47 \\
9,030 \\
9,131 \\
7,434 \\
11,912 \\
4 \\
3\end{array}$ & $\begin{array}{r}40,15 \\
67,17 \\
7,561 \\
3,968 \\
3,036 \\
2,665 \\
4 \\
3\end{array}$ & $\begin{array}{r}7,48 \\
10,80 \\
34,531 \\
16,381 \\
2,581 \\
1,769 \\
4 \\
3\end{array}$ & $\begin{array}{r}10,88 \\
13,87 \\
14,312 \\
4,226 \\
1,556 \\
0,586 \\
4 \\
3\end{array}$ \\
\hline
\end{tabular}


A N E X O 2

Parâmetros da distribuição Weibull determinados para a densidade básica e propriedades mecânicas nas condições verde e seca, tanto para os grupos de espécies como para todas as espécies, conforme definições feitas no item $3 \cdot 7 \cdot 5$.. 
Parâmetros da distribuição Weibull determinados para cada uma das propriedades dos grupos de espécies estudadas na condição verde

\begin{tabular}{|c|c|c|c|c|c|c|}
\hline Classe & $\mathrm{Db}$ & $E_{f}$ & $f_{f}$ & $f_{c}$ & $f_{\text {cn }}$ & $f_{s}$ \\
\hline $0,25-0,34$ & $\begin{array}{l}a=0,240000 \\
b=0,110790 \\
c=2,458800 \\
N=21\end{array}$ & $\begin{array}{l}a=4900,000 \\
b=2265,126 \\
c=2,090475 \\
N=21\end{array}$ & $\begin{array}{l}a=16,00000 \\
b=21,13792 \\
c=2,210360 \\
N=21\end{array}$ & $\begin{array}{l}a=13,60000 \\
b=4,728578 \\
c=1,327647 \\
N=21\end{array}$ & $\begin{array}{l}a=0,900000 \\
b=1,615764 \\
c=1,616916 \\
N=21\end{array}$ & $\begin{array}{l}a=1,900000 \\
b=3,308991 \\
c=2,422080 \\
N=21\end{array}$ \\
\hline $0,35-0,44$ & $\begin{array}{l}a=0,320000 \\
b=0,130770 \\
c=2,366885 \\
N=40\end{array}$ & $\begin{array}{l}a=5100,000 \\
b=4018,017 \\
c=2,046090 \\
N=40\end{array}$ & $\begin{array}{l}a=30,00000 \\
b=21,57127 \\
c=2,097624 \\
N=40\end{array}$ & $\begin{array}{l}a=12,40000 \\
b=11,24278 \\
c=2,708400 \\
N=40\end{array}$ & $\begin{array}{l}a=1,300000 \\
b=1,853802 \\
c=1,732998 \\
N=40\end{array}$ & $\begin{array}{l}a=3,400000 \\
b=3,637705 \\
c=2,302250 \\
N=40\end{array}$ \\
\hline $0,45-0,54$ & $\begin{array}{l}a=0,340000 \\
b=0,188568 \\
c=3,732360 \\
N=85\end{array}$ & $\begin{array}{l}a=5400,000 \\
b=4186,942 \\
c=2,462335 \\
N=85\end{array}$ & $\begin{array}{l}a=38,10000 \\
b=25,73683 \\
c=2,366380 \\
N=85\end{array}$ & $\begin{array}{l}a=18,40000 \\
b=12,09293 \\
c=2,128197 \\
N=85\end{array}$ & $\begin{array}{l}a=1,900000 \\
b=2,670088 \\
c=2,045527 \\
N=85\end{array}$ & $\begin{array}{c}a=3,900000 \\
b=4,531008 \\
c=2,529460 \\
N=85\end{array}$ \\
\hline $0,55-0,64$ & $\begin{array}{l}a=0,420000 \\
b=0,203024 \\
c=3,253345 \\
N=153\end{array}$ & $\begin{array}{l}a=5700,000 \\
b=6051,608 \\
c=3,084220 \\
N=153\end{array}$ & $\begin{array}{l}a=35,80000 \\
b=44,76812 \\
c=3,546580 \\
N=153\end{array}$ & $\begin{array}{l}a=20,30000 \\
b=19,77540 \\
c=2,777120 \\
N=153\end{array}$ & $\begin{array}{l}a=2,600000 \\
b=4,322374 \\
c=1,753232 \\
N=153\end{array}$ & $\begin{array}{c}a=5,000000 \\
b=4,991942 \\
c=2,317410 \\
N=153\end{array}$ \\
\hline $0,65-0,74$ & $\begin{array}{l}a=0,520000 \\
b=0,213746 \\
c=3,202010 \\
N=193\end{array}$ & $\begin{array}{l}a=6200,000 \\
b=6273,934 \\
c=3,472830 \\
N=192\end{array}$ & $\begin{array}{l}a=42,10000 \\
b=56,42431 \\
c=3,236380 \\
N=192\end{array}$ & $\begin{array}{l}a=23,40000 \\
b=26,73451 \\
c=2,721290 \\
N=192\end{array}$ & $\begin{array}{l}a=4,300000 \\
b=4,631846 \\
c=1,810304 \\
N=192\end{array}$ & $\begin{array}{c}a=4,300000 \\
b=7,805075 \\
c=3,498770 \\
N=192\end{array}$ \\
\hline $0,75-0,84$ & $\begin{array}{l}a=0,660000 \\
b=0,160070 \\
c=2,739615 \\
N=121\end{array}$ & $\begin{array}{l}a=9700,000 \\
b=4686,820 \\
c=2,295144 \\
N=121\end{array}$ & $\begin{array}{l}a=52,50000 \\
b=61,27023 \\
c=3,553070 \\
N=121\end{array}$ & $\begin{array}{l}a=30,30000 \\
b=27,35468 \\
c=3,009640 \\
N=121\end{array}$ & $\begin{array}{l}a=4,800000 \\
b=7,696486 \\
c=1,889760 \\
N=121\end{array}$ & $\begin{array}{c}a=4,800000 \\
b=9,027406 \\
c=3,695920 \\
N=121\end{array}$ \\
\hline $0,85-0,94$ & $\begin{array}{l}a=0,700000 \\
b=0,227830 \\
c=3,758540 \\
N=84\end{array}$ & $\begin{array}{l}a=10200,00 \\
b=6025,611 \\
c=2,693590 \\
N=84\end{array}$ & $\begin{array}{l}a=91,20000 \\
b=46,43384 \\
c=2,009033 \\
N=84\end{array}$ & $\begin{array}{l}a=37,90000 \\
b=33,55143 \\
c=2,621680 \\
N=84\end{array}$ & $\begin{array}{l}a=8,300000 \\
b=8,717769 \\
c=1,620536 \\
N=84\end{array}$ & $\begin{array}{c}a=8,500000 \\
b=7,087668 \\
c=2,823840 \\
N=84\end{array}$ \\
\hline $0,95-1,14$ & $\begin{array}{l}a=0,920000 \\
b=0,106443 \\
c=1,620034 \\
N=13\end{array}$ & $\begin{array}{l}a=14300,00 \\
b=2155,601 \\
c=1,438506 \\
N=13\end{array}$ & $\begin{array}{l}a=118,6000 \\
b=25,04257 \\
c=1,666626 \\
N=13\end{array}$ & $\begin{array}{l}a=69,50000 \\
b=11,64561 \\
c=1,062103 \\
N=13\end{array}$ & $\begin{array}{l}a=11,50000 \\
b=11,66676 \\
c=1,796813 \\
N=13\end{array}$ & $\begin{array}{l}a=9,900000 \\
b=7,114779 \\
c=2,145640 \\
N=13\end{array}$ \\
\hline
\end{tabular}


Parâmetros da distribuição Weibull determinados para cada uma das propriedades dos grupos de espécies estudadas na condição seca

\begin{tabular}{|c|c|c|c|c|c|c|}
\hline Classe & $\mathrm{Db}$ & $E_{f}$ & $f_{f}$ & $f_{c}$ & $f_{c n}$ & $f_{s}$ \\
\hline $0,25-0,34$ & $\begin{array}{l}a=0,240000 \\
b=0,113934 \\
c=2,610210 \\
N=21\end{array}$ & $\begin{array}{l}a=6400,000 \\
b=1854,919 \\
c=1,801000 \\
N=21\end{array}$ & $\begin{array}{l}a=36,10000 \\
b=24,05319 \\
c=1,966120 \\
N=21\end{array}$ & $\begin{array}{l}a=24,60000 \\
b=8,414766 \\
c=1,846305 \\
N=21\end{array}$ & $\begin{array}{l}a=1,500000 \\
b=2,497840 \\
c=1,814843 \\
N=21\end{array}$ & $\begin{array}{l}a=3,500000 \\
b=3,446542 \\
c=1,929025 \\
N=21\end{array}$ \\
\hline $0,35-0,44$ & $\begin{array}{l}a=0,320000 \\
b=0,130659 \\
c=2,332018 \\
N=48\end{array}$ & $\begin{array}{l}a=4900,000 \\
b=5837,371 \\
c=2,205460 \\
N=48\end{array}$ & $\begin{array}{l}a=20,00000 \\
b=56,73446 \\
c=3,068720 \\
N=48\end{array}$ & $\begin{array}{l}a=25,10000 \\
b=18,53421 \\
c=1,910043 \\
N=48\end{array}$ & $\begin{array}{l}a=1,800000 \\
b=3,441708 \\
c=2,709350 \\
N=48\end{array}$ & $\begin{array}{c}a=4,200000 \\
b=4,528019 \\
c=2,193125 \\
N=48\end{array}$ \\
\hline $0,45-0,54$ & $\begin{array}{l}a=0,350000 \\
b=0,177706 \\
c=3,447310 \\
N=80\end{array}$ & $\begin{array}{l}a=7100,000 \\
b=4345,643 \\
c=1,981000 \\
N=80\end{array}$ & $\begin{array}{l}a=47,20000 \\
b=45,98859 \\
c=2,294320 \\
N=80\end{array}$ & $\begin{array}{l}a=33,20000 \\
b=18,26199 \\
c=1,993255 \\
N=80\end{array}$ & $\begin{array}{l}a=3,10 \\
b=3,81 \\
c=2,19 \\
N=80\end{array}$ & $\begin{array}{l}a=5,000000 \\
b=5,477278 \\
c=2,348600 \\
N=80\end{array}$ \\
\hline $0,55-0,64$ & $\begin{array}{l}a=0,430000 \\
b=0,196765 \\
c=2,861370 \\
N=135\end{array}$ & $\begin{array}{l}a=8400,000 \\
b=4939,463 \\
c=2,554035 \\
N=135\end{array}$ & $\begin{array}{l}a=67,50000 \\
b=52,19292 \\
c=2,610190 \\
N=135\end{array}$ & $\begin{array}{l}a=27,20000 \\
b=38,19814 \\
c=3,868650 \\
N=135\end{array}$ & $\begin{array}{l}a=3,600000 \\
b=6,302669 \\
c=2,825010 \\
N=135\end{array}$ & $\begin{array}{c}a=7,100000 \\
b=5,962808 \\
c=1,994765 \\
N=135\end{array}$ \\
\hline $0,65-0,74$ & $\begin{array}{l}a=0,520000 \\
b=0,201240 \\
c=3,156110 \\
N=158\end{array}$ & $\begin{array}{l}a=9100,000 \\
b=5495,446 \\
c=2,740750 \\
N=158\end{array}$ & $\begin{array}{l}a=67,50000 \\
b=67,68755 \\
c=3,179220 \\
N=158\end{array}$ & $\begin{array}{l}a=39,40000 \\
b=31,86813 \\
c=2,845784 \\
N=158\end{array}$ & $\begin{array}{l}a=0,900000 \\
b=11,83621 \\
c=4,128640 \\
N=158\end{array}$ & $\begin{array}{c}a=7,400000 \\
b=8,122113 \\
c=2,718040 \\
N=158\end{array}$ \\
\hline $0,75-0,84$ & $\begin{array}{l}a=0,680000 \\
b=0,137784 \\
c=2,193125 \\
N=108\end{array}$ & $\begin{array}{l}a=10600,00 \\
b=5796,318 \\
c=2,430620 \\
N=108\end{array}$ & $\begin{array}{l}a=83,80000 \\
b=78,55748 \\
c=3,168310 \\
N=108\end{array}$ & $\begin{array}{l}a=52,50000 \\
b=32,03891 \\
c=2,619140 \\
N=108\end{array}$ & $\begin{array}{l}a=9,300000 \\
b=5,865404 \\
c=1,993210 \\
N=108\end{array}$ & $\begin{array}{c}a=12,00000 \\
b=6,291434 \\
c=2,075645 \\
N=108\end{array}$ \\
\hline $0,85-0,94$ & $\begin{array}{l}a=0,700000 \\
b=0,223526 \\
c=3,697150 \\
N=91\end{array}$ & $\begin{array}{l}a=13300,00 \\
b=4137,172 \\
c=2,102293 \\
N=91\end{array}$ & $\begin{array}{l}a=106,0000 \\
b=74,74580 \\
c=2,721110 \\
N=91\end{array}$ & $\begin{array}{l}a=56,20000 \\
b=37,83780 \\
c=2,912060 \\
N=91\end{array}$ & $\begin{array}{l}a=9,300000 \\
b=10,68687 \\
c=2,280485 \\
N=91\end{array}$ & $\begin{array}{c}a=10,90000 \\
b=8,795424 \\
c=2,338210 \\
N=91\end{array}$ \\
\hline $0,95-1,14$ & $\begin{array}{l}a=0,780000 \\
b=0,270359 \\
c=2,841950 \\
N=15\end{array}$ & $\begin{array}{l}a=13200,00 \\
b=4739,984 \\
c=2,277604 \\
N=15\end{array}$ & $\begin{array}{l}a=125,4000 \\
b=68,07545 \\
c=2,370650 \\
N=15\end{array}$ & $\begin{array}{l}a=87,80000 \\
b=24,18861 \\
c=1,467158 \\
N=15\end{array}$ & $\begin{array}{l}a=15,40000 \\
b=8,791270 \\
c=2,191575 \\
N=15\end{array}$ & $\begin{array}{l}a=12,90000 \\
b=7,061405 \\
c=1,904722 \\
N=15\end{array}$ \\
\hline
\end{tabular}


Parâmetros da distribuição Weibull determinados para cada uma das propriedades de todas as espécies estudadas na condição verde

\begin{tabular}{|c|c|c|c|c|c|}
\hline $\mathrm{Db}$ & $E_{f}$ & $f_{f}$ & $f_{c}$ & $f_{c n}$ & $f_{s}$ \\
\hline $\begin{array}{l}a=0,190000 \\
b=0,540974 \\
c=3,312490 \\
N=710\end{array}$ & $\begin{array}{l}a=4999,000 \\
b=7999,149 \\
c=2,549440 \\
N=709\end{array}$ & $\begin{array}{l}a=16,00000 \\
b=82,74535 \\
c=2,628300 \\
N=709\end{array}$ & $\begin{array}{l}a=12,40000 \\
b=36,73984 \\
c=2,078320 \\
N=709\end{array}$ & $\begin{array}{l}a=0,900000 \\
b=8,815913 \\
c=1,611080 \\
N=709\end{array}$ & $\begin{array}{l}a=2,400000 \\
b=9,525211 \\
c=2,657040 \\
N=709\end{array}$ \\
\hline
\end{tabular}

Parâmetros da distribuição Weibull determinados para cada uma das propriedades de todas as espécies estudadas na condição seca

\begin{tabular}{|c|c|c|c|c|c|}
\hline $\mathrm{Db}$ & $E_{f}$ & $f_{f}$ & $f_{c}$ & $f_{c n}$ & $f_{s}$ \\
\hline $\begin{array}{l}a=0,190000 \\
b=0,541285 \\
c=3,131890 \\
N=656\end{array}$ & $\begin{array}{l}a=4999,000 \\
b=9726,477 \\
c=3,070750 \\
N=656\end{array}$ & $\begin{array}{l}a=20,00000 \\
b=119,0332 \\
c=2,910560 \\
N=656\end{array}$ & $\begin{array}{l}a=23,00000 \\
b=50,21938 \\
c=2,368140 \\
N=656\end{array}$ & $\begin{array}{l}a=0,900000 \\
b=12,15709 \\
c=2,082845 \\
N=656\end{array}$ & $\begin{array}{l}a=3,500000 \\
b=11,92378 \\
c=2,454510 \\
N=656\end{array}$ \\
\hline
\end{tabular}




\section{A N E X O 3}

Valores máximos, médios, mínimos, coeficientes de variação, desvios padrão e número de amostras da densidade básica e módulo de ruptura à flexão estática dos grupos de espécies estudadas nas condiçōes verde e seca à $12 \%$ de umidade. 
Grupos de espécies estudadas na condição verde

\begin{tabular}{|c|c|c|c|c|c|c|c|}
\hline \multirow{2}{*}{ Grupos } & \multirow{2}{*}{ Propriedades } & \multicolumn{6}{|c|}{ valores } \\
\hline & & máximo & o médio & mínimo & $c . v$. & $\mathbf{s}$ & $\mathbf{N}$ \\
\hline 1 & $\begin{array}{l}D b \\
f_{f}\end{array}$ & $\begin{array}{r}0,43 \\
56,20\end{array}$ & $\begin{array}{r}0,33 \\
35,17\end{array}$ & $\begin{array}{r}0,25 \\
17,80\end{array}$ & $\begin{array}{l}13,552 \\
26,445\end{array}$ & $\begin{array}{l}0,045 \\
9,300\end{array}$ & $\begin{array}{l}21 \\
21\end{array}$ \\
\hline 2 & $\begin{array}{l}D b \\
f_{f}\end{array}$ & $\begin{array}{r}0,57 \\
70,80\end{array}$ & $\begin{array}{r}0,43 \\
49,21\end{array}$ & $\begin{array}{r}0,33 \\
32,30\end{array}$ & $\begin{array}{l}12,228 \\
19,901\end{array}$ & $\begin{array}{l}0,052 \\
9,793\end{array}$ & $\begin{array}{l}40 \\
40\end{array}$ \\
\hline 3 & $\begin{array}{l}D b \\
f_{f}\end{array}$ & $\begin{array}{r}0,64 \\
86,90\end{array}$ & $\begin{array}{r}0,50 \\
60,85\end{array}$ & $\begin{array}{r}0,35 \\
38,20\end{array}$ & $\begin{array}{l}10,089 \\
16,774\end{array}$ & $\begin{array}{r}0,050 \\
10,207\end{array}$ & $\begin{array}{l}85 \\
85\end{array}$ \\
\hline 4 & $\begin{array}{l}D b \\
f_{f}\end{array}$ & $\begin{array}{r}0,79 \\
111,00\end{array}$ & $\begin{array}{r}0,59 \\
76,16\end{array}$ & $\begin{array}{r}0,42 \\
35,90\end{array}$ & $\begin{array}{l}10,244 \\
16,810\end{array}$ & $\begin{array}{r}0,061 \\
12,803\end{array}$ & $\begin{array}{l}153 \\
153\end{array}$ \\
\hline 5 & $\begin{array}{l}D b \\
f_{f}\end{array}$ & $\begin{array}{r}0,90 \\
144,00\end{array}$ & $\begin{array}{r}0,70 \\
92,76\end{array}$ & $\begin{array}{r}0,53 \\
42,20\end{array}$ & $\begin{array}{r}8,917 \\
17,890\end{array}$ & $\begin{array}{r}0,063 \\
16,590\end{array}$ & $\begin{array}{l}193 \\
192\end{array}$ \\
\hline 6 & $\begin{array}{l}D b \\
f_{f}\end{array}$ & $\begin{array}{r}0,98 \\
158,30\end{array}$ & $\begin{array}{r}0,79 \\
107,85\end{array}$ & $\begin{array}{r}0,67 \\
52,50\end{array}$ & $\begin{array}{r}6,903 \\
15,972\end{array}$ & $\begin{array}{r}0,055 \\
17,225\end{array}$ & $\begin{array}{l}121 \\
121\end{array}$ \\
\hline 7 & $\begin{array}{l}D b \\
f_{f}\end{array}$ & $\begin{array}{r}1,07 \\
188,50\end{array}$ & $\begin{array}{r}0,90 \\
132,40\end{array}$ & $\begin{array}{r}0,71 \\
91,30\end{array}$ & $\begin{array}{r}6,624 \\
15,822 \\
\end{array}$ & $\begin{array}{r}0,059 \\
20,949\end{array}$ & $\begin{array}{l}84 \\
84\end{array}$ \\
\hline 8 & $\begin{array}{l}D b \\
f_{f}\end{array}$ & $\begin{array}{r}1,08 \\
140,50\end{array}$ & $\begin{array}{r}0,99 \\
133,71\end{array}$ & $\begin{array}{r}0,95 \\
118,70\end{array}$ & $\begin{array}{l}3,995 \\
5,476\end{array}$ & $\begin{array}{l}0,040 \\
7,322\end{array}$ & $\begin{array}{l}9 \\
9\end{array}$ \\
\hline
\end{tabular}


Grupos de espécies estudadas na condição seca

\begin{tabular}{|c|c|c|c|c|c|c|c|}
\hline \multirow{2}{*}{ Grupos } & \multirow{2}{*}{ Propriedades } & \multicolumn{6}{|c|}{ valores } \\
\hline & & máximo & médio & mínimo & $c . v$. & $\mathbf{s}$ & $\mathbf{N}$ \\
\hline 1 & $\begin{array}{l}\mathrm{Db} \\
\mathrm{f}_{\mathrm{f}}\end{array}$ & $\begin{array}{r}0,43 \\
79,70\end{array}$ & $\begin{array}{r}0,33 \\
57,61\end{array}$ & $\begin{array}{r}0,25 \\
36,20\end{array}$ & $\begin{array}{l}13,019 \\
20,604\end{array}$ & $\begin{array}{r}0,043 \\
11,870\end{array}$ & $\begin{array}{l}21 \\
21\end{array}$ \\
\hline 2 & $\begin{array}{l}\mathrm{Db} \\
\mathrm{f}_{f}\end{array}$ & $\begin{array}{r}0,59 \\
104,00\end{array}$ & $\begin{array}{r}0,42 \\
70,77\end{array}$ & $\begin{array}{r}0,33 \\
21,00\end{array}$ & $\begin{array}{l}12,613 \\
28,152\end{array}$ & $\begin{array}{r}0,053 \\
19,923\end{array}$ & $\begin{array}{l}41 \\
41\end{array}$ \\
\hline 3 & $\begin{array}{l}\mathrm{Db} \\
\mathrm{f}_{f}\end{array}$ & $\begin{array}{r}0,60 \\
114,90\end{array}$ & $\begin{array}{r}0,49 \\
85,03\end{array}$ & $\begin{array}{r}0,35 \\
47,30\end{array}$ & $\begin{array}{r}9,705 \\
18,419\end{array}$ & $\begin{array}{r}0,048 \\
15,663\end{array}$ & $\begin{array}{l}83 \\
83\end{array}$ \\
\hline 4 & $\begin{array}{l}\mathrm{Db} \\
\mathrm{f}_{f}\end{array}$ & $\begin{array}{r}0,79 \\
171,30\end{array}$ & $\begin{array}{r}0,60 \\
114,83\end{array}$ & $\begin{array}{r}0,42 \\
67,60\end{array}$ & $\begin{array}{l}10,884 \\
16,659\end{array}$ & $\begin{array}{r}0,065 \\
19,130\end{array}$ & $\begin{array}{l}141 \\
141\end{array}$ \\
\hline 5 & $\begin{array}{l}\mathrm{Db} \\
\mathrm{f}_{f}\end{array}$ & $\begin{array}{r}0,90 \\
209,30\end{array}$ & $\begin{array}{r}0,70 \\
132,71\end{array}$ & $\begin{array}{r}0,53 \\
67,60\end{array}$ & $\begin{array}{r}9,184 \\
18,656\end{array}$ & $\begin{array}{r}0,064 \\
24,760\end{array}$ & $\begin{array}{l}171 \\
171\end{array}$ \\
\hline 6 & $\begin{array}{l}\mathrm{Db} \\
\mathrm{f}_{f}\end{array}$ & $\begin{array}{r}1,00 \\
199,60\end{array}$ & $\begin{array}{r}0,80 \\
150,75\end{array}$ & $\begin{array}{r}0,68 \\
83,90\end{array}$ & $\begin{array}{r}7,582 \\
15,902\end{array}$ & $\begin{array}{r}0,061 \\
23,972\end{array}$ & $\begin{array}{l}106 \\
106\end{array}$ \\
\hline 7 & $\begin{array}{l}\mathrm{Db} \\
\mathrm{f}_{\mathrm{f}}\end{array}$ & $\begin{array}{r}1,07 \\
243,70\end{array}$ & $\begin{array}{r}0,90 \\
176,51\end{array}$ & $\begin{array}{r}0,77 \\
106,10\end{array}$ & $\begin{array}{r}6,064 \\
14,656\end{array}$ & $\begin{array}{r}0,054 \\
25,870\end{array}$ & $\begin{array}{l}78 \\
78\end{array}$ \\
\hline 8 & $\begin{array}{l}\mathrm{Db} \\
\mathrm{f}_{f}\end{array}$ & $\begin{array}{r}1,10 \\
252,70\end{array}$ & $\begin{array}{r}1,06 \\
189,78\end{array}$ & $\begin{array}{r}0,92 \\
125,50\end{array}$ & $\begin{array}{r}7,384 \\
24,328\end{array}$ & $\begin{array}{r}0,078 \\
46,170\end{array}$ & $\begin{array}{l}5 \\
5\end{array}$ \\
\hline
\end{tabular}




\section{A N E X O 4}

Estimativas do módulo de ruptura à flexão estática, estimado em função da Densidade básica observada dos grupos de espécies estudadas nas condiçōes verde e seca. 
Estimativas de $f_{f}$ em função de Db dos grupos de espécies nas condições verde e seca

\begin{tabular}{|c|c|c|}
\hline Grupos & $f_{f}$ (verde) & $f_{f}($ seca $)$ \\
\hline 1 & $\begin{array}{l}a=18,0738 \\
b=17,0000 \\
c=2,45900 \\
N=21\end{array}$ & $\begin{array}{l}a=35,0403 \\
b=23,2014 \\
c=2,40000 \\
N=21\end{array}$ \\
\hline 2 & $\begin{array}{l}a=28,8906 \\
b=21,5000 \\
c=2,36670 \\
N=40\end{array}$ & $\begin{array}{l}a=46,7787 \\
b=23,8020 \\
c=1,60200 \\
N=48\end{array}$ \\
\hline 3 & $\begin{array}{l}a=34,0948 \\
b=28,6863 \\
c=2,60000 \\
N=85\end{array}$ & $\begin{array}{l}a=55,7133 \\
b=32,0000 \\
c=2,14200 \\
N=80\end{array}$ \\
\hline 4 & $\begin{array}{l}a=43,9116 \\
b=33,7000 \\
c=2,79500 \\
N=153\end{array}$ & $\begin{array}{l}a=74,4517 \\
b=40,8847 \\
c=2,30240 \\
N=135\end{array}$ \\
\hline 5 & $\begin{array}{l}a=56,9326 \\
b=34,2456 \\
c=2,40000 \\
N=193\end{array}$ & $\begin{array}{l}a=85,1247 \\
b=40,1240 \\
c=1,91200 \\
N=158\end{array}$ \\
\hline 6 & $\begin{array}{l}a=79,3620 \\
b=28,9450 \\
c=1,90000 \\
N=121\end{array}$ & $\begin{array}{l}a=120,602 \\
b=36,1240 \\
c=2,21010 \\
N=108\end{array}$ \\
\hline 7 & $\begin{array}{l}a=97,7704 \\
b=37,1020 \\
c=2,00000 \\
N=84\end{array}$ & $\begin{array}{l}a=128,536 \\
b=51,2340 \\
c=2,57210 \\
N=91\end{array}$ \\
\hline 8 & $\begin{array}{l}a=120,017 \\
b=18,0000 \\
c=1,40000 \\
N=13\end{array}$ & $\begin{array}{l}a=137,275 \\
b=53,1877 \\
c=2,84195 \\
N=15\end{array}$ \\
\hline
\end{tabular}




\section{A N E X O 5}

Estimativas do módulo de ruptura à flexão estática, estimado em função da densidade básica observada para as madeiras da Amazônia estudadas nas condições verde e seca. 
Estimativas de $f_{f}$ em função de $D b$ para as madeiras na condição verde e seca

\begin{tabular}{crr}
\hline Parâmetros & $f_{f}$ (verde) & \multicolumn{1}{c}{$f_{f}($ seco) } \\
\hline \hline a & 12,0633 & 31,2038 \\
$b$ & 86,6694 & 106,4869 \\
$\mathrm{C}$ & 3,31249 & 3,13189 \\
$\mathrm{~N}$ & 710 & 656 \\
\hline
\end{tabular}


Frequências de densidade básica estimadas em função das Db observadas das madeiras da floresta amazônica estudadas nas condições verde e seca e do módulo de ruptura à flexão estática estimado em função de densidade básica. 
Frequências de densidades básica das madeiras da floresta amazônica estudadas na condição verde

\begin{tabular}{|c|c|c|c|c|c|}
\hline I.C.C. & $f_{0}$ & $f_{0} / N$ & $F_{0}$ & $f(D b)$ & $F(D b)$ \\
\hline $\begin{array}{l}0,19 \\
0,25 \\
0,35 \\
0,45 \\
0,55 \\
0,65 \\
0,75 \\
0,85 \\
0,95 \\
1,05 \\
1,15\end{array}$ & $\begin{array}{r}6 \\
26 \\
73 \\
120 \\
166 \\
161 \\
95 \\
55 \\
6 \\
2\end{array}$ & $\begin{array}{l}0,008451 \\
0,036620 \\
0,102817 \\
0,169014 \\
0,233803 \\
0,226761 \\
0,133803 \\
0,077465 \\
0,008451 \\
0,0028\end{array}$ & $\begin{array}{l}0,008451 \\
0,045070 \\
0,147887 \\
0,316901 \\
0,550704 \\
0,777465 \\
0,911268 \\
0,988732 \\
0,997183 \\
1,000000\end{array}$ & $\begin{array}{l}0,000686 \\
0,016840 \\
0,066987 \\
0,144036 \\
0,214033 \\
0,231566 \\
0,181049 \\
0,099006 \\
0,036177 \\
0,008372\end{array}$ & $\begin{array}{l}0,000686 \\
0,017526 \\
0,084513 \\
0,228549 \\
0,442582 \\
0,674148 \\
0,855197 \\
0,954203 \\
0,990379 \\
0,998751\end{array}$ \\
\hline $\begin{array}{l}I \cdot C \cdot C . \\
f_{o} \\
f_{o} / N \\
F_{o} \\
f^{\prime}(D b) \\
F(D b)\end{array}$ & $\begin{array}{l}=\mathrm{in} \\
\mathrm{pa} \\
=\mathrm{fr} \\
\mathrm{ce} \\
=\mathrm{Di} \\
=\mathrm{Di} \\
=\mathrm{Di} \\
=\mathrm{Di}\end{array}$ & $\begin{array}{l}\text { ervalos dos } \\
\text { a Db } \\
\text { quência de } \\
\text { tro de clas } \\
\text { tribuição } \\
\text { tribuição } \\
\text { tribuição } \\
\text { tribuição }\end{array}$ & $\begin{array}{l}\text { Db obse } \\
\text { se } \\
\text { robabilíst } \\
\text { cumulada } \\
\text { robabilís } \\
\text { cumulada }\end{array}$ & $\begin{array}{l}\text { ca estimad } \\
\text { timada de }\end{array}$ & $\begin{array}{l}\text { tabelecidos } \\
\text { de cada } \\
\text { de } \mathrm{Db} \\
\text { de } \mathrm{Db}\end{array}$ \\
\hline
\end{tabular}

Frequências de densidades básica das madeiras da floresta amazônica estudadas na condição seca

\begin{tabular}{crccll}
\hline I.C.C. & \multicolumn{1}{c}{$f_{o}$} & $f_{o} / N$ & $F_{\circ}$ & $f(D b)$ & $F(D b)$ \\
\hline \hline 0.19 & & & & & \\
0.25 & 5 & 0.007622 & 0.007622 & 0.001019 & 0.001019 \\
0.35 & 29 & 0.044207 & 0.051829 & 0.020734 & 0.021752 \\
0.45 & 74 & 0.112805 & 0.164634 & 0.073962 & 0.095715 \\
0.55 & 110 & 0.167683 & 0.332317 & 0.147583 & 0.243298 \\
0.65 & 150 & 0.228659 & 0.560976 & 0.208289 & 0.451586 \\
0.75 & 131 & 0.199695 & 0.760671 & 0.219622 & 0.671208 \\
0.85 & 92 & 0.140244 & 0.900915 & 0.173252 & 0.844461 \\
0.95 & 54 & 0.082317 & 0.983232 & 0.100223 & 0.944684 \\
1.05 & 7 & 0.010671 & 0.993902 & 0.041239 & 0.985923 \\
1.15 & 4 & 0.006098 & 1.000000 & 0.011639 & 0.997562 \\
\hline \hline
\end{tabular}


Frequências do $f_{f}$ das madeiras da floresta amazônica estudadas na condição verde

\begin{tabular}{|c|c|c|c|c|c|}
\hline I.C.C. & $f_{0}$. & $\mathrm{f}_{0} / \mathrm{N}$ & $F_{0}$ & $f\left(f_{f}\right)$ & $F\left(f_{f}\right)$ \\
\hline $\begin{array}{r}16,0 \\
25,6 \\
42,8 \\
60,0 \\
77,2 \\
94,4 \\
111,6 \\
128,8 \\
146,0 \\
163,2 \\
180,4\end{array}$ & $\begin{array}{r}13 \\
52 \\
116 \\
148 \\
166 \\
105 \\
63 \\
31 \\
10 \\
5\end{array}$ & $\begin{array}{l}0,018336 \\
0,073343 \\
0,163611 \\
0,208745 \\
0,234133 \\
0,148096 \\
0,088858 \\
0,043724 \\
0,014104 \\
0,007052\end{array}$ & $\begin{array}{l}0,018336 \\
0,091678 \\
0,255289 \\
0,464034 \\
0,698166 \\
0,846262 \\
0,935120 \\
0,978843 \\
0,992948 \\
1,000000\end{array}$ & $\begin{array}{l}0,003472 \\
0,046877 \\
0,122810 \\
0,190867 \\
0,216104 \\
0,188007 \\
0,127278 \\
0,066898 \\
0,027062 \\
0,008327\end{array}$ & $\begin{array}{l}0,003472 \\
0,050349 \\
0,173159 \\
0,364027 \\
0,580131 \\
0,768138 \\
0,895416 \\
0,962314 \\
0,989377 \\
0,997704\end{array}$ \\
\hline
\end{tabular}

I.C.C. = intervalos dos centros de classes estabelecidos para $f_{f}$

$\mathrm{f}_{0}=$ frequências do $\mathrm{f}_{\mathrm{f}}$ observados dentro de cada centro de classe

$\mathrm{f}_{\mathrm{o}} / \mathrm{N}=$ Distribuição probabilística observada do $\mathrm{f}_{\mathrm{f}}$

$\mathrm{F}_{\mathrm{o}} \quad$ Distribuição acumulada observada do $\mathrm{f}_{\mathrm{f}} \mathrm{f}_{\mathrm{f}}$ = Distribuição probabilística estimada do $f_{f}$

$F\left(f_{f}\right)=$ Distribuição acumulada estimada do $f_{f}$

Frequências do $f_{f}$ das madeiras da floresta amazônica estudadas na condição seca

\begin{tabular}{|c|c|c|c|c|c|}
\hline I.C.C. & $f_{0}$ & $\mathrm{f}_{0} / \mathrm{N}$ & $F_{0}$ & $f\left(f_{f}\right)$ & $F\left(f_{f}\right)$ \\
\hline $\begin{array}{r}20,0 \\
32,6 \\
55,8 \\
79,0 \\
102,2 \\
125,4 \\
148,6 \\
171,8 \\
195,0 \\
218,2 \\
241,4\end{array}$ & $\begin{array}{r}5 \\
41 \\
82 \\
134 \\
133 \\
123 \\
90 \\
36 \\
9 \\
3\end{array}$ & $\begin{array}{l}0,007622 \\
0,062500 \\
0,125000 \\
0,204268 \\
0,202744 \\
0,187500 \\
0,137195 \\
0,054878 \\
0,013720 \\
0,004573\end{array}$ & $\begin{array}{l}0,007622 \\
0,070122 \\
0,195122 \\
0,399390 \\
0,602134 \\
0,789634 \\
0,926829 \\
0,981707 \\
0,995427 \\
1,000000\end{array}$ & $\begin{array}{l}0,001449 \\
0,028388 \\
0,091771 \\
0,166908 \\
0,215815 \\
0,209829 \\
0,154425 \\
0,084995 \\
0,034273 \\
0,009876\end{array}$ & $\begin{array}{l}0,001449 \\
0,029837 \\
0,121608 \\
0,288516 \\
0,504331 \\
0,714160 \\
0,868585 \\
0,953579 \\
0,987853 \\
0,997728\end{array}$ \\
\hline
\end{tabular}


Frequências de $f_{f}$ obtidas em função de $\mathrm{Db}$ das madeiras da floresta amazônica estudadas na condição verde

\begin{tabular}{ccrrr}
\hline \hline$I . C . C .[D b]$ & $I . C . C .\left[f_{f}(D b)\right]$ & $f_{0}$ & $f\left[f_{f}(D b)\right]$ & $F\left[f_{f}(D b)\right]$ \\
\hline \hline 0,19 & 12,0633 & & & \\
0,25 & 21,6759 & 6 & 0,000686 & 0,000686 \\
0,35 & 37,6969 & 26 & 0,016840 & 0,017526 \\
0,45 & 53,7179 & 73 & 0,066987 & 0,084513 \\
0,55 & 69,7389 & 120 & 0,144036 & 0,228549 \\
0,65 & 85,7599 & 166 & 0,214033 & 0,442582 \\
0,75 & 101,7809 & 161 & 0,231566 & 0,674148 \\
0,85 & 117,8019 & 95 & 0,181049 & 0,855197 \\
0,95 & 133,8229 & 55 & 0,099006 & 0,954203 \\
1,05 & 149,8439 & 6 & 0,036177 & 0,990379 \\
1,15 & 165,8649 & 2 & 0,008372 & 0,998751
\end{tabular}

\begin{aligned} \hline \hline I.C.C. $[\mathrm{Db}] &$ intervalos dos centros de classes estabe- \\ & lecidos para $\mathrm{Db} \\ \mathrm{I.C.C.}\left[\mathrm{f}_{\mathrm{f}}(\mathrm{Db})\right]= &$ intervalos dos centros de classes estabe- \\ & lecidos para $\mathrm{f}_{\mathrm{f}}$ em função de $\mathrm{Db} \\ = &$ frequências de Db observadas dentro de \\ $\mathrm{f}_{\mathrm{f}} &$ cada centro de classe \\ $\mathrm{f}\left[\mathrm{f}_{\mathrm{f}}(\mathrm{Db})\right] &$ Distribuição probabilística estimada do $\mathrm{f}_{\mathrm{f}} \\ \mathrm{F}\left[\mathrm{f}_{\mathrm{f}}(\mathrm{Db})\right] &$ em função de Db \\ $= &$ Distribuição acumulada estimada do $\mathrm{f}_{\mathrm{f}}$ em \\ & função de Db \end{aligned}

Frequências de $f_{f}$ obtidas em função de $\mathrm{Db}$ das madeiras da floresta amazônica estudadas na condição seca.

\begin{tabular}{ccrrr}
\hline \hline$I . C . C .[D b]$ & $I . C . C .\left[f_{f}(D b)\right]$ & $f_{o}$ & $f\left[f_{f}(D b)\right]$ & $F\left[f_{f}(D b)\right]$ \\
\hline 0,19 & 31,2038 & & & \\
0,25 & 43,0076 & 5 & 0,001019 & 0,001019 \\
0,35 & 62,6809 & 29 & 0,020734 & 0,021752 \\
0,45 & 82,3536 & 74 & 0,073962 & 0,095715 \\
0,55 & 102,0266 & 110 & 0,147583 & 0,243298 \\
0,65 & 121,6996 & 150 & 0,208289 & 0,451586 \\
0,75 & 141,3726 & 131 & 0,219622 & 0,671208 \\
0,85 & 161,0456 & 92 & 0,173252 & 0,844461 \\
0,95 & 180,7186 & 54 & 0,100223 & 0,944684 \\
1,05 & 200,3916 & 7 & 0,041239 & 0,985923 \\
1,15 & 220,0646 & 4 & 0,011639 & 0,997562 \\
\hline \hline
\end{tabular}


DEDALUS - Acervo - ESALQ-BC

(1)

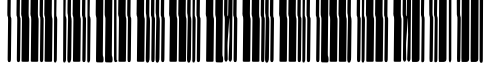

10500007151 